Portland State University

PDXScholar

7-19-1977

\title{
Limit Design of Unbraced Reinforced Concrete Frames
}

Thomas Joseph Gavin

Portland State University

Follow this and additional works at: https://pdxscholar.library.pdx.edu/open_access_etds

Part of the Engineering Commons

Let us know how access to this document benefits you.

\section{Recommended Citation}

Gavin, Thomas Joseph, "Limit Design of Unbraced Reinforced Concrete Frames" (1977). Dissertations and Theses. Paper 2562.

https://doi.org/10.15760/etd.2559

This Thesis is brought to you for free and open access. It has been accepted for inclusion in Dissertations and Theses by an authorized administrator of PDXScholar. Please contact us if we can make this document more accessible: pdxscholar@pdx.edu. 
AN ABSTRACT OF THE THESIS OF Thomas Joseph Gavin for the Master of Science In Applied Sclence presented July 19, 1977.

Title: Limit Design of Unbraced Reinforced Concrete Frames.

APPROVED BY MEMBERS OF THE THESIS CONMITTEE:

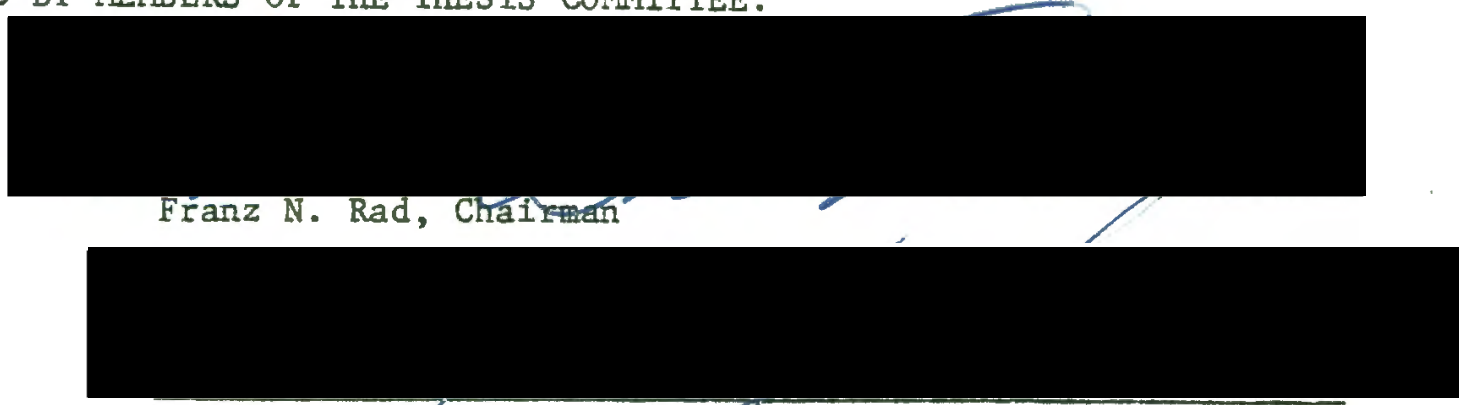

Hacik Erzurunfu

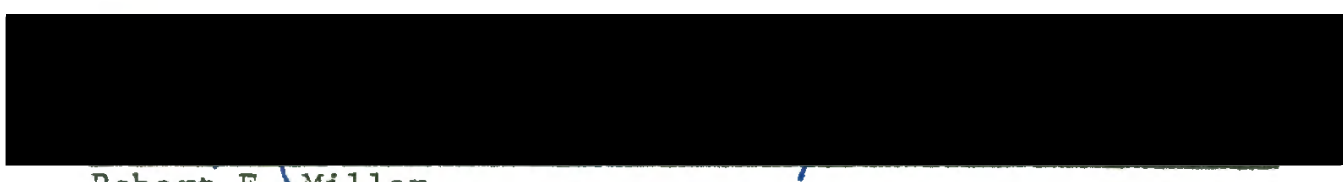

Robert E. Miller

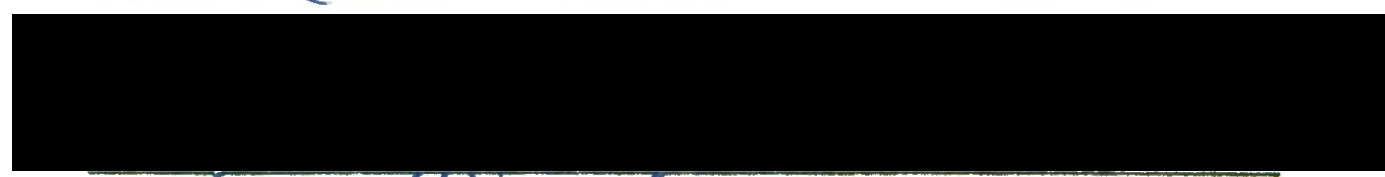

Alan M. Gaylord
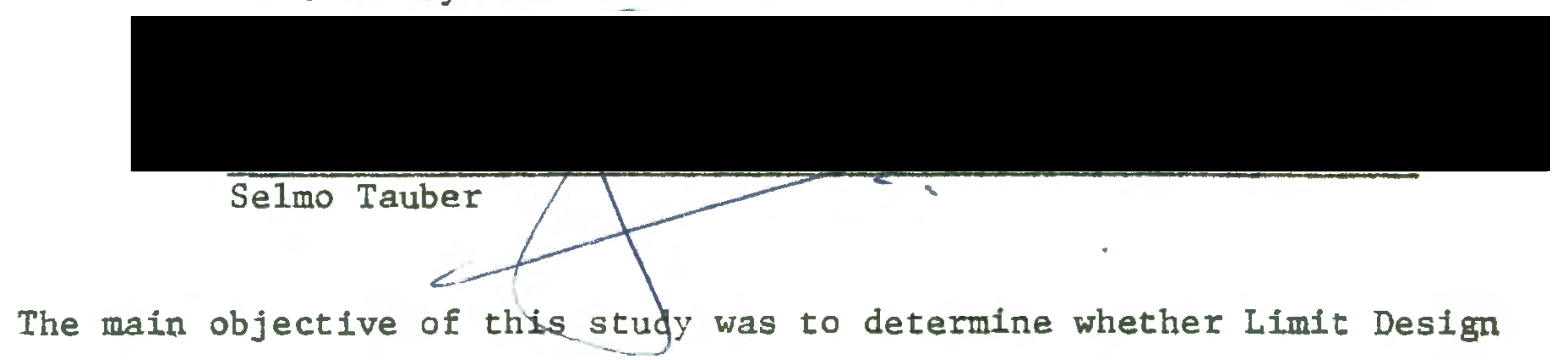

could be applied to low-rise unbraced concrete frames. The investigation

was carried out both analytically and experimentally.

In the analytical part, two mathematical models were used to determine

the behavior of unbraced frames. The first method used a nonlinear computer program, which takes into account the material and geometric nonlinearties of concrete frames. Several cases of frames with different. 
reinforcement ratios and under different beam to colum load ratios were Investigated. For each frame the gravity loads were increased proportionately to $3 / 4$ of the ultimate frame capacity. Then, lateral load was applied to failure while keeping the beam and column loads constant.

The second mathematical model solved for the frame stability equation by assuming elasto-plastic moment curvature relationships for members. Also, the stability solution was carried out by reducing the frame to a column attached to a linear spring.

In the experimental part, two frames were designed for the same loadIng conditions but by two different methods; and were tested to failure. Frame USD-1 was designed by the Ultimate Strength Design, while Frame LD-1 by a Limit Design method. The columns were 21 -in high while the beam was 84-in 1ong. The loading procedure consisted of proportionately loading the beam and colums up to the design load, and then applying the lateral load to failure.

The computer study and the stability model solution showed that frames subjected to low colum thrusts remained in stable equilibrium unt1l two plastic hinges form, thus constituting a mechanism. The two experimental frames remained in stable equilibrium until two plastic hinges formed in the beams. The ultimate lateral loads of Frames USD-1 and LD-1 exceeded the design lateral load by $66 \%$ and $33 \%$, respectively.

Based on this investigation, it appears that Limit Design may be used for low-rise unbraced relnforced concrete structures. 
LIMIT DESIGN OF

UNBRACED REINFORCED CONCRETE FRAMES

by

THOMAS JOSEPH GAVIN

A thesis submitted in partial fulfillment of the requirements for the degree of

\author{
MASTER OF SCIENCE \\ in \\ APPLIED SCIENCE
}

Portland State Unfversity

1977 
TO THE OFFICE OF GRADUATE STUDIES AND RESEARCH:

The members of the Comittee approve the thesis of

Thomas Joseph Gavin presented July 19, 1977.

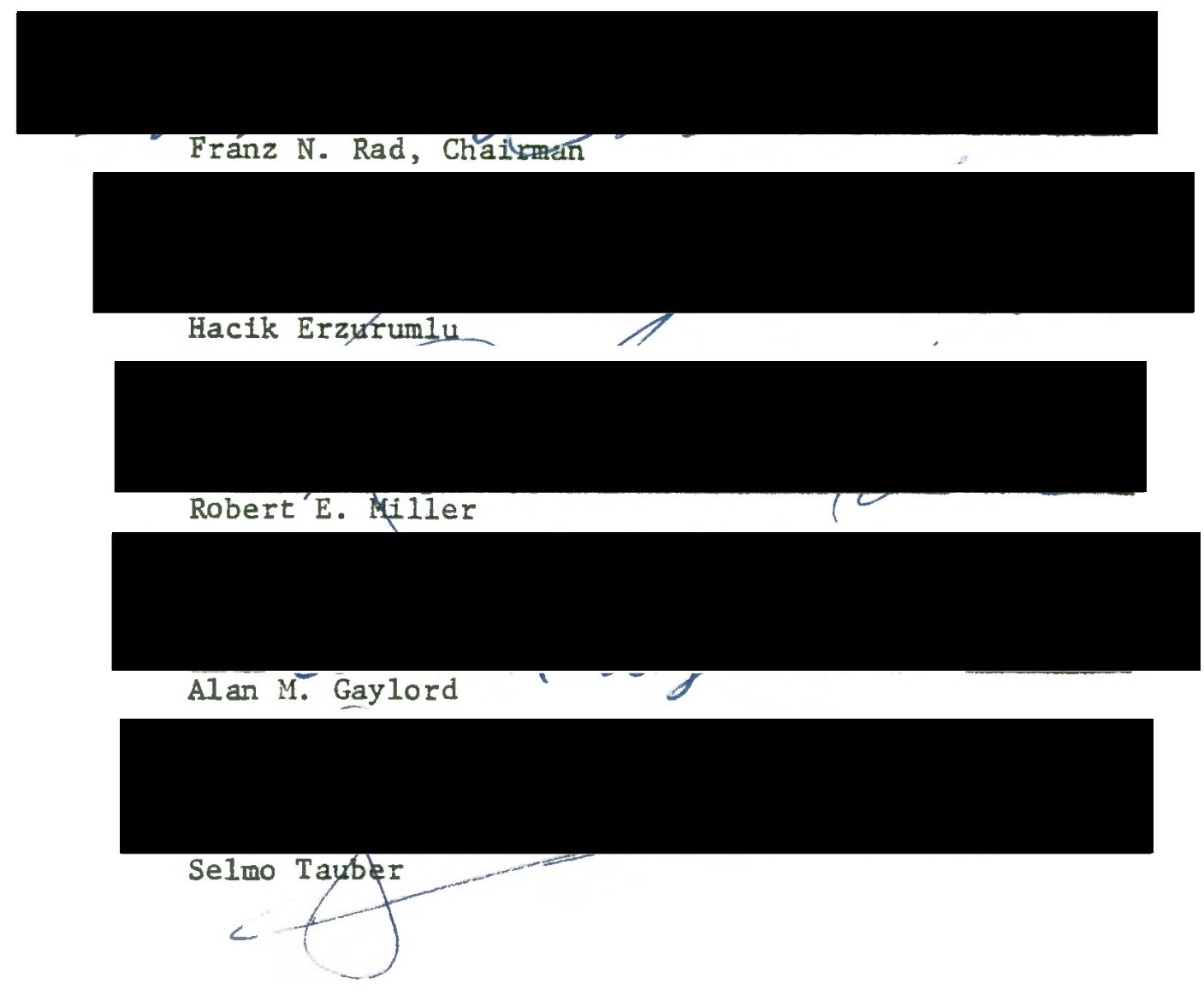

APPROVED :

Fred Young, Department of Engineering and Applied Science

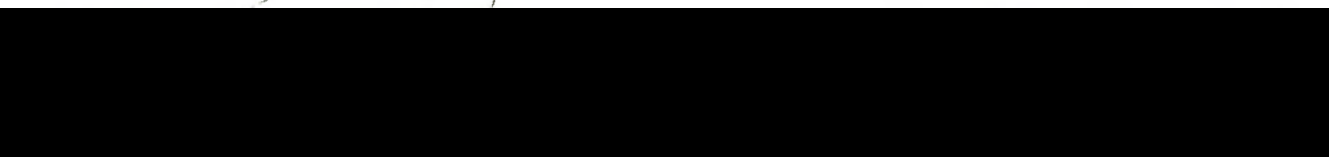

Stanley E. Rauch, Dean of Graduate Studies and Research 
TO MY FATHER

and

IN MEMORY OF MY MOTHER 


\section{ACKNOWLEDGMENTS}

This investigation was carried out under the supervision of Dr. Franz N. Rad. The author is indebted to Dr. Rad for his help, advice, and encouragement throughout this work. The author also would like to express his appreciation to the Engineering and Applied Science Department, especially the Civil-Structural Engineering Section.

The author also would like to thank the other members of his thesis committee, Dr. Hacik Erzurumlu, Dr. Robert Miller, Dr. Selmo Tauber, and Mr. Alan Gaylord for their helpful comments and suggestions. The author would like to extend his appreclation to Mr. Steve Speer for his help during the testing phase of this study. Apprectation Is also due to Messrs. Steve Rinella, Inm Groat, and Nour1 Samfee-Nejad for their help in fabrication and testing of the frames. Thanks are also due to Mr. Mark Borquist for drawing the figures and to Mrs. Donna Mikulic for typing this thesfs. The help of the Computing Services Center staff at Portland State Unfversfty, especfally Mr. Fred Dayton, is also acknowledged and appreciated. Finally, the author would like to thank his father, Mr. Joe Gavin, for his encouragement throughout the author's graduate work. 
ACKNOWLEDGMENTS $\ldots \ldots \ldots \ldots \ldots \ldots \ldots \ldots \ldots \ldots \ldots \ldots \ldots \ldots \ldots \ldots \ldots \ldots \ldots \ldots$ iv

LIST OF TABLES $\ldots \ldots \ldots \ldots \ldots \ldots \ldots \ldots \ldots \ldots \ldots \ldots \ldots \ldots \ldots \ldots \ldots \ldots \ldots \ldots \ldots$

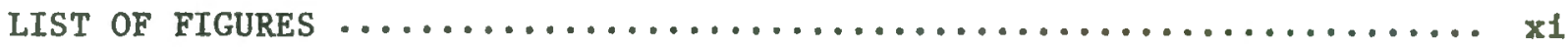

CHAPTER

I INTRODUCTION $\ldots \ldots \ldots \ldots \ldots \ldots \ldots \ldots \ldots \ldots \ldots \ldots \ldots \ldots \ldots \ldots$

1.1 BACKGROUND $\ldots \ldots \ldots \ldots \ldots \ldots \ldots \ldots \ldots \ldots \ldots \ldots \ldots \ldots \ldots \ldots$

1.2 NONLINEAR BEHAVIOR OF REINFORCED CONCRETE........... 2

1.3 PURPOSE OF THIS INVESTIGATION.................. 4

1.4 ORGANIZATION OF THE REPORT .................. 5

II ANALYTICAL TREATMENT $\ldots \ldots \ldots \ldots \ldots \ldots \ldots \ldots \ldots \ldots \ldots \ldots \ldots$

2.1 REDUCTION OF UNBRACED FRAME TO MODEL AND TEST FRAME..... 6

2.2 DESCRIPTION OF FAILURE TYPES $\ldots \ldots \ldots \ldots \ldots \ldots \ldots \ldots \ldots$

2.3 PARAMETRIC STUDY OF MODEL FRAME ................ 11

2.3.1 Program Description ......................... 11

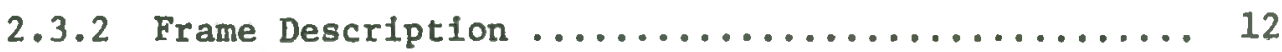

2.3.3 Procedure $\ldots \ldots \ldots \ldots \ldots \ldots \ldots \ldots \ldots \ldots \ldots \ldots \ldots \ldots \ldots$

2.3.4 Interpretation of Computer Output ............ 14

2.3 .5 Results $\ldots \ldots \ldots \ldots \ldots \ldots \ldots \ldots \ldots \ldots \ldots \ldots \ldots \ldots$

2.4 ELASTO-PLASTIC STABILITY MODEL ................ 20

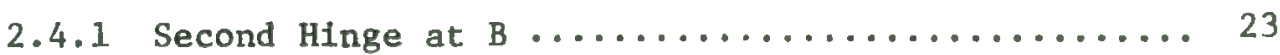

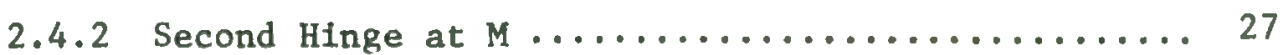

2.4.3 Inelastic Buckling Load by Bolton's Method ...... 30

2.4.4 Stab111ty Domalns Defined by the Elasto-Plastic

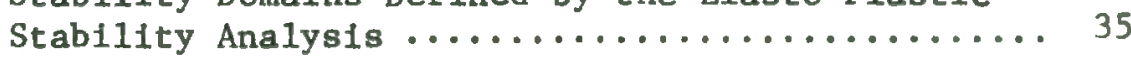


2.4.5 NONFIX7 Results vs Stab1lity Doma1ns ......... 37

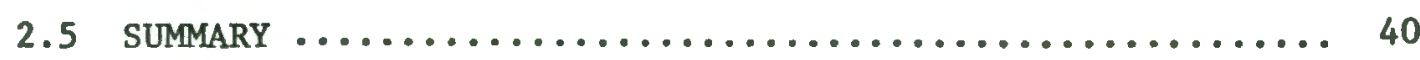

III DESIGN OF TWO FRAMES FOR TESTING .................. 41

3.1 STORY HEIGHT, LOADS, AND GENERAL ASSUMPTIONS ......... 41

3.2 ULTIMATE STRENGTH DESIGN OF FRAME USD $-1 \ldots \ldots \ldots \ldots \ldots \ldots$

3.2 .1 Design Method ....................... 44

3.2.2 Elast1c Frame Analysts .................. 44

a) Condttion I ....................... 45

b) Condttion II $\ldots \ldots \ldots \ldots \ldots \ldots \ldots \ldots \ldots \ldots . \ldots . \ldots 45$

3.2 .3 Column Design ...................... 47

a) Condttion I ....................... 51

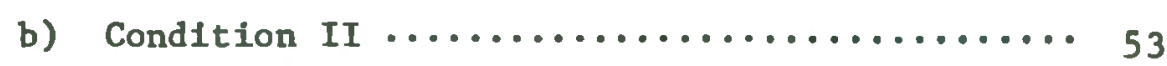

3.2.4 Beam Design and Deta1ling ............... 54

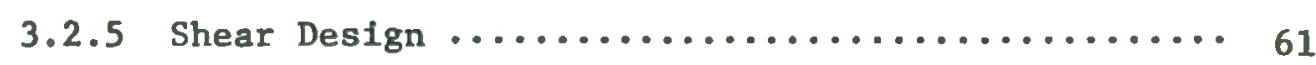

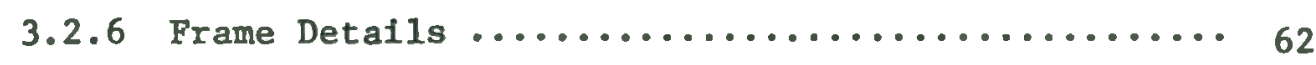

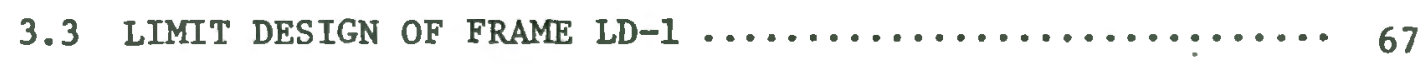

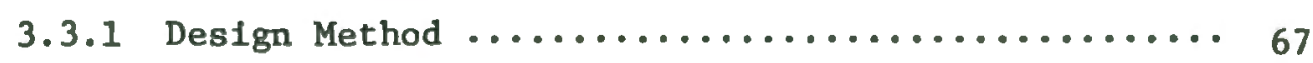

3.3.2 Plast1c Frame Analys1s ................. 67

a) Condition I .......................... 68

b) Condition II ........................ 71

3.3 .3 Consideration of P-A Moments ................ 75

a) Condition I ......................... 80

b) Condttion II ........................ 82

3.3 .4 Column Design ........................... 84

a) Condition I .......................... 84

b) Condition II .......................... 86 
PAGE

3.3.5 Beam Design and Detailing................ 86

3.3.6 Shear Design........................... 90

3.3.7 Ultimate Deflection and Plastic Rotation 91

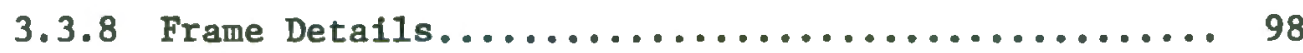

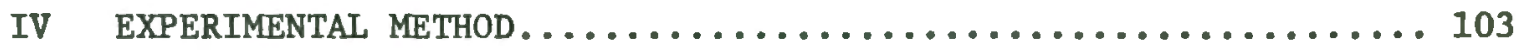

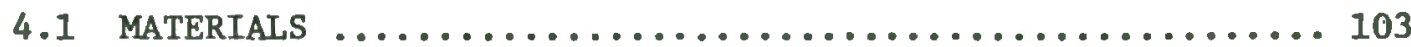

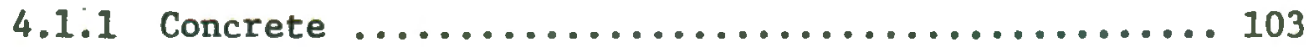

4.1.2 Reinforcing Steel ........................... 104

4.1.3 Number 12 Gage Wire .......................... 104

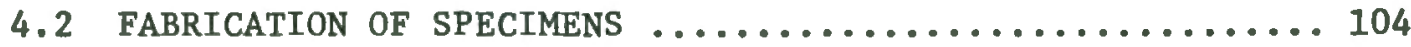

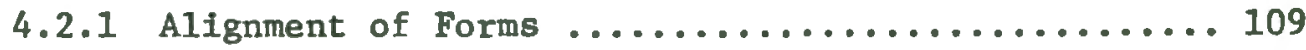

4.2.2 Fabrication of Reinforcing Cages ............. 112

a) Column Cage $\ldots \ldots \ldots \ldots \ldots \ldots \ldots \ldots \ldots \ldots \ldots \ldots \ldots$

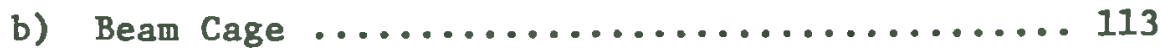

4.2.3 Placement of Reinforcing Cages .............. 113

4.2.4 Casting and Curing of Concrete .............. 114

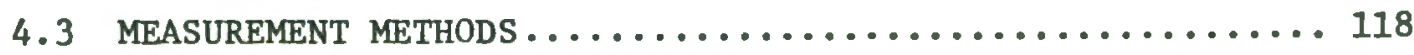

4.3.1 Loads and Pressures ....................... 118

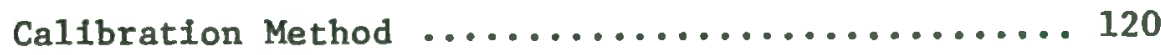

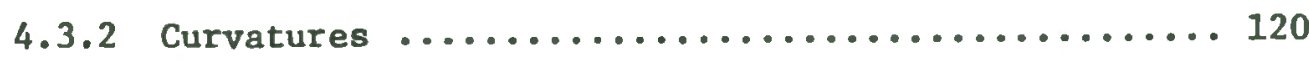

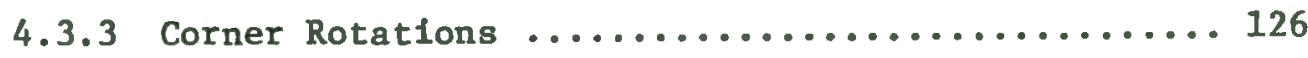

4.3.4 Lateral Deflection Measurement............... 128

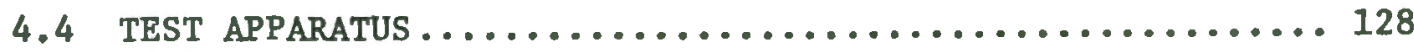

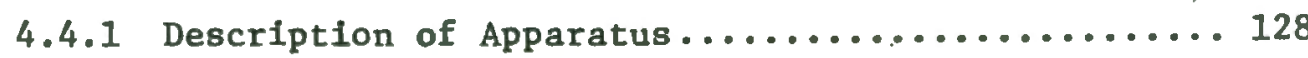

a) Column Load Device .................... 132

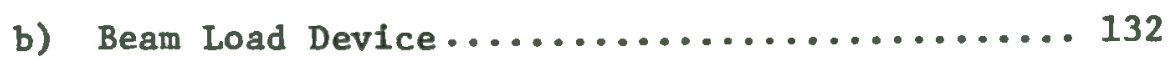


c) Lateral Load Assembly................... 132

d) Concrete Reaction Beam and Movable Steel Beam. 133

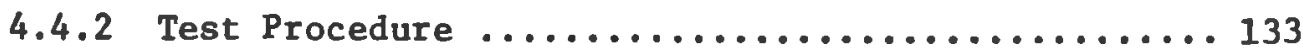

a) Pre-test Procedure ..............................

b) Ultimate Load Test ......................... 134

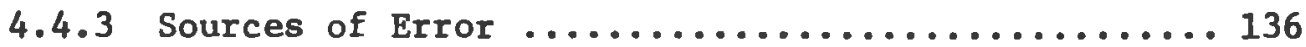

v TEST RESULTS................................. 141

5.1 DATA REDUCTION $\ldots \ldots \ldots \ldots \ldots \ldots \ldots \ldots \ldots \ldots \ldots \ldots \ldots \ldots \ldots \ldots$

5.1.1 Moments at the Curvature-meter Stations.......... 141

5.1.2 Moments at the Critical SectIons............. 143

5.1.3 Description of Results.................... 143

a) Column Thrust vs Indicated Moment.......... 146

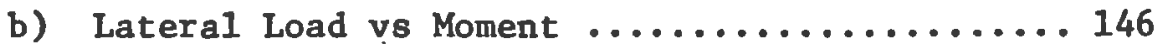

c) Lateral Load vs Deflection.............. 147

d) Lateral Load vs Corner Rotations .......... 147

e) Components of the Moment in the Leeward
Column $\ldots \ldots \ldots \ldots \ldots \ldots \ldots \ldots \ldots \ldots \ldots \ldots \ldots \ldots \ldots$

f) Lateral Load vs Magnification Factor......... 149

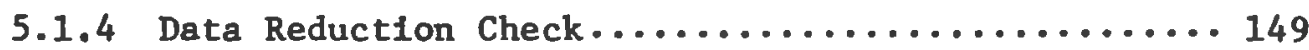

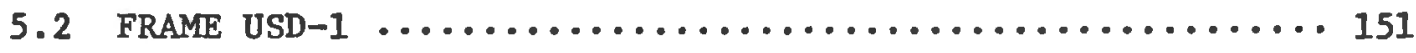

5.2.1 Frame Description.............................. 151

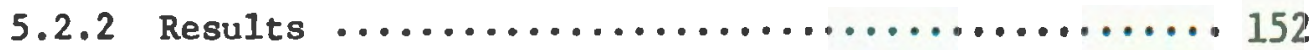

a) Column Thrust vs Indicated Moment......... 152

b) Lateral Load vs Moment................. 153

c) Lateral Load vs Deflection............... 154

d) Lateral Load vs Corner Rotations........... 155

e) Components of the Moment in the Leeward _.. 155 
f) Lateral Load vs Magnification Factor......... 156

\subsubsection{Test History, Sequence of Cracking, and Hinge}

Formation......................... 156

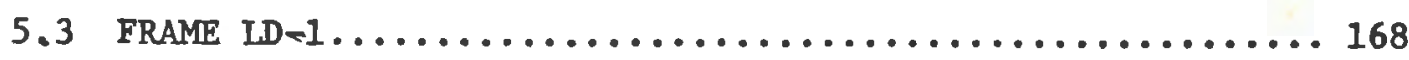

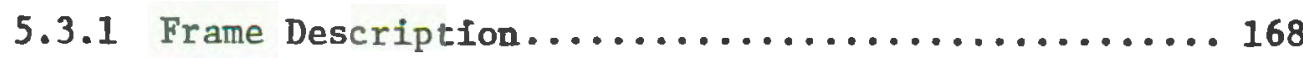

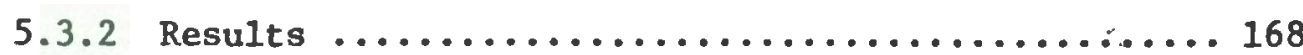

a) Column Thrust vs Indicated Moment.......... 168

b) Lateral Load vs Moment.................. 169

c) Lateral Load vs Deflection.............. 170

d) Lateral Load vs Corner Rotations........... 170

e) Components of the Moment in the Leeward Column.......................... 171

f) Lateral Load vs Magnification Factor........ 171

5.3.3 Test History, Sequence of Cracking, and

Hinge Formation....................... 171

5.4 COMPARISON OF FRAMES USD $-1 \&$ LD $-1 \ldots \ldots \ldots \ldots \ldots \ldots \ldots \ldots$

5.5 COMPARISON OF TEST RESULTS WITH NONFIX7 AND

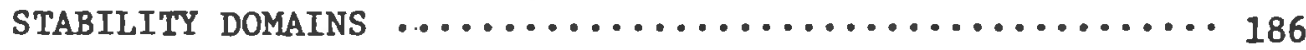

vi SUMMARY, CONCLUSIONS AND RECOMMENDATIONS .............. 192

REFERENCES. ......................................... 195 


\section{LIST OF TABLES}

\section{TABLE}

PAGE

$2.1 \quad$ Frame Parameters $\ldots \ldots \ldots \ldots \ldots \ldots \ldots \ldots \ldots \ldots \ldots \ldots \ldots \ldots$

2.2 Summary of Computer Results $\ldots \ldots \ldots \ldots \ldots \ldots \ldots \ldots \ldots$

2.3 Comparison with Elasto-Plastic Model.............. 39

4.1 Concrete Mix Proportions by Weight............... 115

$4.2 \quad$ Measured Geometry............................. 117

4.3 Princlple Properties of the Frames................. 117

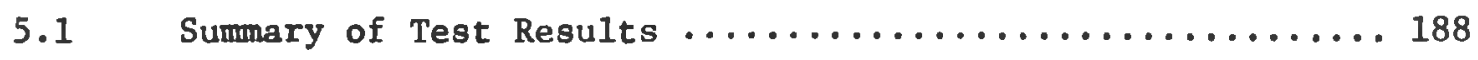

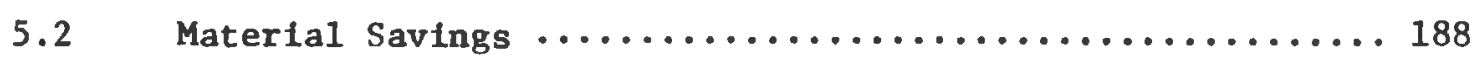


2.1 Multi-story Unbraced Frame.................... 8

2.2 Interior Panel............................ 8

$2.3 \quad$ Reduced Model.$\ldots \ldots \ldots \ldots \ldots \ldots \ldots \ldots \ldots \ldots \ldots \ldots \ldots \ldots \ldots$

$2.4 \quad$ Fallure Modes................................. 10

2.5 Qualitative H-M Curves for Different Stories (n)........ 16

2.6 Moment Redistribution Curve..................... 19

2.7 Loads and Moments at the First Hinge.............. 24

2.8 Loads and Moments after the First Hinge............. 25

2.9 Condition when hinges form at $B$ and $M$ at the same time.... 31

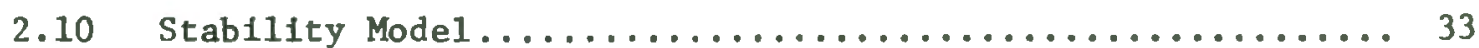

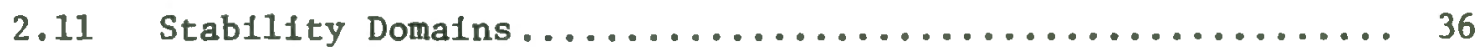

2.12 Flexural Stiffness Calculations.................. 38

3.1 Service \& Factored Loads...................... 43

3.2 Frame Analysis for Condition I................ 46

3.3 Frame Analysis for Condition II ............... 48

3.4 Beam Moment Envelope, USD-1.................. 49

3.5 Column cross-section $\ldots \ldots \ldots \ldots \ldots \ldots \ldots \ldots \ldots \ldots \ldots \ldots \ldots \ldots$

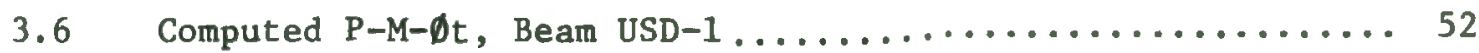

3.7 Typical Computed $\mathrm{P}-\mathrm{M}-\emptyset \mathrm{t}$ for USD-1 Columns............ 55

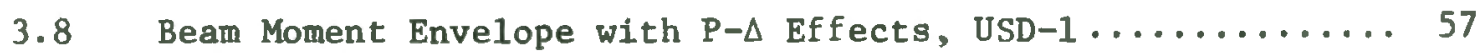

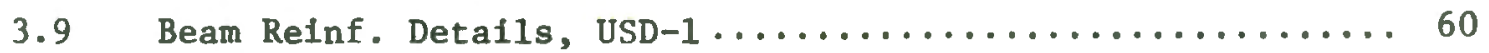

3.10 Test Frame Deta11s, USD $-1 \ldots \ldots \ldots \ldots \ldots \ldots \ldots \ldots \ldots \ldots$

3.11 Cross Sections, Frame USD $-1 \ldots \ldots \ldots \ldots \ldots \ldots \ldots \ldots \ldots \ldots$ 
3.12 Schedule of Reinforcement, USD-1.................6. 65

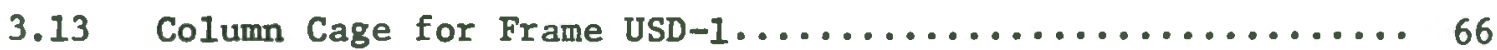

3.14 Mechanisms for Condition I ...................... 69

3.15 Loads and Reactions ............................ 72

3.16 Moment Diagram ............................. 72

3.17 Independent Mechanisms for Condition II............. 74

3.18 Combined Mechanism ............................... $76^{\circ}$

3.19 Loads \& Reactions............................ 77

3.20 Moment Diagram ................................ 77

3.21 Moment Envelope for $L D-1 \ldots \ldots \ldots \ldots \ldots \ldots \ldots \ldots \ldots \ldots . \ldots 78$

3.22 Computed P-M- $\emptyset t$, Beam LD-1...................... 81

3.23 Typical Computed P-M- $\emptyset t$, for LD-1 Columns............ 83

3.24 Beam Moment Envelope with P- $\Delta$ Effects, LD-1........... 85

3.25 Beam Reinf. Details, LD-1.................... 88

3.26 Transformed Section............................ 92

3.27 Slope Deflection Notation...................... 92

3.28 Ultimate Deflection of Frame LD-1................. 93

3.29 Test Frame Deta11s, LD-1..................... 99

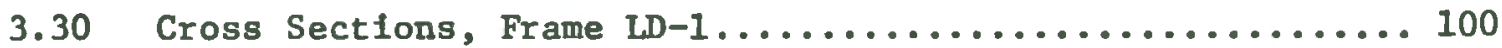

3.31 Schedule of Reinforcement, LD-1,................. 101

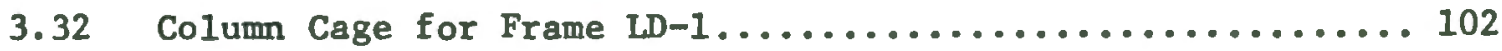

4.1 Concrete Stress-Strain Curve, USD-1............... 105

4.2 Concrete Stress-Strain Curve, LD-1................. 106

4.3 Typical stress-strain Curve for \#3 Reinf. Bar........... 107

4.4 Stress-Strain Curve for $\$ 12$ ga. Wire................ 108

4.5 The Column Cage Positioned in the Forms................110 
4.6 The Beam cage Showing the Beam Stirrups............... 110

4.7 The Beam and Column cage Intersection............... 111

4.8 The Reinforcing cages Positioned in the Forms Before

Concrete Casting............................... 111

4.9 Casting and Consolidating the Concrete.............. 116

4.10 Cleaning the Forms After Casting.................. 116

4.11 Loading Instrumentation......................... 119

4.12 Load Cell \& P.T. Calibration Load Setup............... 121

4.13 Pressure Transducer (no.s $49786 \& 7$ ) Callb............ 122

4.14 Pressure Transducer (no. 49904) Cal1b................. 123

4.15 Load Cel1 (no. 2146) Calibration.................... 124

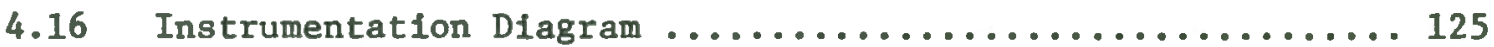

4.17 Plan View of a Curvature-meter................... 127

4.18 Corner Rotation Measurement System.................. 127

4.19 Curvature-meters in Position..................... 129

4.20 Lateral Deflection Measuring Device ................. 129

4.21 Schematic Diagram of Loading System ............... 130

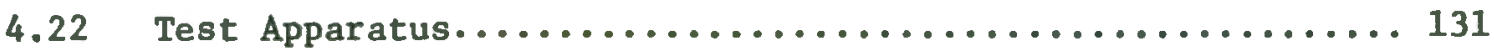

4.23 Sway Adjustment Ram and Dial Gage .................. 131

4.24 Aligning the Right Column Strand.................. 138

4.25 Reading the Curvature-meter Dials.................. 138

4.26 Marking Flexural Cracks at the Positive Moment Region of the

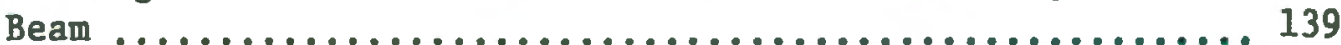

4.27 Monitoring Loads and Pressures With the Strain Indicator... 139

4.28 Frames With Idealized Imperfections.................. 140

5.1 Critical Sections............................ 144

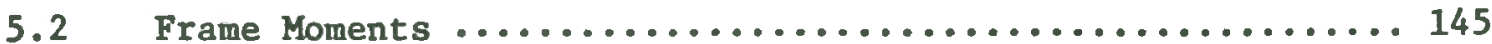


5.3 Spread of Hinging at Corner $\mathrm{C} \ldots \ldots \ldots \ldots \ldots \ldots \ldots \ldots$

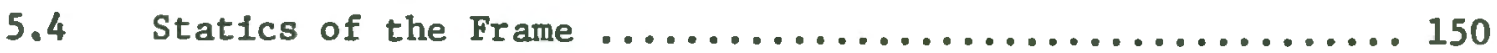

5.5 Axial Load vs. Moment, Frame USD-1 ................ 159

5.6 Lateral Force vs. Moment, Frame USD $-1 \ldots \ldots \ldots \ldots \ldots \ldots$

5.7 Lateral Force vs. Lateral Deflection................. 161

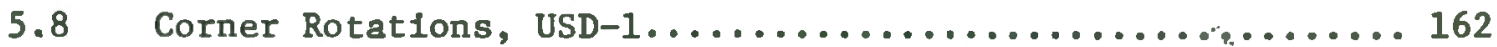

5.9 Components of Moment in Leeward Column, USD-1.......... 163

5.10 Lateral Force vs. $\delta$, USD $-1 \ldots \ldots \ldots \ldots \ldots \ldots \ldots \ldots \ldots \ldots \ldots$

5.11 Overall View of Frame USD-1 After Fallure............. 165

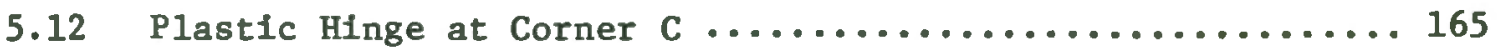

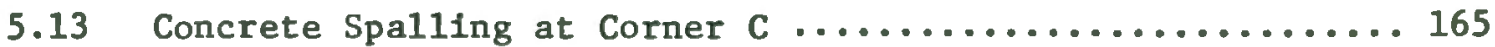

5.14 Flexural Cracks in the Middle Third of the Beam......... 166

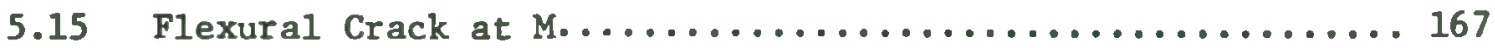

5.16 Flexural-shear Crack at $M^{\prime}$ (positive moment cutoff point).. 167

5.17 Axial Load vs. Moment, LD-1 ..................... 174

5.18 Lateral Force vs. Moment, LD-1.................... 175

5.19 Lateral Force vs. Lateral Deflection................ 176

5.20 Corner Rotations, LD-1........................ 177

5.21 Components of Moment in Leeward Column, LD-1.......... 178

5.22 Lateral Force vs. $\delta$, Frame LD-1................... 179

5.23 Overall View of Frame LD-1 After Fallure............... 180

5.24 Overall view of Frame LD-1 After Fallure.............. 180

5.25 Plastlc Hinge at Corner C ....................... 181

5.26 Flexural-shear Crack at Negative Moment Cutoff Point...... 181

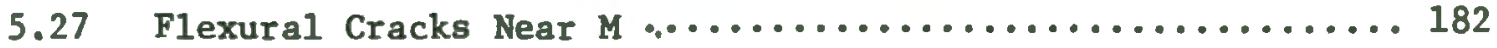

5.28 Flexural-shear Crack at $M^{\prime}$ (positive moment cutoff point).. 182 
5.29 Flexural Crack at B (occurred during reload cycle)....... 183

5.30 Collapse Mechanism for Frames USD-1 \& LD-1 ........... 189

5.31 Lateral Force vs. Lateral Deflection.................. 190

5.32 Frame Tests Compared to Stability Domains.............. 191 
CHAPTER I

INTRODUCTION

\subsection{BACKGROUND}

During the first half of this century indeterminate reinforced concrete structures were analyzed for moments, shears and reactions by linear-elastic theory. The members were then designed by assuming a straight-line stress-strain relationship and using allowable stresses for the concrete and relnforcing steel. This method for proportioning members was used primarily because of 1 ts mathematical simplicity. In 1956, the American Concrete Institute (1) allowed the member crosssections to be designed according to their inelastic properties, that 1s, their ultimate strengths. In this method, referred to as the Ultimate Strength Design Method, the service loads are multiplied by load factors depending on the required factor of safety. However, the linearelastic theory is st111 used to calculate the moments, shears, and reactions.

Another method to design structures is the plastic or ultimate load method. This method is an inelastic theory for indeterminate structures in which internal moment readjustments are taken into consideration. This technique has been widely accepted for steel structures in recent decades, but lags behind in its application to relnforced concrete. This can be attributed to two main causes:

1. For steel the section response to load may be assumed elastoplastic with considerable ductility. However, concrete is not a perfectly plastic material and is limited in ductility 
unless compression reinforcement or hoops are used.

2. In relnforced concrete structures, service loads may cause unacceptable flexural cracks.

Despite the complexities involved in applying an inelastic theory to refnforced concrete, there still remains the fact that concrete behaves inelastically at ultimate loads. Therefore, linear elastic theory is only a convenfent method to calculate the design moments. As a recognition of the inelastic behavior of reinforced concrete, the present Code (1) does allow some moment redistribution by modifying the calculated elastic moments.

\subsection{NONLINEAR BEHAVIOR OF REINFORCED CONCRETE}

If an inelastic theory is to be applied to refnforced concrete structures, the behavior of 1 ts members must first be well understood. Some of the early investigations were done to verffy the existence of moment redistribution (2). Later work (3) showed that in addition to moment redfstribution at or near the ultimate load, signiffcant moment redistribution occurred even at service loads.

Many investigations have been carried out to establish the rotational capactity of beams $(4,5)$. These studies have shown that concrete compression strains greatly exceed the usually assumed .003 .

Tests on columns $(6,7)$ have shown the affect of a number of variables on the strength of hinged and restrafned columns. The significant variables were the slenderness ratio, end eccentricities, and the ratto of end eccentricties.

Tests on columns were conducted at the Unfversfty of Texas to study the behavior of long columns as part of frames. The frames were loaded so as to study the behavfor of long columns in reversed 
curvature (8), single curvature (9), sidesway (10), and in frames where restraining beams develop yielding through strain hardening (11).

In developing an inelastic theory for unbraced frames, an assumption is that the structure remain in stable equilibrium as plastic hinges form. This is important for unbraced frames because of the secondary moments caused by the lateral sway of the frame. As plastic hinges form, the overall frame stiffness lowers which decreases the structure's resistance against an instability failure.

Recently, an investigation (12) was carried out to study the effects of high column thrusts on the stability of unbraced structures. It was concluded, based on analytical and experimental work, that unbraced frames subjected to high column thrusts and lateral loads remained in stable equilibrium until two hinges formed in the leeward foints of the structure. Consequently, Limit or Ultimate Load Design may not be applied to frames that carry high column thrusts. However, It was shown analytically (12) that a frame will remain in stable equilibrium until it reaches its ultimate load by forming a mechanism if the columns carry small axial loads.

If a frame remains in stable equilibrium until it forms a mechanism then limit design concepts may be applied. Some internal moment readfustment will then occur which will tend to reduce the peak moments at beam-column intersections. This decrease w11l cause moments to increase elsewhere. However, the decreased peak moment may help relleve the congestion of steel at the beam-column intersection. In addition, the inelastic design procedure is more realistic than linear-elastic theory. 
If Limit Design is applicable to unbraced frames, some important questions have to be answered concerning their behavior:

1. What is the affect of hinging on the stability of unbraced frames loaded to collapse? What affect does the column thrust have on frame stability?

2. From an economical and detalling point of view, how does a frame designed by a limit design method compare to a frame designed by the conventional ultimate strength design method?

3. How do the test behaviors of two frames that are designed by two different methods compare?

In order to answer the above questions, analytical work using computers, as well as physical tests on reinforced concrete frames are needed.

\subsection{PURPOSE OF THIS INVESTIGATION}

Generally, the objective of this study is to determine whether Limit Design can be applied to low-rise unbraced reinforced concrete structures. Specifically, the objectives are as follows:

1. To determine analytically the behavior of frames under gravity and lateral loading. The speciflc parameters will be the column-to-beam stiffness ratio and the beam-tocolumn load ratio.

2. To design two frames for the same load conditions; however, one frame by the Ultimate Strength method while the other by a LImit Design method.

3. To describe the test behavior of the two frames designed by different methods. 
4. To compare the two frames from an economical and detalling st andpoint.

\subsection{ORGANIZATION OF THE REPORT}

The analytical part of this study is discussed in Chapter II. Two mathematical models are used; one a program that takes material and geometric nonlinearity into account, and the other a hand calculated solution that assumes the members to possess elasto-plastic momentcurvature relationships. In Chapter III, the design methods and calculations are described for the two test frames. The fabrication, instrumentation, and testing of the test frames is discussed in Chapter IV, while the test results and predicted behavior are given in Chapter V. Finally, Chapter VI contains the summary and conclusions of this study, and recommendations for further research. 


\section{CHAPTER II}

\section{ANALYTICAL TREATMENT}

In this chapter, the stability of unbraced frames will be discussed, using two analytical methods.

The first method is by using a computer program that takes nonlinear geometry and force-deformation properties into account. This program is applied to three model frames that possess the same overal1 geometry but different beam and column reinforcement ratios. Each frame w111 be loaded with different values of column thrust.

The second method is a mathematical solution of an elasto-plastic stability model that w11 define the boundarfes where limit design can be applied.

Finally, the computer solution w11l be compared to the mathematical solution.

\subsection{REDUCTION OF UNBRACED FRAME TO MODEL AND TEST FRAME}

There are several loading patterns to consider in designing a reinforced concrete bullding frame. However, the worst loading pattern for frame instabllity occurs when all the floors are fully loaded. Shown In Figure 2.1 is a symmetrical n-story unbraced frame under beam loads $Q$, roof loads $Q / 2$ at beam third polnts and lateral loads. The bays have an equal width of $L_{b}$ and a story-ta-story height of $L_{c}$. The beams and columns are assumed to be rigfdly connected. 
The highest column thrusts occur at the first floor level. An interior panel is shown in Figure 2.2. The lateral load $\mathrm{H}$ is the total lateral load that must be resisted by this panel. This panel represents all interior panels from the first floor level on up. It also represents the first floor panel if the point of inflection is assumed at one-half the column height $\left(\mathrm{L}_{\mathrm{c}} / 2\right)$. This would be true for building footings that have soll-structure interaction stiffnesses equivalent to the connecting beam stiffness values. Since the frame is antisymmetrical about the midheight $\left(\mathrm{L}_{c} / 2\right)$ of the columns, a reduced frame may be analyzed, as shown in Figure 2.3.

The column load $\mathrm{P}$ at the first floor level for number of stories (n) can be expressed as a function of beam loads Q. Therefore, the Q/P ratio, excluding the increased column loads caused by the lateral load, is

$$
Q / P=1 /(2 n-2)
$$

Likewise, the relationship between the column thrust, $T$, and the beam load, $Q$, is

$$
Q / T=1 /(2 n-1)
$$

As shown by the above equations, the $Q / P$ and $Q / T$ ratios decrease as the number of stories is increased.

\subsection{DESCRIPTION OF FAILURE TYPES}

The main purpose of this work is to study the response of unbraced reinforced concrete frames under the Influence of gravity and lateral loads. According to the 71 ACI Code, Art. 9.3.2, 75\% of factored gravity loads and lateral loads must be considered in design. Therefore, the response of the frames acted on by $75 \%$ of the factored gravity loads 


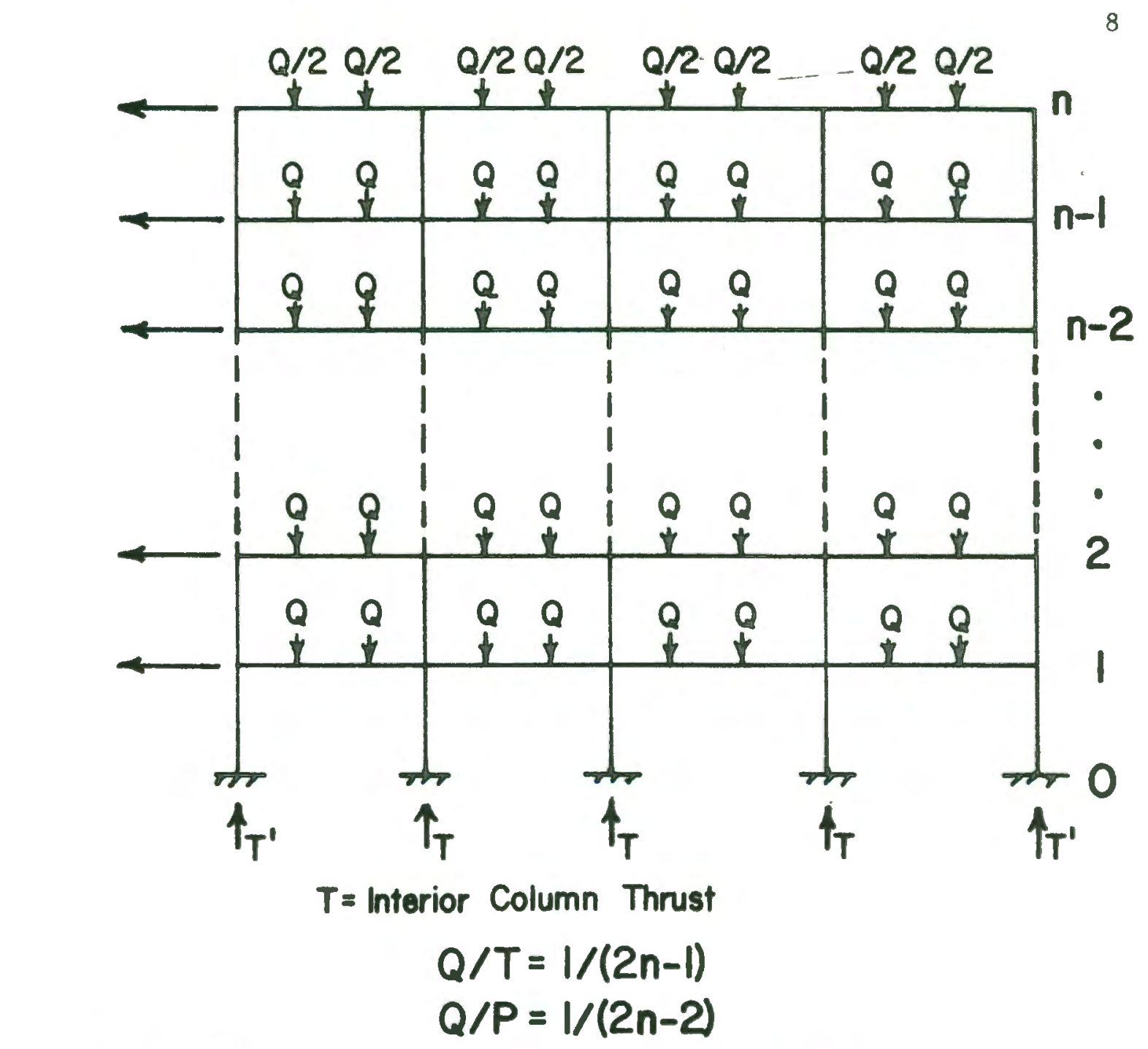

FIG.2.I MULTI-STORY UNBRACED FRAME
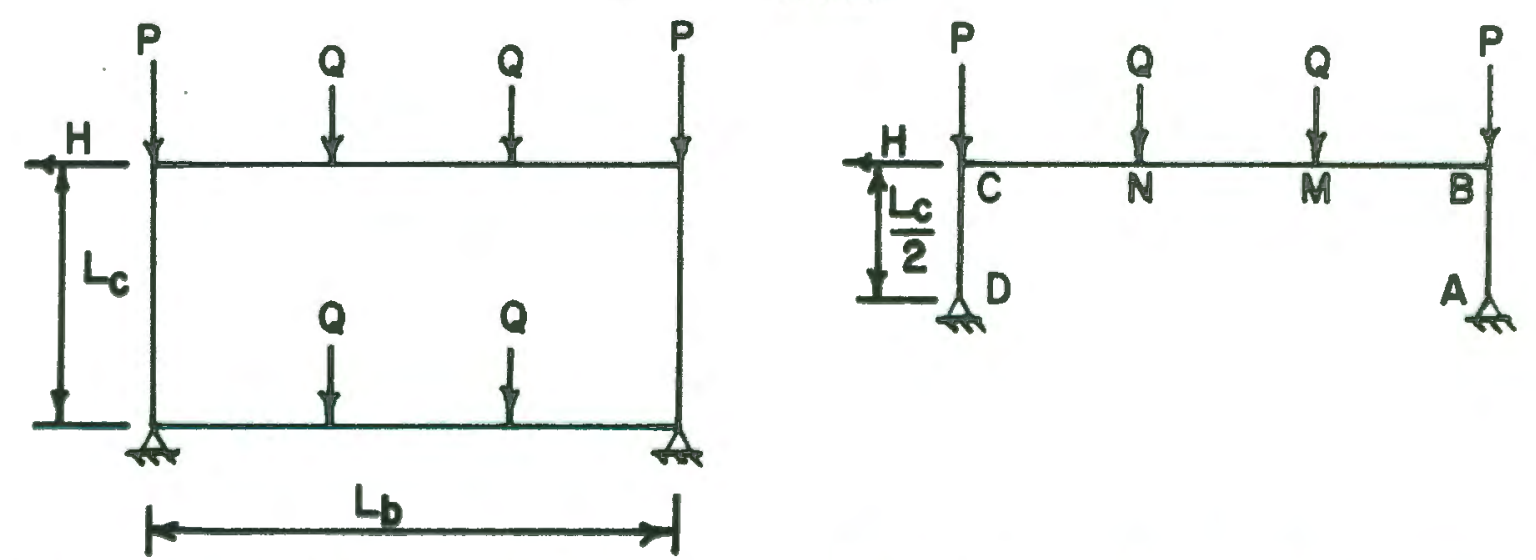

FIG.2.2 INTERIOR PANEL

FIG.2.3 REDUCED MODEL 
will be studied. The design of frames, however, will consider both loading conditions specified in 71 ACI Code, Art. 9.3.2. The frame loading sequence is

1. Apply gravity loads up to $75 \%$ of their design values

2. Apply lateral load H

Four types of failures, as described by Rad (12), can occur for the reduced model of Figure 2.3 as a result of gravity and lateral loads. The four types of fallure are shown in Figure 2.4 .

1. Type I: Elastic Frame Instability. This frame, as shown in Figure 2.4a, becomes unstable under large column loads. The frame fails within the elastic limits of the material.

2. Type II: Material Fallure. This failure occurs when a column section fails by crushing of the concrete, as shown in Figure 2.4b. 3. Type III: Frame Instability with Partial Plasticity. When the lateral load is applied to this structure it remains in stable equilibrium until a plastic hinge forms at the peak moment section, c. The lateral load that causes this hinge to form is denoted by $\mathrm{H}_{1}$. The frame, due to loss of stiffness, will not stay in a stable equilibrium position after the first hinge forms. This frame failure is shown in Figure $2.4 \mathrm{c}$.

4. Type IV: Instabilfty with Combined Mechanism. This structure remains in stable equilibrium until two critical sections have reached their bending capacity values, $M_{p}$. The extra lateral load that is needed to form a mechanism is denoted by $\mathrm{H}_{2}$. This failure type is shown in Figure $2.4 \mathrm{~d}$.

In this section the boundary between Types III and IV faflure will 


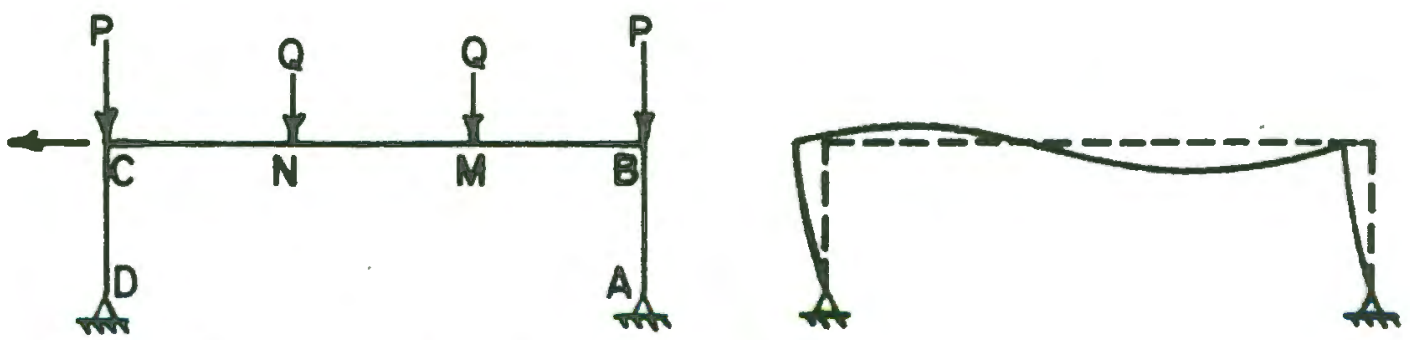

(a) TYPE I, ELASTIC INSTABILITY

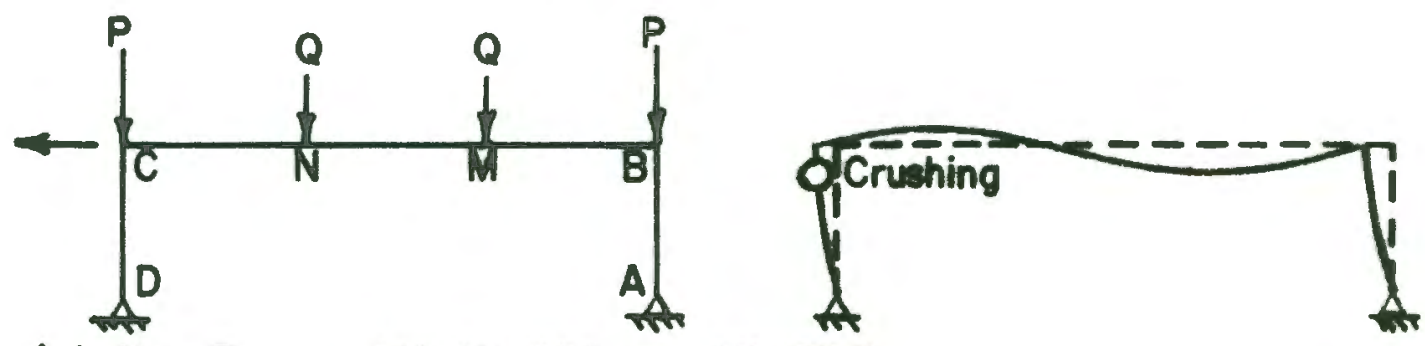

(b) TYPE II, MATERIAL FAILURE

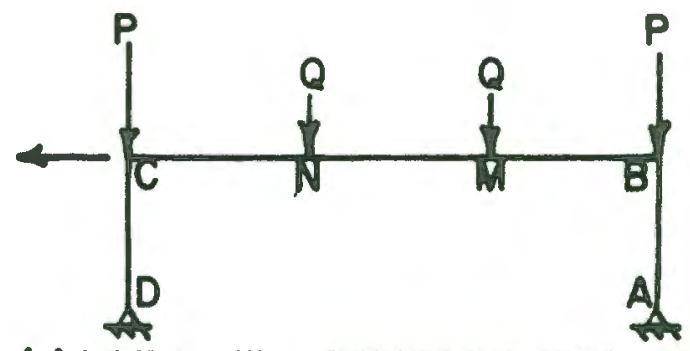

(c) TYPE III, INSTABILITY WITH PARTIAL PLASTICITY

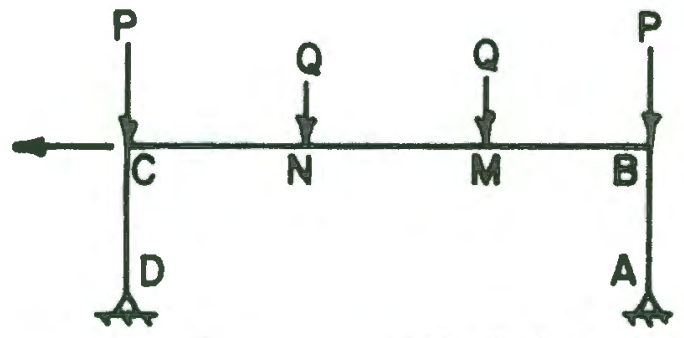

(d) TYPE IV, INSTABILITY WITH

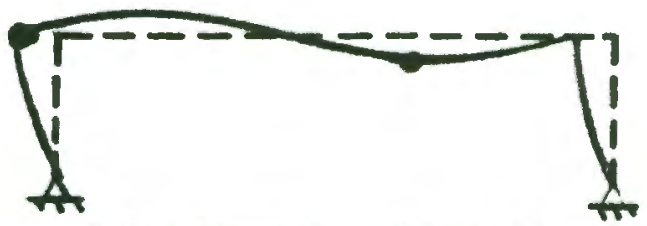

COMBINED MECHANISM

FIG. 2.4 FAILURE MODES 
be examined. The difference between these two types of failure is the additional lateral load, $\mathrm{H}_{2}$, that the frame can withstand after the first hinge forms. If Type III fallures occurs, $\mathrm{H}_{2}=0$, however, if Type IV fallures occurs then $\mathrm{H}_{2}>0$.

A useful index may be defined as the percentage of moment redistribution $B$ :

$$
B=\left(\mathrm{H}_{2} / \mathrm{H}\right) \times 100
$$

where $\mathrm{H}_{2}=$ the lateral load after the first hinge forms

$\mathrm{H}=$ Total lateral load capactty

For Type III fallure $\beta=0$, and for Type IV fallure $\beta>0$.

\subsection{PARAMETRIC STUDY OF MODEL FRAME}

In this section a nonlinear computer program is used to study the response of three different Interior panels under varlous Q/P ratios. The Q/P ratio relates directly to the number of stories that the panel is representing by Equation (2.1). For each panel, the maximum number of storles, $n$, that causes a Type IV fallure w111 be investigated.

\subsubsection{Program Description}

A program called "NONFIX7", (12), which is a modified version of program NONFIX5, developed by Gunnin (13), was used to analyze the frames.

The program uses the nonlinear force deformation properties (thrustmoment-curvature relationship) of the members. Therefore, the change In member stiffnesses caused by moments and thrusts are taken into account. The program uses polynomlals to describe the thrust-momentcurvature $(P-M-\emptyset)$ relationships. The $P-M-\emptyset$ relationships are generated 
by a subroutine (14) which assumes Hognestad's (15) stress-strain relationship for concrete in compression and an elasto-plastic stressstrain relationship for the steel (without strain hardening). The member sections are assumed to be symmetrically retnforced $\left(\rho=\rho^{\prime}\right)$ with a single steel layer on opposite faces.

The maximum ordinate on the concrete stress-strain curve was assumed as $1.0 \mathrm{f}_{\mathrm{c}}^{\prime}$; and the maximum concrete strain, $\varepsilon_{\mathrm{u}}$, as .0038 .

In addition to the nonlinear behavior of the material, the program includes the $P-\Delta$ moments caused by joint displacements.

\subsubsection{Frame Description}

Three cases of Interlor panels with overall geometry shown qualitatively in Figure 2.2, were analyzed by program NONFIX7.

The length of the columns $\left(L_{c}\right)$ and beams $\left(L_{b}\right)$ were 42-in. and 84-in. respectively. The cross-sections for the columns and beams were 6-in wide and 4-in deep with reinforcing in a single layer on two opposite faces throughout the length of the member $\left(p=p^{\prime}\right) \cdot A_{c} / h$ ratio of .25 was assumed for all sections, where $d_{c}=d i s t a n c e$ from the bar centrold to the nearest face. The relnforcement was assumed as grade $60\left(f_{y}=60 \mathrm{ksi}\right)$ and the concrete strength $f_{c}^{\prime}=4.0 \mathrm{ks}$.

The difference between the three cases was the percentage of reInforcement. For case $I$, the beams and columns were reinforced with four \#3 reinforcing bars which gave a beam reinforcement rat to of $\rho=\rho^{\prime}=.0122$, and column reinforcement ratio of $\rho_{t}=.0183$. Case II had 4-\#3 bars in the beam $\left(O=O^{\prime}=.0122\right)$ and $4-\# 4$ bars in the columns $\left(\rho_{t}=.0333\right)$. For Case III, the Eeams included 4-\#4 bars $\left(\rho=\rho^{2}=.0222\right)$ and columns 4-\#3 bars $\left(\rho_{t}=.0183\right)$. 
Therefore, the main difference between the three cases was the bending moment capacity $M_{p}$ and the relative folnt stiffness, $\psi$. However, the relative joint stiffness, if based on gross areas, is equal to $\psi_{\text {nom }}=$ 2,0 for all three cases.

\subsection{3-Procedure}

This section describes the computer output. All three cases were run on the computer starting with a $Q / P$ ratio of .25 ( $n=3$ stories). The loading sequence, consistent with 71 ACI Code, Art. 9.3.2, was applied as follows

1. Beam and column loads were proportionately applied to $75 \%$ of the capacity of the frame under gravity loads. The Q/P ratio depended on the number of stories the frame represented.

2. The beam and column loads remained constant as the lateral load was increased to failure.

The output from the computer consisted of joint displacements, member forces, and reactions. The above procedure, steps $1 \& 2$, was repeated for a Q/P ratio of $.167(n=4)$ and then repeated again with higher values of $n$ until a type III failure occured $\left(H_{2}=0\right)$. Therefore, the maximum number of stories was determined for each case in which a panel mechanism failure occurred (Type IV). Table 2.1 gives the beam to column load ratio (story number) and the beam and column reinforcement ratios for each case. 
TABLE 2.1

FRAME PARAMETERS

\begin{tabular}{|c|c|c|c|c|c|c|c|c|c|}
\hline Case & $\begin{array}{c}\text { Keep } \\
\text { Constant }\end{array}$ & \multicolumn{8}{|c|}{ Vary } \\
\hline I & $\begin{array}{l}\rho_{\mathrm{col}}=.0183 \\
\rho_{\mathrm{bm}}=.0120\end{array}$ & \multirow[t]{2}{*}{$\mathrm{n}$} & \multirow[t]{2}{*}{3} & \multirow[t]{2}{*}{4} & \multirow[t]{2}{*}{5} & \multirow[t]{2}{*}{6} & \multirow[t]{2}{*}{7} & \multirow[t]{2}{*}{8} & \multirow[t]{2}{*}{9} \\
\hline II & $\begin{array}{l}\rho_{\mathrm{co} 1}=.0333 \\
\rho_{\mathrm{bm}}=.0120\end{array}$ & & & & & & & & \\
\hline III & $\begin{array}{l}\rho_{\mathrm{col} 1}=.0183 \\
\rho_{\mathrm{bm}}=.0222\end{array}$ & $Q / P$ & .25 & .167 & .125 & .100 & .083 & .071 & .063 \\
\hline
\end{tabular}

\subsubsection{Interpretation of Computer Output}

From the computer output, three relationships were studied for each frame: column thrust-moment relationship $(\mathrm{P}-\mathrm{M})$ for joints $\mathrm{B}$ and C, lateral load-moment relationship $(H-M)$, and lateral load-deflection curve $(H-\Delta)$. The column thrust-moment curve gives the eccentricity ratios, e/h, for the column under gravity loading. Also, it shows if the plastic hinge forms in either the beam or column at corner $C$. The most useful plot is the lateral load-moment curve which is used to study the inelastic behavior of different sections. It helps determine the level of lateral load $\left(\mathrm{H}_{2}\right)$ that causes hinging at corner $\mathrm{C}$. The $\mathrm{H}-\Delta$ relationship does give some idea about the level of lateral load $\left(\mathrm{H}_{2}\right)$, but not as accurately as the $\mathrm{H}-\mathrm{M}$ response.

The response of each frame was studled by plotting the lateral load versus moment for corners $B$ and $C$, and point $M$. Three different $\mathrm{H}-\mathrm{M}$ curves, which represented different $\mathrm{Q} / \mathrm{P}$ ratios (stories $\mathrm{n}$ ), are 
shown qualitatively in Figure 2.5. These curves describe the behavior for case $I$. Because the bending capacity for the entire beam is $M_{p}$, the bending capacity at sections $B, C$ and $M$ is shown as a single value.

Shown in Figure 2.5, the first case, $n=3-4$, will now be examined. The moments at zero lateral load are caused by the beam loads Q. With increasing lateral load the moments at C, B and $M$ change almost linearly until the bending capacity at $\mathrm{C}$ is reached. Because the moment curvature relationship of beams include a slight transition curve from yield moment to the ultimate moment, there is a slight knee for moment at C as the bending capactty is approached. As more lateral load is applied, the moments at $B$ and $M$ increase more rapidly as shown by the change in slope. However, the bending moment at corner $C$ remains at $M_{p}$ whlle the moment at $M$ reaches 1 ts bending capacity. The moments at $B$ and $M$ increase more rapidly because of the decreased frame stiffness caused by hinging at $C$. After two sections $C$ and $M$ reach $M_{p}$, the frame deflects continuously, signifying instability failure (mechanism motion).

The response for $n=5-6$, as shown in Figure 2.5, is different from $n=3-4$ after the first hinge forms. This is because of higher column thrusts which cause higher $P-\Delta$ moments in the frame. Therefore, the slope of the $H-M$ curve for $B$ and $M$, after the first hinge forms, is flatter than for $n=3-4$. Nevertheless, the capacity at $M$ is reached which also causes a mechanism (Type IV).

The response for $n=8-9$, as shown by Figure 2.5 , was close to a Type III failure. The descending part of the moment curves for $B$ and M is determined by speclfying a lateral deflection in the input of program NONFIX7. Therefore, the lateral load needed to cause this dis- 

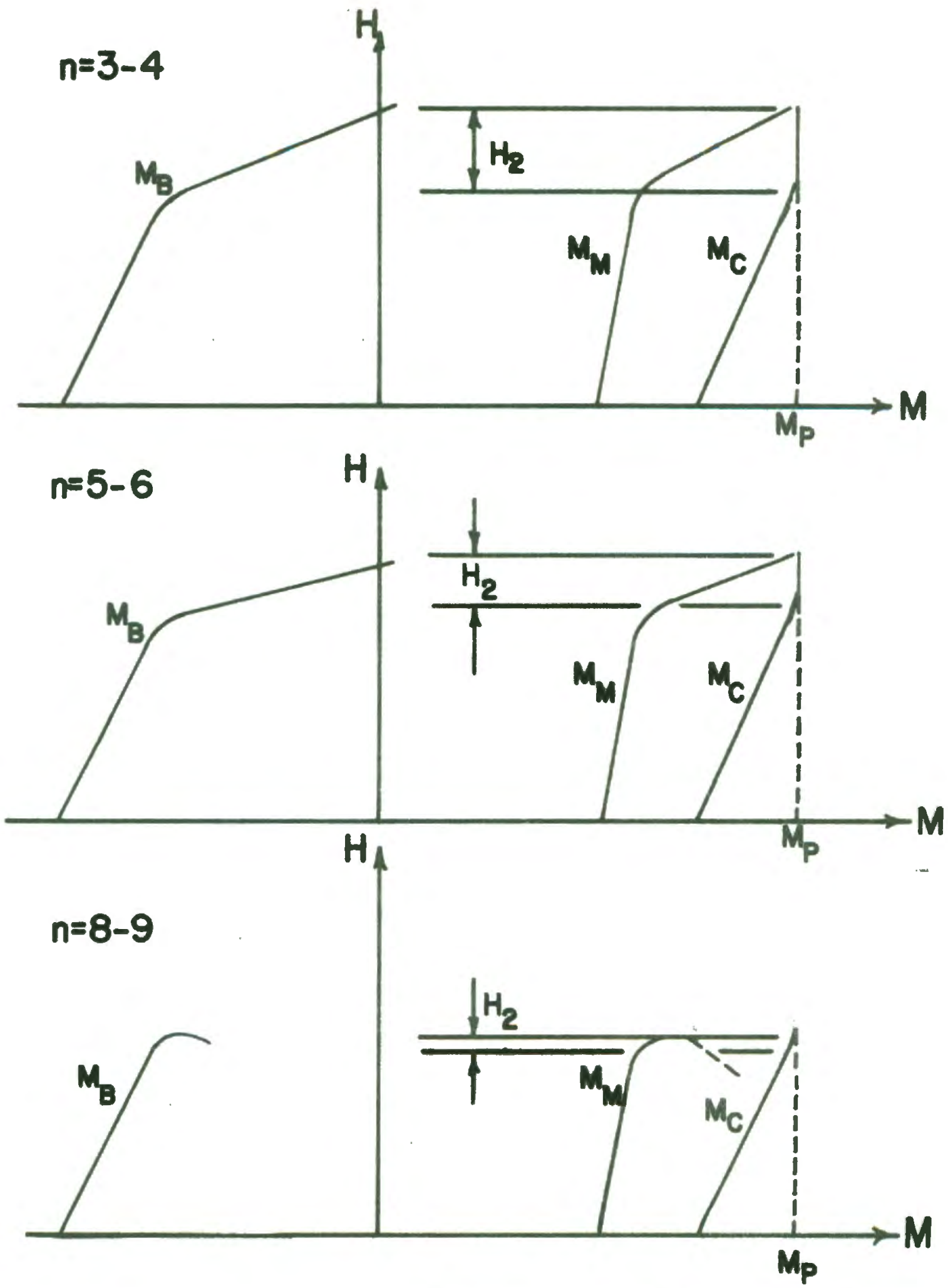

FIG.2.5 QUALITATIVE H-M CURVES FOR DIFFERENT STORIES (n) 
placement can be found. These $Q / P$ ratios (or $n$-values) help distinguish the boundary between Types III and IV failure.

The lateral load capacity for each frame was broken down into two parts; $\mathrm{H}_{1}$ and $\mathrm{H}_{2}$; where $\mathrm{H}_{1}$ is the lateral load that causes the first hinge to form, and $\mathrm{H}_{2}$ is the added lateral load causing a mechanism. As shown in Figure 2.5, the ultimate lateral load $\mathrm{H}$ and $\mathrm{H}_{2}$ decrease with increasing stories $n$.

The lateral load that causes the first hinge to form, $\mathrm{H}_{1}$, was determined by studying the $H-M$ plot for the moment at $C$. Essentially, the curve consists of two approximately linear parts which are connected by a curved segment. These linear parts were extended unt11 they intersected. Value of $\mathrm{H}_{1}$ was defined as the intersection of these two 11nes.

\section{$\underline{2.3 .5 \quad \text { Results }}$}

The results for each case are shown in Table 2.2. For each case, the table gives the eccentricity ratio e/h under gravity loads, column thrust $\mathrm{T}$, lateral load capacity $\mathrm{H}, \mathrm{H}_{1}, \mathrm{H}_{2}$ and percentage of moment redistribution $\mathrm{B}=\mathrm{H}_{2} / \mathrm{H}$.

For each case, a mechanism failure (Type IV fallure) occurred for frames up to nine storles. However, the percentage of moment redistribution decreased with increasing number of stories, $n$. The eccentricity ratio, e/h, decreased to an average value of 0.26 for $\mathrm{n}=9$. Also, the lateral load capacity of the frames decreased with increasing stories.

Figure 2.6 shows the moment redistribution index, $B=\mathrm{H}_{2} / \mathrm{H}$, as a function of the number of stories $n$. The top right hand corner gives 
TABLE 2.2

SUMMARY OF COMPUTER RESULTS

\begin{tabular}{|c|c|c|c|c|c|c|c|}
\hline CASE & $\mathrm{n}$ & $\begin{array}{c}\mathrm{T} \\
(\mathrm{k})\end{array}$ & $\mathrm{e} / \mathrm{h}$ & $\begin{array}{c}\mathrm{H} \\
(1 \mathrm{~b})\end{array}$ & $\begin{array}{c}\mathrm{H}_{1} \\
(1 \mathrm{~b})\end{array}$ & $\begin{array}{c}\mathrm{H}_{2} \\
(1 \mathrm{~b}) \\
\end{array}$ & $\begin{array}{r}\mathrm{H}_{2} / \mathrm{H} \\
(\%)\end{array}$ \\
\hline \multirow{7}{*}{ I } & 3 & 8.1 & .90 & 1600 & 800 & 800 & 50 \\
\hline & 4 & 11.6 & .64 & 1300 & 700 & 600 & 46 \\
\hline & 5 & 15.8 & .50 & 900 & 550 & 350 & 39 \\
\hline & 6 & 18.7 & .41 & 800 & 600 & 200 & 25 \\
\hline & 7 & 20.6 & .33 & 950 & 800 & 150 & 16 \\
\hline & 8 & 23.6 & .29 & 750 & 700 & 50 & 7 \\
\hline & 9 & 30.0 & .25 & 400 & 400 & 0 & 0 \\
\hline \multirow{7}{*}{ II } & 3 & 8.1 & .88 & 1600 & 750 & 850 & 53 \\
\hline & 4 & 11.6 & .65 & 1200 & 700 & 500 & 42 \\
\hline & 5 & 14.6 & .50 & 1150 & 700 & 450 & 39 \\
\hline & 6 & 17.6 & .42 & 1000 & 700 & 300 & 30 \\
\hline & 7 & 20.5 & .34 & 850 & 650 & 200 & 24 \\
\hline & 8 & 23.6 & .30 & 750 & 700 & 50 & 7 \\
\hline & 9 & 25.5 & .28 & 650 & 650 & 0 & 0 \\
\hline \multirow{7}{*}{ II I } & 3 & 13.1 & .88 & 2550 & 1500 & 1050 & 41 \\
\hline & 4 & 18.6 & .65 & 2000 & 1200 & 800 & 40 \\
\hline & 5 & 24.2 & .49 & 1700 & 1100 & 600 & 35 \\
\hline & 6 & 29.1 & .40 & 1450 & 1100 & 350 & 24 \\
\hline & 7 & 33.5 & .33 & 1250 & 1100 & 150 & 12 \\
\hline & 8 & 38.5 & .29 & 1030 & 1000 & 50 & 5 \\
\hline & 9 & 42.4 & .26 & 950 & 950 & 0 & 0 \\
\hline
\end{tabular}




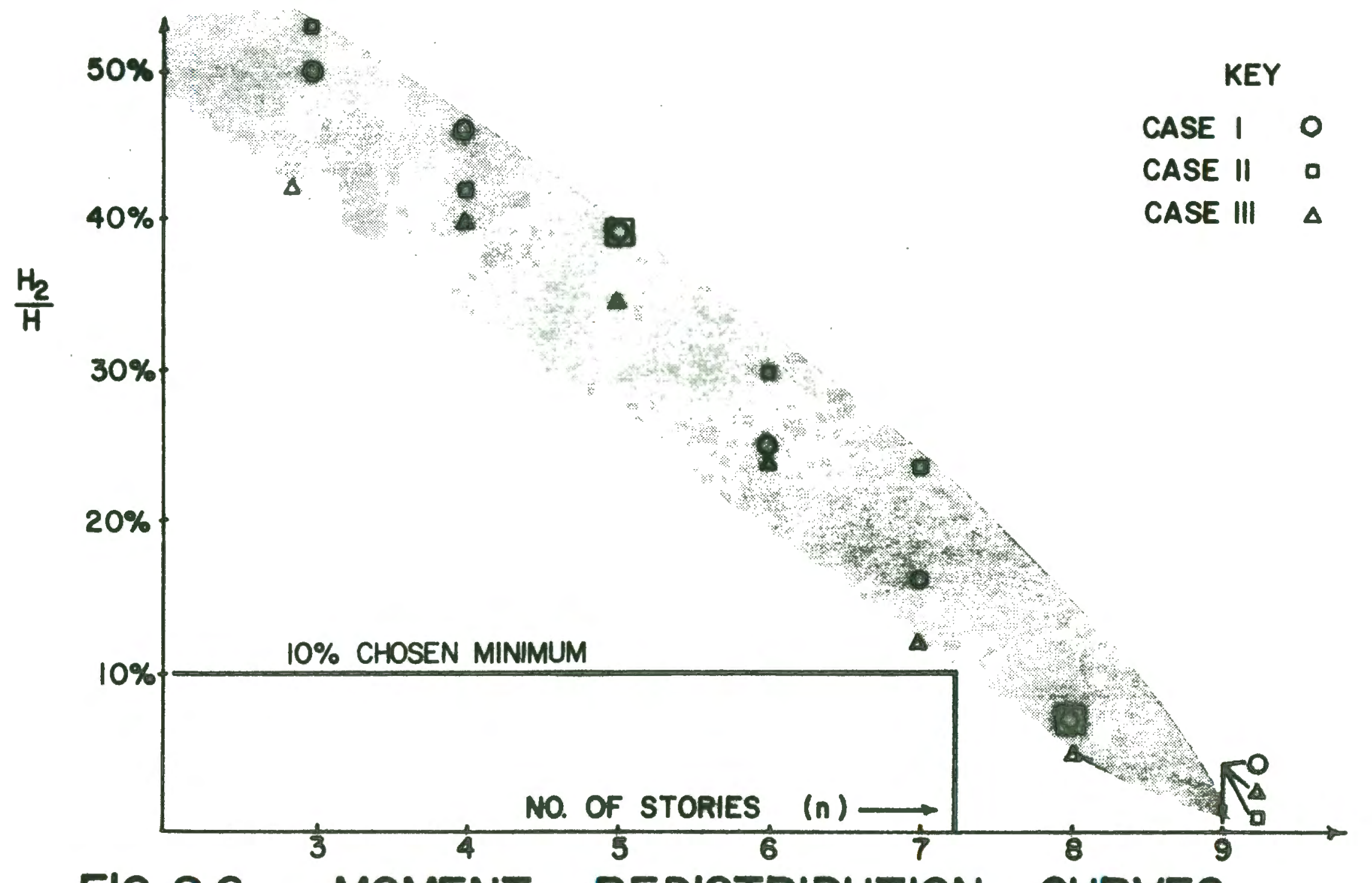

FIG. 2.6 MOMENT REDISTRIBUTION CURVES 
the symbols used for each case,

The points generally fall in a banded area, shown as the shaded area in Figure 2.6. The shaded part graphically shows the decreasing moment redistribution with increasing number of stories, $n$.

If limit design is applicable, the frame must have some degree of moment redistribition capability. A minimum $\beta$ of $10 \%$ was arbitrarily chosen, which Indicates a maximum number of stories of about 7; as shown in Figure 2.6.

\subsection{ETASTO=PLASTIC STABIJITY MODEL.}

In this section, the inelastic buckling 1oad for the reduced model of Figure 2.3 is investigated using two methods. The first method uses an equilibrium equation that includes $\mathrm{P}-\Delta$ moments. The stability equation is determined by the princtple of neutral equilibrium. This method Is applied to two cases; one when the second hinge forms at $B$ and the other when the second hinge forms at $M$.

The solution to the Inelastic buckling load has been shown by Rad (12) for the first case, that is, when the second hinge forms at B. The solution will be summarlzed here so as to introduce the notation and method.

The loading sequence is the same as the computer analysis and frame tests. First, the column loads $P$ and beam loads $Q$ are applied proportionately up to a certain level. For generality, the gravity loads are not necessar 11 y increased to $75 \%$ of their ultimate values. Then, the lateral load is applied unt il the frame fails.

The assumptions made in the analysts of the reduced model are as. foilows (12): 
1. The beam and column cross section possess elasto-plastic moment-curvature relations. Also, the flexural stiffnesses, $E I_{b}$ and $E I_{c}$, do not change along the length of the members.

2. The change in column thrust caused by the lateral load is neglected.

3. The moment caused by the product of column thrust and the column deflection from the chord connecting the column ends is neglected. This means that the moment diagram caused by frame deflection along each column is linear rather than curved.

4. The beam bending capacity, $M_{p}$, is the same for negative and positive bending and is constant throughout the length of the beam.

The reduced frame is studied for two different loading stages. The first stage exists until the first hinge forms at corner $C$. This hinge is caused by gravity loads $P$ and $Q$, and lateral load $H_{1}$. The second stage exists after the second hinge forms at $B$. The second hinge forms because of additional lateral load $\mathrm{H}_{2}$.

The definitions of symbols used in the following discussion are given below:

P Axial load on the column

Q Applied load on the beam at third points

$\mathrm{L}_{b} \& \mathrm{~L}_{c}$ Lengths of the beam and column

$M_{P} \quad$ Plastic moment capacity of either the heam or column

EI $I_{b} \quad$ Flexura1 stiffness of the beam

EI Flexural stiffness of the column 
$\psi \quad$ Relative flexural stiffness of the column and beam $=\frac{E I_{c} / L_{c}}{E I_{b} / L_{b}}$

H Lateral load applied at corner C

$\mathrm{H}_{1} \quad$ Lateral load needed to form the first hinge

$\mathrm{H}_{2} \quad$ Additional lateral load needed to form the second hinge

$\Delta \quad$ Lateral deflection of the frame

$\Delta_{1} \quad$ Lateral deflection of the frame when the first hinge forms

$\Delta_{2}$ Additional lateral deflection of the frame when the second hinge forms

Sign convention: Clockwise moment on the columns at corners $\mathrm{B}$ or $\mathrm{C}$ is position.

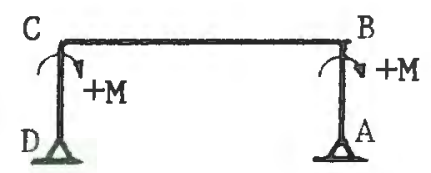

All moments are drawn on the compression side of the members.

The gravity moments at corners $\mathrm{B}$ and $\mathrm{C}$ are determined by moment distribution. Because the column base is hinged and the beam is bent symmetrically, the distribution factor (D.F.) for the column is

$$
\text { D.F. }=\frac{\left(\frac{E I_{c}}{E_{c} / 2}\right)}{\frac{E I_{c}}{L_{c} / 2}+.50\left(\frac{E I_{b}}{L_{b} / 2}\right)}
$$

The expression for $\psi$ is substituted into the above:

$$
\text { D.F. }=\frac{3 \psi}{3 \psi+1}
$$

This is multiplied by the fixed end moment caused by the beam loads $Q$. Therefore, the moment is 


$$
\dot{M}=\left(\frac{3 \psi}{3 \psi+1}\right)\left(\frac{2}{9} Q_{b}\right)=\left(\frac{2 \psi}{9 \psi+3}\right) Q_{b}=F_{Q} L_{b}
$$

where $F=\frac{2 \psi}{9 \psi+3}$

\subsubsection{Second Hinge at B}

Figure 2.7 shows the moments up to the first hinge. For ease of calculation the moments were broken into two parts and then added together. The moments caused by beam loads are shown In Figure 2.7a while the moments caused by the lateral load $\mathrm{H}_{1}$ and lateral deflection $\Delta_{1}$ are shown in Figure $2.7 \mathrm{~b}$.

Since the peak moment is at corner $C$ the flrst hinge will form here in either the beam or column. The expression for the moment at $C$ is set equal to $M_{p}$ :

$$
\mathrm{FQL}_{\mathrm{b}}+\mathrm{H}_{1} \mathrm{~L}_{c} / 4+(\mathrm{P}+\mathrm{Q}) \Delta_{1}=\mathrm{M}_{\mathrm{P}}
$$

This is rearranged:

$$
\mathrm{H}_{1} \mathrm{~L}_{c} / 4+(\mathrm{P}+\mathrm{Q}) \Delta_{1}=\mathrm{M}_{\mathrm{P}}-\mathrm{FQL}
$$

After the first hinge forms the additional moments are caused by the lateral load $\mathrm{H}_{2}$ and the added deflection $\Delta_{2}$. The loads and moments after the first hinge forms are shown in Figure 2.8. As the frame deflects, the moment at corner $C$ must remain constant at $M_{p}$. Therefore, the added moment $(P+Q) \triangle_{2}$ on column $C D$ must be opposed by a horizontal shear force equal to $2(P+Q) \Delta_{2} / L_{c}$. This shear force is transferred to column $A B$ so as to keep the frame in equilibrlum. This added shear force is shown in F1gure 2.85.

The moment at corner $B$, which is caused by lateral load $\mathrm{H}_{1}$, gravity loads $Q$ and $P$, and lateral deflection $\Delta_{1}$, is 

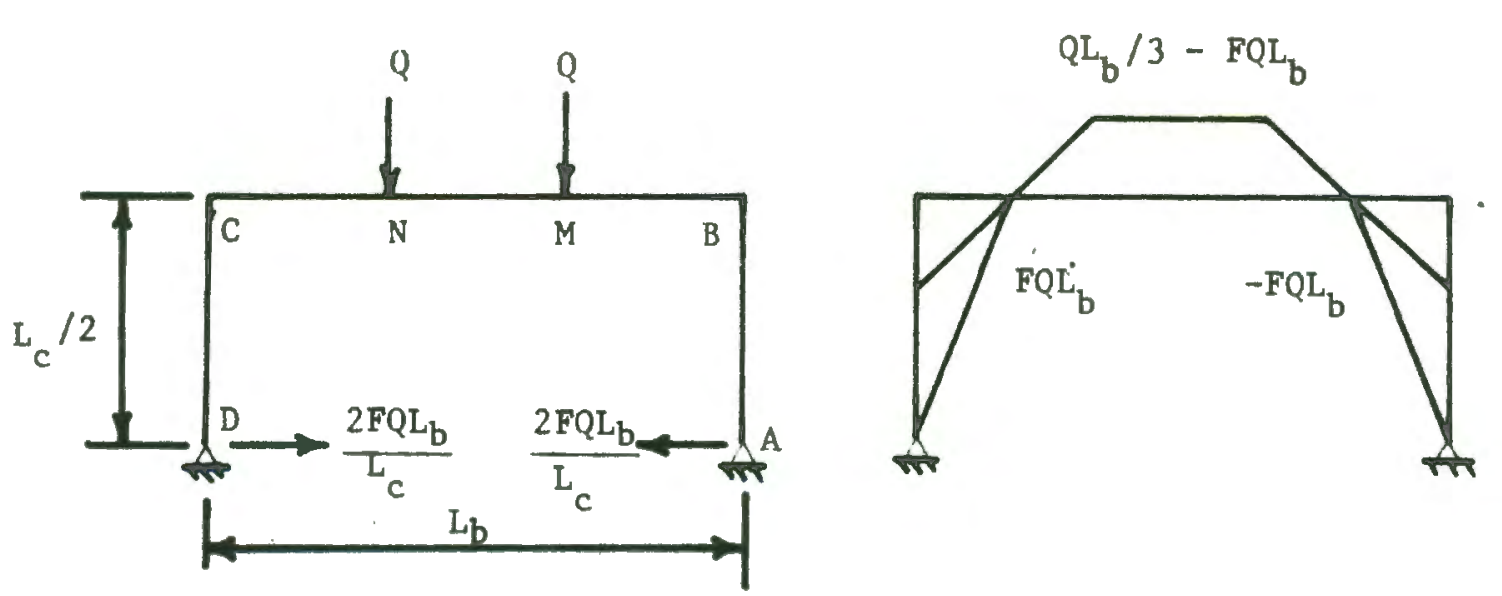

(a) BEAM LOADS Q AND MOMENTS

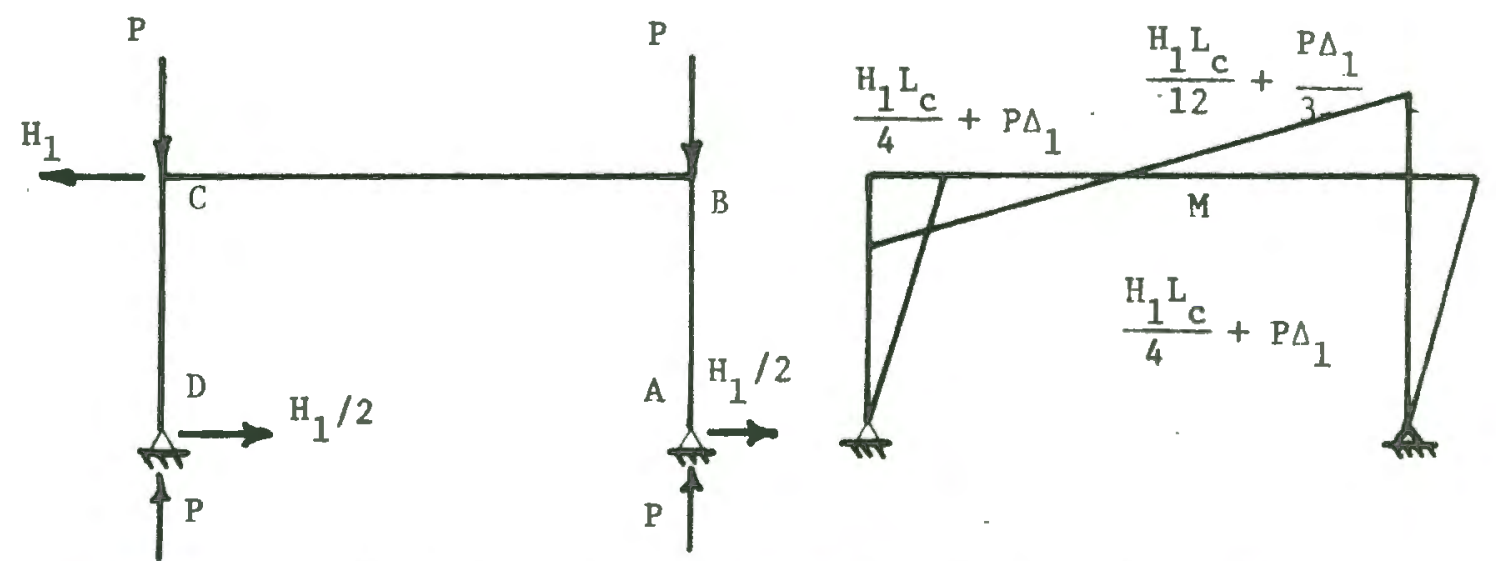

(b)SWAY LOAD $H_{1}$, COLUMN LOADS P, AND MOMENTS
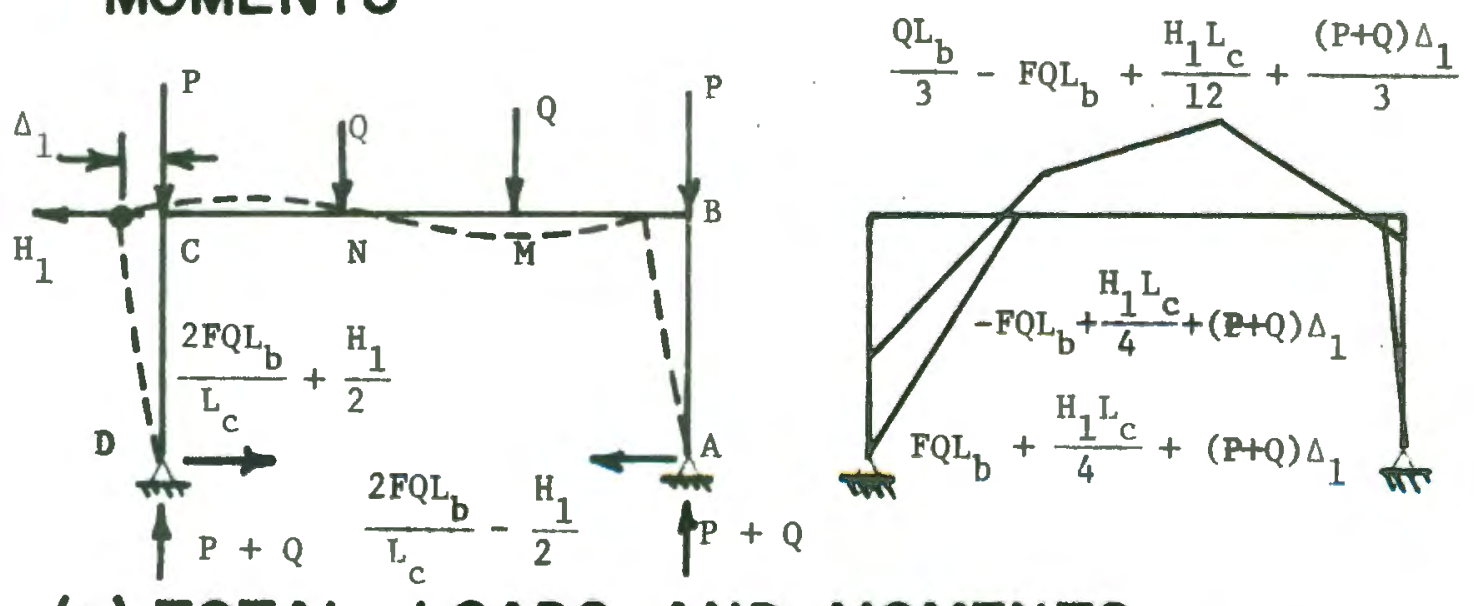

(c) TOTAL LOADS AND MOMENTS FIG.2.7 LOADS AND MOMENTS 


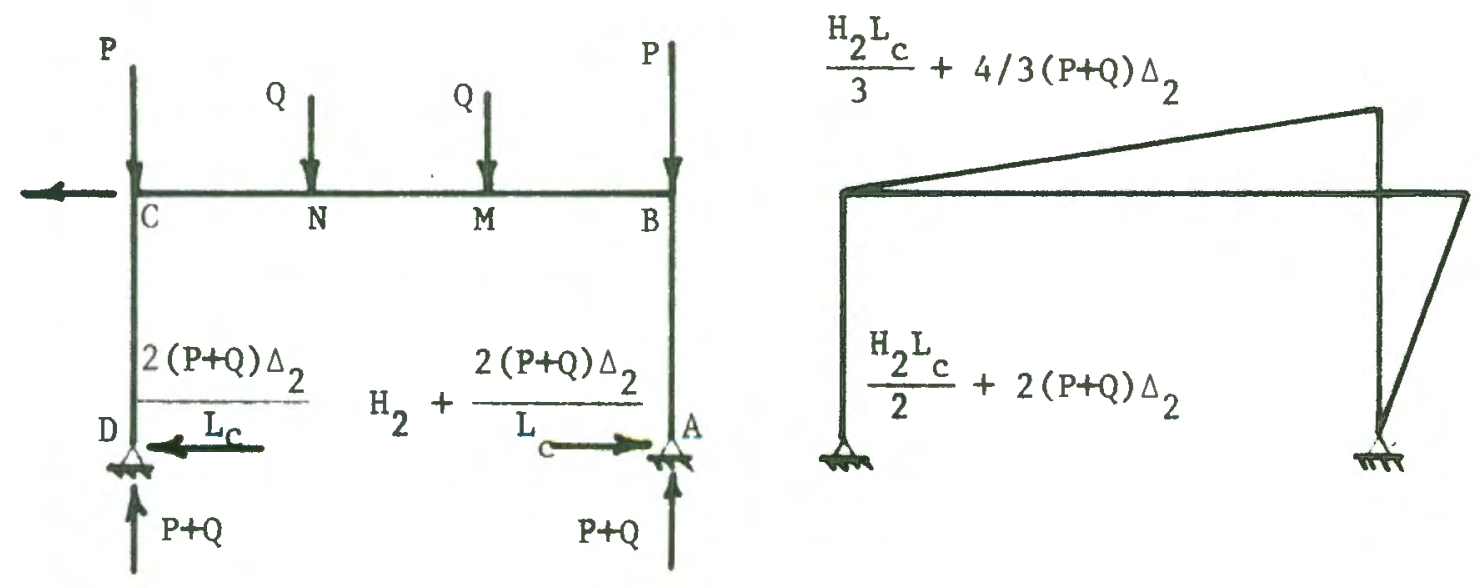

(a)SWWAY LOAD $\mathrm{H}_{2}$, AND MOMENTS

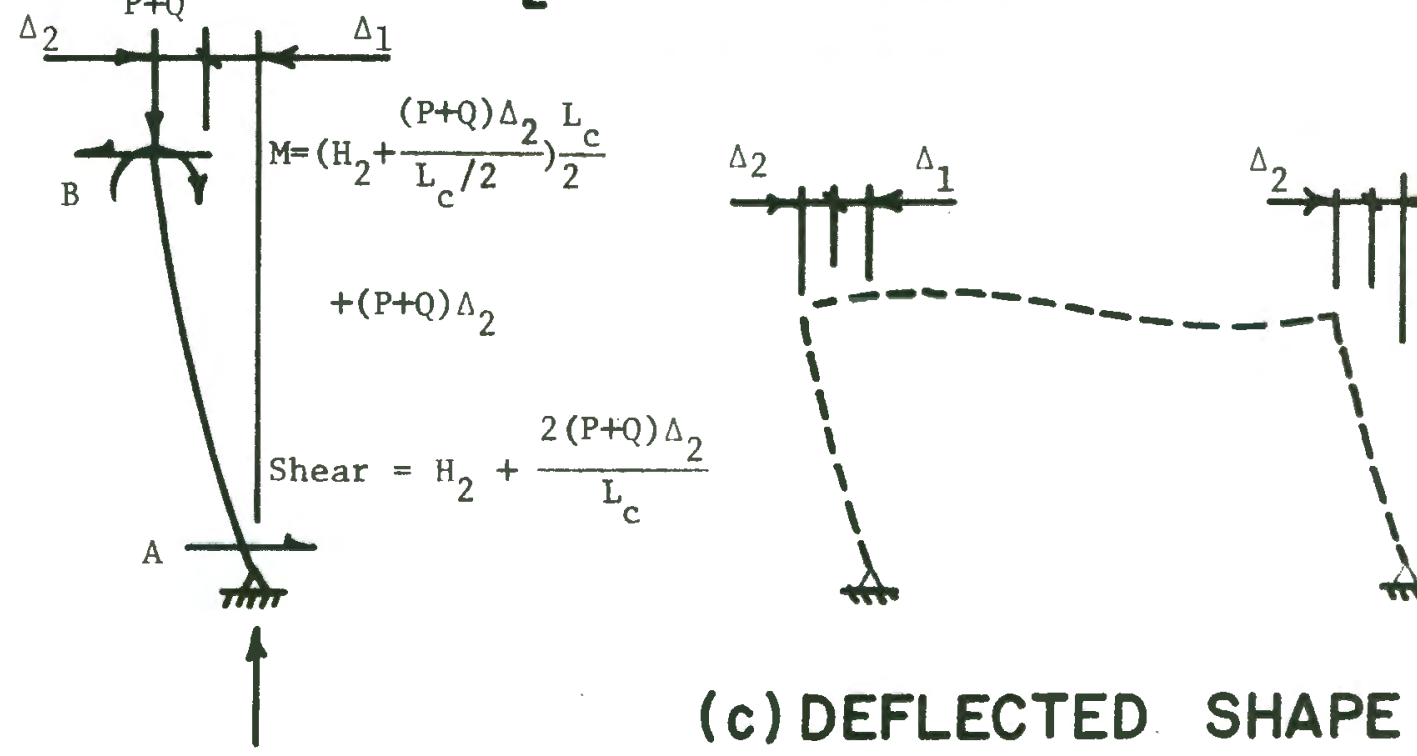

(b) FB.D. OF COLUMN AB

FIG.2.8 LOADS AND MOMENTS AFTER THE FIRST HINGE 


$$
M_{B}=-F Q L_{b}+H_{1} L_{c} / 4+(P+Q) \Delta_{1}
$$

The moment caused by lateral load $\mathrm{H}_{2}$ and lateral deflection $\Delta_{2}$ is

$$
M_{B}=\left(H_{2}+\frac{(P+Q) \Delta_{2}}{L_{c} / 2}\right) L_{c} / 2+(P+Q) \Delta_{2}=H_{2} L_{c} / 2+2(P+Q) \Delta_{2}
$$

The total moment at B is found by adding equations (2.5) and (2.6). Also, at collapse, $M_{B}$ equals $M_{P}$. This gives

$$
\begin{aligned}
& M_{P}=-\mathrm{FQL}_{b}+\mathrm{H}_{1} \mathrm{~L}_{c} / 4+(\mathrm{P}+\mathrm{Q}) \Delta_{1}+\mathrm{H}_{2} \mathrm{~L}_{c} / 2+2(\mathrm{P}+\mathrm{Q}) \Delta_{2} \text { or } \\
& \mathrm{H}_{2} \mathrm{~L}_{c} / 2=\mathrm{M}_{\mathrm{P}}+\mathrm{FQL}_{\mathrm{b}}-\mathrm{H}_{1} \mathrm{~L}_{c} / 4-(\mathrm{P}+\mathrm{Q}) \Delta_{1}-2(\mathrm{P}+\mathrm{Q}) \Delta_{2}
\end{aligned}
$$

The value of $\mathrm{H}_{1} \mathrm{~L}_{\mathrm{c}} / 4+(\mathrm{P}+\mathrm{Q}) \Delta_{1}$ from equation (2.4) is substituted into the same expression contained in equation (2.7):

$$
\begin{aligned}
& \mathrm{H}_{2} \mathrm{~L}_{c} / 2=M_{\mathrm{P}}+F \mathrm{~L}_{b}-M_{P}+F Q L_{b}-2(P+Q) \Delta_{2} \\
& \mathrm{H}_{2} \mathrm{~L}_{c} / 2=2 F Q L_{b}-2(P+Q) \Delta_{2}
\end{aligned}
$$

The lateral load $\mathrm{H}_{2}$ and lateral deflection $\Delta_{2}$ can be related by using the area-moment theorem. This theorem is applied to the triangular moment diagram shown in Figure $2.8 \mathrm{~b}$.

$$
\Delta_{2}=\frac{\mathrm{ML}_{\mathrm{b}}}{3 \mathrm{EI}_{\mathrm{b}}} \times \frac{\mathrm{L}_{\mathrm{c}}}{2}+\frac{\mathrm{ML}_{\mathrm{c}}^{2}}{12 \mathrm{EI}}
$$

But

$$
\mathrm{M}=\mathrm{H}_{2} \mathrm{~L}_{\mathrm{c}} / 2+2(\mathrm{P}+\mathrm{Q}) \Delta_{2}
$$

Therefore

$$
\Delta_{2}=\frac{\left[\mathrm{H}_{2} \mathrm{~L}_{c} / 2+2(\mathrm{P}+\mathrm{Q}) \Delta_{2}\right]}{6 \mathrm{EI}_{\mathrm{b}}}+\frac{\left[\mathrm{H}_{2} \mathrm{~L}_{\mathrm{c}} / 2+2(\mathrm{P}+\mathrm{Q}) \Delta_{2}\right] \mathrm{L}_{c}{ }^{2}}{12 \mathrm{EI} \mathrm{I}_{\mathrm{c}}}
$$

since $\quad \psi=\frac{E I_{c} / L_{c}}{E I_{b} / I_{b}}$

$$
\Delta_{2}=\frac{\mathrm{H}_{2} \mathrm{~L}_{c}^{2}(2 \psi+1)}{24 \mathrm{EI} / \mathrm{L}_{c}-4(P+Q) \mathrm{L}_{c}(2 \psi+1)}
$$


Now equation $(2.11)$ is substituted into equation (2.8):

$$
\begin{aligned}
& \mathrm{H}_{2} \mathrm{~L}_{c} / 2=\mathrm{FQL}_{\mathrm{b}}-2(\mathrm{P}+\mathrm{Q}) \frac{\mathrm{H}_{2} \mathrm{~L}_{c}^{2}(2 \psi+1)}{24 \mathrm{EI} \mathrm{C}^{/ \mathrm{L}_{c}}-4(\mathrm{P}+\mathrm{Q}) \mathrm{L}_{c}(2 \psi+1)} \\
& \mathrm{H}_{2}=\frac{2 \mathrm{FQL}_{\mathrm{b}}}{\mathrm{L}_{c} / 2+\frac{2(\mathrm{P}+\mathrm{Q}) \mathrm{L}_{c}{ }^{2}(2 \psi+1)}{24 E \mathrm{I}_{c} / \mathrm{L}_{c}-4 \mathrm{~L}_{c}(\mathrm{P}+\mathrm{Q})(2 \psi+1)}}
\end{aligned}
$$

or

$$
\mathrm{H}_{2}=\frac{F Q L_{b}}{L_{c}}\left[4-\frac{2 L_{c}^{2}}{3 E I_{c}}(P+Q)(2 \psi+1)\right]
$$

The index value for the critical buckling load, $P_{E}=\frac{\pi^{2} E I c}{L_{c}{ }^{2}}$, is substituted into the above equation:

$$
\mathrm{H}_{2}=\frac{\mathrm{FQL}_{\mathrm{b}}}{\mathrm{L}_{\mathrm{c}}}\left[4-\frac{2 / 3 \pi^{2}(\mathrm{P}+\mathrm{Q})(2 \psi+1)}{\mathrm{P}_{\mathrm{E}}}\right.
$$

Now the condition of neutral equilibrium will be applied. If the frame is unstable after the first hinge forms then $\mathrm{H}_{2}$ is equal to zero. From equation (2.12), $\mathrm{H}_{2}$ is zero when the bracketed expression is zero. Therefore

$$
\frac{2 / 3 \pi^{2}(P+Q)(2 \psi+1)}{P_{E}}=4
$$

and

$$
\frac{P+Q}{P_{E}}=\frac{6}{\pi^{2}(2 \psi+1)}
$$

\subsubsection{Second Hinge at $M$}

The second hinge will now be assumed to form at $M$. The moment at $M$ up to the first hinge, as shown in Figure 2.7 , is

$$
M_{M}=Q_{b} / 3-F Q L_{b}+H_{1} L_{c} / 12+1 / 3(P+Q) \Delta_{1}
$$

The moments caused by lateral deflection $\Delta_{2}$ and lateral load $\mathrm{H}_{2}$ is 


$$
\begin{aligned}
M_{M} & =\left(H_{2}+\frac{(P+Q) \Delta_{2}}{L_{c} / 2}\right) L_{c} / 3+2 / 3(P+Q) \Delta_{2} \\
& =H_{2} L_{c} / 3+4 / 3(P+Q) \Delta_{2}
\end{aligned}
$$

The total moment is found by adding equations (2.14) and (2.15). Also, at collapse, $\mathrm{M}_{\mathrm{M}}$ equals $\mathrm{M}_{\mathrm{P}}$

$$
\mathrm{M}_{\mathrm{P}}=\mathrm{QL}_{\mathrm{b}} / 3-\mathrm{FQL}_{\mathrm{b}}+\mathrm{H}_{1} \mathrm{~L}_{\mathrm{c}} / 12+1 / 3(\mathrm{P}+\mathrm{Q}) \Delta_{1}+\mathrm{H}_{2} \mathrm{~L}_{\mathrm{c}} / 3+4 / 3(\mathrm{P}+\mathrm{Q}) \Delta_{2}
$$

or

$$
\mathrm{H}_{2} \mathrm{~L}_{c} / 3=\mathrm{M}_{\mathrm{P}}-\mathrm{QL}_{\mathrm{b}} / 3+\mathrm{FQL_{b }}-\mathrm{H}_{1} \mathrm{~L}_{c} / 12-1 / 3(\mathrm{P}+\mathrm{Q}) \Delta_{1}-4 / 3(\mathrm{P}+\mathrm{Q}) \Delta_{2}
$$

or

$$
\mathrm{H}_{2} \mathrm{~L}_{c} / 3=\mathrm{M}_{\mathrm{P}}-\mathrm{QL}_{\mathrm{b}} / 3+\mathrm{FQL}_{\mathrm{b}}-1 / 3\left(\mathrm{H}_{1} \mathrm{~L}_{\mathrm{c}} / 4+(\mathrm{P}+\mathrm{Q}) \Delta_{1}\right)
$$

$$
4 / 3(\mathrm{P}+\mathrm{Q}) \Delta_{2}
$$

The value of $\mathrm{H}_{1} \mathrm{~L}_{\mathrm{c}} / 4+(\mathrm{P}+\mathrm{Q}) \Delta_{1}$ from equation (2.4) is substituted into the expression inside the parenthesis of equation (2.16)

$$
\mathrm{H}_{2} \mathrm{~L}_{\mathrm{c}} / 3=2 / 3 \mathrm{M}_{\mathrm{P}}-\mathrm{QL}_{\mathrm{b}} / 3+4 / 3 \mathrm{FQL}_{\mathrm{b}}-4 / 3(\mathrm{P}+\mathrm{Q}) \Delta_{2}
$$

The expression for $\Delta_{2}$ from the moment-area theorem, as given by equation (2.11), is substituted into equation (2.17):

$$
\mathrm{H}_{2} \mathrm{~L}_{c} / 3=2 / 3 \mathrm{M}_{\mathrm{P}}-\mathrm{QL}_{\mathrm{b}} / 3+4 / 3 \mathrm{FQL}_{\mathrm{b}}-\frac{4 / 3(\mathrm{P}+\mathrm{Q}) \mathrm{H}_{2} \mathrm{~L}_{c}^{2}(2 \psi+1)}{24 \mathrm{EI} / \mathrm{L}_{c}-4(\mathrm{P}+\mathrm{Q}) \mathrm{L}_{c}(2 \psi+1)}
$$

This equation is simplified:

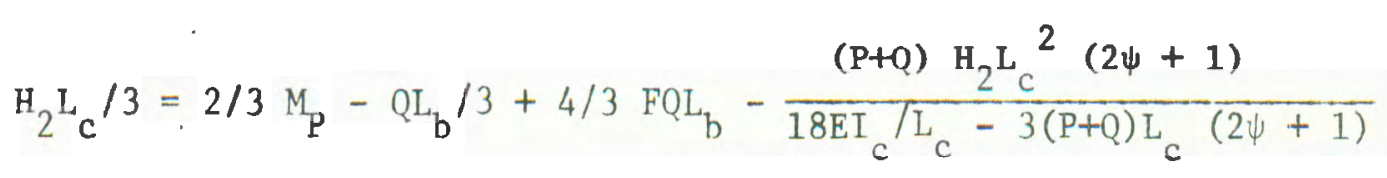


The equation is solved for $\mathrm{H}_{2}$ :

$$
\begin{aligned}
& \mathrm{H}_{2}=\frac{2 / 3 \mathrm{M}_{\mathrm{P}}-\mathrm{QL}_{\mathrm{b}} / 3+4 / 3 \mathrm{FQI}_{\mathrm{b}}}{\left(\mathrm{P}+\mathrm{Q}_{\mathrm{L}} \mathrm{L}_{c}^{2}(2 \psi+1)\right.} \\
& 18 \mathrm{EI}_{\mathrm{c}} / \mathrm{L}_{\mathrm{c}}-3(\mathrm{P}+\mathrm{Q}) \mathrm{L}_{\mathrm{c}}(2 \psi+1) \\
& =\left[2 / 3 \mathrm{M}_{\mathrm{P}}-\mathrm{QL}_{\mathrm{b}} / 3+4 / 3 \mathrm{FQI}_{\mathrm{b}}\right]\left[\frac{\mathrm{CEI}}{\mathrm{c}}\right] \\
& =\left[2 / 3 M_{P}-Q L_{b} / 3+4 / 3 F Q L_{b}\right]\left[3 / L_{c}-\frac{L_{c}(P+Q)(2 \psi+1)}{2 E I_{c}}\right] \\
& \mathrm{H}_{2}=\left[2 / 3 \mathrm{M}_{\mathrm{P}}-\mathrm{QL}_{\mathrm{b}} / 3+4 / 3 \mathrm{FQL}_{\mathrm{b}}\right] 1 / \mathrm{L}_{\mathrm{c}}\left[3-\frac{\mathrm{L}_{\mathrm{c}}{ }^{2}(\mathrm{P}+\mathrm{Q})(2 \psi+1)}{2 \mathrm{EI}}\right]
\end{aligned}
$$

The expression inside the second pair of brackets is now put into the same form as equation (2.12):

$$
\mathrm{H}_{2}=\left[2 / 3 \mathrm{M}_{\mathrm{P}}-\mathrm{QL}_{\mathrm{b}} / 3+4 / 3 \mathrm{FQL}_{\mathrm{b}}\right] 3 / 4 \mathrm{~L}_{c}\left[4-\frac{2 / 3 \mathrm{~L}_{c}^{2}(\mathrm{P}+\mathrm{Q})(2 \psi+1)}{\mathrm{EI}}\right]
$$

The critical buckling load, $P_{E}=\frac{\pi^{2} E I_{C}}{L_{C}^{2}}$, is substituted into the above:

$$
\mathrm{H}_{2}=\left[\frac{\mathrm{M}_{\mathrm{P}}}{\mathrm{L}_{\mathrm{c}}}-\frac{\mathrm{QL}_{\mathrm{b}}}{4 \mathrm{~L}_{\mathrm{c}}}+\frac{\mathrm{FQL}_{\mathrm{b}}}{\mathrm{L}_{\mathrm{c}}}\right]\left[4-\frac{2 / 3 \pi^{2}(\mathrm{P}+\mathrm{Q})(2 \psi+1)}{\mathrm{P}_{\mathrm{E}}}\right]
$$

Because the second pair of brackets has the same expression as equation (2.12) the inelastic buckling load is the same. Therefore, the stability equation is:

$$
\frac{P+Q}{P_{E}}=\frac{6}{\pi^{2}(2 \psi+1)}
$$


The second hinge is more likely to form at $M$ rather than at corner $B$. The following discussion will derive the level of gravity load, $Q$, that will cause hinges to form at $M$ and corner $B$ at the same time. The moment diagram for this case is shown in Figure 2.9.

The first hinge forms at $c$, and since the gravity moment ordinate, $\mathrm{QL}_{\mathrm{b}} / 3$, must remain constant the dashed 1 ine will only rotate about $\mathrm{C}$. Therefore, from Figure 2.9, the moment at $M$ which is $M_{P}$, equals $Q_{b} / 3+$ $\mathrm{M}_{\mathrm{P}} / 3$. Thus $\mathrm{M}_{\mathrm{P}}=\mathrm{QL}_{\mathrm{b}} / 2$.

The gravity moment at $C, F Q L_{b}$, as a percentage of $M_{P}$, is:

$$
\mathrm{x}=\frac{\mathrm{FQL}_{\mathrm{b}}}{\mathrm{M}_{\mathrm{P}}}
$$

The expression for $M_{p}$ is substituted into the above:

$$
\mathbf{x}=2 \mathbf{F}
$$

If $\psi=2$, which is the case for the frames studied by the computer, then

$$
x=(2)(.19)=.38
$$

which means the gravity moments are $38 \%$ of their ultimate. However, 71 ACI Code, Article 9.3.2, requires that $75 \%$ of the ultimate gravity loads or moments be applied before any lateral load is added. Thus, the second hinge will form at $M$ if the structure is 10 aded with $75 \%$ of the ultimate gravity loads.

\subsubsection{Inelast1c Buckling Load by Bolton's Method}

Bolton (16), in a recent paper, has shown that elastic critical buckling loads can be calculated by using a simple model. The model 


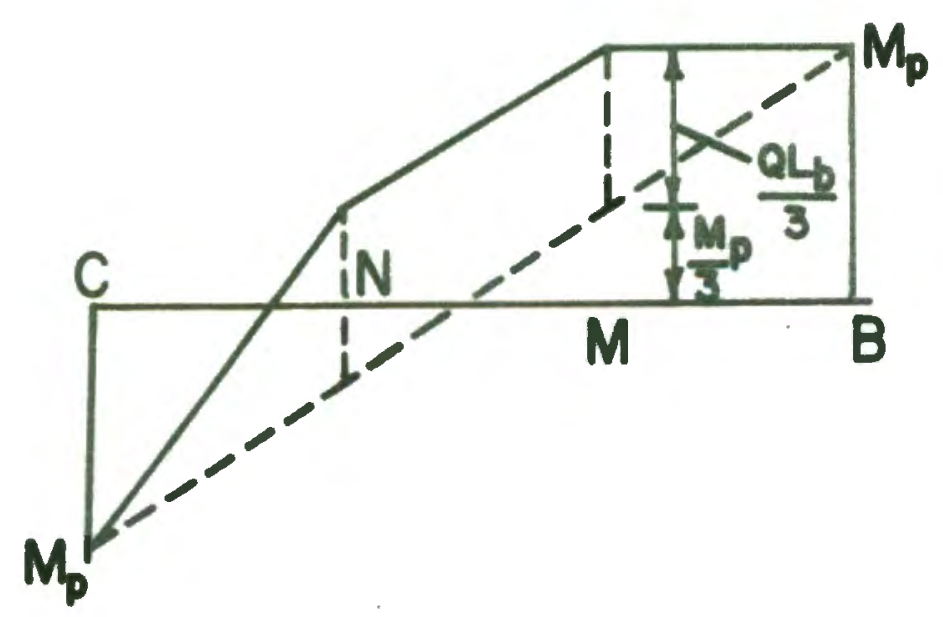

FIG.2.9 CONDITION WHEN HINGES FORM AT B AND M AT THE SAME TIME 
consists of a linear spring connected to the top of an axially loaded vertical bar. The bar is then displaced by a disturbing lateral force which causes overturning moments $(P-\Delta$ moments) and elastic restoring forces from the linear spring. Then, an equilibrium equation is written which is used to solve for the critical load by the condition of zero structural stIffness. This method will be used here to solve for the inelastic buckling load of the reduced model.

The reduced model will first be replaced by an equivalent spring and an equivalent column load. The model is shown in Figure 2.10.

After the first hinge forms the structure must resist the overturning moment caused by the added shear force needed to keep column CD In equilibrium. This shear force, as derived in section 2.4 .1 , is $\frac{2(P+Q) \Delta_{2}}{L_{C}}$. Thus, the total overturning moment on the reduced model after the first hinge forms is

$$
(P+Q) \Delta_{2}+\frac{2(P+Q) \Delta_{2}}{L_{c}} \times L_{c} / 2=2(P+Q) \Delta_{2}
$$

Therefore, the load on the strut shown in Figure 2.10, is $2(P+Q)$.

The stiffness of the spring, $K$, is found by displacing the reduced model a unit distance. The reduced model has a hinge at corner $\mathrm{C}$ which represents the structure at this stage. The deflection of the frame has already been calculated and from equation (2.9)

$$
\Delta_{2}=\frac{M_{c}^{2}}{12 E I_{c}}+\frac{M_{b} L_{c}}{6 \mathrm{EI}_{b}}
$$

The value of $M$ from equation (2.10) is substituted into the above equation. Since the spring is assumed to be linear, the moment is $\left(M=H_{2} L_{c} / 2\right)$. 


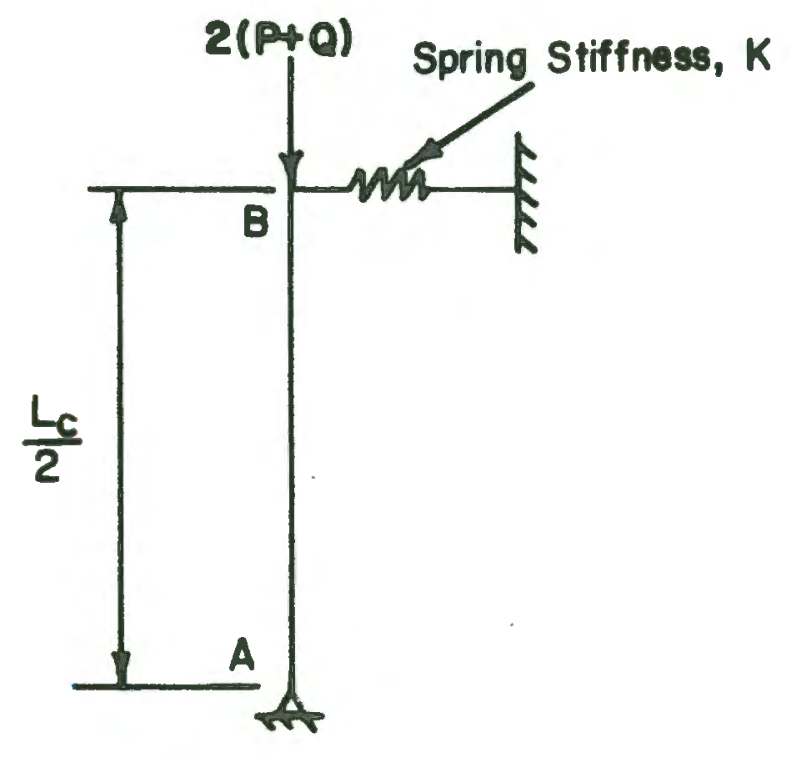

(a) MODEL

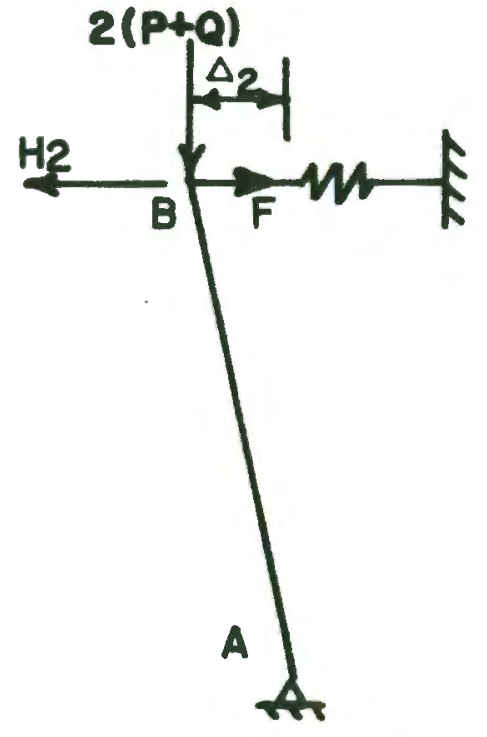

(b) DISPLACEMENT OF BAR AB BY $\mathrm{H}_{2}$

FIG.2.10 STABILITY MODEL 
Thus

$$
\Delta_{2}=\frac{\mathrm{H}_{2} \mathrm{~L}_{\mathrm{c}}^{3}}{24 \mathrm{EI}}+\frac{\mathrm{H}_{2} \mathrm{~L}_{\mathrm{b}} \mathrm{L}_{c}^{2}}{12 \mathrm{EI}_{\mathrm{b}}}
$$

This equation is solved for $\mathrm{H}_{2}$ :

$$
\mathrm{H}_{2}=\frac{24 \mathrm{EI} \mathrm{C}_{c} / \mathrm{L}_{c}^{3}}{2 \psi+1} \Delta_{2}
$$

Stiffness, $K$, is defined as the force needed to cause a unit displacement. Therefore, if $\Delta_{2}=1$, then

$$
K=\frac{24 E I_{c} / L_{c}^{3}}{2 \psi+1}
$$

Now, the vertical bar is displaced, $\Delta_{2}$, by the load $\mathrm{H}_{2}$ as shown in Figure 2.10. Equilibrium is found by taking moments about A:

$$
2(\mathrm{P}+\mathrm{Q}) \Delta_{2}+\left(\mathrm{H}_{2}\right)\left(\mathrm{L}_{\mathrm{c}} / 2\right)-(\mathrm{F})\left(\mathrm{L}_{\mathrm{c}} / 2\right)=0
$$

The force $F$ is found by multiplying its stiffness, $K$, by its extension, $\Delta_{2}$

$$
2(\mathrm{P}+\mathrm{Q}) \Delta_{2}+\left(\mathrm{H}_{2}\right)\left(\mathrm{L}_{\mathrm{c}} / 2\right)-\left(\mathrm{K} \times \Delta_{2}\right)\left(\mathrm{L}_{\mathrm{c}} / 2\right)=0
$$

or

$$
\frac{\mathrm{H}_{2} \mathrm{~L}_{\mathrm{c}}}{\Delta_{2}}=\mathrm{KL}_{\mathrm{c}}-4(\mathrm{P}+\mathrm{Q})
$$

The structural stiffness, $\mathrm{H}_{2} \mathrm{~L}_{\mathrm{c}} / 2$, is zero when the axial load reaches its critical value

$$
\begin{aligned}
\therefore \quad 0=\mathrm{KL}_{\mathrm{c}}-4(\mathrm{P}+\mathrm{Q}) \\
\mathrm{P}+\mathrm{Q}=\mathrm{KL}_{\mathrm{c}} / 4
\end{aligned}
$$

The stiffness, $K$, from equation $(2.20)$ is substituted Into equation (2.21):

$$
P+Q=\frac{6 E I_{c} / L_{c}^{2}}{(2 \psi+1)}
$$


This equation is divided by $P_{E}=\frac{\pi^{2} E I}{L_{c}{ }^{2}}$ to result in

$$
\frac{P+Q}{P_{E}}=\frac{6}{\pi^{2}(2 \psi+1)}
$$

This gives the same equation as the two previous solutions.

\subsubsection{Stability Domains Defined by the Elasto-Plastic Analysis}

The stability of the reduced model will now be presented in graphtcal form. The inelastic buckling load, that is, values of $(P+Q) / P E$ and $\psi$ where $\mathrm{H}_{2}=0$, has been found in previous sections. The elastic buckling load exists for cases where $H=0$. Therefore, the elastic buckling load for the reduced model, before a hinge forms at corner $C$, is defined as $P=\frac{\pi^{2} E I_{c}}{\left(K L_{c}\right)^{2}}$. The effective length factor, $K$, can be found from the relative flexural stiffness of the column and beam by using alignment charts.

The two equations for instability, elastic and inelastic, are plotted as functions of $(P+Q) / P_{E}$ and $\psi$. The elastic stability equation is called curve A while the inelastic stability equation is called curve B. The curves, as shown in Figure 2.11, divide the figure into 3 parts (domains).

The first part, Domain I, is to the right of curve A. This region represents frames that are unstable before any lateral load can be applied. Therefore $\mathrm{H}_{1}=\mathrm{H}_{2}=0$. The second part, Domain II, 11es between curve $A$ and $B$ and represents cases where the frame is stable for lateral loads up to $H_{1}$. Therefore $H_{2}=0$. Frames that lie to the left of curve B, Domain III, are stable unt11 a mechanism forms. Therefore $\mathrm{H}_{2}>0$. 


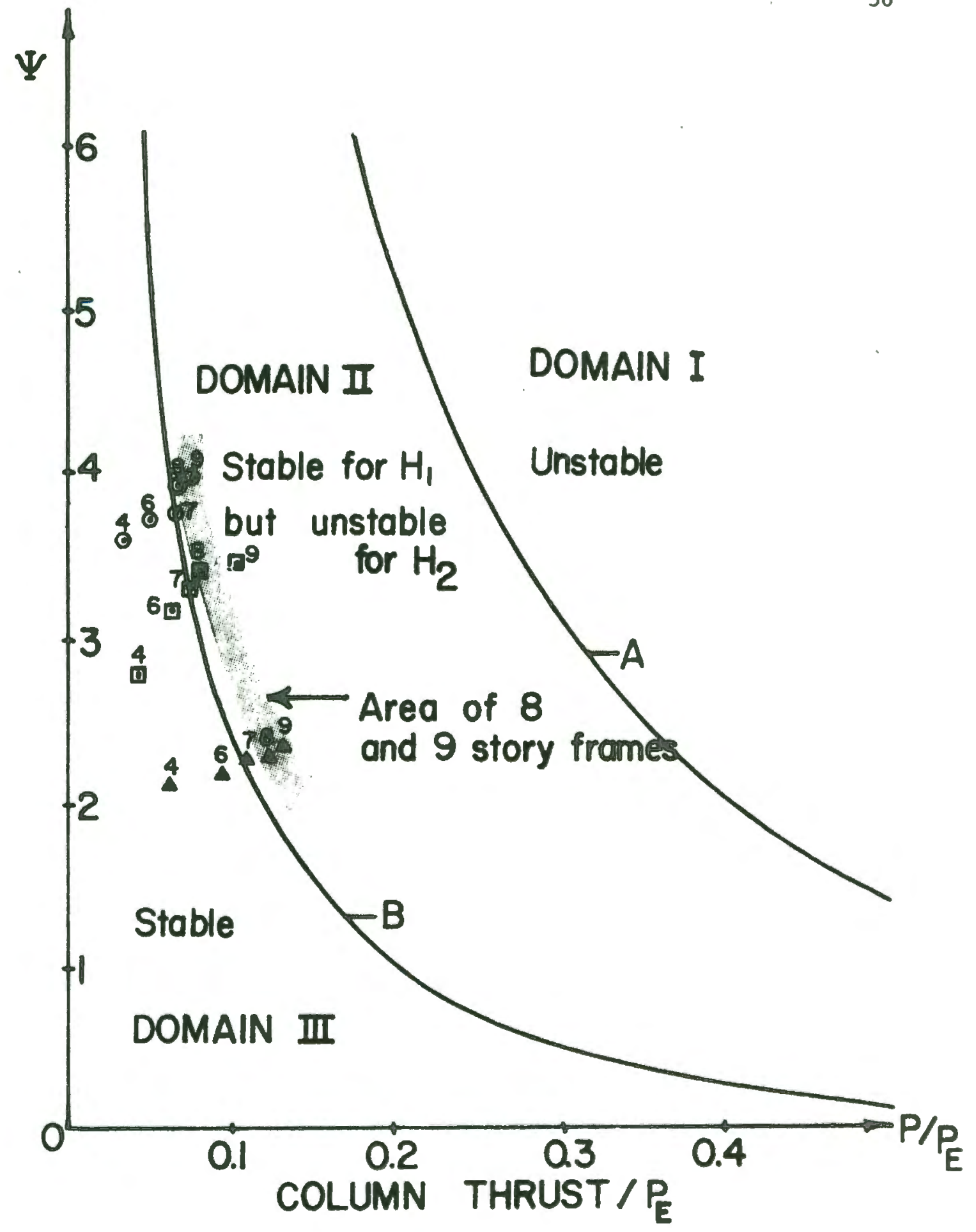

FIG. 2.II STABILITY DOMAINS 


\subsubsection{NONFIX7 Results vs. Stability Domains}

The frames studied in Section 2.3 using the computer program can be compared to the stability domain of Figure 2.11. For five different Q/P ratios from each case, the results given by the elasto-plastic stability model are plotted on Figure 2.11.

The relative column stiffness, $\psi$, is calculated from the flexural stiffnesses of the beam and column. Computer program PMPHI (14), which is a subroutine of NONFIX7, was used to generate the axial thrustmoment-curvature relationships. The beam flexural stiffness $\mathrm{EI}_{\mathrm{b}}$ is shown in Figure 2.12a. However, the column $P-M-\emptyset$ relationship is nonlinear and changes for different axial load levels. Therefore, the stiffness of the column, EI ${ }_{c}$, was defined as the average slope of the two lines described below:

1. A line drawn from the origin through (1/2) M

2. A line drawn from the origin through $M_{p}$ The construction, which will be consistently used in this paper, is shown in Figure 2.12b.

Table 2.3 gives the beam flexural stiffness $\mathrm{EI}_{b}$, the column flexural stiffness $E I_{c}$, the relative flexural stiffness $\psi$, and the ratio $T / P_{E^{*}}$ The values $\psi$ and $T / P_{E}$ are plotted in Figure 2.11 for 4,6 , 7,8 , and 9-story frames of each case. Table 2.1 is a list of the frame parameters for each case.

The results for each case, as shown in Figure 2.11 , tend to cluster together. Also, each cluster of frames appears to follow the general shape of curve B. As the column to beam stiffness ratio $\psi$ decreases, the centroid of each cluster (or case of frames) tends to shift to the 


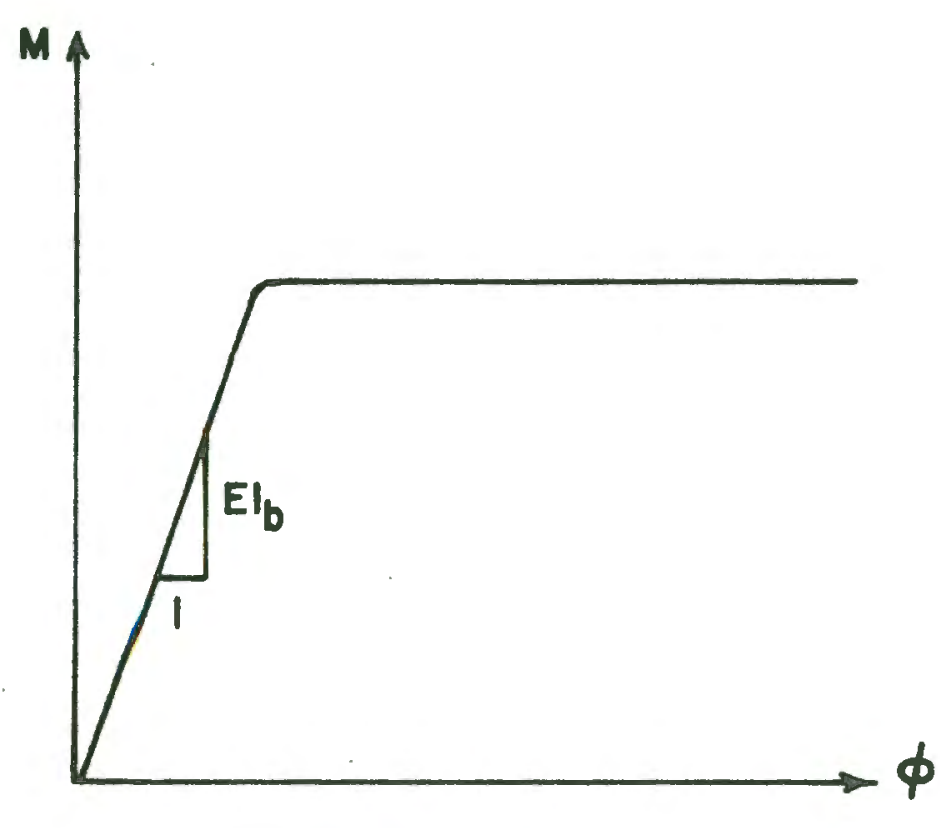

(a) BEAM

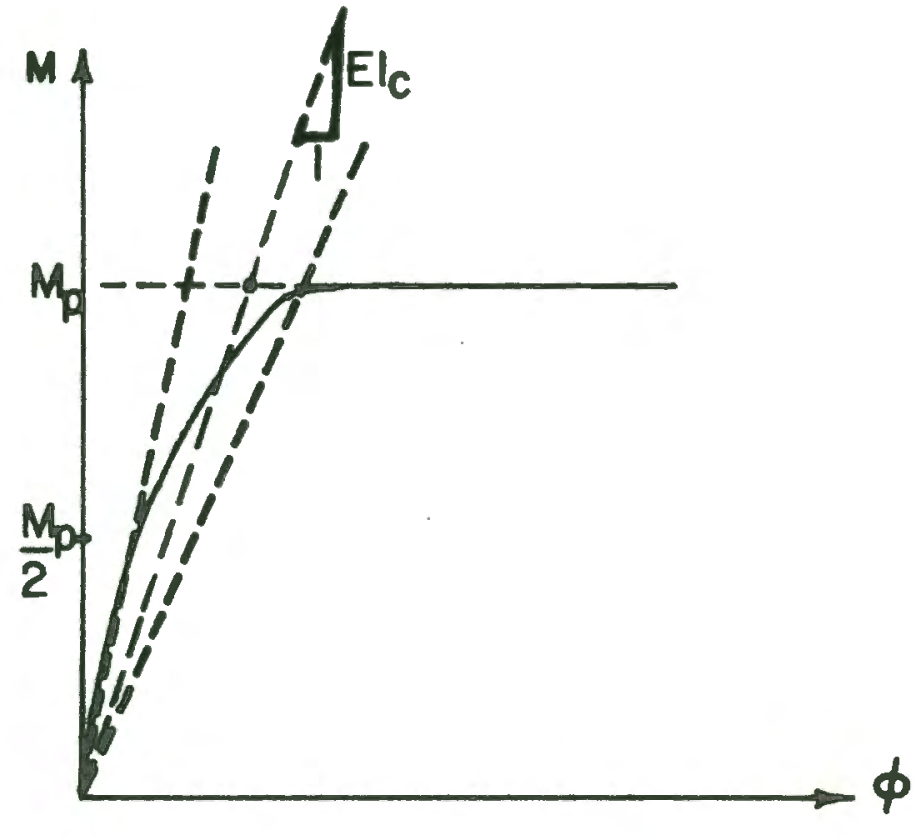

(b) COLUMN

FIG.2.12 FLEXURAL STIFFNESS CALCULATIONS 
TABLE 2.3

COMPARISON WITH ELASTO PLASTIC MODEL

\begin{tabular}{|c|c|c|c|c|c|c|c|c|}
\hline $\begin{array}{l}\text { Case } \\
\text { Symbol }\end{array}$ & $\mathbf{n}$ & $\mathrm{Q} / \mathrm{P}$ & $\begin{array}{c}T \\
(k)\end{array}$ & $\underset{\left(k-1 n^{2}\right)}{E I_{b}}$ & $\begin{array}{c}E I_{C} \\
\left(k-1 n^{2}\right)\end{array}$ & $\psi$ & $\begin{array}{l}P_{E} \\
(k)\end{array}$ & $\frac{T}{P_{E}}$ \\
\hline \multirow{5}{*}{$\begin{array}{c}\text { I } \\
(\square)\end{array}$} & 4 & .250 & 11.6 & 31000 & 42000 & 2.71 & 235 & .049 \\
\hline & 6 & .100 & 18.7 & 31000 & 48000 & 3.10 & 269 & .070 \\
\hline & 7 & .083 & 20.6 & 31000 & 49100 & 3.17 & 275 & .075 \\
\hline & 8 & .071 & 23.6 & 31000 & 50900 & 3.28 & 285 & .083 \\
\hline & 9 & .063 & 30.0 & 31000 & 51000 & 3.29 & 285 & .105 \\
\hline \multirow{5}{*}{$\begin{array}{l}\text { II } \\
\text { (O) }\end{array}$} & 4 & .250 & 11.6 & 31000 & 54000 & 3.48 & 302 & .038 \\
\hline & 6 & .100 & 17.6 & 31000 & 56000 & 3.61 & 313 & .056 \\
\hline & 7 & .083 & 20.5 & 31000 & 56000 & 3.61 & 313 & .065 \\
\hline & 8 & .071 & 23.6 & 31000 & 59200 & 3.82 & 331 & .071 \\
\hline & 9 & .063 & 25.5 & 31000 & 58600 & 3.78 & 328 & .078 \\
\hline \multirow{5}{*}{$\begin{array}{l}\text { III } \\
(\Delta)\end{array}$} & 4 & .250 & 18.6 & 47000 & 48000 & 2.04 & 269 & .069 \\
\hline & 6 & .100 & 29.1 & 47000 & 51000 & 2.17 & 285 & .102 \\
\hline & 7 & .083 & 33.5 & 47000 & 51700 & 2.20 & 289 & .116 \\
\hline & 8 & .071 & 38.5 & 47000 & 52000 & 2.21 & 291 & .132 \\
\hline & 9 & .063 & 42.4 & 47000 & 53800 & 2.29 & 301 & .141 \\
\hline
\end{tabular}


right.

The data points also lie in the same sequence, that $1 \mathrm{~s}$, as the number of stories increases the points move to the right and slightly upwards. Clearly, for each case, the 4 and 6 story frames were within Domain III (stable for $\mathrm{H}_{1}$ and $\mathrm{H}_{2}$ ). The moment redistribution curve (Figure 2.6) for the 4 and 6 story frames, as derived from the computer study of Section 2.3, shows moment redistribution percentages of about $33 \%$ and $17 \%$, respectively. The 7,8 , and 9 story frames were either near or beyond curve B. The area represented by the 8 and 9 story frames is shaded, as shown in Figure 2.11. This area correlates we11 with the computer analysis which shows that these frames had less than $5 \%$ moment redistribution.

From the above comparisons it appears that there is good agreement between the elasto-plastic model stability domains and the results from the nonlinear computer analyses.

\subsection{SUMMARY}

The computer analysis of Section 2.3 showed that frames representing up to 9 story buildings remained in stable equilibrium until a mechanism occurred. Therefore, moment redistribution occurs which is the basic requirement of Limit Design. However, a minimum percentage of moment redistribution was arbitrarily selected at $10 \%$. This allows a 7 -story building to be designed by Limit Design methods.

The frames representing $4,6,7,8$, and 9 story buildings, from the computer analyses, were then plotted on Stability Domains that were mathematically derived. The two approaches showed good correlation. 
DESIGN OF TWO FRAMES FOR TESTING

This chapter explains the design of Frames USD-1 and LD-1. The frames were designed under the same loading conditions. Since the frames had the same overall geometry, the major variable was the bending capactty $M_{p}$ at different locations. This chapter will explain the assumptions and methods used in the design of the two frames.

\section{1 - STORY HEIGHT, LOADS, AND GENERAL ASSUMPTIONS}

The story helght was chosen so that 11mit design could be applled. The computer analysis of Chapter II shows that frames modelling a six or seven story bullding will remain in stable equilibrium after the first plastic hinge forms. However, little moment redistribution will occur. Therefore, a frame was chosen to model the lowest level of a flve story bullding. This causes $Q / P$ and $Q / T$ ratios of .125 and .111 . The index of moment redistribution for the flve-story frame of case 1 , as determined by the computer analysis of Chapter II, was about 39 percent.

The frame designed by the Ultimate Strength method, designated as Frame USD-1, was analyzed by elastic theory. The ultimate load of the frame occurs when the first plastic hinge forms. The frame designed by the Limit Design method, designated as Frame LD-1, was designed based on moment redistribution. The ultimate load for this frame is based on the frame undergolng moment redistribution to form a mechanism. Therefore, the two frames are deslgned according to two different 
princ1ples.

The design of Frame USD-1 follows the specification "BuIlding Code Requirements for Reinforced Concrete" ACI 318-71 (1). The columns of both frames were designed using "Ultimate Strength Design Handbook" ACI SP-17A (17). The design of Frame LD-1 uses the provisions of ACI 318-71 for detalling and serviceabllity. Also, the notation used in the design calculation are consistent with the ACI 318-71 notation.

The assumed service loads are shown in Figure $3.1 \mathrm{a}$ while the ultimate loads are determined by applying code equation 9-1 and 9-2. The factored loads for gravity and gravity plus lateral loading are shown in Figures $3.1 \mathrm{~b}$ and $3.1 \mathrm{c}$.

Since both frames were cast horizontally and a high quality control was excercised in frame fabrication, all capacity reduction factors $(\emptyset)$ were assumed equal to 1.0 . Also, no distinction was made between top and bottom reinforcing bars for development lengths con siderations. Since the frames were chosen to approximate a one-quarter scale factor, ties and stirrups were made from 112 gage wire. The beam stirrups were closed to account for possible torsional shear. Also, the beam sections for both frames were detalled so that the $z$-numbers (ACI 318-71, Art. 10.6) were about the same. This was done to keep the cracking serviceability criterion consistent for both frames.

To prevent plastic hinge formation in the columns the bending strength in the column was designed 10 percent stronger than the beam. The column relnforcing steel was anchored to top and bottom steel plates which also formed the column bearing plate and reaction base plate. 


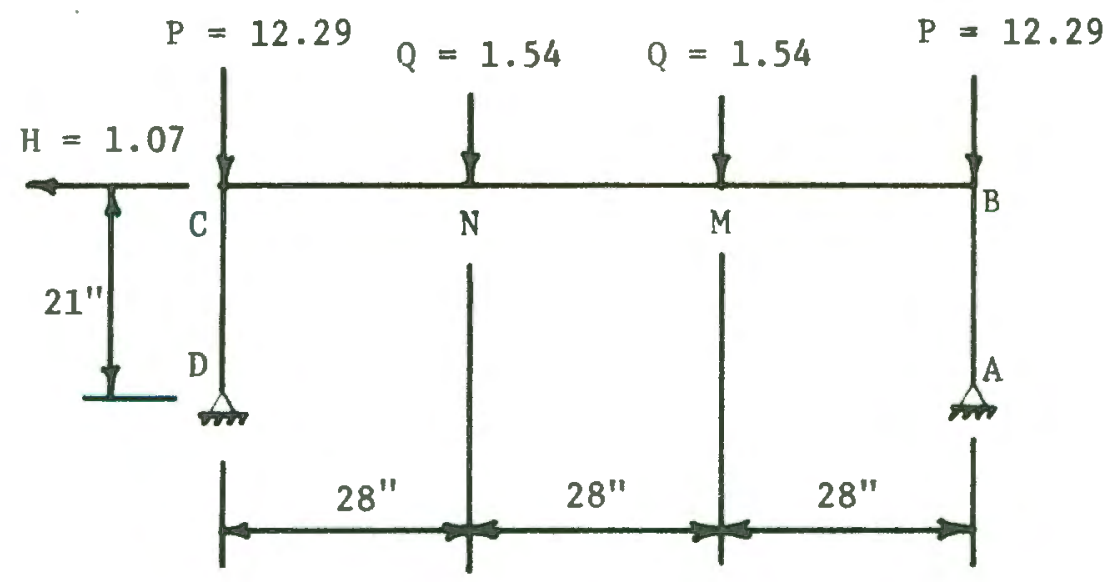

(a) SERVICE LOADS (kips)

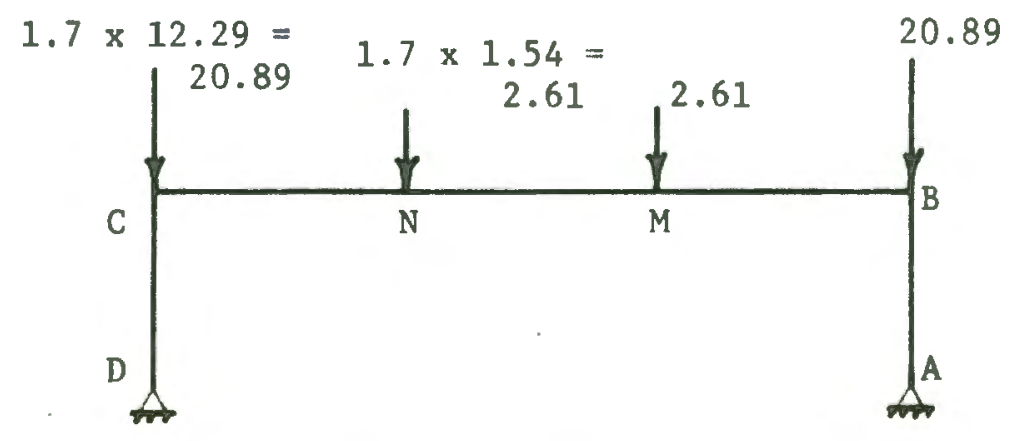

(b) CONDITION I (ACI9-I) (kips)

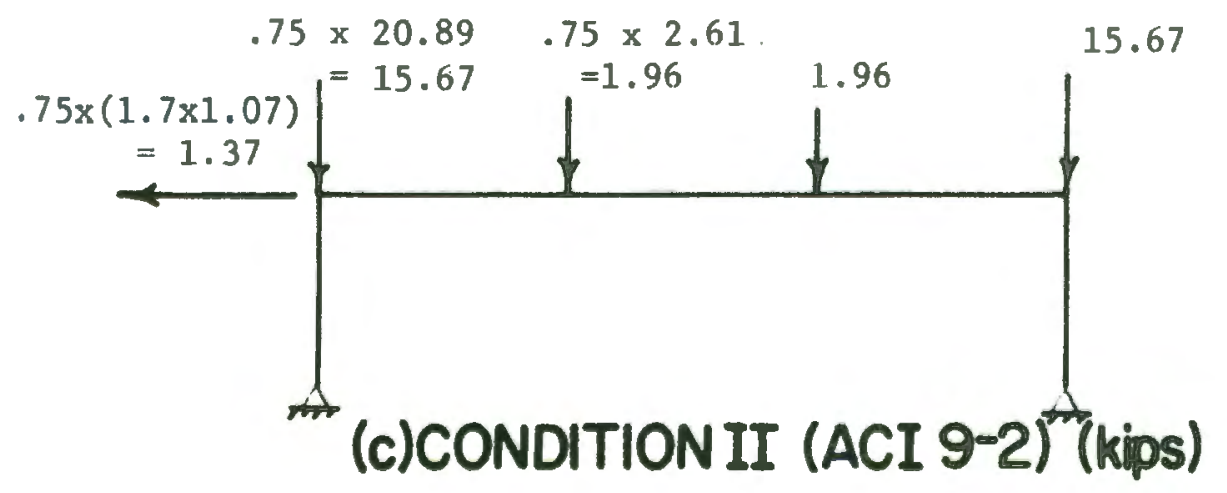

FIG.3.I SERVICE \& FACTORED LOADS 
As permitted by the ACI (Art. 10.11.5), using a precise analysis, flexural stiffnesses EI values were calculated (program PMPHI). Otherwise, both frames were analyzed and designed by hand; 1.e., without the use of computers.

Finally, all calculations are shown for final cross sections. However, no iterative steps are shown.

\subsection{ULTIMATE STRENGTH DESIGN OF FRAME USD-1}

\subsubsection{Design Method}

The main steps in the design of Frame USD-1 were:

1. Elastic frame analysis

2. Column design

3. Beam flexure design and detailing

4. Beam shear design

First, the moments were calculated based on elastic moment distribution. Then the columns were designed and the $P-\Delta$ moments were added to the beam moment diagram. With a complete moment diagram the flexural refnforcement and stirrups were designed. The beam steel was proportioned according to the envelope moment diagram. Also, cracking serviceability conditions were checked at the negative and positive moment critical regions.

A detalled explanation of the above steps is described in the following sections.

\subsubsection{Elastic Frame Analysis}

The moments, shears and reactions were calculated from conventional elastic theory. The moment distribution formula $M=F Q L_{b}$, as described 
In section 2.4, was used to find the moments at corners $B$ and $C$ caused by gravity loads $Q$. The length $\mathrm{L}$ is defined as the distance between the centerlines of the columns. The factor $F$ was based on gross concrete cross sections, excluding all steel. According to elastic frame analysis lateral load $H$ was distributed equally to the two columns. The column and beam cross section dimensions were $33 / 4 \times 6$ in. and $4 \times 6$ in.

a) Condition 1. The loads for this loading condition are shown in Figure 3.1b. The moment at the intersection of the member centerlines for corners $B$ and $C$ is $M=F Q L_{b}=(.185)(2.61)(84)=40.6$ in-k. The moment at the beam load points, $M$ and $N$, is $M=Q_{b} / 3-F Q L_{b}=(2.61)(84) / 3-$ $40.6=32.5 \mathrm{in}-\mathrm{k}$. Since the frame is symmetrical, equilibrium in the vertical direction gives vertical reactions at $A$ and $D$ of $R_{A V}=R_{D V}=$ $P+Q=20.89+2.61=23.5 \mathrm{k}$. The horizontal reactions at $A$ and $D$ are found by isolating the column members $\mathrm{AB}$ and $\mathrm{CD}$ and taking moments about $\mathrm{B}$ and $\mathrm{C}$.

$$
\mathrm{M}_{\mathrm{B} \text { or } \mathrm{C}}=0: \mathrm{R}_{\mathrm{AH}}=-\mathrm{R}_{\mathrm{DH}}=\mathrm{FQL}_{\mathrm{b}} / 21=40.6 / 21=1.03 \mathrm{k}
$$

The reactions, shears and moments for this loading condition are shown in Figures 3.2a through 3.2c.

b) Condition II. The loads for condition II are shown in Figure 3.1c. The vertical reaction at $D, R_{D V}$, is found by taking moments about $A$. Likewise, the vertical reaction at $A, R_{A V}$, is found by summing forces in the vertical direction.

$$
\begin{array}{ll}
\mathrm{M}_{\mathrm{A}}=0: & \mathrm{R}_{\mathrm{DV}}=17.97 \mathrm{k} \\
\mathrm{F}_{\mathrm{V}}=0: & \mathrm{R}_{\mathrm{AV}}=17.29 \mathrm{k}
\end{array}
$$




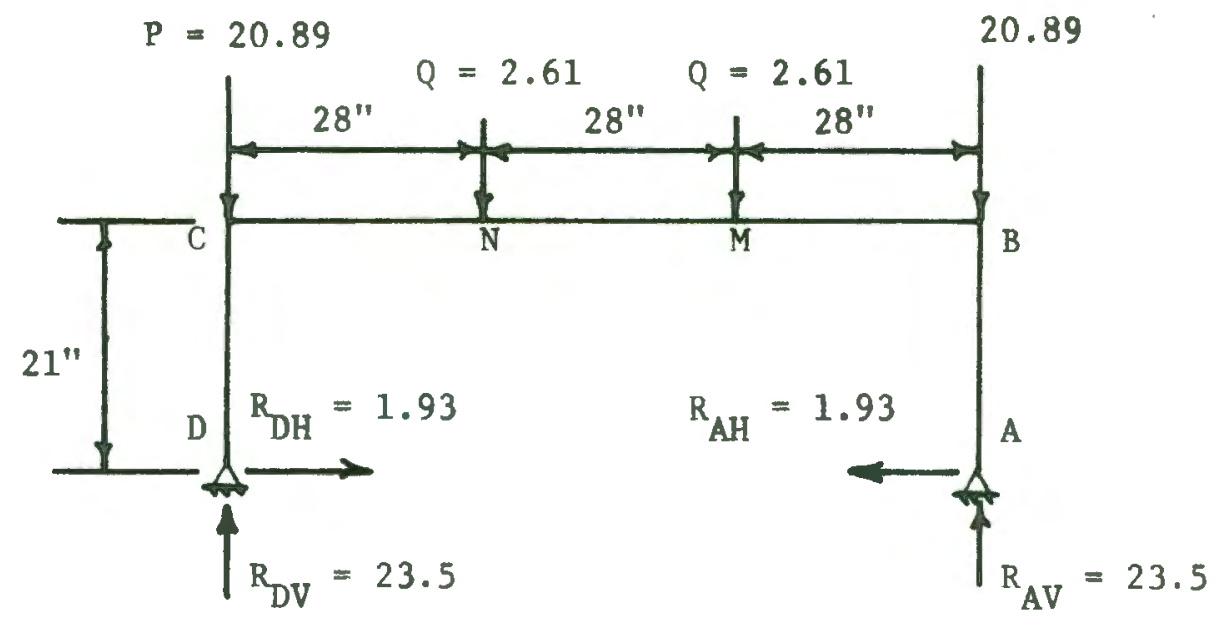

(a) LOADS AND REACTIONS, $k$

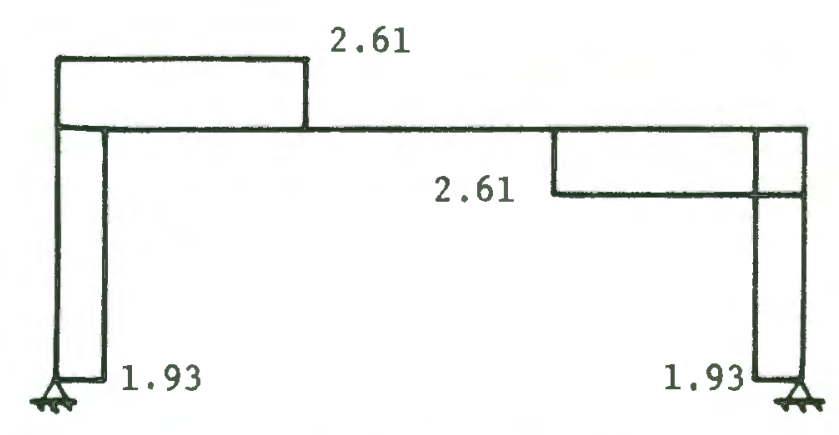

(b)SHEAR DIAGRAM, $k$

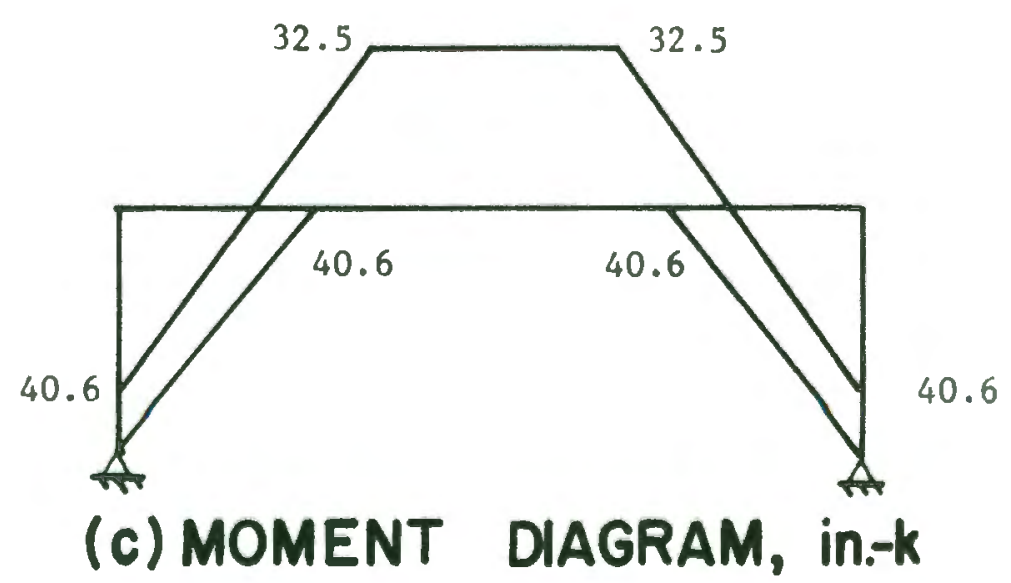

FIG.3.2FRAME ANALYSIS FOR COND. I 
The moments in corners $B$ and $C$ are found by adding the lateral load moment $\mathrm{HL}_{\mathrm{c}} / 4$ to the gravity load moment.

$$
\begin{aligned}
& \mathrm{M}_{\mathrm{B}}=\mathrm{FQL}_{\mathrm{b}}-\mathrm{HL}_{\mathrm{c}} / 4=(.185)(1.96)(84)-(1.37)(42) / 4=16.1 \text { In-k } \\
& \mathrm{M}_{\mathrm{C}}=\mathrm{FQL}_{\mathrm{b}}+\mathrm{L}_{\mathrm{c}} / 4=(.185)(1.96)(84)+(1.37)(42) / 4=44.9 \text { in-k }
\end{aligned}
$$

The two horizontal reactions at $A$ and $D$ are found by isolating the column members $\mathrm{AB}$ and $\mathrm{CD}$ and taking moments about $\mathrm{B}$ and $\mathrm{C}$.

$$
\begin{array}{ll}
\mathrm{M}_{\mathrm{B}}=0: & \mathrm{R}_{\mathrm{AH}}=.77 \mathrm{k} \\
\mathrm{M}_{\mathrm{C}}=0 & \mathrm{R}_{\mathrm{DH}}=2.14 \mathrm{k}
\end{array}
$$

The moment at $M$ was found by isolating the right part of the structure $A B M$ and then taking moments about $M$. This step was repeated for the left part of the structure, DCN, to find the moment at $\mathrm{N}$

$$
\begin{array}{ll}
M_{M}=0: & M_{M}=29.2 \text { in-k } \\
M_{N}=0: & M_{N}=19.5 \text { in-k }
\end{array}
$$

The reactions, shears, and moments for this loading condition are shown in Figures $3.3 \mathrm{a}$ through $3.3 \mathrm{~b}$. The moments from the two loading conditions, which do not include $P-\Delta$ moments, are drawn on the same figure as shown in Figure 3.4 .

\subsubsection{Column Design}

Because Frame USD-1 is unbraced, secondary moments caused by P- $\Delta$ effects exist in the columns and beams. Also, shears w111 increase In the beam because of the Increased end moments.

ACI 318-71, Article 10.11 gives provisions for evaluating $P-\Delta$ effects 


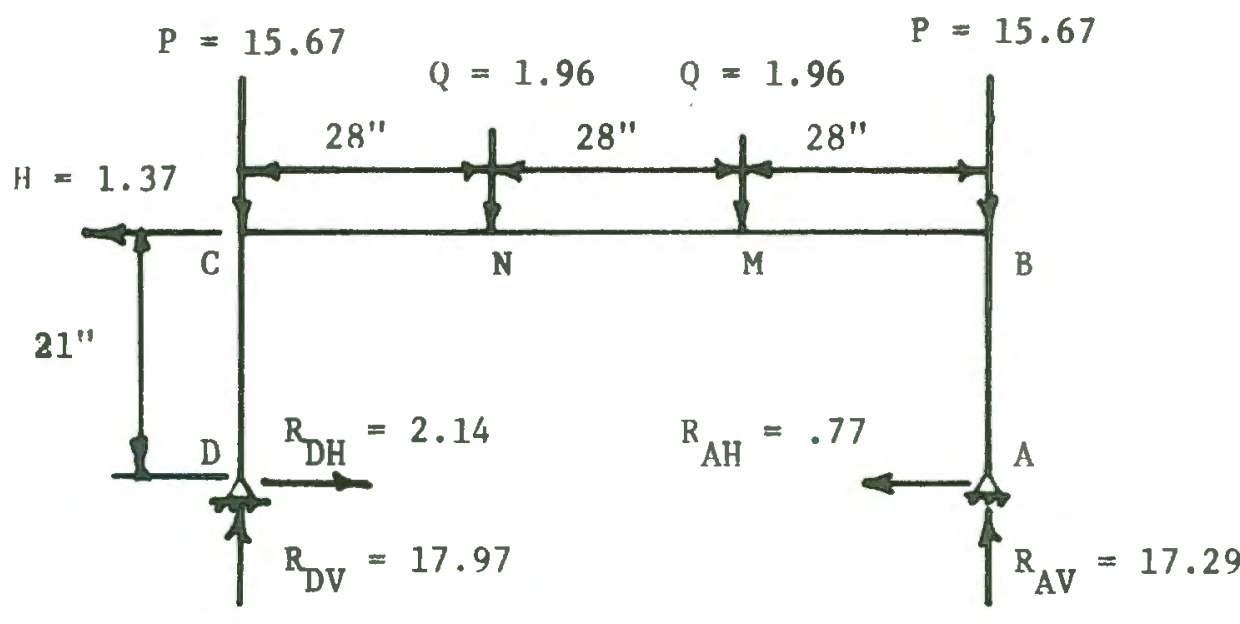

(a) LOADS AND REACTIONS, $k$

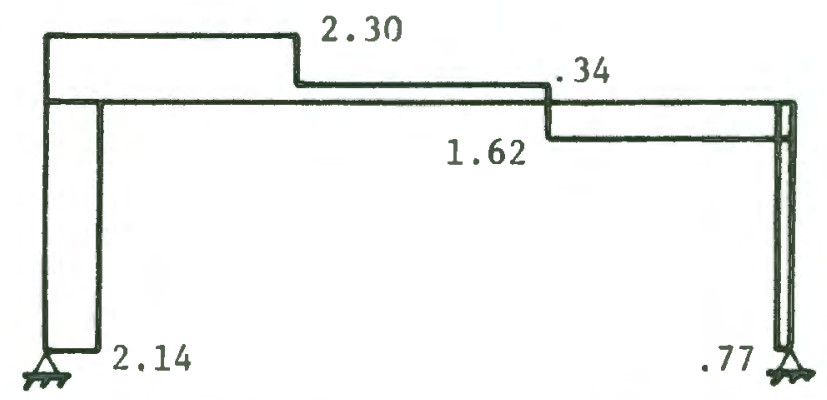

(b) SHEAR DIAGRAM, $k$

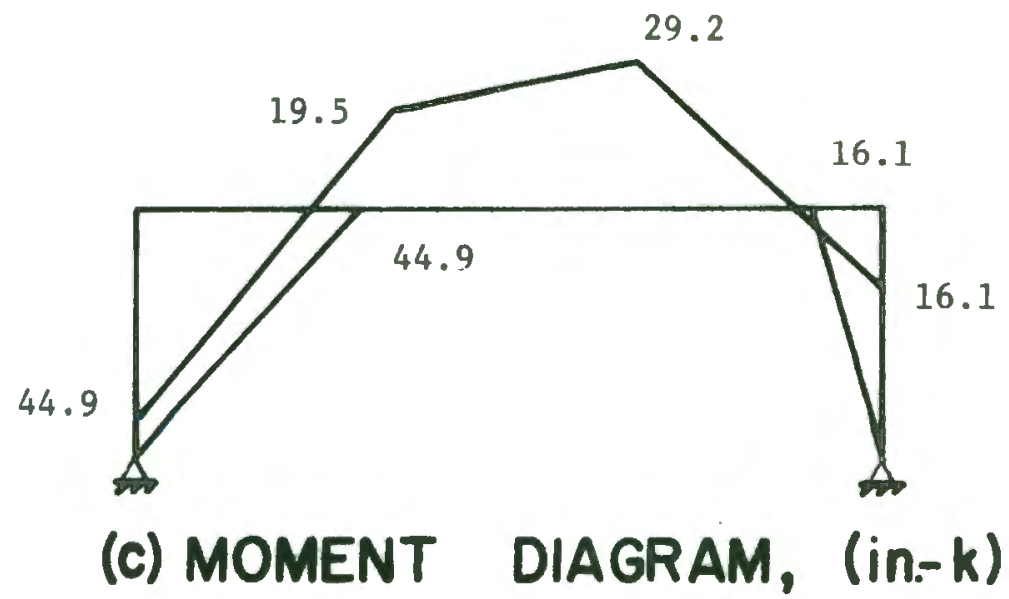




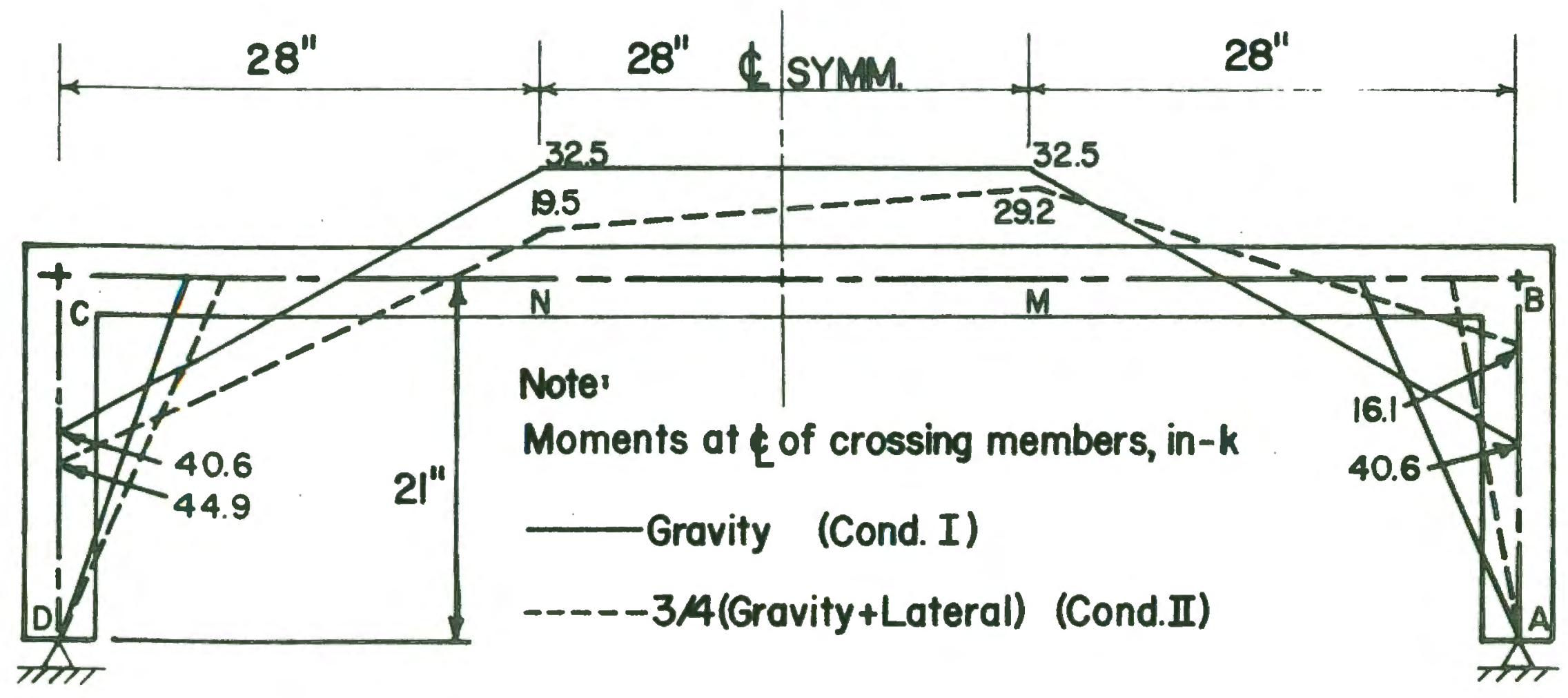

FIG. 3.4 BEAM MOMENT ENVELOPE, USD-I 
in columns. It consists of multiplying the column end moments by a magnification factor $\delta$. Primarily, two equations are used to determine $\delta$. The first equation, ACI code equation 10-6, is used to calculate the elastic critical buckling load:

$$
P_{c}=\frac{\pi^{2} E I}{\left(k 1_{u}\right)^{2}}
$$

where EI = flexural stiffness of the column

$$
k_{u}=\text { equivalent length of the column }
$$

This value is then used to determine the magnification factor $\delta$, which from ACI code equation 10-5:

$$
\delta=\frac{\mathrm{C}_{\mathrm{m}}}{1-\emptyset \mathrm{P}_{\mathrm{u}} / \mathrm{P}_{\mathrm{c}}}
$$

where $\mathrm{P}_{\mathrm{u}}=$ column design thrust

$\mathrm{C}_{\mathrm{m}}=1.0$ for unbraced frames

$\emptyset=$ capacity reduction factor

Finally, the magnified column moment is $M_{c}=\delta M$, where $M$ is from the first order analysis.

The primary step involved calculating the elastic critical buckling load $P_{c}$, which is a function of the equivalent length factor $k$, and the column flexural stiffness EI. The equivalent length factor $k$ was determined by first establishing the relative column stiffness ratio $\psi$ at each end of the column. The expression is:

$$
\psi=\frac{E I_{c} / L_{c}}{E I_{b} / L_{b}}
$$


where $E I_{c}=$ flexural stiffness of the column, including the steel, at the beam soffit level

$E I_{b}=$ flexural stiffness of the beam, including the steel, at corner $C$ in negative bending

With the two values of $\psi$ the equivalent length factor $k$ was determined by using the alignment chart of Jackson and Moreland (18). Hence, $P_{c}$ and $\delta$ were calculated.

The following calculations are shown for the final design cross section. The section capacity will be checked for the two loading conditions with the help of the ACI SP17 handbook (17). The column critical section is at the beam sofftt level which gives a slightly smaller moment than at the centerline of the beam.

a) Condition $I$. The cross section capacity is calculated to check its adequacy. The cross section is shown in Figure 3.5.

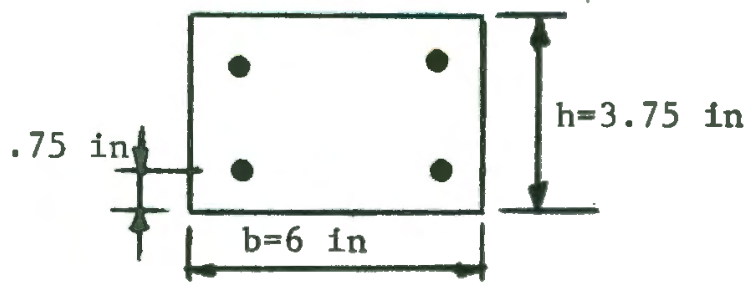

$$
\begin{aligned}
& f_{c}^{\prime}=4000 \mathrm{psi} \\
& f_{y}=59.1 \mathrm{ksi} \\
& A_{s}=4-\# 3=.44 \mathrm{in}^{2}
\end{aligned}
$$

Fig. 3.5. Column cross-section

The required design strength for the column is $P_{u}=23.5 k$ and $M_{u}=\left(1_{u}\right) x$ (Base shear $)=(19)(1.93)=36.7$ ln $-k$.

The flexural stiffness of the column and beam were determined by using the computer program"PMPHI":

$$
\begin{aligned}
& E I_{c}=37500 \mathrm{k}=1 \mathrm{n}^{2}(\mathrm{P}-\mathrm{M}-\emptyset \mathrm{t} \text { not shown) } \\
& \left.\mathrm{EI}_{\mathrm{b}}=38700 \mathrm{k}-1 \mathrm{n}^{2} \text { (see Figure } 3.6\right)
\end{aligned}
$$




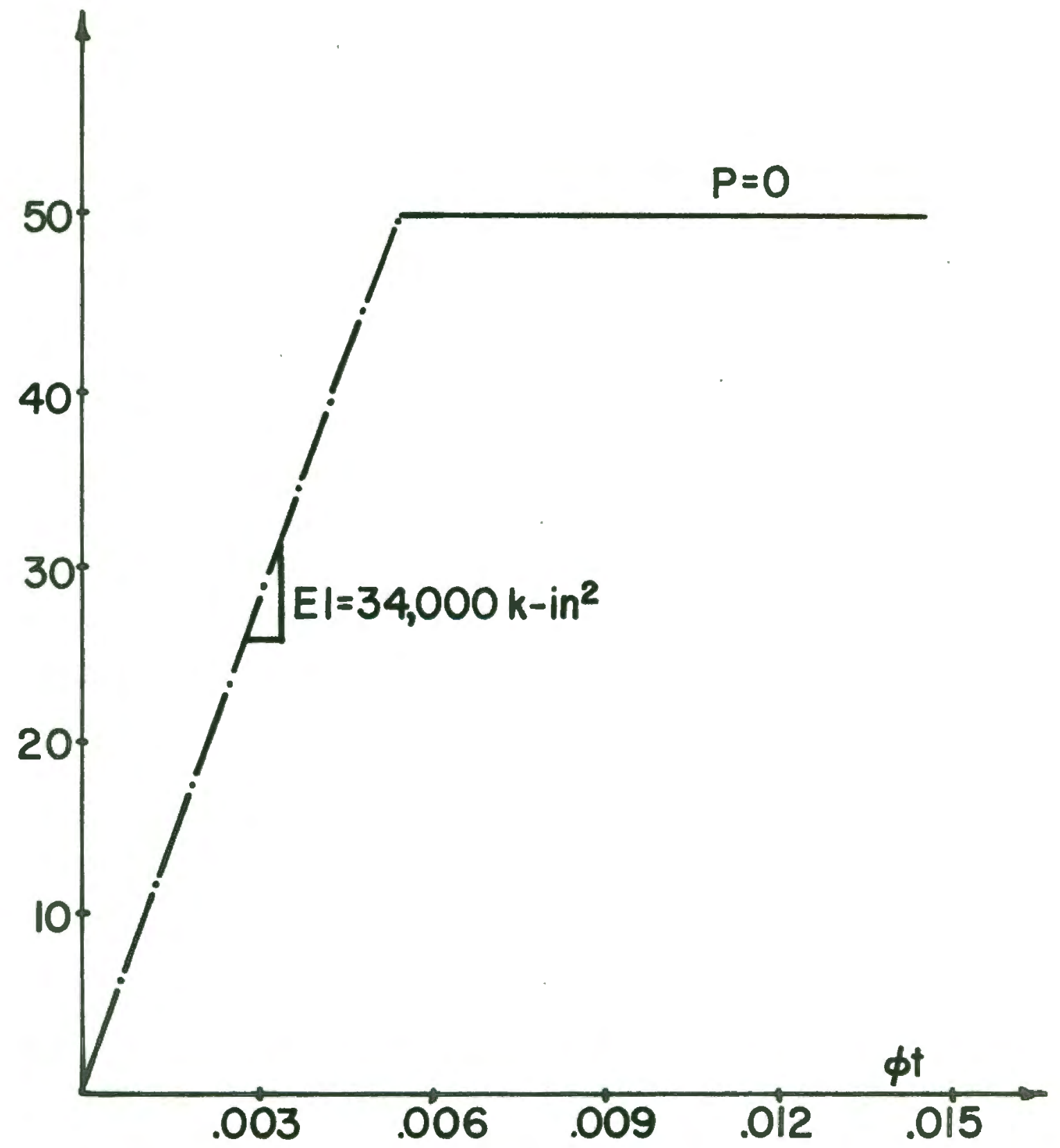

FIG.3.6 COMPUTED P-M- $\phi$, BEAM USD-I 


$$
\begin{aligned}
& E I_{c}=37500(\text { see Figure } 3.7) \\
& E I_{b}=38700(\text { see Figure } 3.6)
\end{aligned}
$$

The above values give flexural stiffnesses of $\mathrm{EI} \mathrm{c}_{\mathrm{c}} / \mathrm{L}_{\mathrm{c}}=37500 / 21=$ 1785 in-k for the columns, and $\mathrm{EI}_{\mathrm{b}} / \mathrm{L}_{\mathrm{b}}=38700 / 84=461 \mathrm{in}-\mathrm{k}$ for the beam. The flexural rigidity ratios at joints $C$ and $D$ are:

$$
\begin{aligned}
& \psi_{C}=1785 / 461=3.87 \\
& \psi_{D}=\infty \text { (Hinge) }
\end{aligned}
$$

From Jackson and Morelands alignment chart (18) the equivalent length factor is $k=3.25$.

The elastic critical load is

$$
P_{C}=\frac{\pi^{2} E I_{c}}{\left(k 1_{u}\right)^{2}}=\frac{\pi^{2} \times 37500}{(3.25 \times 19)^{2}}=97.1 \mathrm{k}
$$

With $C_{m}=1.0$ for unbraced frames the moment magnification factor is

$$
\delta=\frac{\mathrm{C}_{\mathrm{m}}}{1-\mathrm{P}_{\mathrm{u}} / \mathrm{P}_{\mathrm{C}}}=\frac{1.0}{1-17.97 / 97.1}=1.23
$$

This gives a design moment of $M_{c}=\delta M=(1.23)(48.4)=50.1$ in-k.

The eccentricity ratio is $\mathrm{e} / \mathrm{h}=50.1 /(17.97)(3.75)=.74$ and $\rho_{t} m=.35$. The capacity $P_{u} / f_{c}^{\prime} b h$, as found from reference (17), $\left.p .121\right)$ is .17 . The true capacity with $\emptyset=1$ is $.17 / .7=.24$. The required capacity is $\mathrm{P}_{\mathrm{u}} / \mathrm{f}_{\mathrm{c}}^{\prime} \mathrm{bh}=17.97 /(4)(6)(3.75)=.20$

$\therefore$ Design is adequate for Condition II.

\subsubsection{Beam Design and Detailing}

As the frame sways under the applied loads, the columns and beam moments will be affected by the P $-\triangle$ moments. Article 10.11.7 of the code states that flexural members shall be designed for the total magnified end moment. For the design of Frame USD-1, the moment magnifier $\delta$, as determined from the column design, was applied to beam end moment. The 


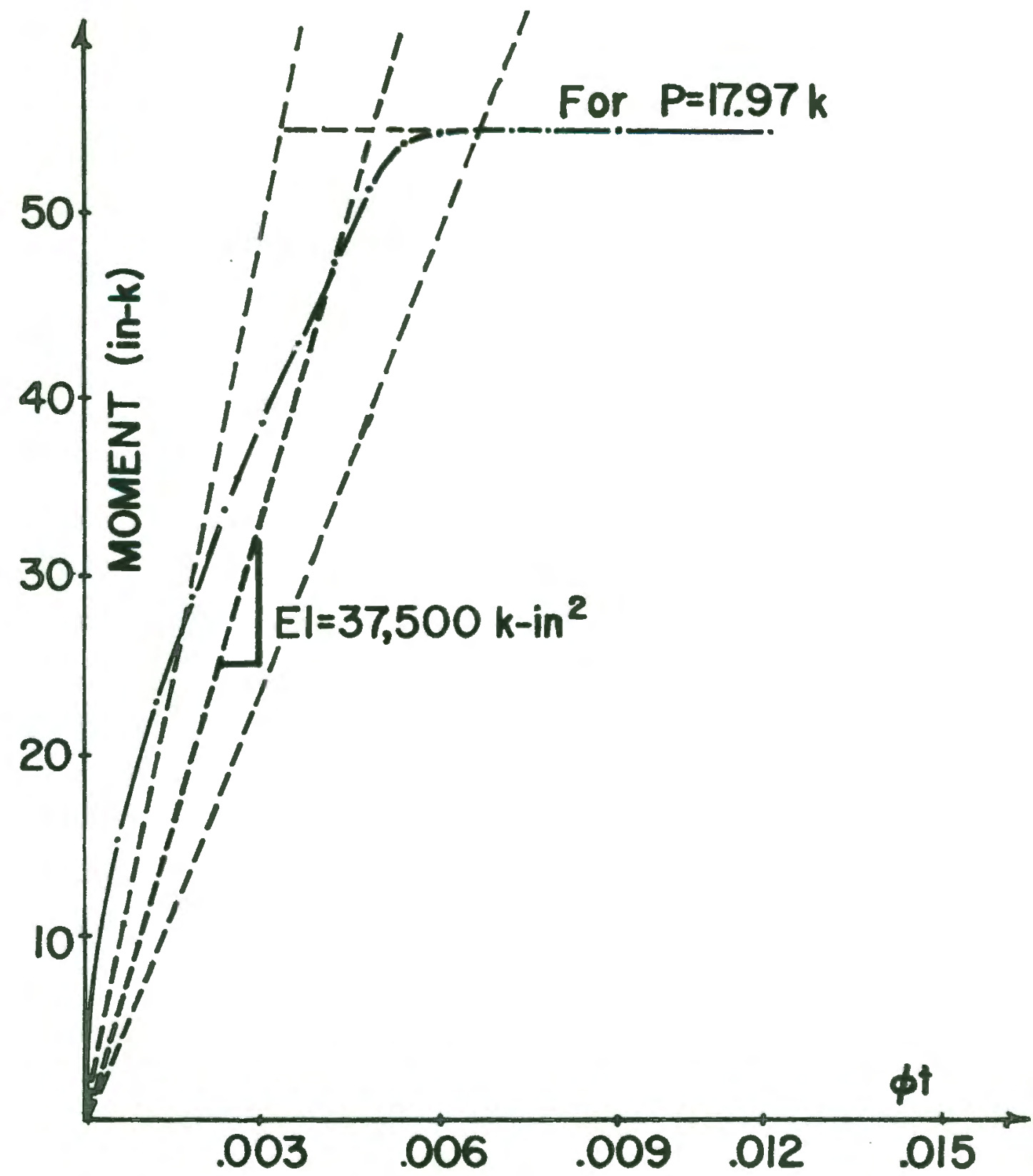

FIG.3.7 TYPICAL COMPUTED P-M- $\phi \dagger$ FOR USD-I COLUMNS 
P $-\Delta$ moment along the length of the beam was also calculated.

First, the moment at the support face of corner $C$ was multiplied by the moment magnifier. Next, the P- $\Delta$ moment was calculated as $\mathrm{M}_{\mathrm{P}-\Delta}=$ $\delta M-M$. This $P-\Delta$ moment Increases the moment at corner $C$ and decreases the moment at corner B the same amount when the lateral load is directed to the left. Likewise, the $P-\Delta$ moment at $M$ is $+M_{P-\Delta} / 3$ while at $N$ 1t is $-M_{\mathrm{P}-\Delta} / 3$. Therefore 1 t was necessary to change the moment diagram of Figure 4.4 by either adding or subtracting the P- $\Delta$ moments.

For loading condition I the design moment at the critical section $1 \mathrm{~s}$

At support face: $M_{B}$ or $c=40.6-(1.875)(2.61)=35.7$ in-k

The magnified moment is $(\delta)(35.7)=(1.32)(35.7)=47.1$ in-k. This gives a P- $\Delta$ moment of $\delta M-M=47.1-35.7=11.41 \mathrm{n}-\mathrm{k}$. The moment at corner B lowers to $35.7-11.4=24.3$ in-k while the moments at $M$ and $\mathrm{N}$ become $32.5+11.4 / 3=36.4 \mathrm{In}-\mathrm{k}$ and $32.5-11.4 / 3=28.7$ in-k respectively. The total moment including the $\mathrm{P}-\Delta$ moments are shown in Figure 3.8 as a solid line.

For loading condition II the design moments at the critical sections are:

At support face: ${ }_{C}=44.9-(1.875)(2.30)=40.6$ in-k At support face: $M_{B}=16.1-(1.875)(1.62)=13.1$ in-k The magnified moment at corner $C$ is $(\delta)(40.6)=(1.23)(40.6)=49.9$ in-k. This gives a $P-\Delta$ moment of $\delta M-M=49.9=40.6=9.3$ in $-k$. The moment at corner $B$ lowers to $13.1-9.3=3.8$ in $r$, whlle the moments at $M$ and $\mathrm{N}$ become $29.2+9.3 / 3=32.3 \mathrm{in}-\mathrm{k}$ and $19.5-9.3 / 3=16.4 \mathrm{in}-\mathrm{k}$ respectively. The total moment diagram is shown In Figure 3.8 by a dashed line. 


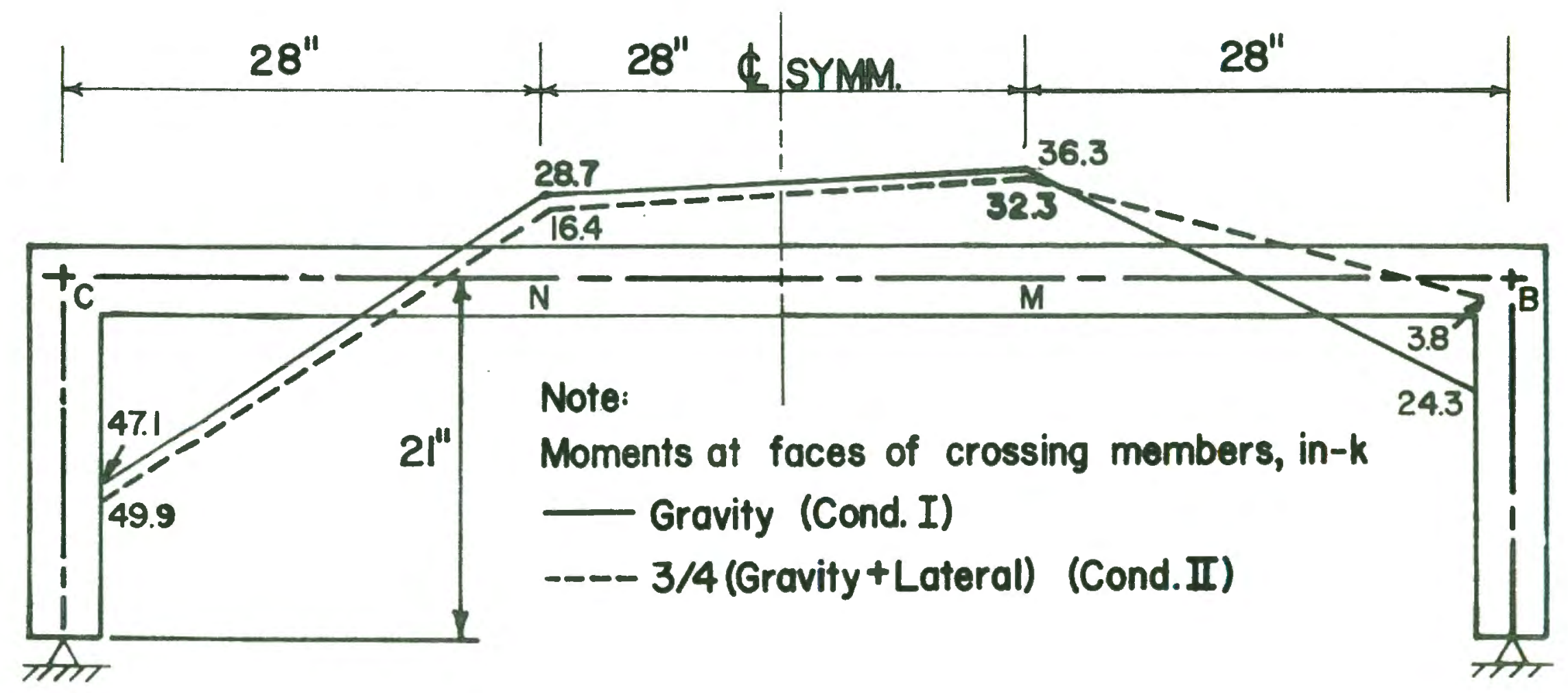

FIG.3.8 BEAM MOMENT ENVELOPE WITH P- $\triangle$ EFFECTS, USDI 
The design moments for the column and beam at corner $C$ are not equal even though the same magnification factor is applied. This is caused by differences in the shearing forces at the faces of the joint block.

From Figure 3.8 , the maximum negative and positive moments are 49.9 in-k at $C$ and 36.3 in-k at $M$.

Design of Beam Sections:

Negative moment $=49.9 \mathrm{ln}-\mathrm{k}$ (see Figure 3.8$)$

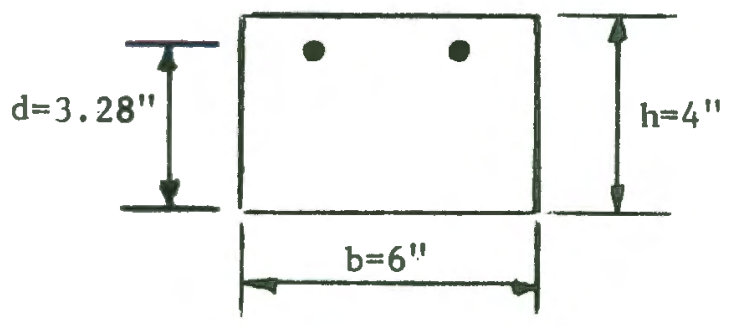

$$
\begin{aligned}
& \mathrm{f}_{\mathrm{c}}^{\prime}=4.0 \mathrm{ksI} \\
& \mathrm{f}_{\mathrm{y}}=79.6 \mathrm{ksi} \\
& \mathrm{A}_{\mathrm{s}}=2-\# 3=.22 \mathrm{in}^{2}
\end{aligned}
$$

$d=3.28^{\prime \prime}$ (after several trials)

$\bar{T}=A_{s} f_{y}=(2)(.11)(79.6)=17.5 \mathrm{k}$

$\overline{\mathrm{C}}=\overline{\mathrm{T}}$

$.85 \mathrm{f}_{\mathrm{c}}^{\prime} \mathrm{ab}=17.5 \quad \mathrm{a}=\frac{17.5}{.85 \mathrm{f}_{\mathrm{c}}^{\prime} \mathrm{b}}=\frac{17.5}{(.85)(4)(6)}=.858 \mathrm{in}$

$\overline{\mathrm{M}}=\overline{\mathrm{T}}=\overline{\mathrm{T}}(\mathrm{d}-\mathrm{a} / 2)=17.5(3.28-.858 / 2)$

$M=49.9$ in-k $0 . K$.

Positive moment $=36.3$ in-k (see Figure 3.8 )

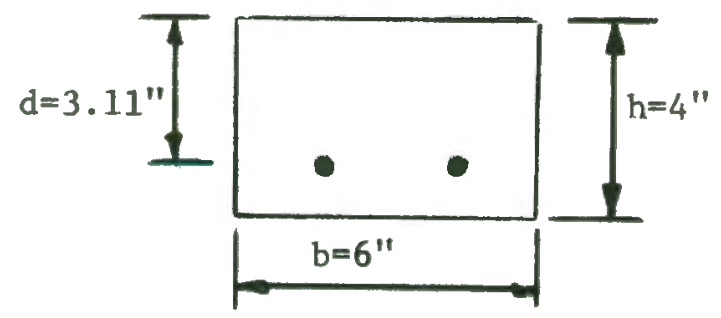

$$
\begin{aligned}
& \mathrm{f}_{c}^{\prime}=4.0 \mathrm{ksi} \\
& \mathrm{f}_{\mathrm{y}}=59.1 \mathrm{ksi} \\
& \mathrm{A}_{\mathrm{s}}=2-\# 3=.22 \mathrm{in}^{2}
\end{aligned}
$$

$d=3.11$ (after several trials) 


$$
\begin{aligned}
& \bar{T}=A_{s} f_{y}=(2)(.11)(59.1)=13.0 k \\
& \vec{C}=\bar{T} \\
& .85 \mathrm{~F}_{c}^{\mathrm{ab}}=13.0 \quad \mathrm{a}=\frac{13.0}{.85 \mathrm{f}_{\mathrm{c}}^{\prime b}}=\frac{13.0}{(.85)(4)(6)}=.637 \\
& \mathrm{M}=\mathrm{TZ}=\mathrm{T}(\mathrm{d}-\mathrm{a} / 2)=13.0(3.11-.637 / 2) \\
& =36.3 \mathrm{in}-\mathrm{k} \quad 0 . \mathrm{K} .
\end{aligned}
$$

The beam moment envelope for one half the frame is shown in Figure 3.9. This diagram was used to find the cutoff points for positive and negative reinforcement. The detailing followed the provisions of Chapter 12 of ACI 318-71. Also, as specified in ACI 318-71, Art. 12.1.4, the moment diagram was assumed to shift the greater of $12 \mathrm{~d}_{\mathrm{b}}$ or $\mathrm{d}$ which is $4.5 \mathrm{in.}$ The shifted moment diagram is shown in Figure 3.9 by a dashed line. For development length calculations the remaining bar was assumed to yield at the cutoff point. Since the bars are cut in a tension zone the shear requirements will be checked in section 3.2 .5 . As shown in Figure 3.9 for negative reinforcing, one bar can be tentatively stopped at $9.83+4.5=14.33$ in $\left(1^{\prime}-21 / 2^{\prime \prime}\right)$ from the support face. This gives enough distance for the bar to yield at the support face $\left(1^{\prime}-21 / 2^{\prime \prime}>1_{d}=12^{\prime \prime}\right)$. Since the remaining bar is assumed to yield at the cutoff point it must extend $1_{d}=12$ in. past the cutoff point. The remaining bar is stopped at $1^{\prime}-21 / 2^{\prime \prime}+12^{\prime \prime}=2^{\prime}-21 / 2^{\prime \prime}$ from the support face. This bar extends $26.50-19.66=6.84$ in. past the point of inflection, which is greater than $12 d_{b}$ or $1_{n} / 16$ as required by ACI code, Art. 12.3.3.

One positive moment bar can be tentatively stopped at $10.24^{\prime \prime}+$ $4.5^{\prime \prime}=14.74^{\prime \prime}\left(1^{\prime}-3^{\prime \prime}\right)$ from point $M$. This is enough distance for the bar 


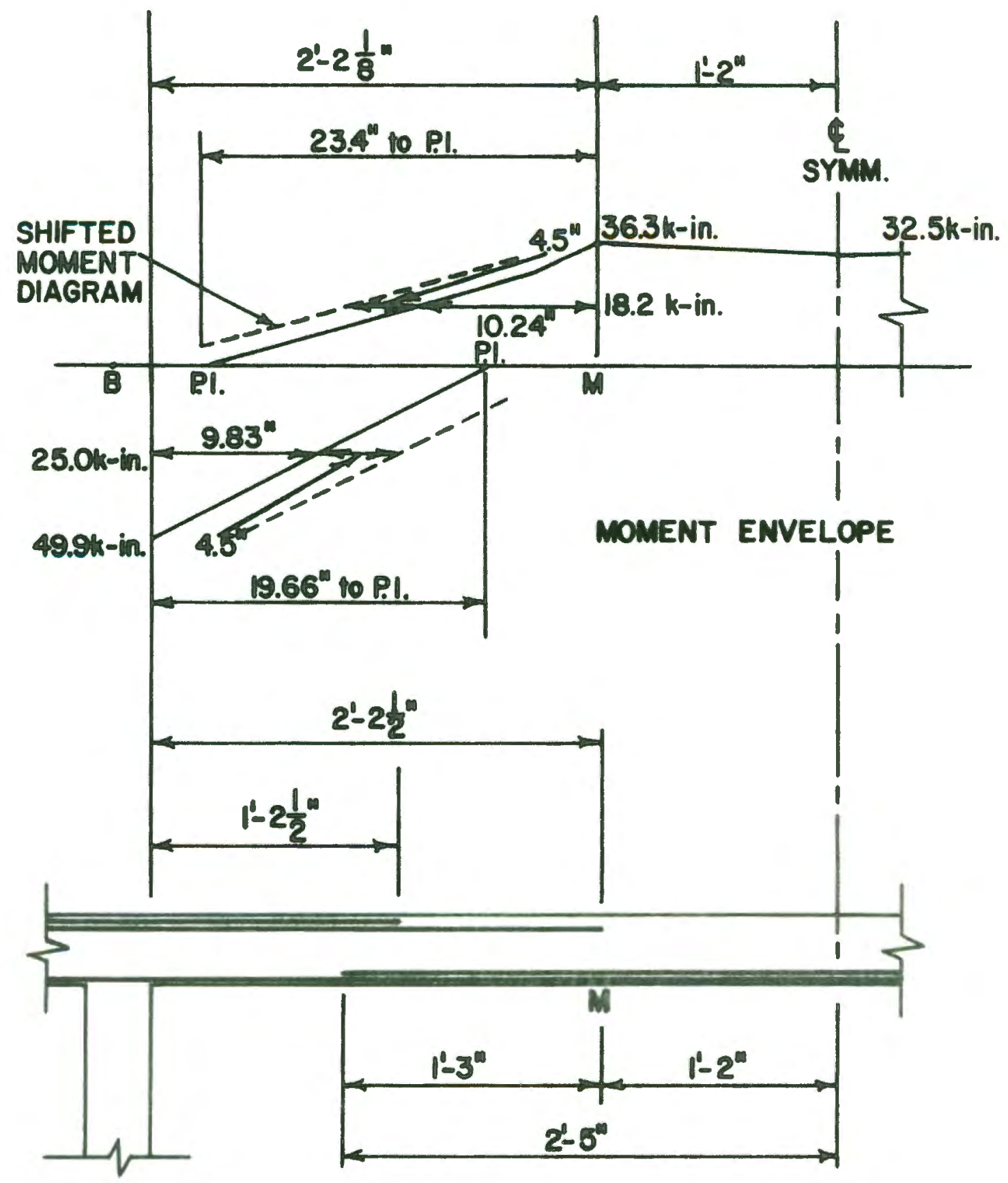

FIG.3.9 BEAM REINF. DETAILS, USD-I 
to yleld at point $M$. The remaining bar must extend through the support face so as to develop its yleld strength at that point. This satisfles ACI Code Articles 12.2.1 and 12.2.2.

To satisfy cracking serviceability, the $z$-numbers are calculated at the negative and positive moment critical regions ( $C$ and $M$ ). Therefore, according to ACI code equation 10-2, the $\mathrm{z}$-number at corner C with a reinforcing steel stress of $.6 \mathrm{~F}_{\mathrm{y}}$ is

$$
z=f_{s} \sqrt[3]{d_{c} A}=(.6)(79.6) \sqrt[3]{(.72)(4.32)}=69.7
$$

Likewise, the z-number at $M$ is

$$
z=(.6)(59.1) \sqrt[3]{(.89)(5.34)}=59.6
$$

The $z$-number for negative and positive moment critlcal section are below the maximum allowable $z$ of 150 .

\subsubsection{Shear Design}

The shear dlagram for the two loading conditions are shown in Figures $3.2 \mathrm{~b}$ and $3.3 \mathrm{~b}$. However, added shear forces will occur in the beam because of Increased beam end moments caused by lateral deflection of the frame. Therefore, the design shears are calculated from the moment diagram of Figure 3.8 .

The maximum shear between points $B$ and $M$ and between points $C$ and $\mathrm{N}$ is

$$
\mathrm{v}_{\mathrm{BM}, \mathrm{CN}}=\frac{47.1+28.7}{28}=2.90 \mathrm{k}
$$

The maximum shear between points $M$ and $N$ is

$$
\mathrm{V}_{\mathrm{MN}}=\frac{32.3-16.4}{28}=.57 \mathrm{k}
$$

For spans $B M$ and $C N$ the shear stress is $v_{u}=v_{u} / b d=2900 /(6)(3.11)=$ 155 ps1. The shearing stress carved by the concrete is $v_{c}=2 \sqrt{f_{c}^{\prime}}=$ 
$2 \sqrt{4000}=127 \mathrm{ps1}$. The excess shear stress $\left(v_{u}-v_{c}\right)$ is $28 \mathrm{ps} 1$, however the stirrups must carry a minimum stress of 50 ps1 (ACI, Art. 11.1.2). With \#12 gage closed stirrups the required spacing is

$$
s=\frac{A_{v} f}{v_{s} b}=\frac{(2)(.0874)(60000)}{(50)(6)}=3.50 \mathrm{in}
$$

However, the maximum spacing must not exceed $s=d / 2=3.11 / 2=1.56$ in . Therefore $\#_{12}$ gage closed stirrups at 1.56 in. spacing in spans BM and $C N$ were used.

The shear stress in the midspan region is $v_{u}=v_{u} / b d=570 /(6)(3.11)=$ 31 psi. As stated in the ACI Code, Art. 11.1.1, no stirrups are required If the shear stress is less than $v_{c} / 2=63$ psi.

As mentioned in section 3.2 .4 , the cutoff bar must meet added shear requirements. The ultimate shear capacity, including stirrups, is

$$
\begin{aligned}
& v_{\text {ALL }}=v_{c}+v_{s}=2 \sqrt{f_{c}^{\prime}}+\frac{A_{v} f}{b s} \\
& =127+\frac{(2)(.00874)(6000)}{(6)(1.56)}=239 \mathrm{psi}
\end{aligned}
$$

The shearing stress at the cutoff point is $155 \mathrm{ps1}$, which is less than two-thirds of $239 \mathrm{psi}$. Therefore, as permitted by ACI Article 12.1.6, the bars may be stopped in the tension zone.

\subsubsection{Frame Details}

Figure 3.10 gives the reinforcement arrangements and dimensions for the Frame. The cross-sections of the beam and columns are shown in Figure 3.11. A schedule of reinforcement is shown in Figure 3.12, while the details of the column cage are shown in Figure 3.13. 


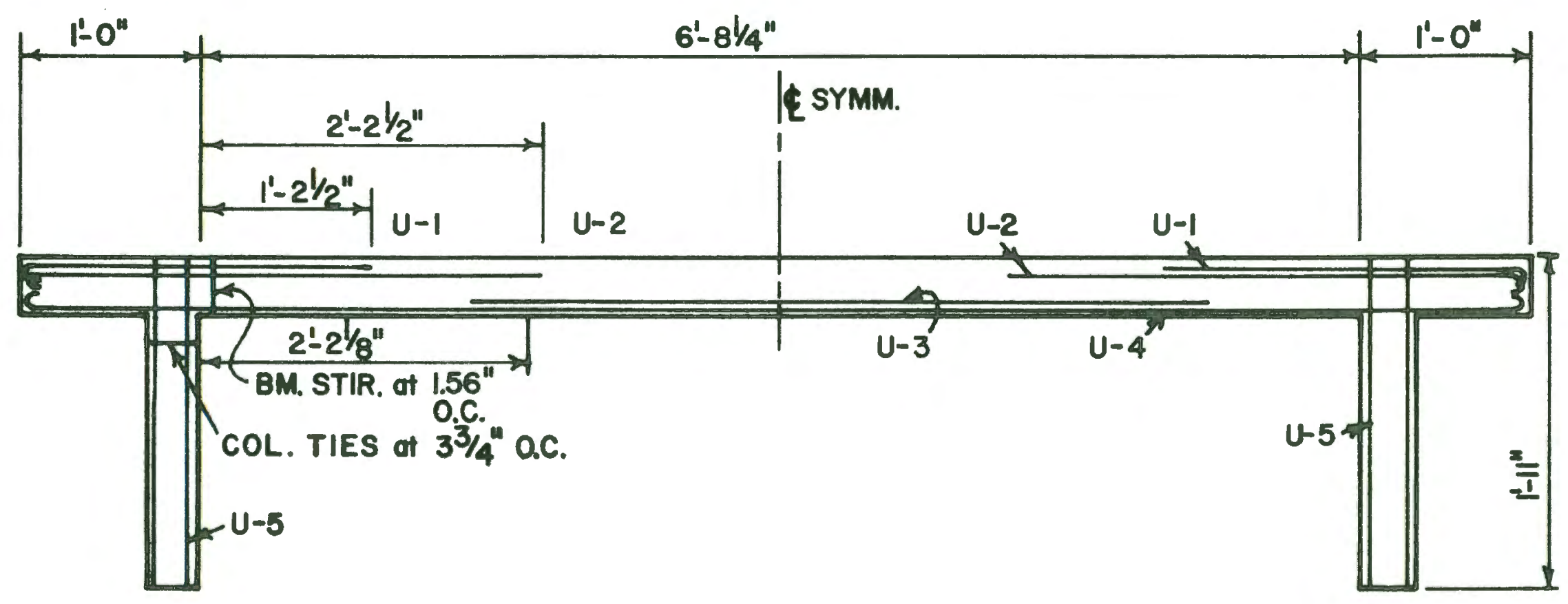

FIG.3.10 TEST FRAME DETAILS, USD-I 


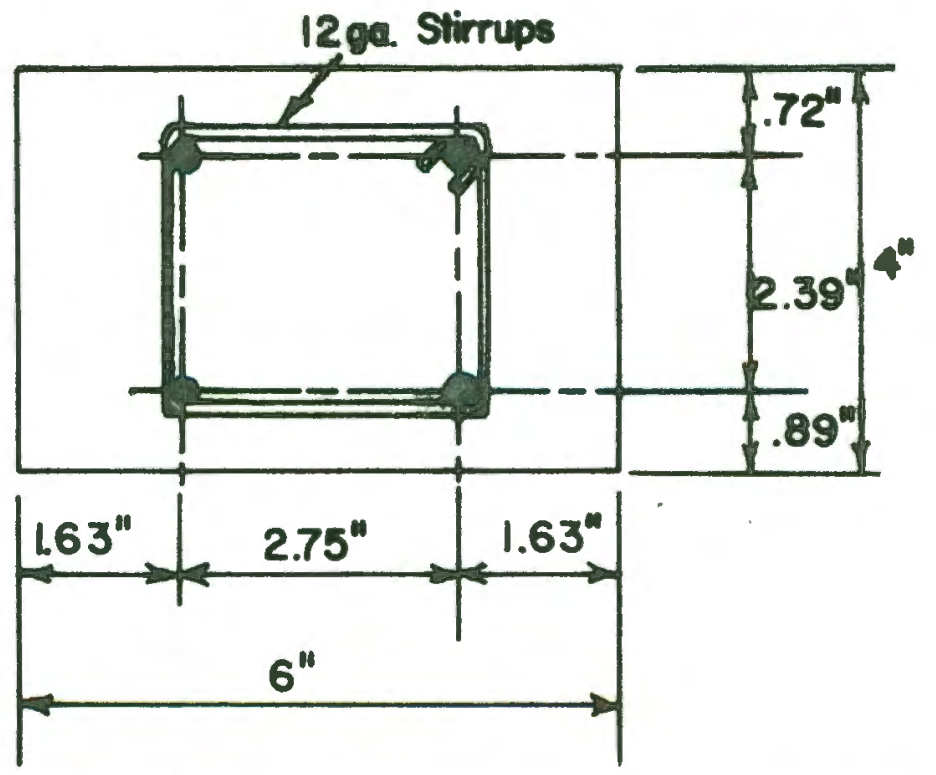

\section{BEAM CROSS SECTION}

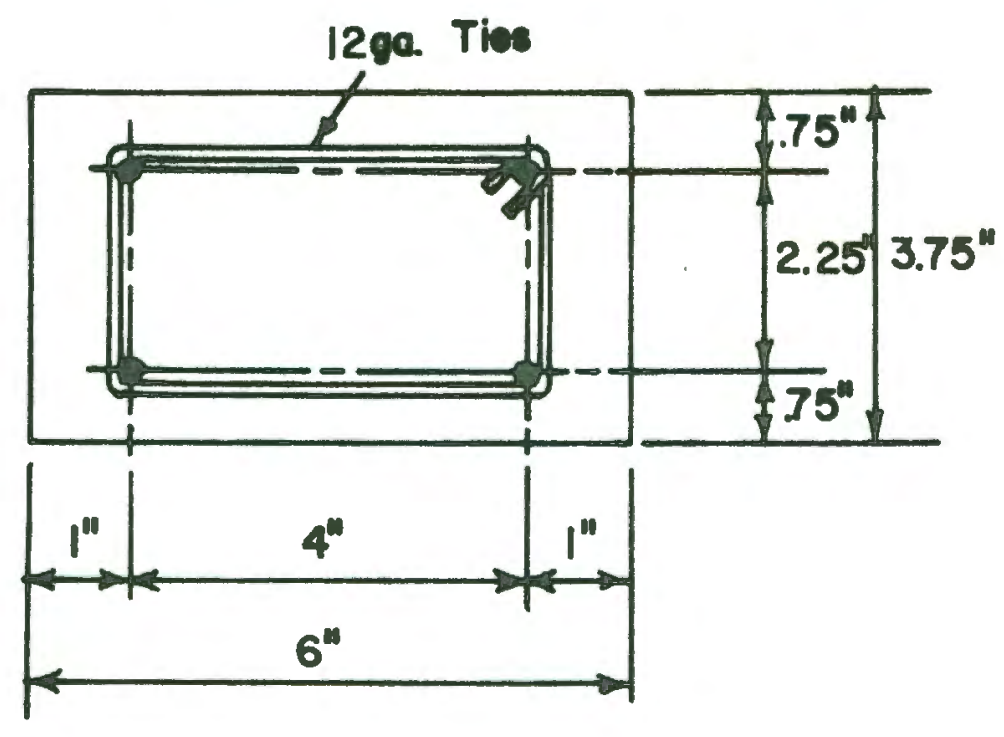

COLUMN CROSS SECTION

FIG.3.II CROSS SECTIONS,

FRAME USD-I 


\begin{tabular}{|c|c|c|c|c|c|c|}
\hline \multicolumn{4}{|c|}{ CHEDULE } & \multicolumn{3}{|c|}{ FRAME USD-I } \\
\hline BAR & $\begin{array}{l}\text { TOTAL } \\
\text { NO. EAARS }\end{array}$ & SIZE & fy(mi) & TYPE & DIM. "A" & $\begin{array}{l}\text { TOTAL } \\
\text { LENGTH }\end{array}$ \\
\hline U-1 & 2 & 3 & 79.6 & 1 & $2-1 \frac{1}{2}$ & $2^{\frac{1}{-6}}-\frac{1}{2}$ \\
\hline$U-2$ & 2 & 3 & 79.6 & 1 & $3^{\prime}-1 \frac{1}{2}{ }^{11}$ & $3-6 \frac{1}{2}{ }^{100}$ \\
\hline$U-3$ & 1 & 3 & 59.1 & STR & - & $4^{\prime}-10^{\prime \prime}$ \\
\hline$u-4$ & 1 & 3 & 59.1 & 2 & 8'6" & $9^{\prime}-6^{\prime \prime}$ \\
\hline$U-5$ & 8 & 3 & 59.1 & STR & - & $|-\||^{\prime \prime}$ \\
\hline
\end{tabular}

TYPE I

TYPE 2
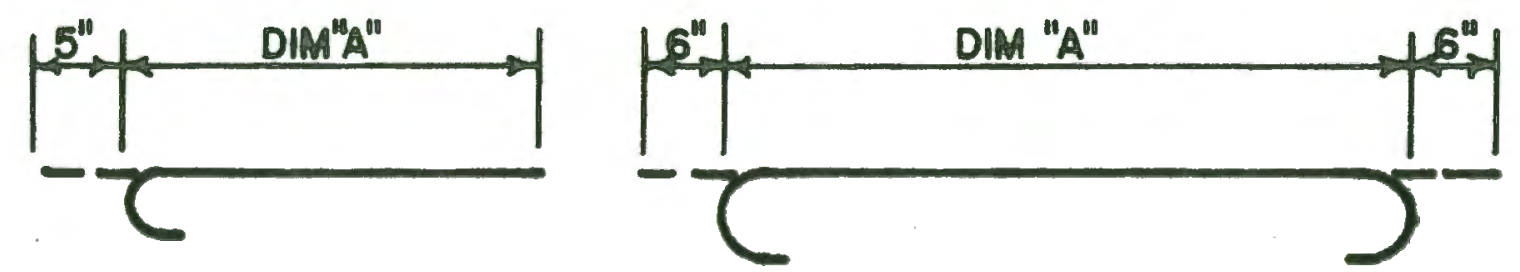

FIG.3.12 SCHEDULE OF REINFORCEMENT, USD-I 


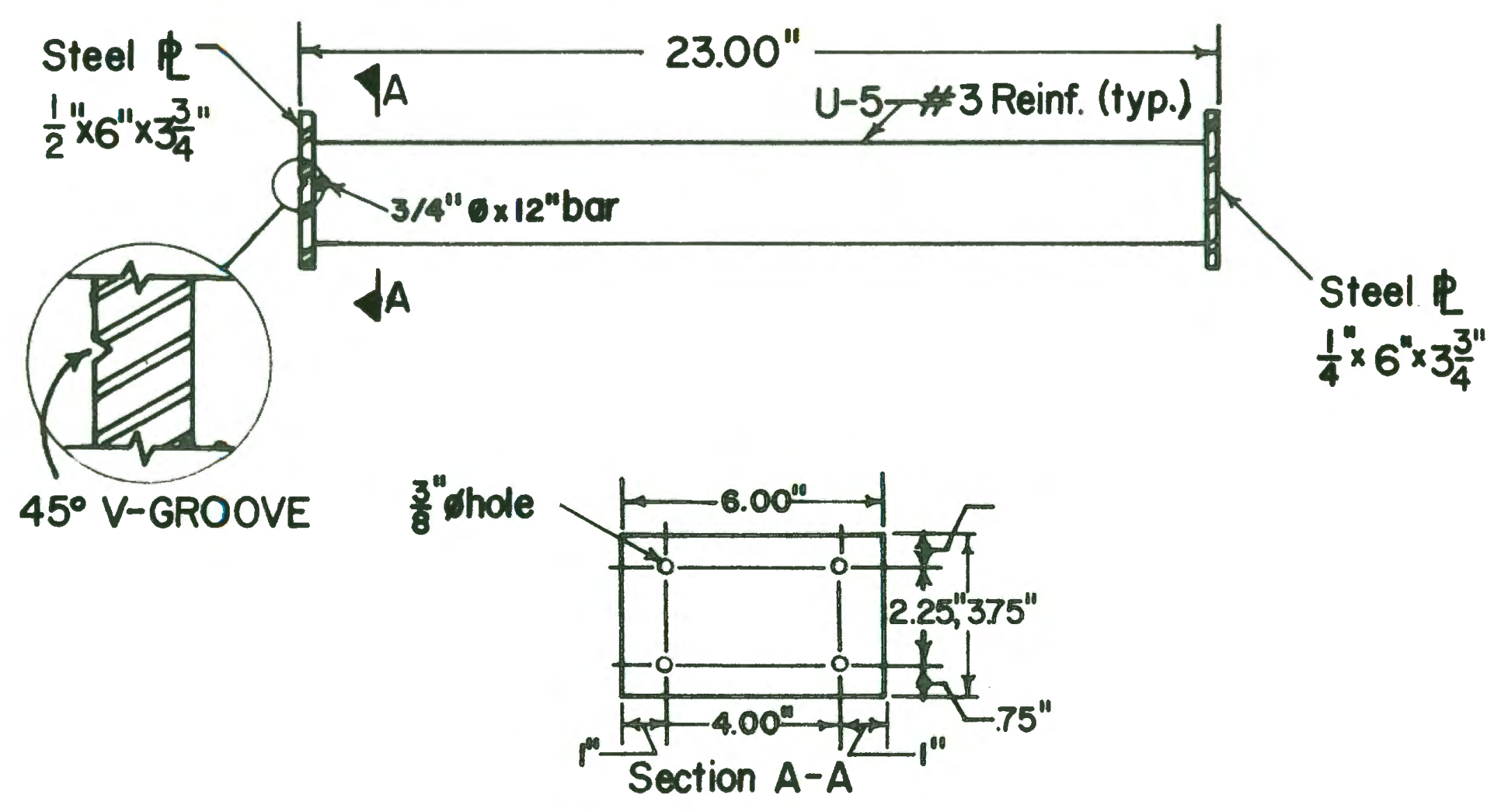

FIG.3.13 COLUMN CAGE FOR FRAME USD-I 


\subsection{LIMIT DESIGN OF FRAME LD-1}

\subsubsection{Design Method}

The main steps in the design of Frame $\mathrm{LD}-1$ were:

1. Plastic frame analysis

2. Consideration of $P-\Delta$ moments

3. Column design

4. Beam design and detalling

5. Shear design

A five-story frame, as discussed in Chapter II, can redistribute moments to less stressed regions after the first hinge is formed. Eventually, the frame will form a collapse mechanism. At collapse mechanism, plastic analyses can be used to solve for the moments. The plastic moments will have to include the additional $\mathrm{P}-\Delta$ moments. A semi-empirical formula was used to complete the design moment diagram. The beam and columns were then designed and detailed according to the moment envelope diagram. Finally, separate checks were made for shear, and the rotational capacity at the first plastic hinge.

\subsubsection{Plastic Frame Analysis}

The "mechanism method"(19) was used to calculate the plastic limit load $\mathrm{P}_{\mathrm{p}}$ of the frame. In this method enough plastic hinges are assumed, at points of peak moment, to reduce the structure to a mechanism. The load, which is needed to form the plastic hinges, is then calculated. Since this load ignores $P=\Delta$ effects it, will be called the plastic limit load $P_{P}$ rather than the ultimate load $P_{u}$. The $P-\Delta$ effects are included in the next section. 
Since the frame can form various comblnations of mechanisms, it is necessary to determine the mechanism which requires the smallest plastic limit load $\mathrm{P}_{\mathrm{p}}$. The following assumptions were made in the plastic analysis of Frame LD-1:

1. The frame will remain in stable equilibrium after the first hinge is formed. This was discussed in Chapter II.

2. The moment-curvature relations are idealized as elasto-plastic.

3. Plastic hinges are assumed to occur at a polnt rather than a finite length.

4. The value of $M_{p}$, both positive and negative, was assumed to be the same for the beam.

5. The strength of the column $M_{p}$ col. was overdesigned by 10 percent to insure beam hinging.

6. The bending strength of the joint block is greater than the bending strength of the connecting beam and column. This is shown to be true by earlier investigators $(12,14,26)$.

7. The equations of equilibrium are based on the original frame geometry.

8. The members of the frame have adequate shear capacity so as to allow a flexural mechanism fallure.

9. The first plastic hinge has enough rotational capacity.

a) Condition I. The loads for condition I, as shown in Figure 3.14a, are expressed as a function of column load P. The three mechanisms that can form are shown in Figures $3.14 \mathrm{~b}$ through $3.14 \mathrm{~d}$. The hinges at corners $B$ and $C$ are drawn at the support face in accordance with assumptions 5 and 6 . The first two mechanisms are independent mechanisms 


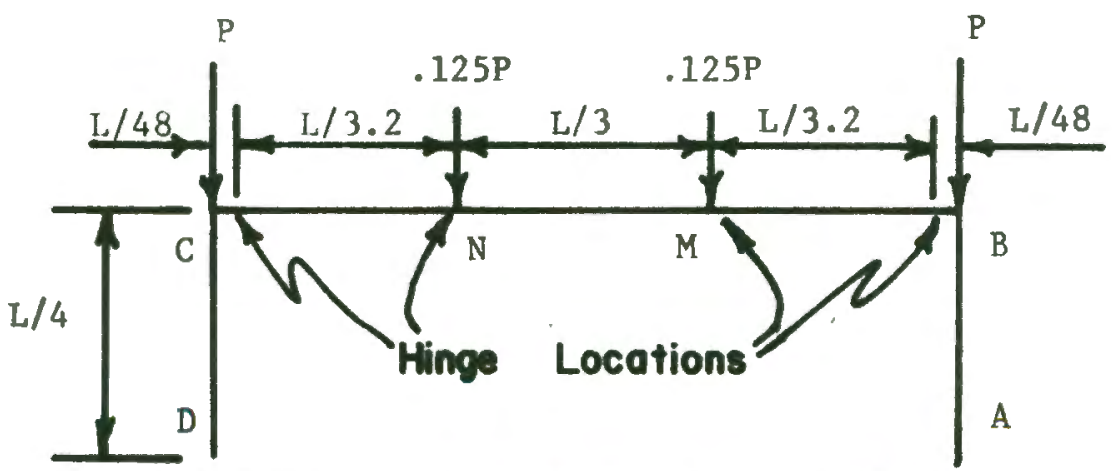

(a) STRUCTURE Q LOADING

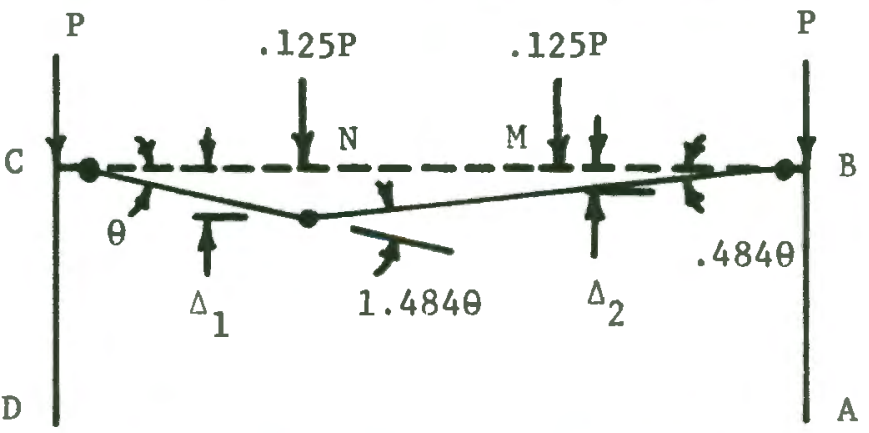

(b) BEAM MECHANISM

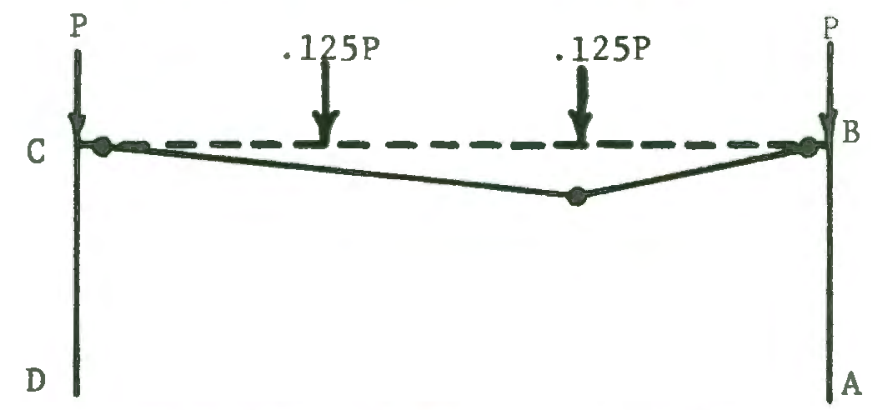

(c) BEAM MECHANISM

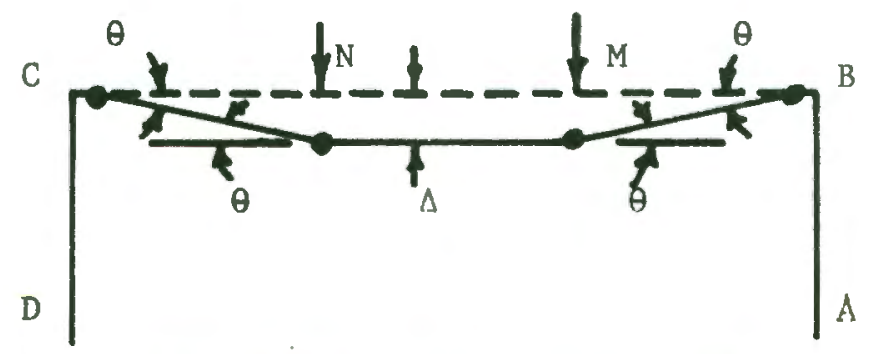

(d) COMBINED MECHANISM

FIG.3.14 MECHANISMS FOR COND. I 
while the last one is a combination of the first two.

For all three mechanisms, the principle of virtual work was applied to determine the plastic limit load.

Mathematically, the expression is

$$
\mathrm{W}_{\mathrm{E}}=\mathrm{W}_{\mathrm{I}}
$$

where $\mathrm{W}_{\mathrm{E}}=$ external virtual work

$\mathrm{W}_{\mathrm{I}}=$ internal virtual work

The moment diagram was drawn to meet the following three conditions:

1. The structure is in equilibrium.

2. Enough plastic hinges occur to form a mechanism.

3. All the moments, except in the jolnt block region and columns, are less than the plastic moment $\mathrm{M}_{\mathrm{p}}$

The beam mechanism, as shown in Figure $3.14 \mathrm{~b}$, is one of two Independent mechanisms. Since the frame and loads are symmetrical, the beam mechanism in Figure $3.14 \mathrm{C}$ has the same plastic limit load, $\mathrm{P}_{\mathrm{P}}$.

The principle of virtual work is applied by giving the hinge at $C$ a small rotation, $\theta$. The displacement at $\mathrm{N}$ is $\Delta_{1}=\theta \mathrm{L} / 3.2=.313$ eL. The rotation at $B$ is $.484 \theta$, and the angle change at $N$ is $\theta+.484 \theta=$ $1.484 \theta$. Finally, the displacement at $\mathrm{M}$ is $\Delta_{2}=(.484 \theta)(\mathrm{L} / 3.2)=.1 .51 \theta \mathrm{L}$. For this mechanism the external work is

$$
\begin{aligned}
W_{E} & =.125 \mathrm{P} \Delta_{1}+.125 \mathrm{PA}_{2}=(.125 \mathrm{P})(.313 \theta \mathrm{L})+(.125 \mathrm{P})(.151 \theta \mathrm{L}) \\
& =.058 \mathrm{P} \theta \mathrm{L}
\end{aligned}
$$

The internal work is

$$
\mathrm{W}_{I}=\mathrm{M}_{\mathrm{P}}(\theta+1.484 \theta+.484 \theta)=2.968 \mathrm{M}_{\mathrm{P}} \theta
$$


Equating external and internal work gives

$$
\mathrm{P}_{\mathrm{P}}=51.28 \mathrm{M} / \mathrm{L}
$$

Figure 3.14d is a combined mechanism of the first two beam mechanisms. The hinge rotations are $\theta$ which gives a displacement at $\mathrm{N}$ and $\mathrm{M}$ of $\Delta=$ $\theta \mathrm{L} / 3.2=.313 \mathrm{\theta L}$. The external work is

$$
\mathrm{W}_{\mathrm{E}}=(.125 \mathrm{P})(.313 \theta \mathrm{L})+(.125 \mathrm{P})(.313 \theta \mathrm{L})=.078 \theta \mathrm{L}
$$

The internal work is

$$
\mathrm{W}_{\mathrm{I}}=\mathrm{M}_{\mathrm{p}}(\theta+\theta+\theta+\theta)=4 \mathrm{M}_{\mathrm{p}} \theta
$$

Equating the above two equations gives

$$
P_{p}=51.28 \mathrm{M}_{\mathrm{p}} / \mathrm{L}
$$

Therefore, the plastic limit load is $\mathrm{P}_{\mathrm{p}}=51.28 \mathrm{M}_{\mathrm{p}} / \mathrm{L}$ which gives hinges at $B, M, N$ and $C$. The required $M_{p}$, excluding $P-\Delta$ effects, is found by substituting in the value of $\mathrm{P}_{\mathrm{u}}$. This gives $\mathrm{M}_{\mathrm{P}}=\mathrm{PL} / 51.2=$ $\frac{(1.7 \times 12.29)(84)}{51.2}=34.3$ in-k. The entire bending moment diagram is determined by considering the free body diagram of Figure 3.15 where al1 column forces are determined by considering the free body diagrams of individual columns.

The moment at the centerline of the joint block is $1.13 \mathrm{M}_{\mathrm{p}}$. As stated in assumption 6 , the column joint block has greater strength than the connecting members. The moments for the entire structure are shown in Figure 3.16.

b) Condition II. The loads for Condition II are shown in Figure 3.17a. The independent mechanisms are the same as for loading Condition I except that there is an added panel mechanism. The first two mechanisms, 


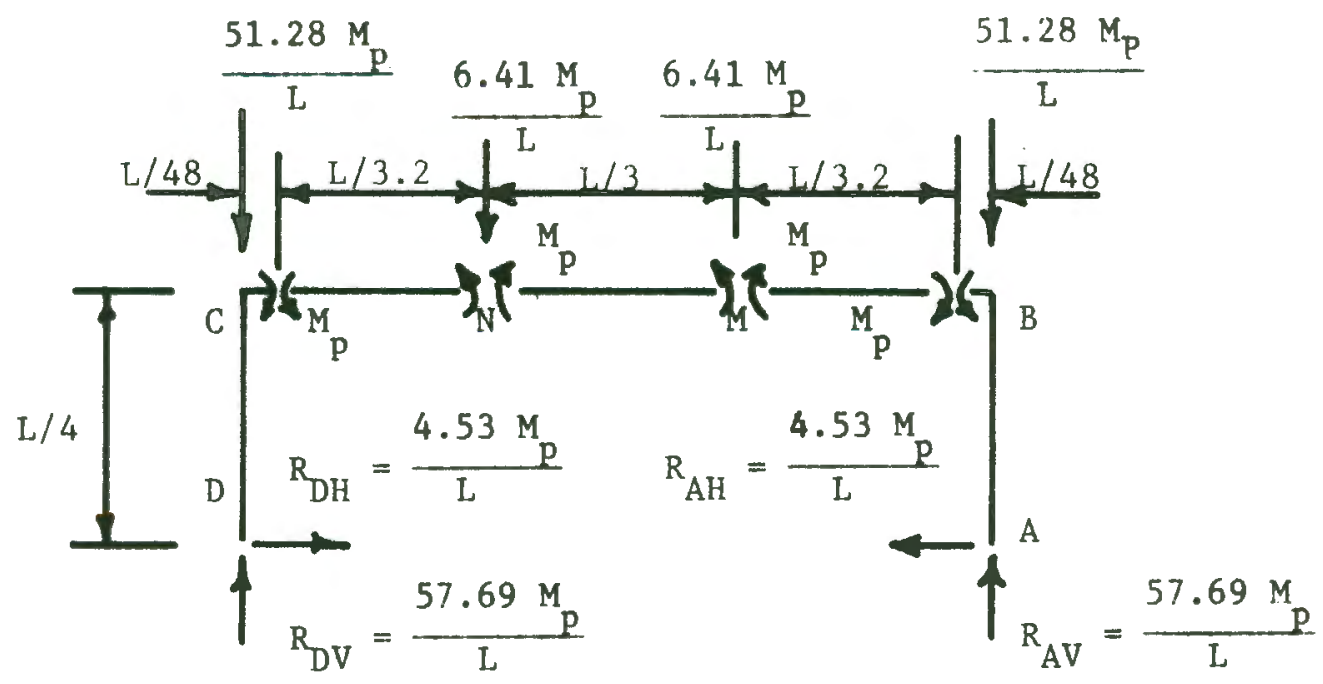

FIG.3.15 LOADS AND REACTIONS

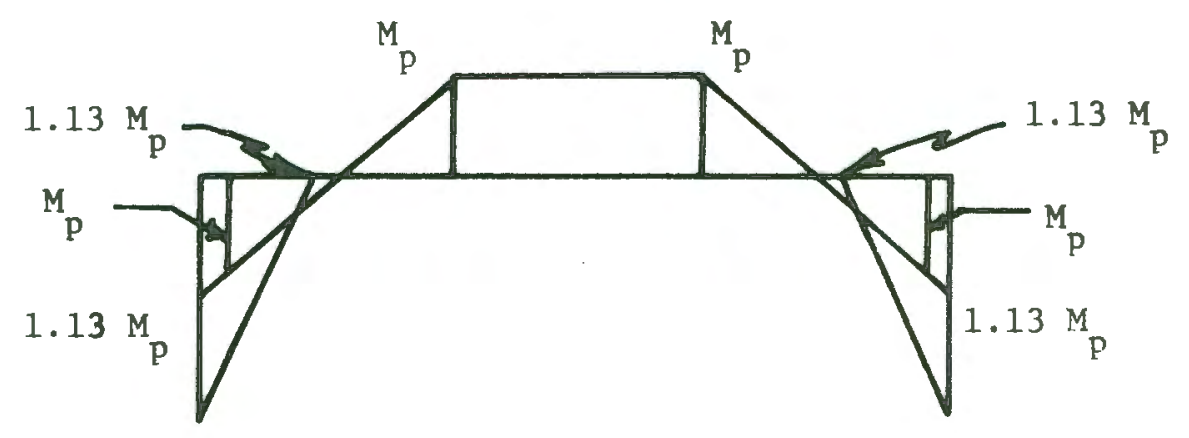

FIG.3.16 MOMENT DIAGRAM 
as shown in Figures $3.17 \mathrm{~b}$ and $3.17 \mathrm{c}$, are beam mechanisms which give the same expression for $P_{P}$ as equation (3.4). The third mechanism is a panel mechanism while the fourth mechanism is a combination of a beam and pane1 mechanisms.

For the panel mechanism shown in Figure $3.17 \mathrm{~d}$, the added rotation at $C$ is caused by the inclination of member $B C$. If the columns rotate $\theta$, then hinge $C$ rises a distance $\Delta_{2}=(\theta)(L / 48)=.0208$ oL while the hinge at $B$ lowers the same amount. Therefore, the rotation of this member is

$$
\theta_{1}=\frac{.0208 \theta \mathrm{L}+.0208 \theta \mathrm{L}}{\mathrm{L} / 1.043}=.0434 \theta
$$

This gives a hinge rotation at $B$ and $C$ of $\theta+.0434 \theta=1.0434 \theta$. The horizontal displacement of the frame is $\Delta_{1}=(\theta)(\mathrm{L} / 4)=.250 \theta \mathrm{L}$. Therefore, the external work is

$$
\mathrm{W}_{\mathrm{E}}=(.087 \mathrm{P})(.25 \theta \mathrm{L})=.0218 \mathrm{P} \theta \mathrm{L}
$$

The external work at $M$ and $N$ cancel each other. The internal work is

$$
W_{I}=M_{P}(1.0434 \theta+1.0434 \theta)=2.0868 M_{p} \theta
$$

Equating external and internal work gives

$$
P_{P}=95.72 M_{p} / L
$$

Figure 3.18 is a combined mechanism with hinges at $C$ and $M$.

Because the hinge at $\mathrm{C}$ displaces vertically it is necessary to calculate the rotation $\theta_{1}$. The rotation $\theta_{1}$ is solved by considering the geometry of the mechanism. This gives

$$
\theta_{1}=\frac{\Delta_{1}+\Delta_{2}}{\mathrm{~L} / 3+\mathrm{L} / 3.2}
$$

The vertical deflection at $C$ is $\Lambda_{2}=(\theta)(L / 48)=.02080 \mathrm{~L}$, while the 

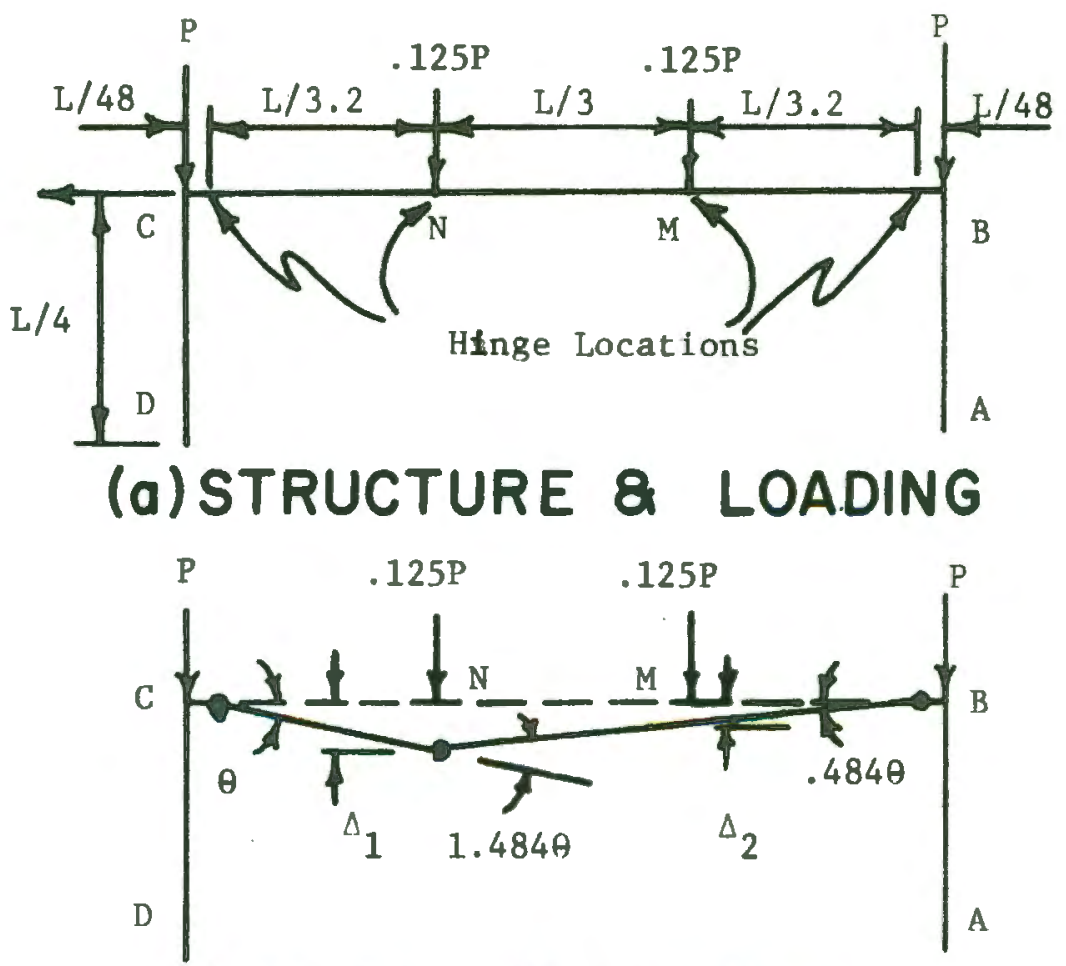

(b) BEAM MECHANISM

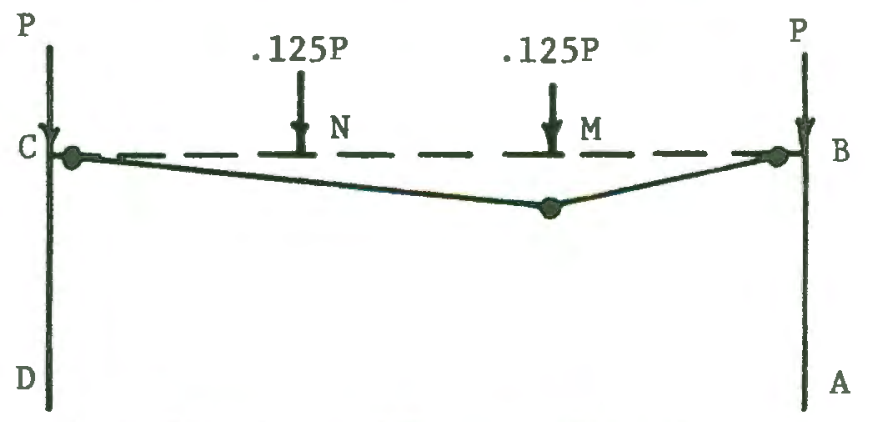

(c) BEAM MECHANISM

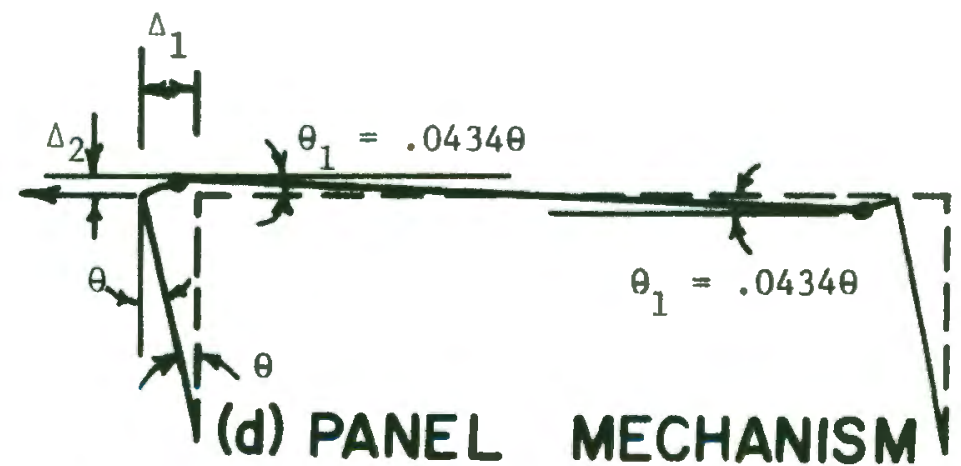

FIG.3.17 INDEPENDENT MECHANISMS FOR CONDITION II 
vertical deflection at $M$ is $1=(\theta)(L / 3)=.3333 \theta L$. Therefore

$$
\theta_{i}=\frac{.333 \theta L+.0208 \theta L}{L / 3+L / 3.2}=.548 \theta
$$

This gives a rotation at $C$ and $M$ of $\theta+.548 \theta=1.548 \theta$. The displacement at $\mathrm{N}$ is $\Delta_{3}=(.548 \theta)(\mathrm{L} / 3.2)-(\theta)(\mathrm{L} / 48)=.150$ 日L.

The external work is

$$
\begin{aligned}
W_{E} & =(.087 \mathrm{P})(.25 \theta \mathrm{L})+(.125 \mathrm{P})(.150 \theta \mathrm{L})+(.125 \mathrm{P})(.3333 \theta \mathrm{L} \\
& =.082 \mathrm{P} \theta \mathrm{L}
\end{aligned}
$$

The internal work is

$$
W_{I}=M_{p}(1.548 \theta+1.548 \theta)=3.096 M_{p} \theta
$$

Equating external and internal work gives

$$
P_{p}=37.76 \mathrm{M}_{\mathrm{p}} / \mathrm{L}
$$

which is the controlling mechanism. This gives a required $M_{p}=P L / 37.76=$ $\frac{(15.67)(84)}{37.76}=34.9$ In-k.

The fallure mechanism is checked by considering the equilibrium of the entire structure as shown in Figure 3.19. The moments are shown in Figure 3.20.

The moments for both loading conditions, excluding the column moments, are shown in Figure 3.21.

\subsubsection{Consideration of $\mathrm{P}-\Delta$ Moments}

The plastic limit loads calculated for each load condition in previous sections did not include $P-\Delta$ effects. To complete the moment diagram of Figure 3.21, the $P-\Delta$. effect is estimated using an empirical equation as described in the following.

An equation used to predict the fallure load of steel frames is given by the Merchant-Rankine formula (20):

$$
\frac{1}{\lambda_{F}}=\frac{1}{\lambda_{P}}+\frac{1}{\lambda_{C}} \text { or } \quad \lambda_{F}=\frac{{ }^{\lambda_{P}}}{1+\lambda_{P} / \lambda_{C}}
$$




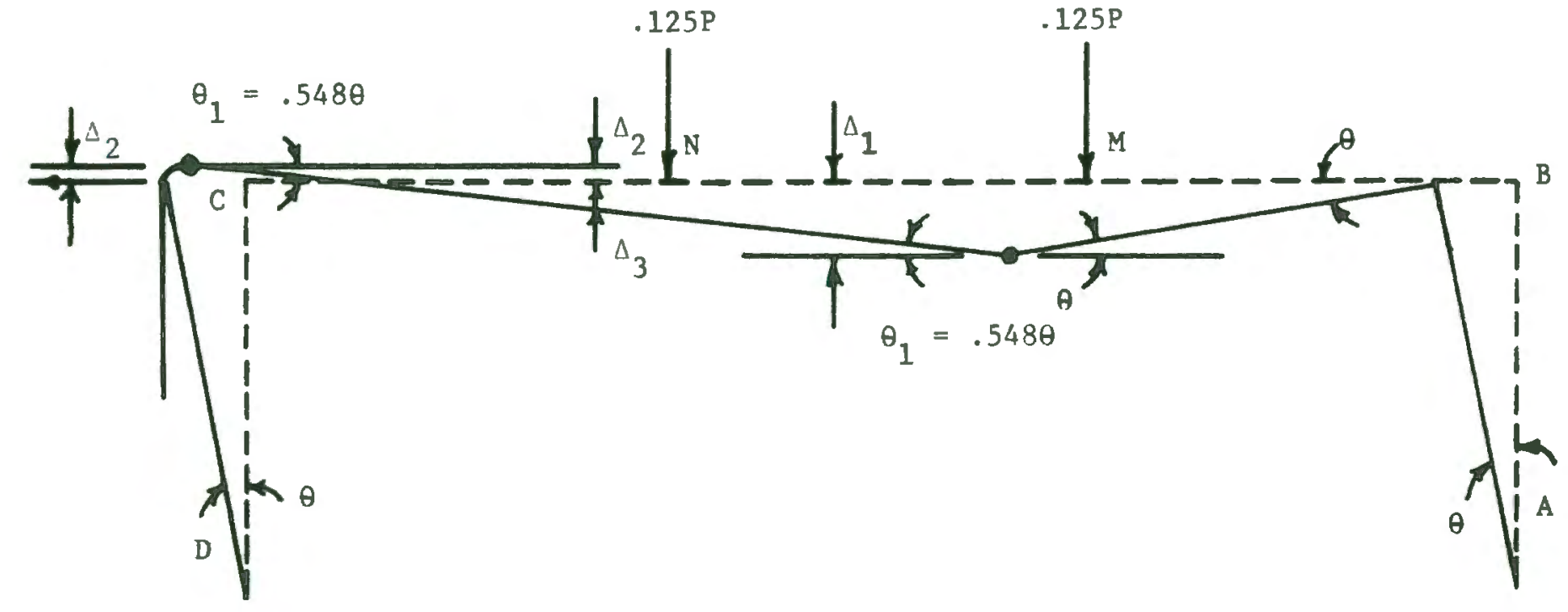

FIG.3.18 COMBINED MECHANISM 


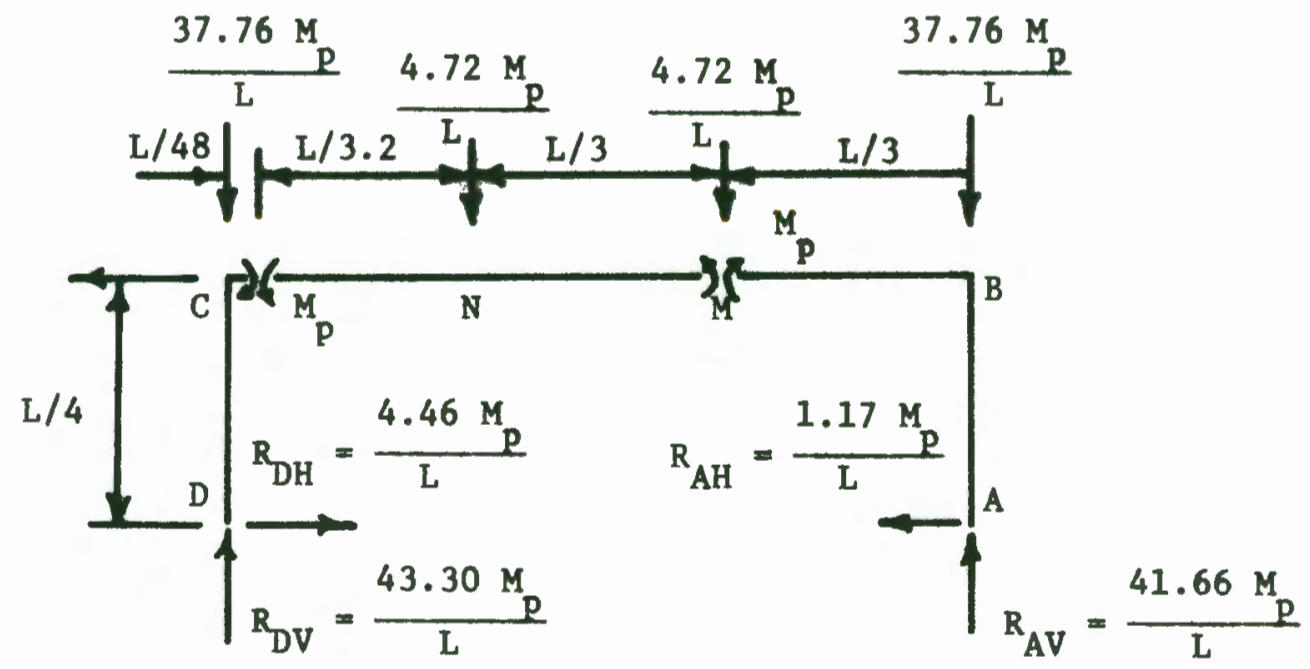

FIG.3.19 LOADS \& REACTIONS

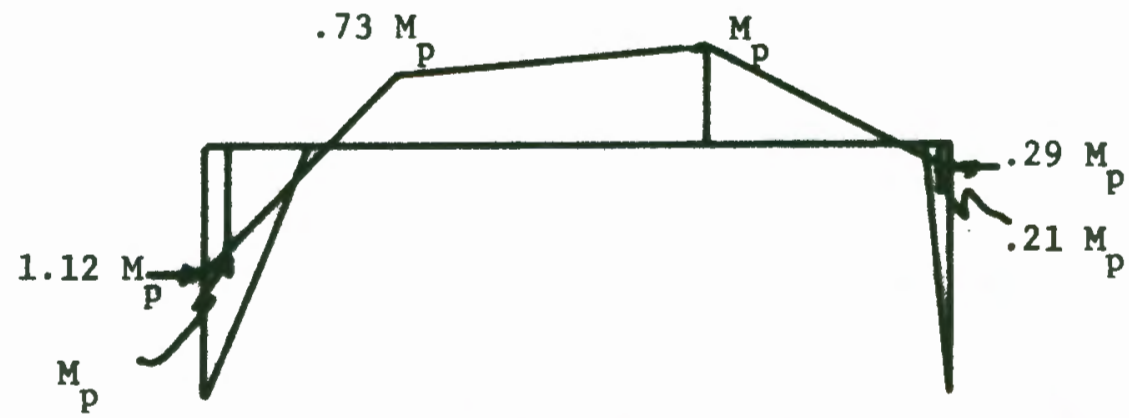

FIG.3.2OMOMENT DIAGRAM 


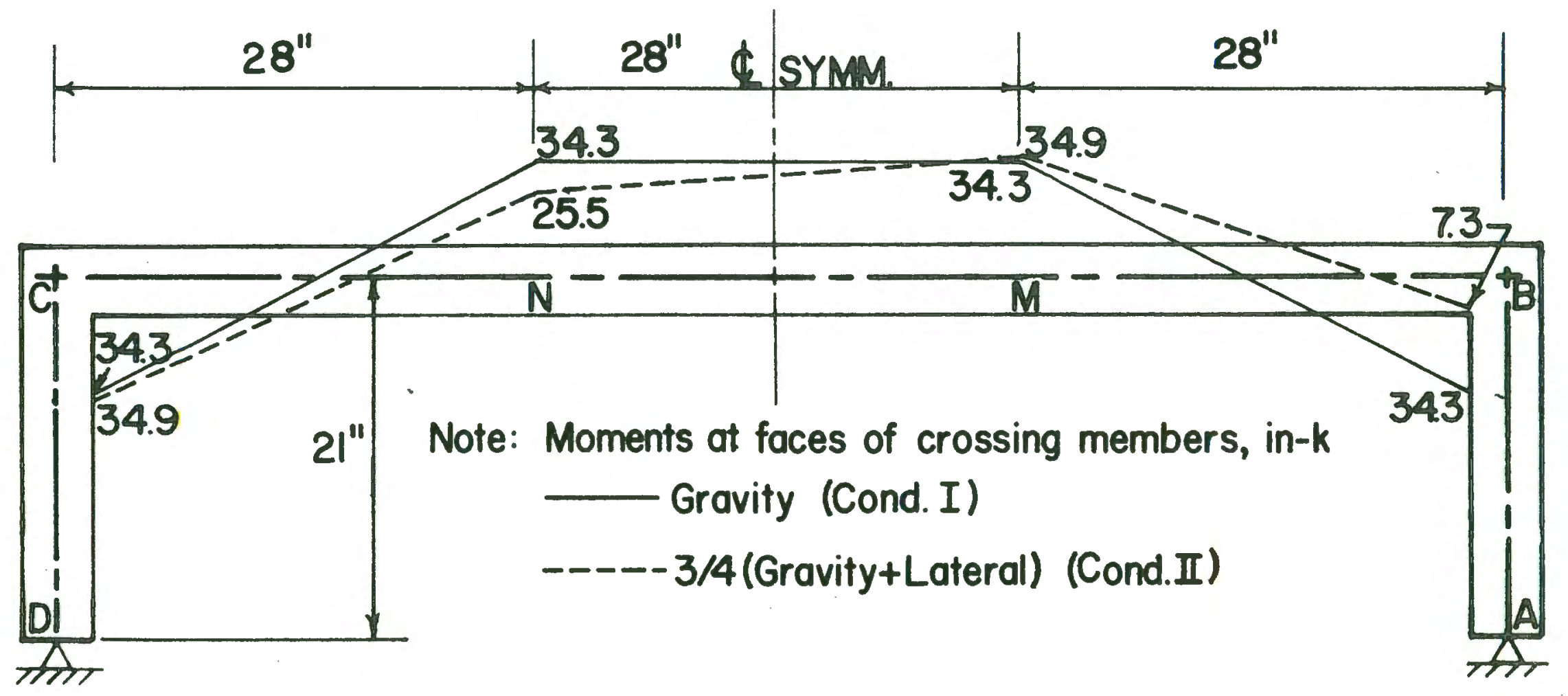

FIG.32IBEAM MOMENT ENVELOPE FOR LD-I 
where $\lambda_{F}=$ collapse load factor

$$
\begin{aligned}
& =\frac{\left.P_{u} \text { (Code equations } 9-1 \text { or } 9-2\right)}{\text { service load. }} \\
\lambda_{c} & =\text { Elastic critical load factor } \\
& =\frac{\left.P_{c} \text { (equation } 3.1\right)}{\text { service load }} \\
\lambda_{P} & =\text { Idealized rigid-plastic collapse load factor } \\
& =\frac{P_{p} \text { (From controlling mechanism) }}{\text { service load }}
\end{aligned}
$$

This equation combines purely elastic behavior $\left(\lambda_{c}\right)$ with purely plastic behavior $\left(\lambda_{\mathrm{p}}\right)$ to find the collapse load factor.

More recently, Wood (21) modifled the Merchant-Rankine formula

as follows:

$$
\lambda_{F}=\frac{\lambda_{p}}{.9+\lambda_{p} / \lambda_{c}}
$$

Wood changed the formula primarily because of the effect of strain hardening and cladding on the strength and stiffness of steel frames. This equation was used to predict the collapse load factor of Frame LD- 1 . First, the frame critical sections, excluding $P-\Delta$ effects, were designed according to the moments of Figure 3.21. From the cross sections and frame geometry, the elastic critical buckling load was determined from equation 3.1. Then the collapse load factor was determined from equation (3.9) which gave a lower value than specified by code equations 9-1 and 9-2. Therefore, the failure load had to be increased by either stiffening or strengthening the member critical sections. It was decided to strengthen the member so that the plastic collapse load factor would increase. To do this, equation 3.9 was rearranged to give 
the needed plastic collapse load factor:

$$
\lambda_{P}=\frac{.9 \lambda_{F} \lambda_{C}}{\lambda_{C}-\lambda_{F}}
$$

The collapse load factors are defined as $\lambda_{F}=1.7$ and 1.4 as specified by ACI 318-71. The elastic critical load factor $\lambda_{\mathrm{E}}$ was calculated from the final design cross sections. Hence, the required $\lambda_{P}$ ( or $P_{P}$ ) could be calculated. Finally, the required $M_{p}$, which is a function of $P_{p}$, was determined.

a) Condition I. The required $M_{p}$ is calculated for loading condition I. The cross section details of the beam and column are shown in Figure 3.30.

The flexural stiffness of the column and beam is

$$
\begin{aligned}
& \left.\mathrm{EI}_{\mathrm{b}}=38750 \mathrm{in}^{2}-\mathrm{k} \quad \text { (see Figure } 3.22\right) \\
& \mathrm{EI} I_{c}=31500 \mathrm{in}^{2}-\mathrm{k} \quad\left(\mathrm{P}-\mathrm{M}-\emptyset_{\mathrm{t}}\right. \text { not shown) }
\end{aligned}
$$

The above values give flexural stiffnesses of $\mathrm{EI}_{\mathrm{c}} / \mathrm{L}_{\mathrm{c}}=31500 / 21=$ 1500 in-k for the column and $\mathrm{EI}_{\mathrm{b}} / \mathrm{L}_{\mathrm{b}}=38750 / 84=461 \mathrm{in-k}$ for the beam. At joints $C$ and $D$ the rigidity ratios are

$$
\begin{aligned}
& \psi_{C}=\frac{\sum \mathrm{EI}_{\mathrm{c}} / \mathrm{L}_{\mathrm{c}}}{\sum \mathrm{EI}_{\mathrm{b}} / \mathrm{L}_{\mathrm{b}}}=\frac{1500}{461}=3.25 \\
& \Psi_{D}=\infty \text { (Hinge) }
\end{aligned}
$$

From reference (18), the equivalent factor $k$ is 3.0 . The elastic critical buckling load according to equation (3.1) is

$$
P_{c}=\frac{\pi^{2} E I_{c}}{\left(k 1_{u}\right)^{2}}=\frac{\pi^{2} \times 31500}{(3 \times 19)^{2}}=95.7 \mathrm{k}
$$

The elastic critical load factor is

$$
\lambda_{c}=\frac{\text { Elastic critical load }\left(\mathrm{P}_{c}\right)}{\text { Service load }(\mathrm{P}+\mathrm{Q})}=\frac{95.7}{12.29+1.54}=6.92
$$




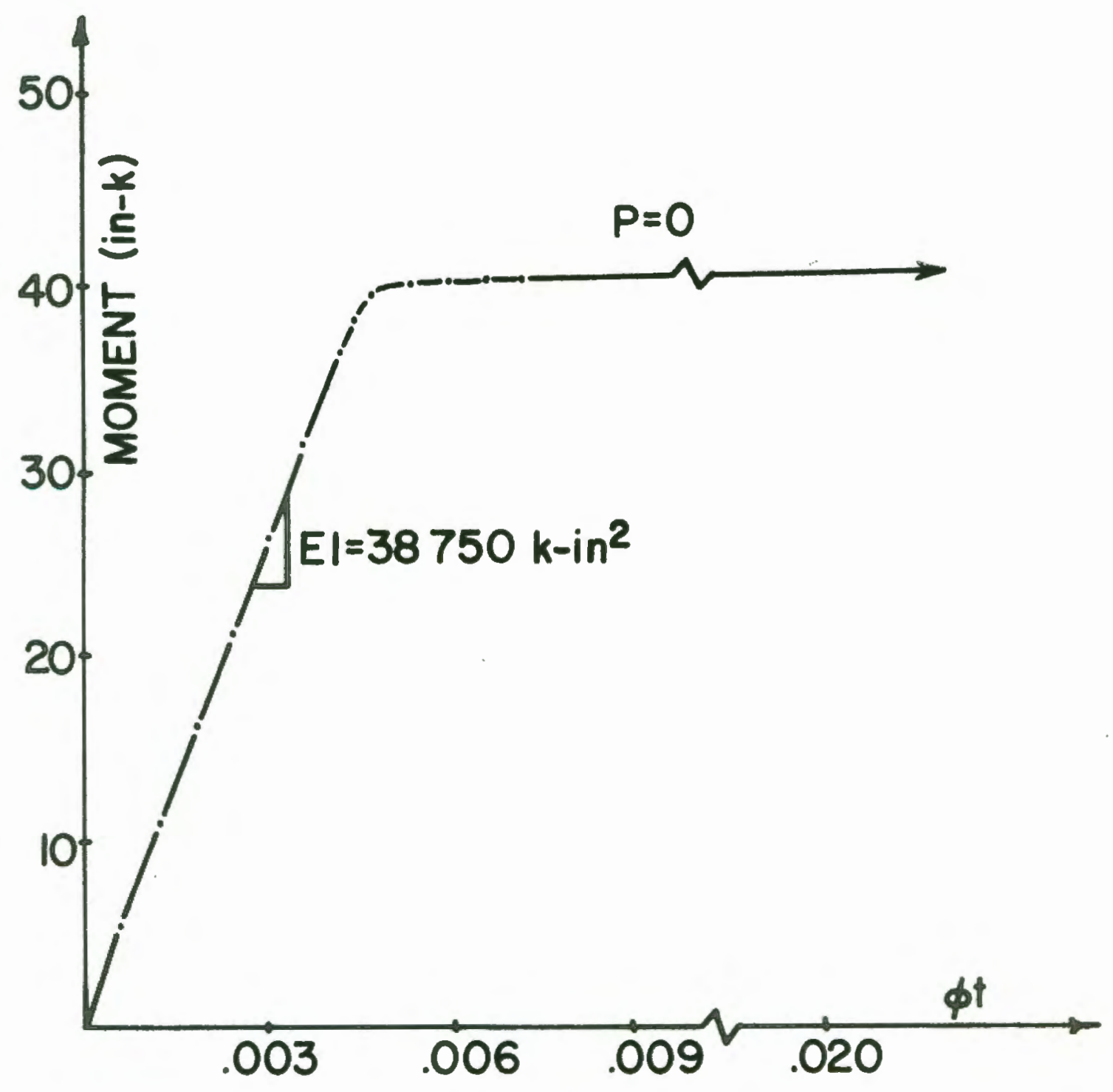

FIG.3.22 COMPUTED P-M- $\phi \dagger$, BEAM LD-I 
The required idealized rigid-plastic collapse load factor $\lambda_{p}$ ' according to equation $(3.10)$, is

$$
\lambda_{P}=\frac{.9 \lambda_{F} \lambda_{C}}{\lambda_{C}-\lambda_{F}}=\frac{(.9)(1.7)(6.92)}{6.92-1.70}=2.03
$$

Finally, the required $M_{p}$ for this loading condition is calculated from the controlling mechanism:

$$
M_{P}=\frac{P_{p}{ }^{L}}{51.28}=\frac{(2.03 \times 12.29)(84)}{51.28}=40.91 \mathrm{in-k}
$$

The moment diagram for loading condition $I$ is shown in Figure 3.24 as a solid line.

b) Condition II. For loading condition II, the flexural stiffnesses of the column and beam are

$$
\begin{aligned}
& \mathrm{EI}_{\mathrm{b}}=38750 \mathrm{in}^{2}-\mathrm{k} \quad \text { (see Figure 3.22) } \\
& \mathrm{EI}_{\mathrm{c}}=33000 \mathrm{in}^{2}-\mathrm{k} \quad \text { (see Figure 3.23) }
\end{aligned}
$$

These values give flexural stiffnesses of $\mathrm{EI}_{\mathrm{c}} / \mathrm{L}_{\mathrm{C}}=33000 / 21=$ 1571 in-k for the column, and $\mathrm{EI}_{\mathrm{b}} / \mathrm{L}_{\mathrm{b}}=38750 / 84=461$ for the beam. At joints $C$ and $D$ the rigidity ratios are

$$
\begin{aligned}
& \psi_{C}=\frac{\sum \mathrm{EI}_{\mathrm{c}} / \mathrm{L}_{\mathrm{C}}}{\sum \mathrm{EI}_{\mathrm{b}} / \mathrm{L}_{\mathrm{b}}}=\frac{1571}{461}=3.41 \\
& \psi_{D}=\infty \text { (Hinge) }
\end{aligned}
$$

From reference (18), the equivalent length factor $k$ is 3.0 . The elastic critical buckling load according to equation (3.1) is

$$
P_{c}=\frac{\pi^{2} E I_{c}}{\left(k 1_{u}\right)^{2}}=\frac{\pi^{2} \times 33000}{(3 \times 19)^{2}}=100.2 \mathrm{k}
$$

The elastic critical load factor, Including the lateral load effect on the axtal load, is

$$
\lambda_{c}=\frac{P_{c}}{\text { Service load }}=\frac{100.2}{.75\left(12.29+1.54+\frac{(1.07)(42)}{(2)(84)}\right)}=9.48 \mathrm{k}
$$




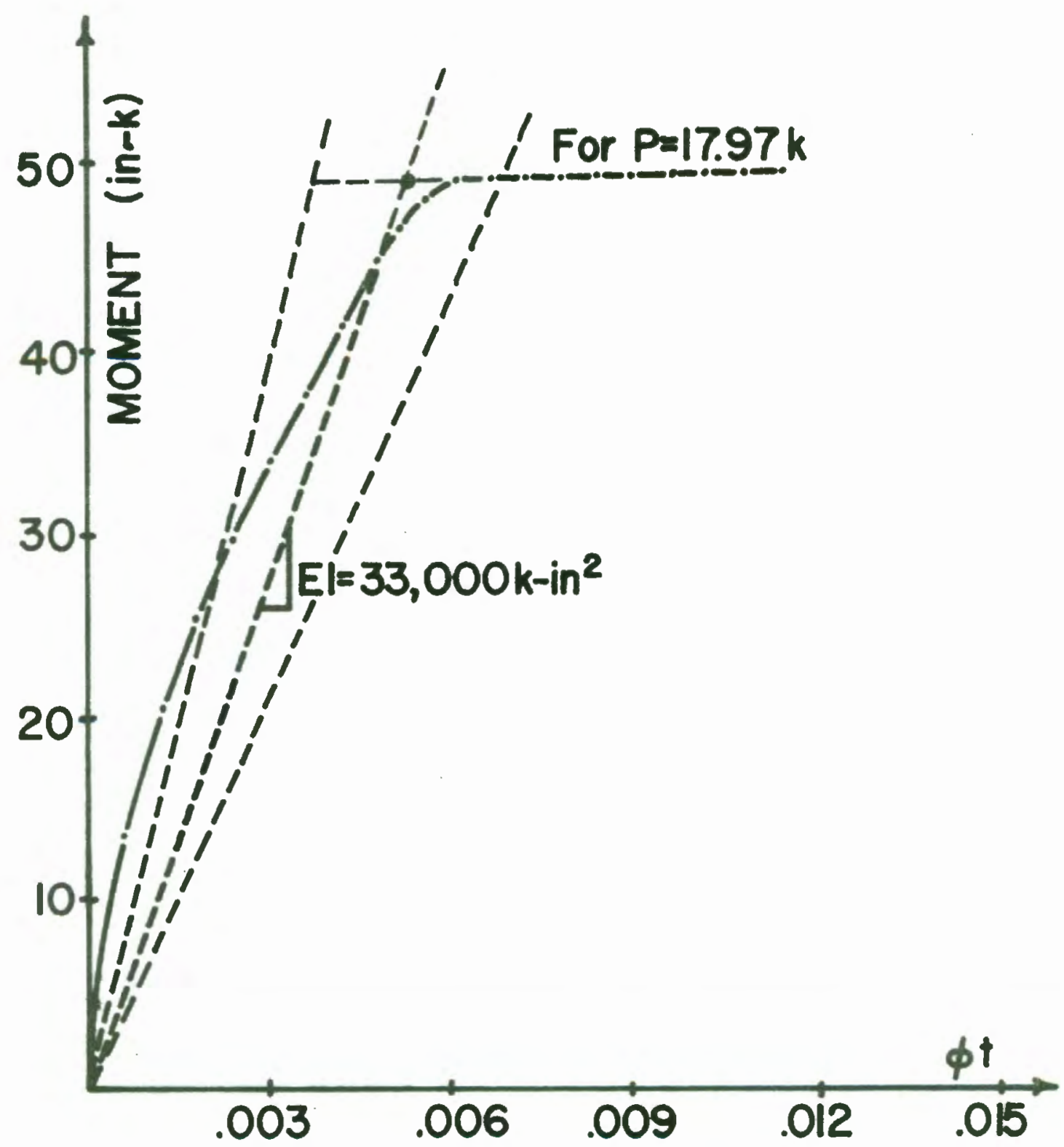

FIG.3.23 TYPICAL COMPUTED P-M- $\phi$, FOR LD-I COLUMNS 
The required 1dealized rigld-plastic collapse load factor, according to equation $(3.10)$, is

$$
\lambda_{P}=\frac{.9 \lambda_{F} \lambda_{C}}{\lambda_{C}-\lambda_{F}}=\frac{(.9)(1.7)(9.48)}{(9.48-1.70)}=1.86
$$

Finally, the required $M_{p}$ for this loading condition is calculated from the controlling mechanism:

$$
M_{p}=\frac{P_{p}^{L}}{37.76}=\frac{(1.86 \times 9.22)(84)}{37.76}=38.21 \mathrm{in}-\mathrm{k}
$$

The moment diagram for loading condition II is shown in Figure 3.24 as a dashed line.

\subsubsection{Column Design}

The $P-\Delta$ effects for the column were included in the design $M_{p}$ by increasing the plastic collapse load factor. Thus, the design moment for the column already includes the $\mathrm{P}-\Delta$ moment. The moments are determined at the critical sections from the reactions of the frame, as shown in Figures 3.15 and 3.19. The column cross section is shown in Figure 3.30.

a) Condition $I$. The required strength for the column is $P_{u}=23.5 \mathrm{k}$ and $M_{p}=\left(1_{u}\right)($ Base shear $)=(19)\left(\frac{4.53 M_{P}}{L}\right)=(19)\left(\frac{4.53 \times 40.9}{84}\right)$ $=41.9$ in $-k$.

The values used in the column design are the eccentricity ratio $\mathrm{e} / \mathrm{h}=41.9 /(23.5)(3.50)=.51$ and $\rho_{t} \mathrm{~m}=(.021)((60) /(.85)(4))=.37$. For this section, $\gamma / h=.57=.6$, so chart 85 of reference $(17, \mathrm{p} .121)$ is used. This gives a capac1ty of $\mathrm{P}_{u} / \mathrm{f}_{c}^{\prime} \mathrm{bd}=.27$. The true capacity with $\emptyset=1$ is $.27 / .7=.39$. The required is $\mathrm{P}_{u} / \mathrm{f}_{c}^{\prime} \mathrm{bh}=23.5 /(4)(6)(3.5)=$ 28. 


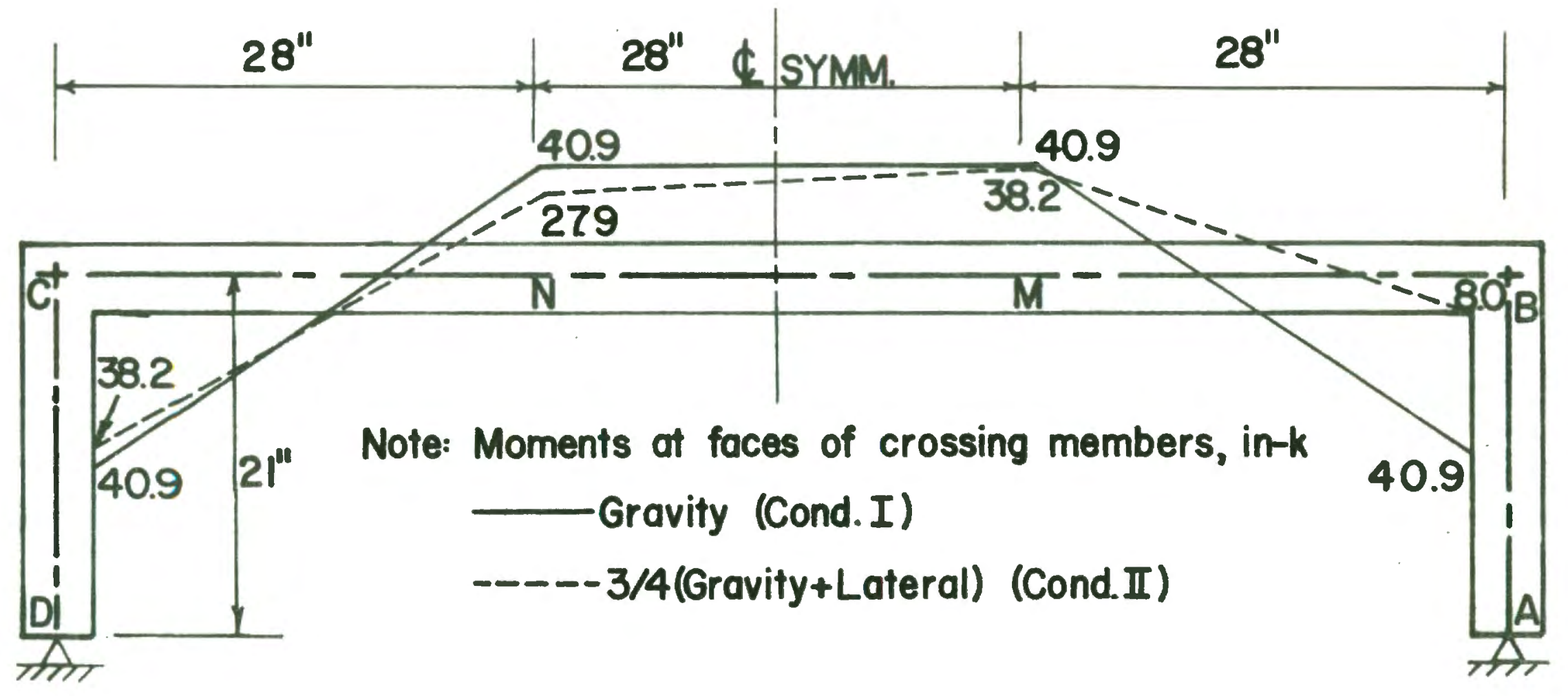

FIG.3.24 BEAM MOMENT ENVELOPE WITH P- $\triangle$ EFFECTS, LD-I 
$\therefore$ Design is adequate for Condition I.

b) Condition II. The required strength, excluding column thrusts caused by lateral loading, is $\mathrm{P}_{4.46 \mathrm{M}} \mathrm{u}=15.67+1.96=17.63 \mathrm{k}$ and $\mathrm{M}_{\mathrm{p}}=$ $\left(1_{u}\right)$ (Base shear) $=(19)\left(\frac{4.46 \mathrm{M}_{\mathrm{P}}^{\mathrm{U}}}{\mathrm{L}}\right)=(19)\left(\frac{4.46 \times 38.2}{84}\right)=38.5 \mathrm{in-k}$.

The eccentricity ratio is $\mathrm{e} / \mathrm{h}=38.5 /(17.63)(3.30)=.62$ and $t^{\mathrm{m}}=.37$. The capacity as determined from reference $(17, \mathrm{p} .121)$, is $\mathrm{P}_{\mathrm{u}} / \mathrm{f}_{\mathrm{c}}^{\mathrm{b} h}=.22$. The true capacity with $\emptyset=1 \mathrm{is} \cdot 22 / .7=.31$. The required is $\mathrm{P}_{\mathrm{u}} / \mathrm{f}_{\mathrm{c}}^{\mathrm{b}} \mathrm{bh}=17.63 /(4)(6)(3.5)=.21$

$\therefore$ Design is adequate for Condition II.

\subsubsection{Beam Design and Detalling}

The required plastic moments, $M_{p}$, as shown in Figure 3.24, are 40.9 in-k for condition $I$ and 38.2 in-k for condition II. Therefore, gravity loads control the design at critical sections $M$ and $C$. The section design and detailing is similar to the beam design of Frame USD-1. However, only one cross-section is designed. The required plastic rotational capacity is checked in section 3.3 .7 .

$$
M_{p}=M_{u}=40.9 \text { in-k }
$$

$$
\begin{aligned}
& d=3.17^{\prime \prime} \\
& d=3.17 \text { (after several trials) } \\
& \vec{T}=A_{s^{y}} f=(2)(.11)(66.0)=14.52 \mathrm{k} \\
& \begin{array}{l}
\mathrm{f}_{\mathrm{c}}^{\prime}=4.0 \mathrm{ksi} \\
\mathrm{f}_{\mathrm{y}}=66.0 \mathrm{ksi} \\
A_{s}=2-\# 3=.22 \mathrm{in}^{2}
\end{array}
\end{aligned}
$$




$$
\begin{aligned}
& \bar{C}=\bar{T} \\
& .85 \mathrm{f}_{\mathrm{c}}^{\mathrm{a}} \mathrm{ab}=14.52 ; \quad \mathrm{a}=\frac{14.52}{(.85)(4)(6)}=.712 \\
& \overline{\mathrm{M}}=\overline{\mathrm{T}}(\mathrm{d}-\mathrm{a} / 2)=14.52(3.17-.712 / 2)=40.9 \mathrm{In}-\mathrm{k}
\end{aligned}
$$

The moment envelope for one-half the frame is shown in Figure 3.25. The same assumptions and procedure are used as for Frame USD-1. The shear requirements at the cutoff points will be checked in section 3.3.6. As shown in Figure 3.25, for negative moment relnforcing, one bar can be tentatively stopped at $7.02^{\prime \prime}+4.5^{\prime \prime}=11.52^{\prime \prime}\left(1^{\prime}-0^{\prime \prime}\right)$. Thts glves enough distance for the bar to yleld at the support face $\left(1^{\prime}-0^{\prime \prime}=1_{\mathrm{d}}=1^{\prime}-0^{\prime \prime}\right)$. Since the remaining bar is assumed to yield at the cutoff point, it must extend $1_{d}=12$ in. past this point. Therefore, the remaining bar is stopped at $1^{\prime}-0^{\prime \prime}+12^{\prime \prime}=2^{\prime}-0^{\prime \prime}$ from the support face. This bar extends $24^{\prime \prime}-15.17 "=8.83^{\prime \prime}$ past the point of inflection which is greater than $12 d_{b}$ or $1_{n} / 16$ as required by the ACI $318-71$ code (Art. 12.3.3).

One positive moment bar can be tentatively stopped at $10.06 "+$ $4.5^{\prime \prime}=14.51^{\prime \prime}\left(1^{\prime}-3^{\prime \prime}\right)$ from point $M$. This is enough distance for the bar to yfeld at point $M$. The remaining bar must extend through the support so as to develop its yield strength at that joint. This satisfles 71 ACI Code Articles 12.2 .1 and 12.2.2.

To make sure the refnforcement is in the elastic range at service loads, the elastic stresses are calculated. The highest service load moment is in the beam at corner $C$. The service load moments for the two loading conditions are calculated according to the provistons of reference (22). 


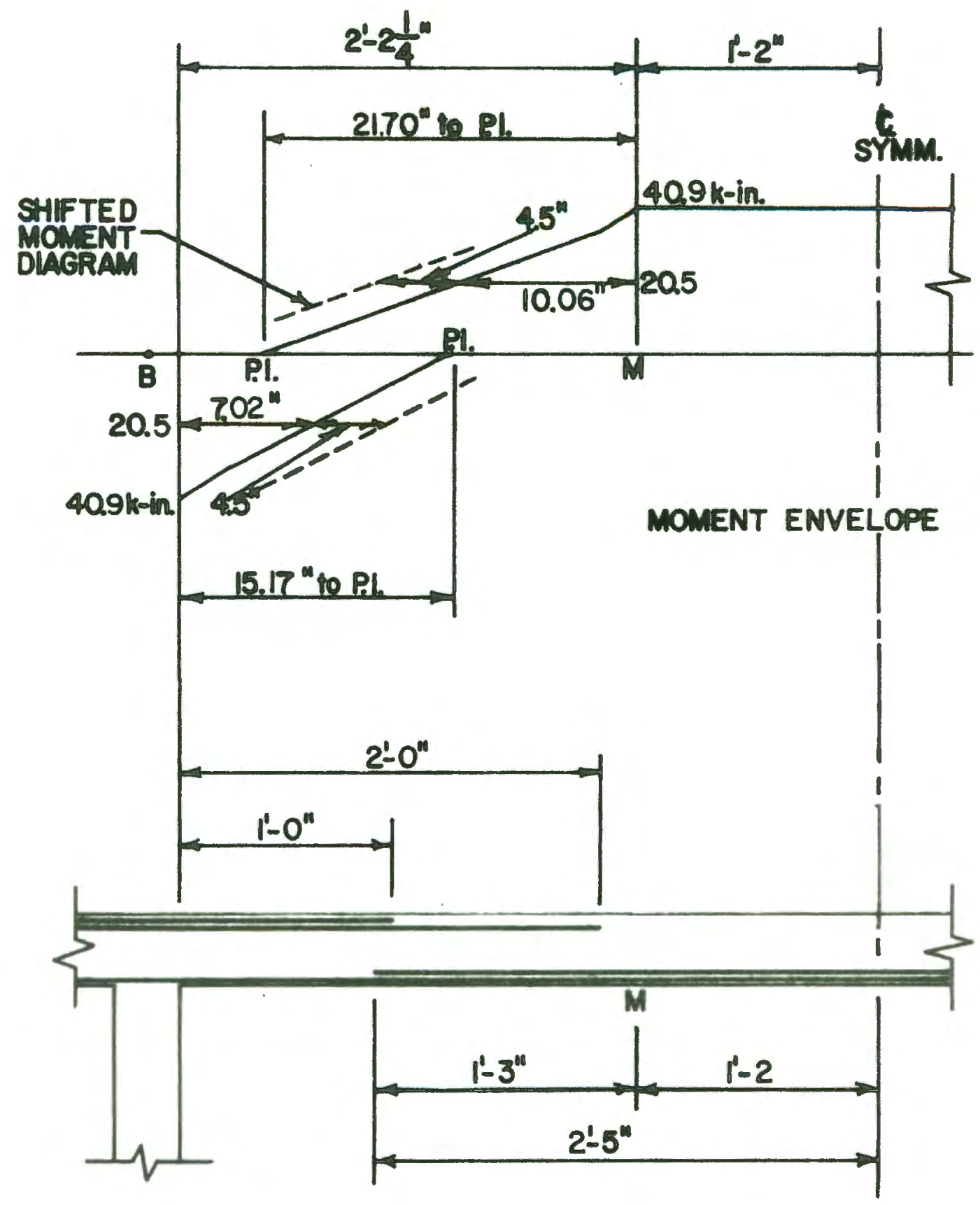

FIG.3.25 BEAM REINF DETAILS, LD-I 
The service loads for gravity (condition I) are multiplied by 1.2 while the service loads for gravity and lateral (condition II) are multiplied by 1.0. Next, the elastic moments are calculated from these loads. Finally, the elastic stresses are calculated from the transformed section.

The moment at corner $C$, in condition $I$, is:

$$
M=F Q L_{b}=(.178)(1.2 \times 1.54)(84)=27.6 \text { in-k }
$$

This moment reduces to $24.9 \mathrm{in}-\mathrm{k}$ at the support face. The moment at corner $C$ in condition II, is:

$$
\begin{aligned}
M_{c} & =F_{b}+H_{c} / 4=(.178)(1.54)(84)+\frac{(1.07)(42)}{4} \\
& =34.3 \mathrm{in}-\mathrm{k}
\end{aligned}
$$

This moment reduces to 31.1 in-k at the support face.

The transformed section is shown in Figure 3.26. The section properties are calculated to be:

$$
\mathrm{kd}=1.10 \mathrm{in} \text { (neutral axis depth) }
$$

and

$$
I=10.63 \mathrm{In}^{4}
$$

The elastic stresses are

$$
\begin{aligned}
& \mathrm{f}_{\mathrm{c}}=\frac{M \mathrm{kd}}{\mathrm{I}}=\frac{(31.1)(1.10)}{10.63}=3.22 \mathrm{ksi} \\
& \mathrm{f}_{\mathrm{s}}=\mathrm{n} \times \frac{\mathrm{M}(\mathrm{d}-\mathrm{kd})}{\mathrm{I}}=8 \times \frac{(31.1)(3.17-1.10)}{10.63}=48.4 \mathrm{ksi}
\end{aligned}
$$

The steel stress is 73 percent of the yield strength which is less than the maximum service load stress of $.90 \mathrm{~F}_{\mathrm{y}^{\circ}}$

The $z$-number, according to 71 ACI Code Equation 10-2, is calculated from the service load stress: 


$$
z=f_{s} \sqrt[3]{d_{c}^{A}}=48.4 \sqrt[3]{(.83)(4.98)}=77.7
$$

This is less than 150 as required by the code. Therefore, the beam cross-section meets the requirements of yleld safety and cracking serviceabllity.

\subsubsection{Shear Design}

The maximum design shear in the beam is determined from the moment diagram of Figure 3.21. The beam must form plastlc moments at $C$ and $\mathrm{N}$ under gravity loads. These moments rotate the member ends in opposite directions. Therefore, the maximum shear between $\mathrm{C}$ and $\mathrm{N}$, in condition $\mathrm{I}$, is

$$
\mathrm{v}_{\mathrm{CN}, \mathrm{BM}}=\frac{40.9+40.9}{26.25}=3.12 \mathrm{k}
$$

The maximum shear stress between $M$ and $N$ is caused by condition II loading :

$$
\mathrm{V}_{\mathrm{MN}}=\frac{38.2-27.9}{28}=.37 \mathrm{k}
$$

Since these shear loads are simflar to the shear loads for Frame USD-1, the stirrups spacing, s, is controlled by the effective depth, d. Therefore, use $\#_{12}$ gage closed stirrups at $\mathrm{s}=3.17 / 2=1.58 \mathrm{in}$. for spans $B M$ and $C N$. Likewise, in span $M N$, no stirrups are required.

As for Frame USD-1, the cutoff bar must meet added shear requirements. The ultimate shear capacity, Including stirrups, is

$$
\begin{aligned}
v_{A L L} & =v_{c}+v_{s}=2 \sqrt{f_{c}^{\prime}}+\frac{A_{v} f}{b s} \\
& =127+\frac{(2)(.00874)(60000)}{(6)(1.58)} \\
& =237 \mathrm{psi}
\end{aligned}
$$


The shearing stress at the cutoff point is $v_{c}=v_{u} / b d=3120 / 3.17=$ 164 psi. Which is approximately equal to $2 / 3 \times 237=158$ psi. Furthermore, the frame will be tested under condition.II loading which will induce smaller shearing stresses.

\subsubsection{U1timate Deflection and Plastic Rotation Requirements}

The ultimate frame deflections, at the collapse load, are calculated just before the second hinge at point $M$ forms. Also, the required plastic rotation $\theta_{p}$ is calculated for the hinge at corner $C$. The required rotation is checked against the plastic rotation capacity of the beam cross section.

The method used for calculating deflections and rotations follows the procedure by Beedle (19) for steel frames. In this method, the plastic hinges are replaced with frictionless hinges which are allowed to rotate freely. The members between the plastic hinges are assumed to remain elastic. The correct boundary condition is with continuity assumed at the last plastic hinge to form. The same assumptions are used as for the plastic analysis discussed in Section 3.3.2.

Slope deflection equation is used to calculate deflections:

$$
\theta_{\mathrm{A}}=\theta_{\mathrm{A}}^{\prime}+\frac{\Delta}{\ell}+\frac{\ell}{3 \mathrm{E} 1}\left(\mathrm{M}_{\mathrm{AB}}-\frac{1}{2} \mathrm{M}_{\mathrm{BA}}\right)
$$

These terms are shown in Figure 3.27 for a member with length $=\ell$. Clockwise moments and rotations are positive while the flexural stiffness EI is constant over the span.

The loading diagram, mechanism, moment dlagram, and free body diagram are shown in Figure 3.28. The moments at $B$ and $C$ are taken at the centerline of the foint so as to simplify the analysts. Therefore, the hinges are assumed to form at the center of the joint blocks. 


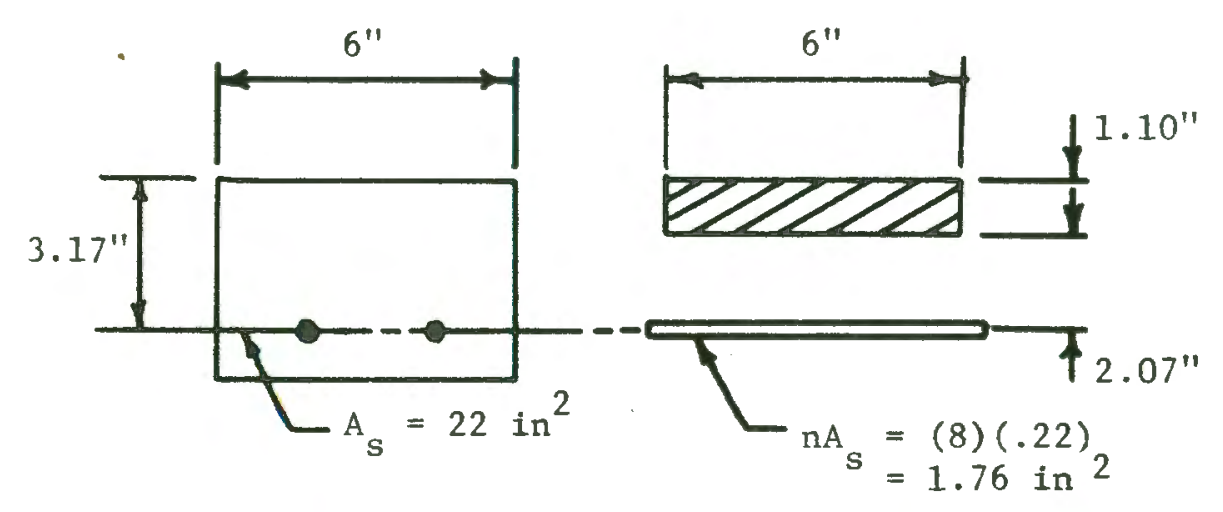

(a) SECTION (b) TRANSFORMED SECTION
FIG.3.26 TRANSFORMED SECTION
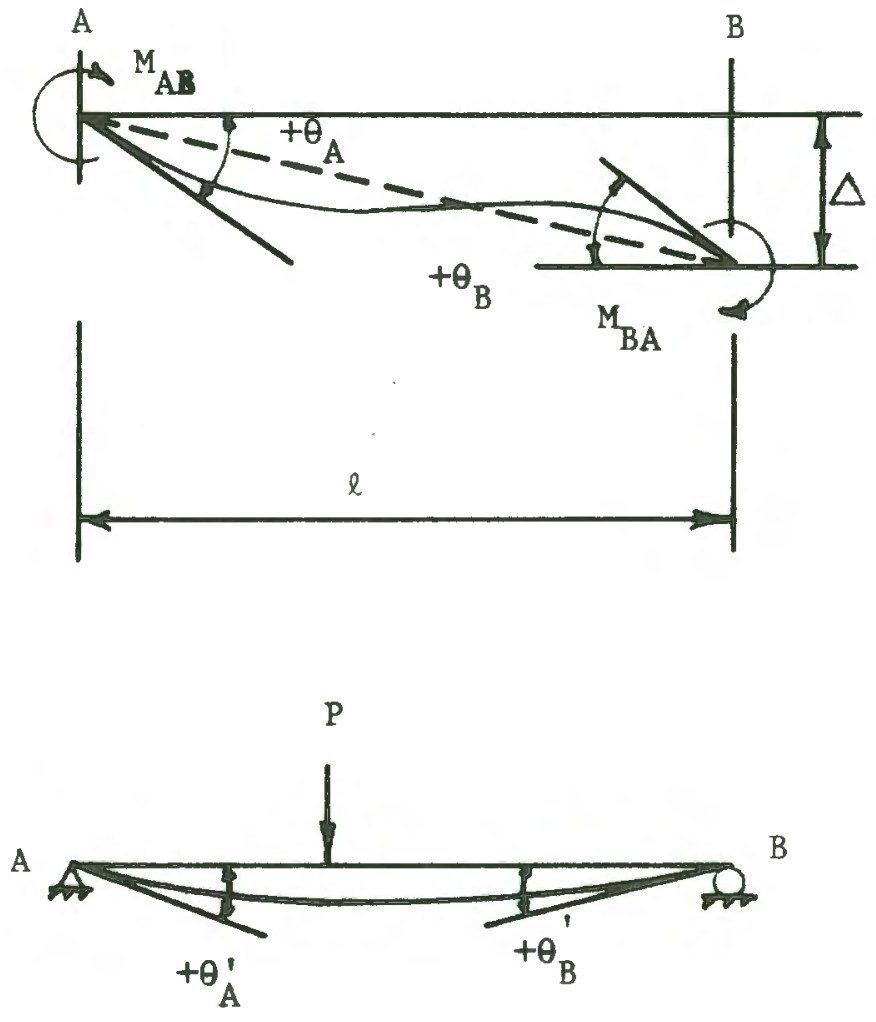

FIG.3.27 SLOPE DEFLECTION NOTATION 

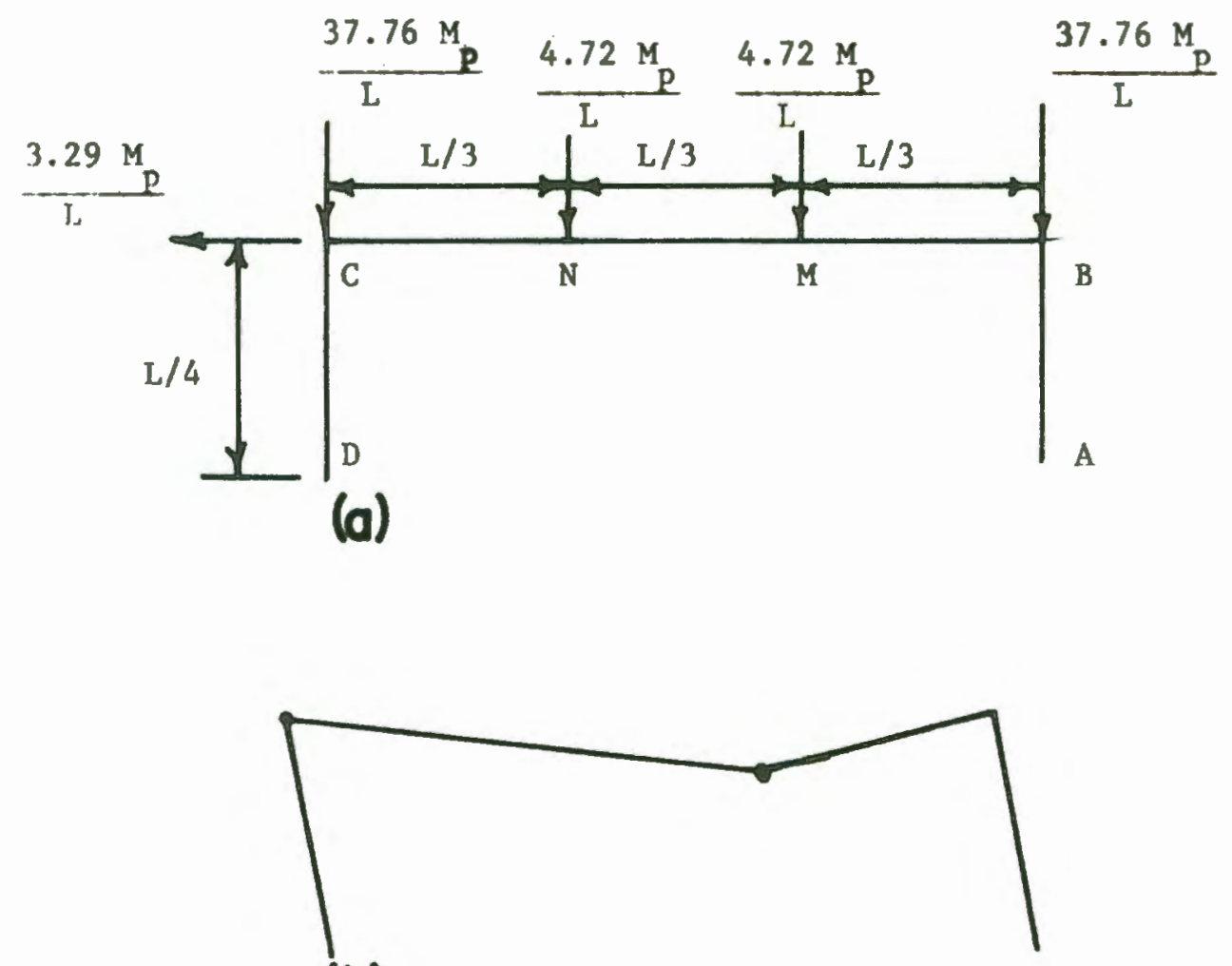

(b)
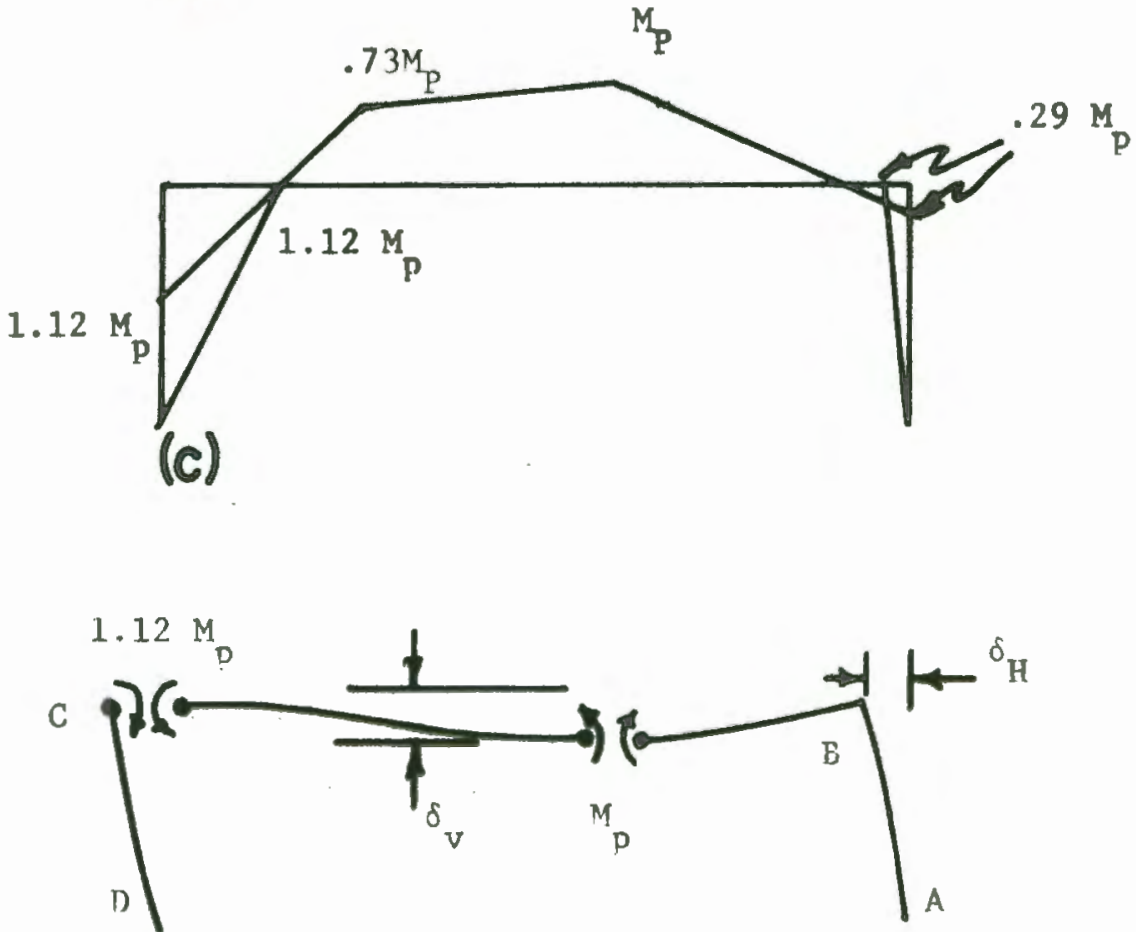

(d)

FIG.3.28 ULTIMATE DEFLECTION OF FRAME LD-I 
The deflections $\delta_{\mathrm{V}}$ and $\delta_{\mathrm{H}}$ are solved with two boundary conditions. The first boundary condition is at joint $B$ where $\theta_{B M}$ equals $\theta_{B A}$. The second boundary condition is at $M$ where $\theta_{\mathrm{MB}}$ equals $\theta_{\mathrm{MC}}$. This boundary condition is valid just before the last hinge forms.

The rotation $\theta_{\mathrm{BA}}$, for the column segment $\mathrm{BA}$, is

$$
\begin{aligned}
& \theta_{B A}=0-\frac{\delta_{H}}{L / 4}+\frac{L / 4}{3 E I_{C}}\left(-.29 M_{P}-0\right) \\
& \theta_{B A}=-\frac{4 \delta_{H}}{L}-.024 \frac{M_{P} L}{E I_{C}}
\end{aligned}
$$

Next, the rotation $\theta_{B M}$ is found by using equation (3.11) for segment BM:

$$
\begin{aligned}
& \theta_{B M}=0-\frac{\delta_{v}}{L / 3}+\frac{L / 3}{3 E I_{b}}\left(.29 M_{P}-\frac{M_{P}}{2}\right) \\
& \theta_{B M}=\frac{3 \delta}{L}-.023 \frac{M_{P} L}{E I_{b}}
\end{aligned}
$$

Since joint $B$ has continuity, ${ }^{\theta_{B A}}$ equals $\theta_{B M}$ :

$$
\begin{gathered}
-\frac{4 \delta_{H}}{\mathrm{~L}}-.024 \frac{\mathrm{M}_{\mathrm{P}} \mathrm{L}}{\mathrm{EI}}=-\frac{3 \delta_{\mathrm{v}}}{\mathrm{L}}-.023 \frac{\mathrm{M}_{\mathrm{P}} \mathrm{L}}{E \mathrm{I}_{\mathrm{b}}} \\
\delta_{\mathrm{H}}=.75 \delta_{\mathrm{V}}+.0058 \frac{\mathrm{M}_{\mathrm{P}} \mathrm{L}}{\mathrm{EI}_{\mathrm{b}}}-.006 \frac{\mathrm{M}_{\mathrm{P}} \mathrm{L}}{\mathrm{EI}}
\end{gathered}
$$

The last plastic hinge forms at $M$, therefore $\theta_{M B}=\theta_{M C}$ just before the frame begins mechanism motion. The rotation $\theta_{M B}$ is

$$
\begin{aligned}
& \theta_{M B}=0-\frac{\delta_{v}}{L / 3}+\frac{L / 3}{3 E I_{b}}\left(M_{P}-\frac{.29 M_{P}}{2}\right) \\
& \theta_{M B}=-\frac{3 \delta_{v}}{L}+.095 \frac{M_{P}^{L}}{E I_{b}}
\end{aligned}
$$

Next, segment MC is considered. This gives a rotation $\theta_{M C}$ of

$$
\theta_{\mathrm{MC}}=\theta_{\mathrm{MC}}^{\prime}+\frac{\delta_{\mathrm{v}}}{2 \mathrm{~L} / 3}+\frac{2 \mathrm{~L} / 3}{3 \mathrm{EI}}\left(-\mathrm{M}_{\mathrm{P}}+\frac{1.12 \mathrm{M}_{\mathrm{P}}}{2}\right)
$$

where $\theta_{M C}^{\prime}=$ simple beam slope $=-.131 \mathrm{M}_{\mathrm{p}} \mathrm{L} / \mathrm{EI}$ 
This gives

$$
\theta_{\mathrm{MC}}=\frac{3 \delta \mathrm{v}}{2 \mathrm{~L}}-.229 \frac{\mathrm{M}_{\mathrm{p}} \mathrm{L}}{\mathrm{EI}_{\mathrm{b}}}
$$

Since $\theta_{M C}$ is equal to $\theta_{M B}$

$$
-\frac{3 \delta_{v}}{\mathrm{~L}}+.095 \frac{\mathrm{M}_{\mathrm{P}} \mathrm{L}}{\mathrm{EI}_{\mathrm{b}}}=\frac{3 \delta_{\mathrm{v}}}{2 \mathrm{~L}}-.229 \frac{\mathrm{M}_{\mathrm{p}} \mathrm{L}}{\mathrm{EI}_{\mathrm{b}}}
$$

and

$$
\delta_{v}=.072 \frac{\mathrm{M}_{\mathrm{p}} \mathrm{L}}{\mathrm{EI}_{\mathrm{b}}}
$$

This expression is substituted into equation (4.12)

$$
\delta_{H}=.054 \frac{M_{p} L^{2}}{E I_{b}}+.0058 \frac{M_{P} L^{2}}{E I_{b}}\left(1-.100 \frac{E I_{b}}{E I_{c}}\right.
$$

For Frame $\mathrm{LD}-1 \quad \mathrm{M}_{\mathrm{p}}=40.9 \mathrm{In-k}$, and $\mathrm{EI}_{\mathrm{b}}$ and $\mathrm{EI}_{\mathrm{c}}$ as calculated from the P-M- Dt plots are 38750 and $33000 \mathrm{k}-\mathrm{in}^{2}$. Therefore, the lateral deflection $\delta_{H}$, according to equation (3.14) is

$$
\begin{aligned}
& \delta_{H}=\frac{(.0598)(40.9)(84)^{2}}{38750}\left(1-\frac{(.100)(38750)}{33000}\right) \\
& \delta_{H}=.390 \mathrm{in}
\end{aligned}
$$

The plastic hinge rotation at corner $C$ is given by the expression

$$
\theta_{p}=\dot{\theta}_{C M}-\theta_{C D}
$$

The rotation $\theta_{\mathrm{CM}}$ is

where $\theta^{\prime} \mathrm{CM}=.131 \mathrm{M}_{\mathrm{p}} \mathrm{L} / \mathrm{EI}_{\mathrm{b}}$

$$
\theta_{C M}=\theta_{C M}^{\prime}+\frac{\delta_{v}}{2 L / 3}+\frac{2 L / 3}{3 E I_{b}}\left(-1.12 M_{p}+\frac{M_{p}}{2}\right)
$$

$$
\delta v=\text { equation (3.13) }
$$

Therefore

$$
\theta_{C M}=.101 \frac{M_{p} L}{E_{b}}
$$

LIkewIse 


$$
\theta_{C D}=0-\frac{\delta_{H}}{L / 4}+\frac{L / 4}{3 E I_{C}}\left(1.12 M_{P}-0\right)
$$

where $\delta_{H}=$ equation (3.14)

Therefore

$$
\theta_{C D}=-.239 \frac{M_{p} L}{E_{b}}\left(1-.489 \frac{E_{b}}{E I_{c}}\right)
$$

From equation (3.15) the required plastic hinge rotation is

$$
\begin{aligned}
& \theta_{P}=.101 \frac{M_{p} L}{E I_{b}}+.239 \frac{M_{p} L}{E_{b}}\left(1-.489 \frac{E I_{b}}{E I_{c}}\right) \\
& \theta_{\mathrm{P}}=.34 \frac{\mathrm{M}_{\mathrm{p}} \mathrm{L}}{\mathrm{EI}_{\mathrm{b}}}-.117 \frac{\mathrm{M}_{\mathrm{P}} \mathrm{L}}{\mathrm{EI}}
\end{aligned}
$$

The required plastic rotation, with $M_{p}=40.9$ in-k, $E I_{b}=38750$, and $E I_{c}=33000$, is

$$
\begin{aligned}
& \theta_{P}=\frac{(.34)(40.9)(84)}{38750}-\frac{(.117)(40.9)(84)}{33000} \\
& \theta_{P}=.018 \mathrm{rad} .
\end{aligned}
$$

This value will now be checked against the available plastic rotation. The plastic rotation capacity $\theta_{p}$, as given by Park and Paulay (23), is

$$
\theta_{P}=\left(\phi_{u}-\phi_{y}\right) \ell_{p}
$$

where $\emptyset_{\mathrm{u}}=$ ultimate curvature

$$
\begin{aligned}
& \emptyset_{y}=\text { curvature at first yield } \\
& \ell_{p}=\text { equivalent length of plastic hinge }
\end{aligned}
$$

This formula is an idealization of the actual plastic rotation at a critical section. It replaces the true curvature diagram with a rectangle of equal area.

Since the curvature is the slope of the strain diagram for the cross-section, equation (3.16) may be expressed as a function of strain (23): 


$$
\theta_{p}=\left(\frac{\varepsilon_{u}}{c}-\frac{\varepsilon_{c e}}{k d}\right) l_{p}
$$

where $\varepsilon_{u}=$ ultimate concrete strain

$c=$ neutral axis depth at ultimate curvature

$\varepsilon_{\text {ce }}=$ concrete strain at first yield

kd = neutral axis depth at first yield

The values for ultimate concrete $\operatorname{strain} \varepsilon_{u}$ and equivalent length of the plastic hinge $1_{p}$ are found by an empirical formula proposed by Corley (5). These expressions are results of tests on simply supported beams. Mattock (24), however, simplified these expressions as follows:

$$
\ell_{p}=0.5 d+0.05 z
$$

and

$$
\varepsilon_{u}=.003+0.02 \mathrm{~b} / \mathrm{z}+0.2 \rho_{\mathrm{s}}
$$

where $z=$ distance from the critical section to point of contra

\section{flexura1}

$b=$ width of the beam

$p_{S}=$ ratio of volume of continuing steel to volume of concrete core.

The above expressions give $I_{p}=(0.5)(3.17)+(.05)(15.17)=$

$2.34 \mathrm{in}$. which is $.74 \mathrm{~d}$. The ultimate concrete strain $\varepsilon_{u}$, with $\rho_{s}=.0088$, Is

$$
\begin{aligned}
\varepsilon_{u} & =0.003+\frac{(0.02)(6)}{15.17}+(.2)(.0088) \\
& =.013 \mathrm{in} / \mathrm{in}
\end{aligned}
$$

From section $3.3 .5, \mathrm{kd}=1.10 \mathrm{in}, c=.712 \mathrm{in}$, and $\varepsilon_{c e}=\mathrm{F}_{\mathrm{y}} / \mathrm{E}_{\mathrm{s}} \mathrm{x}(\mathrm{kd} / \mathrm{d}-\mathrm{kd})=$ (66) $(1.1) /(29,000)(2.17-1.10)=00.12 \mathrm{in} / \mathrm{In}$. Therefore, the plastic rotation capacity as given by equation (3.17) is 


$$
\begin{aligned}
& \theta_{\mathrm{P}}=\left(\frac{.013}{.712}-\frac{.0012}{1.1}\right) 2.34 \\
& \theta_{\mathrm{P}}=.040 \mathrm{rad} .>.018 \mathrm{rad} . \text { required }
\end{aligned}
$$

Adequate plastic rotation capacity exists.

\subsubsection{Frame Details}

The plan view of Frame LD-1, as shown In Figure 3.29 , gives the reinforcement arrangements and dimensions for the Frame. The crosssections for the beam and column are shown in Figure 3.30. A schedule of relnforcement is shown in Figure 3.31 whtle the details of the column cage are shown in Figure 3.32 . 


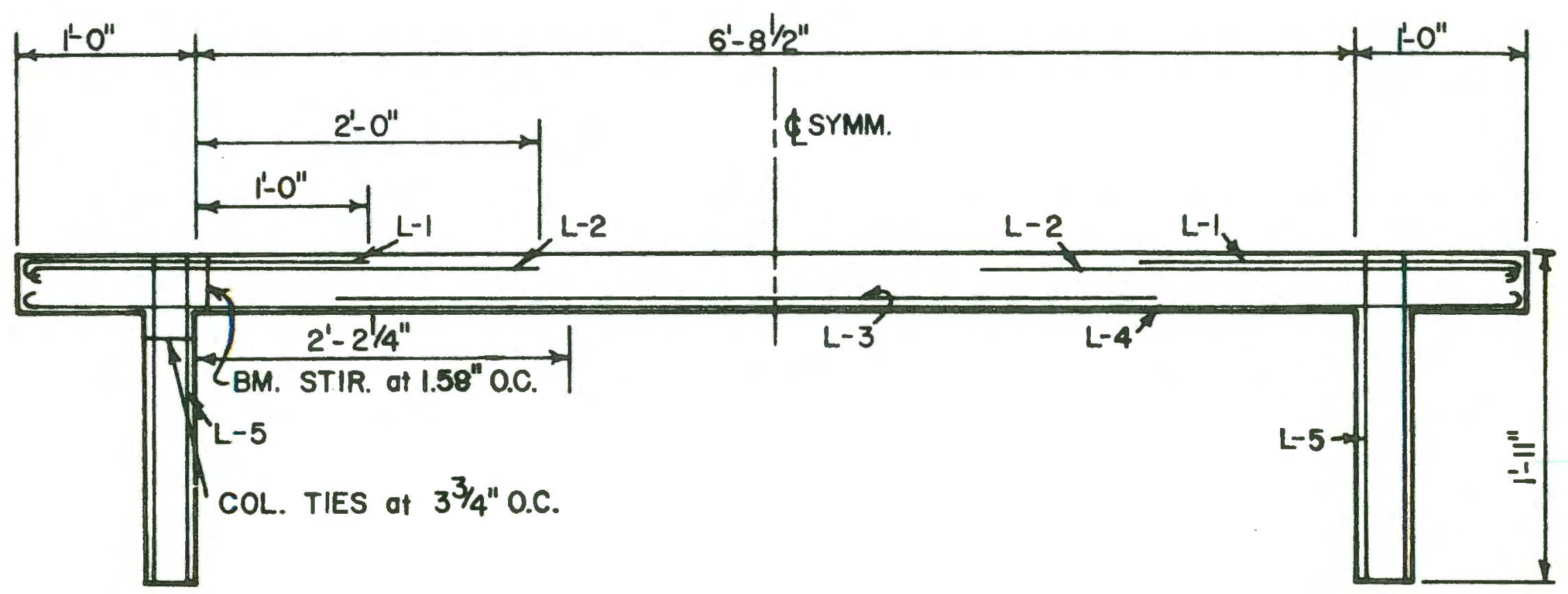

FIG.3.29 TEST FRAME DETAILS, LD-I 


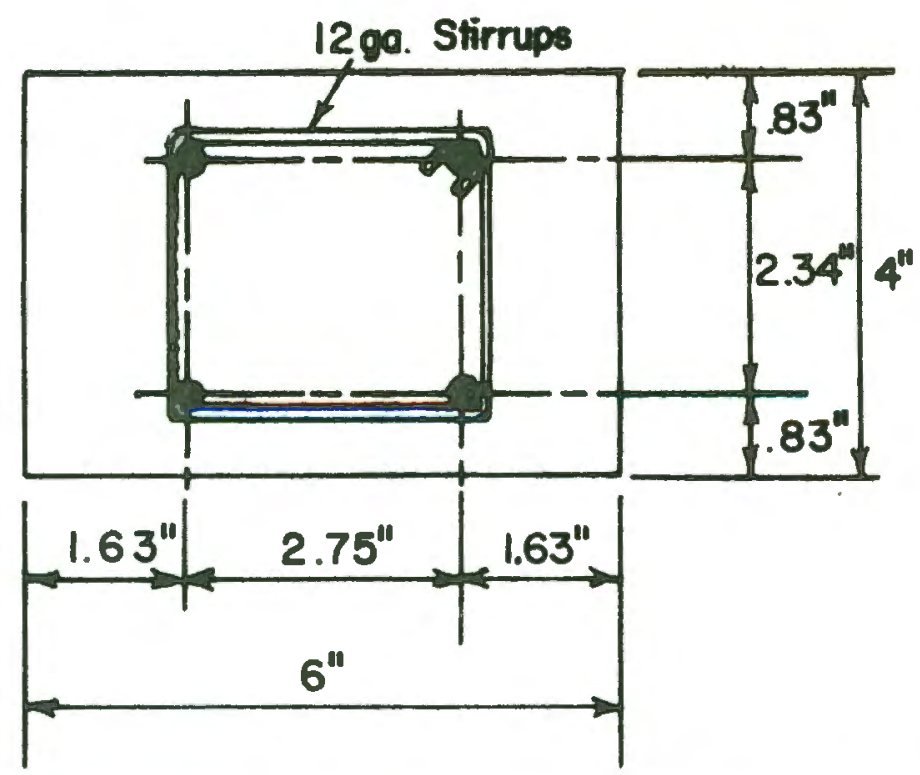

\section{BEAM CROSS SECTION}

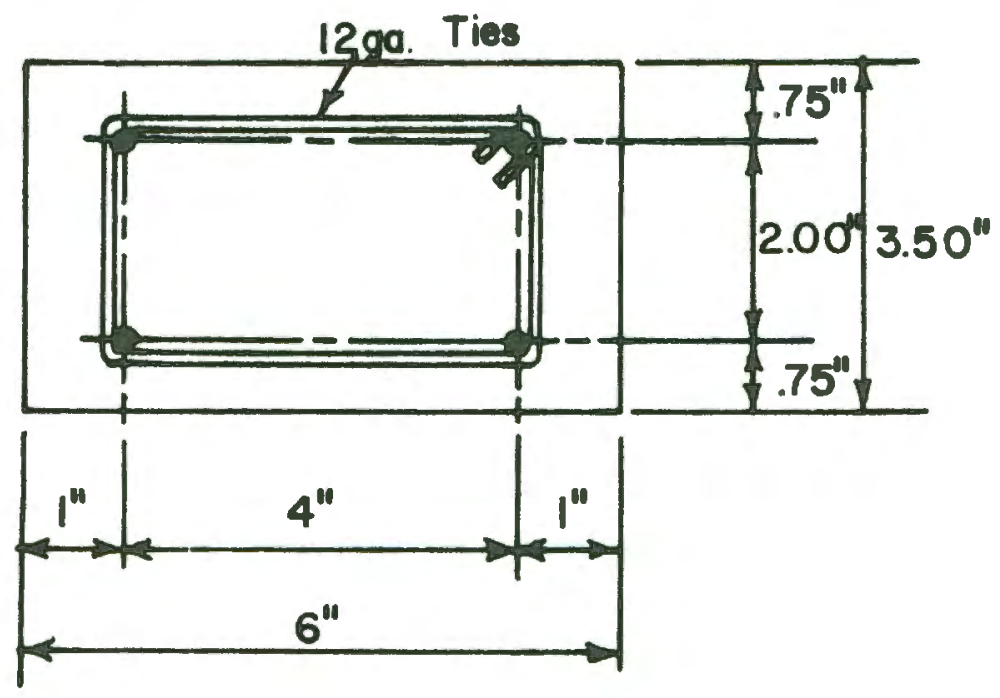

\section{COLUMN CROSS SECTION}

FIG.3.30 CROSS SECTIONS,

FRAME LD-I 


\begin{tabular}{|c|c|c|c|c|c|c|}
\hline \multicolumn{4}{|c|}{ SCHEDULE } & \multicolumn{3}{|c|}{ FRAME LD-I } \\
\hline BAR & $\begin{array}{l}\text { TOTALA } \\
\text { WOA EARS }\end{array}$ & SIZE & fyched & TYPE & DIM. "A" & $\begin{array}{l}\text { TOTAL } \\
\text { LENGTH }\end{array}$ \\
\hline$L-1$ & 2 & 3 & 66.0 & 1 & $\mid '-\| I^{\prime \prime}$ & $2-4^{\prime \prime}$ \\
\hline$L-2$ & 2 & 3 & 66.0 & 1 & $2-111$ & $3 '-4 "$ \\
\hline$L-3$ & 1 & 3 & 66.0 & STR & - & 4'-10" \\
\hline$L-4$ & 1 & 3 & 66.0 & 2 & $8^{\prime}-4^{\prime \prime}$ & $9 !-4^{\prime \prime}$ \\
\hline$L-5$ & 8 & 3 & 59.1 & STR & - & |'ו" \\
\hline
\end{tabular}

TYPE I

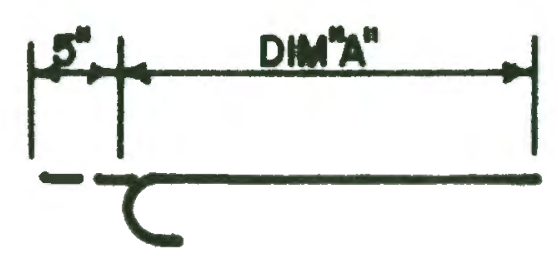

FIG.3.3I SCHEDULE OF REINFORCEMENT, LD-I

TYPE 2

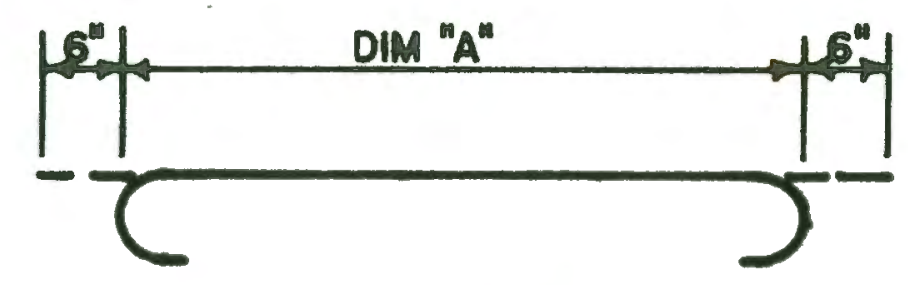




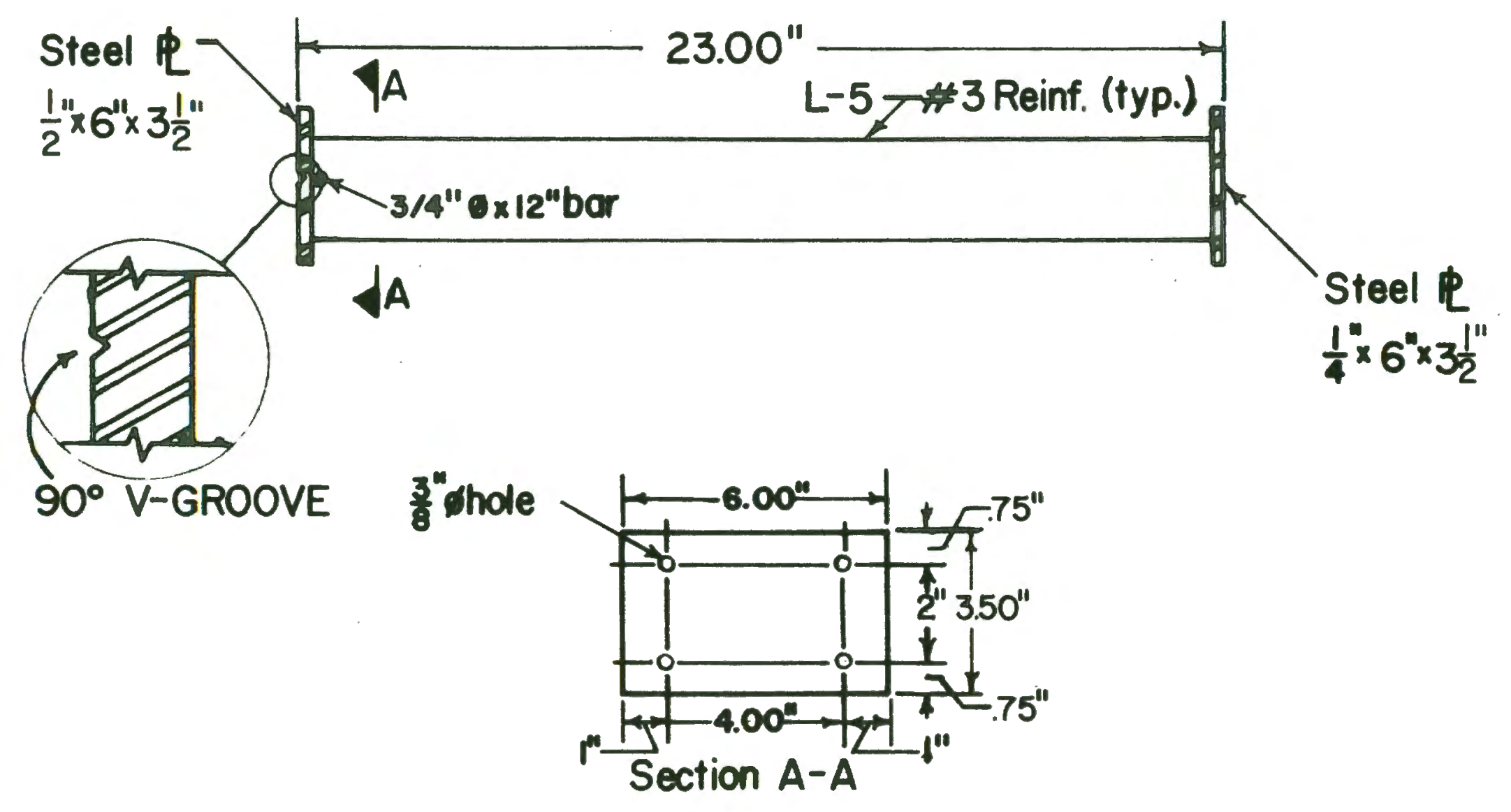

FIG.3.32 COLUMN CAGE FOR FRAME LD-I 
This chapter describes the materials, fabrication of test frames, measurement methods, and testing apparatus. The detalls of the test frames are shown in the previous chapter, therefore references w111 be made to figures in Chapter III. The "as bullt" dimensions are shown In Table 4.2 and Table 4.3.

\subsection{MATERIALS}

\section{$\underline{4.1 .1}$ Concrete}

Because the design called for concrete with a compressive strength of $4000 \mathrm{psi}$ at seven days, three trial batches were made so as to determine the proper design $\mathrm{mix}$. From the strength tests of these trial batch cylinders, a design $\mathrm{mix}$ was chosen which was used for Frames USD-1 and LD-1. The cement was type III (high early strength), the coarse aggregate pea gravel with a maximum aggregate size of $3 / 8-1 \mathrm{n}$, and the fine aggregate a well graded fine sand. The coarse and fine aggregates were Willamette River aggregates.

Stress-straln curves of standard cylinders for Frames USD-1 and LD-1 are shown In Figures 4.1 and 4.2. The dashed line, as shown in these figures, stands for the secant modulus of elasticity at $1 / 2 \mathrm{f}_{\mathrm{c}}^{\prime}$. The equipment used for the test was a 250-kip capacity hand operated hydraulic testing machine and a compressometer with a 6-In gage length. A pressure gage, callbrated in kips, measured the load. 


\subsubsection{Reinforcing Stee1}

Number 3 reinforcing bars, conforming to ASTM-A615, were used for the longitudinal reinforcement. Twelve inch long coupons were cut from 20-ft. long stock bars and tested using the Material Testing System (MTS) electro-hydraulic testing machine. By plotting the load vs. strain on the MTS plotter, the yield point load was determined. Finally, the yield strength was calculated from the yield polnt load. Yleld strengths of the bars used in the test frames are shown in Figures 3.12 and 3.31 A typical stress-strain curve is shown in Figure 4.3.

\subsubsection{Number 12 Gage Wire}

The beam stirrups and column ties, which are shown in Figures 3.11 and 3.30, were made from $\$ 12$ gage cold drawn steel wires. The tensile test procedure was similar to the one used for the reinforcing bars. The load vs. strain plot, as shown in Figure 4.4 exhibited gradual yielding rather than a definite yield point. Therefore, the 0.2 percent offset method was used to determine the yleld strength. The yleld strength exceeds the maximum design value of $60 \mathrm{ksi}$ allowed by the ACI 318-71. Therefore a yield strength of $60 \mathrm{ksi}$ was assumed when designing the test frame ties and stirrups.

\subsection{FABRICATION OF SPECIMENS}

Specimen fabrication consisted primarily of aligning the formwork, fabricating the relnforcement cages, placing the cages in the forms, and casting and curing of the test frames. 


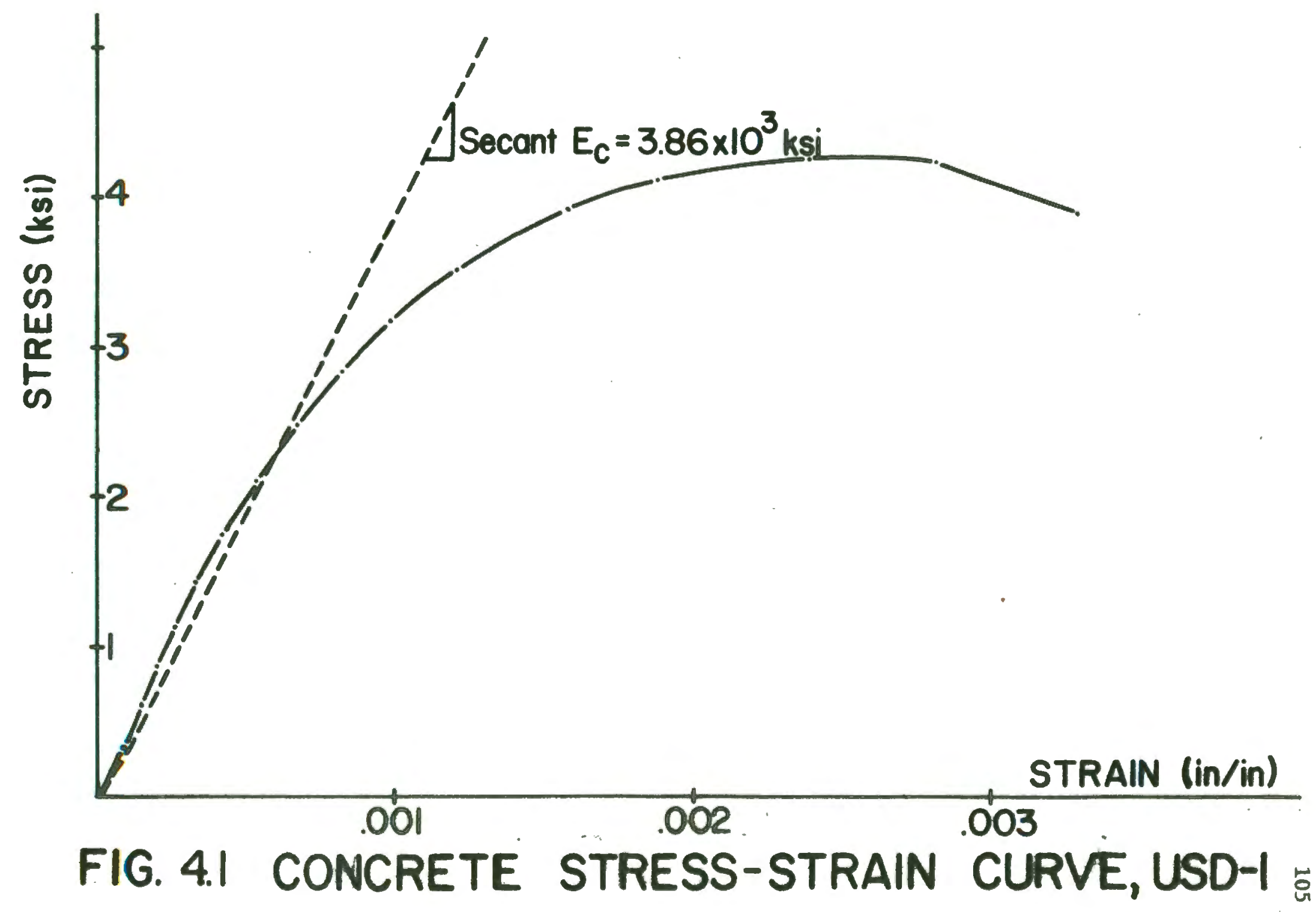




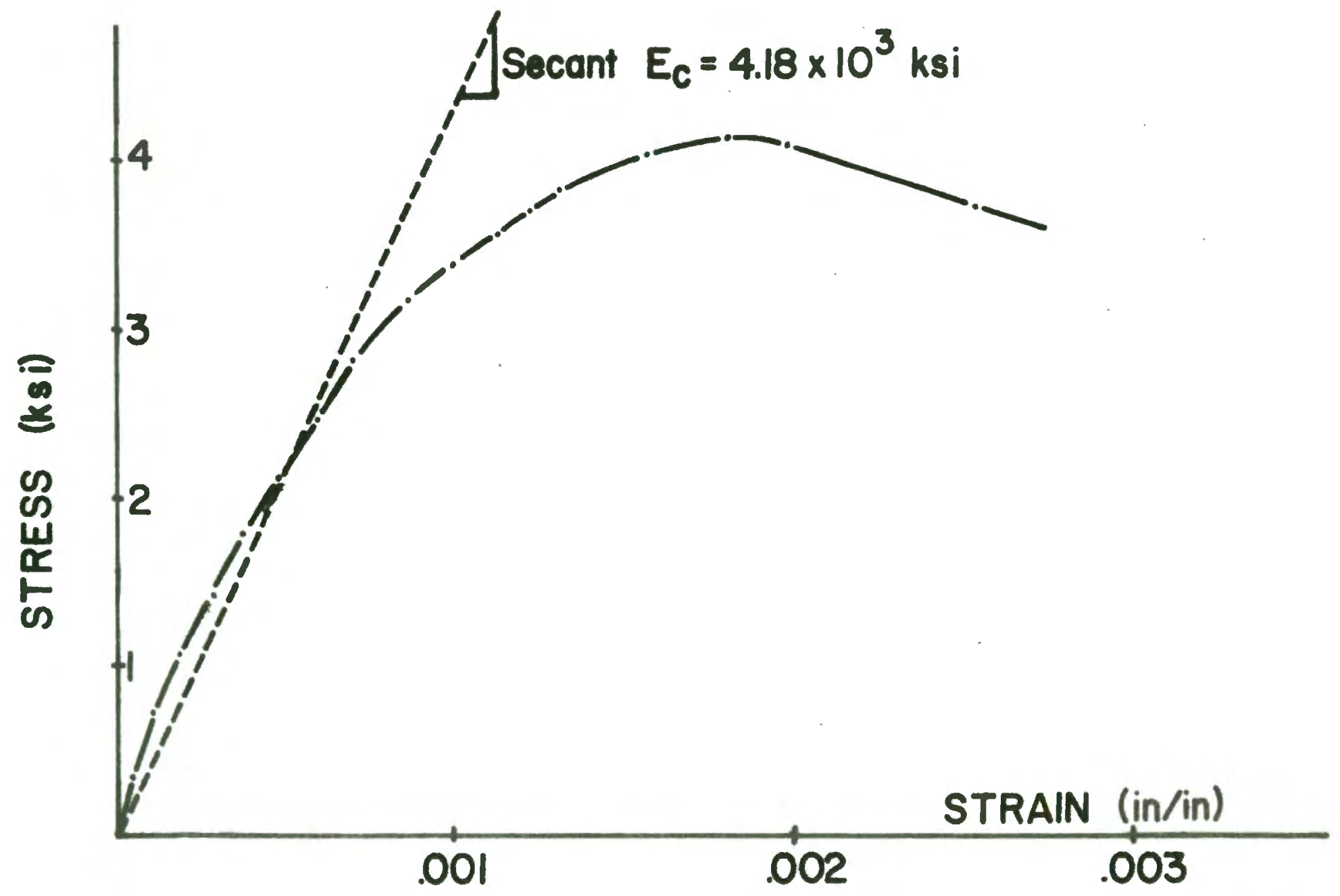

FIG.4.2 CONCRETE STRESS-STRAIN CURVE, LD-I 


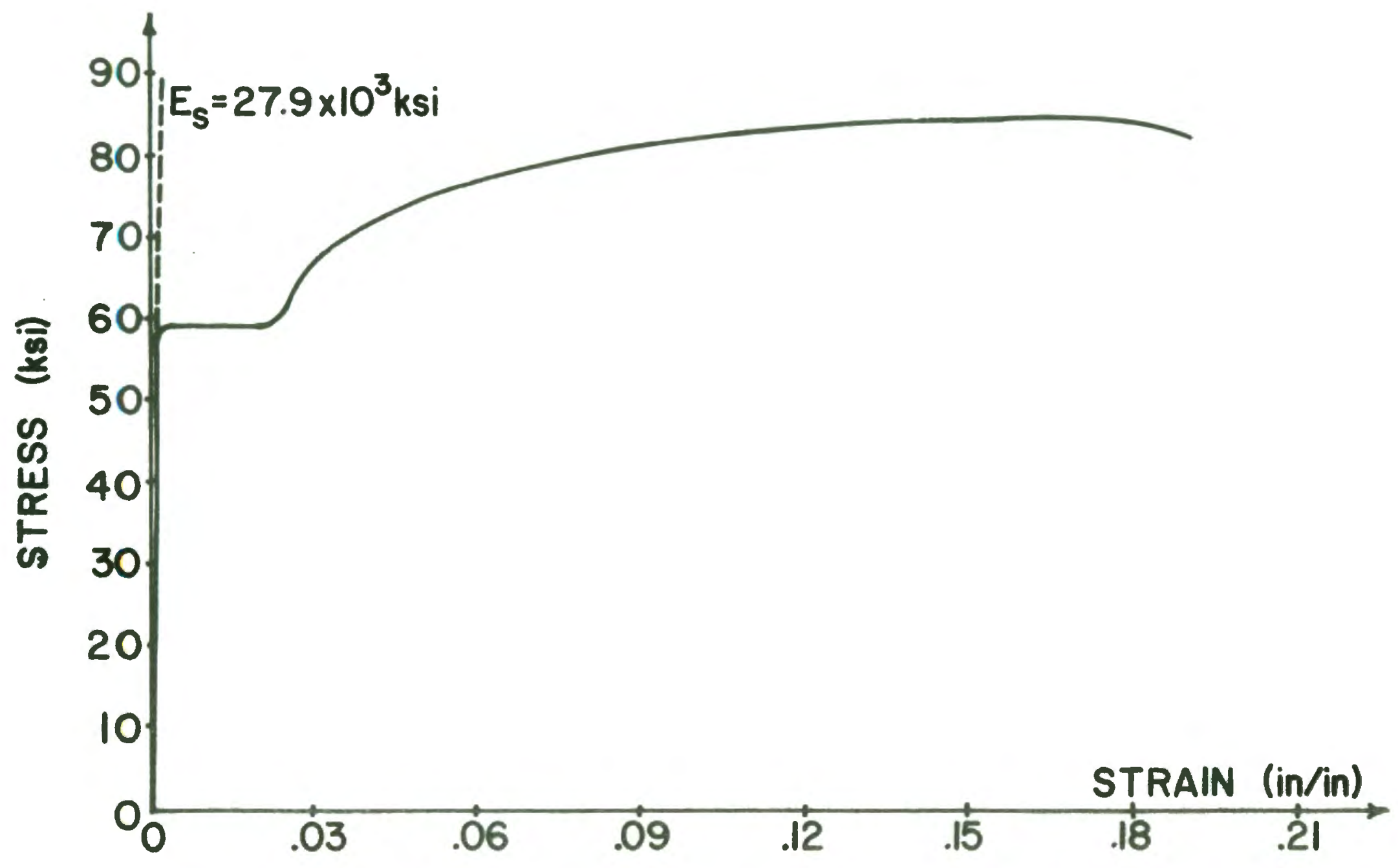

FIG. 4.3 TYPICAL STRESS-STRAIN CURVE FOR \#3 REINF. BAR 点 


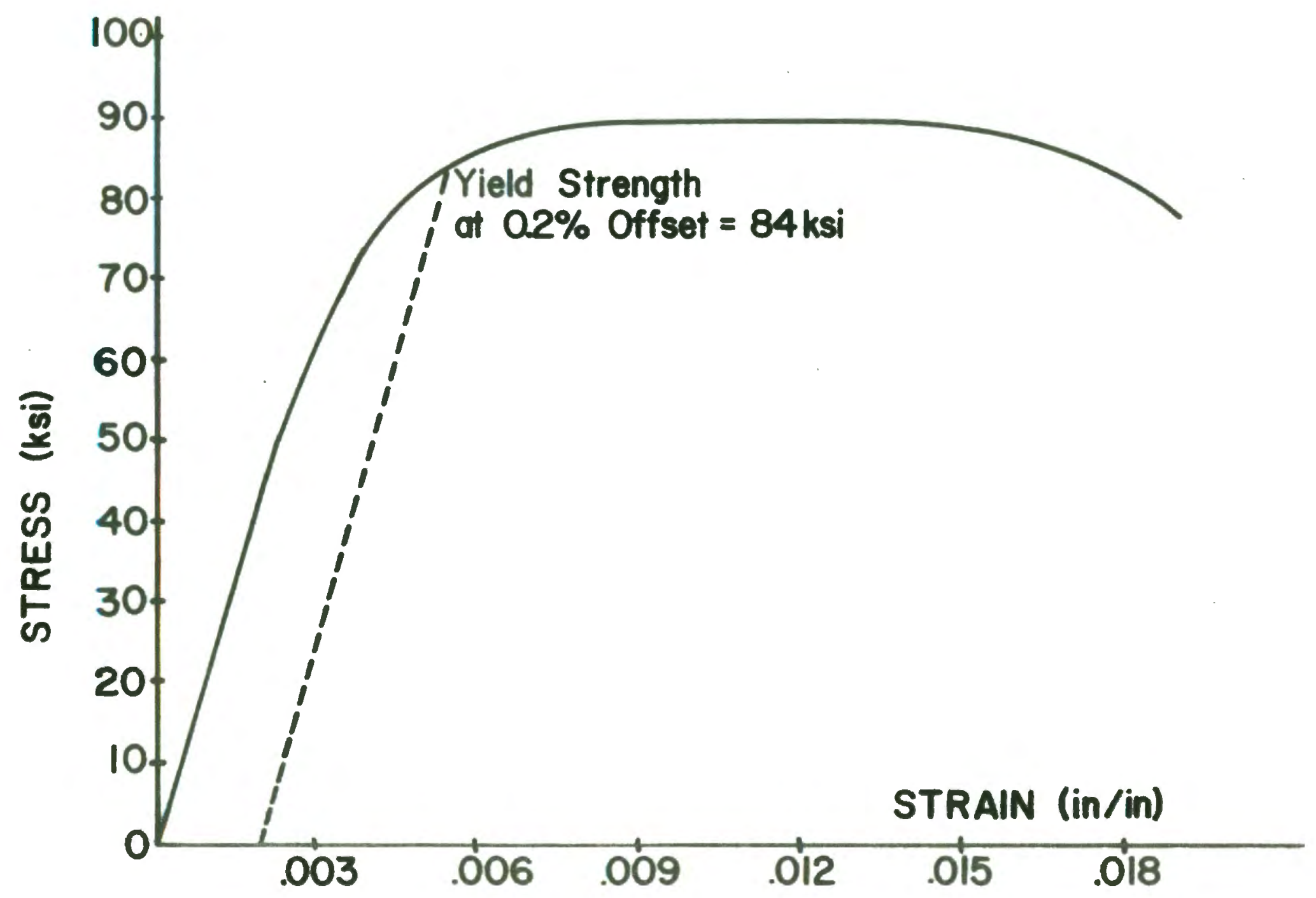

FIG. 4.4 STRESS-STRAIN CURVE FOR \#I2 GA. WIRE 点 


\subsubsection{Alignment of Forms}

Figures 4.5 through 4.8 show the formwork and cages. The bottom of the formwork consisted of a steel base made from three sections of $\mathrm{C9} \times 13.4$ steel channels. The two channels, which form the legs, were butt-welded to the maln channel. The sides of the test frames were formed with elght sections of $C 6 \times 8.2$ steel channels which were bolted to the base through slotted holes drilled in the bottom flange. These slotted holes were used so as to provide adjustable member depths for the test frames. As discussed by Rad (12), the most critical dimension was the diagonals. When the intersecting diagonals were nearly equal, perpendicularity of the beam-column junction was satisfied.

Three centerlines, which colncided with the centerlines of the test frames, were drawn on the base channels. Next, the rear channel, which forms the top of the beam, was bolted securely to the base at the required distance from the beam centerline. The top dimension was maintained by using a tri square and an adjustment angle. One-quarter Inch bolts welded to the tops of the sldeforms, were fastened to adjustment angles consisting of steel angle stubs welded to the base channels. By turning the nut on the bolt, the top of the slde channel could move In either direction perpendicular to the member centerline. The above procedure was repeated for the other seven side forms.

After the side forms were in place, the Intersecting diagonals were measured by stretching nylon thread from four reference points center-punched on the top flange of the side forms. If the four intersecting diagonals were within a selected tolerance of $1 / 16-1 n$. of each other, the form allgnment was considered satisfactory. 


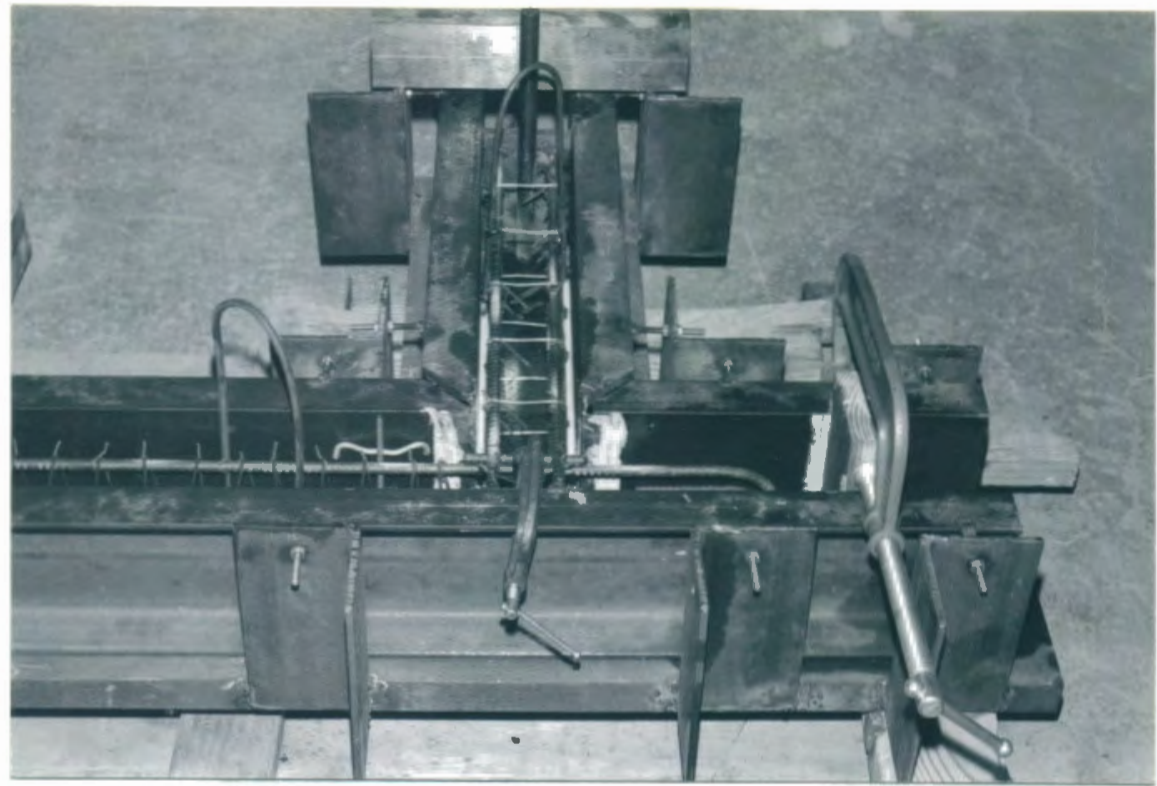

F18. 4.5. The column cage positioned in the forms

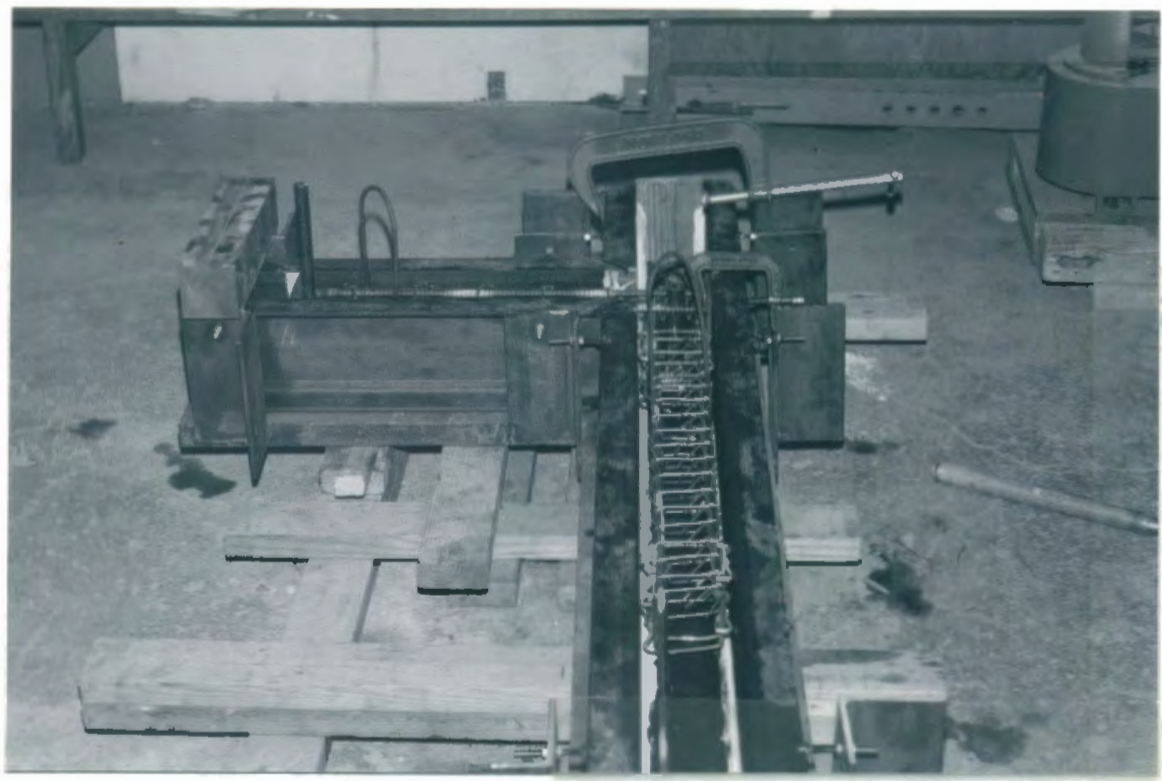

Fig. 4.6. The beam cage showing the beam stirrups 


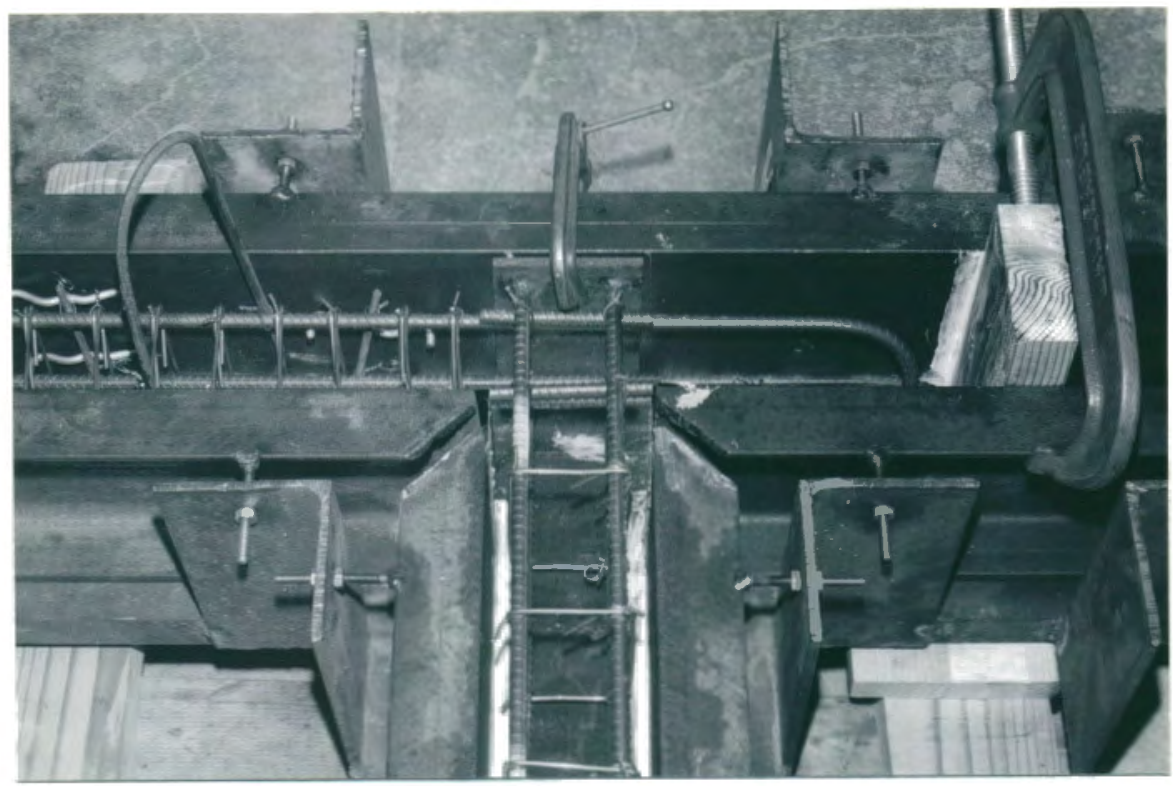

Fig. 4.7. The beam and column cage intersection

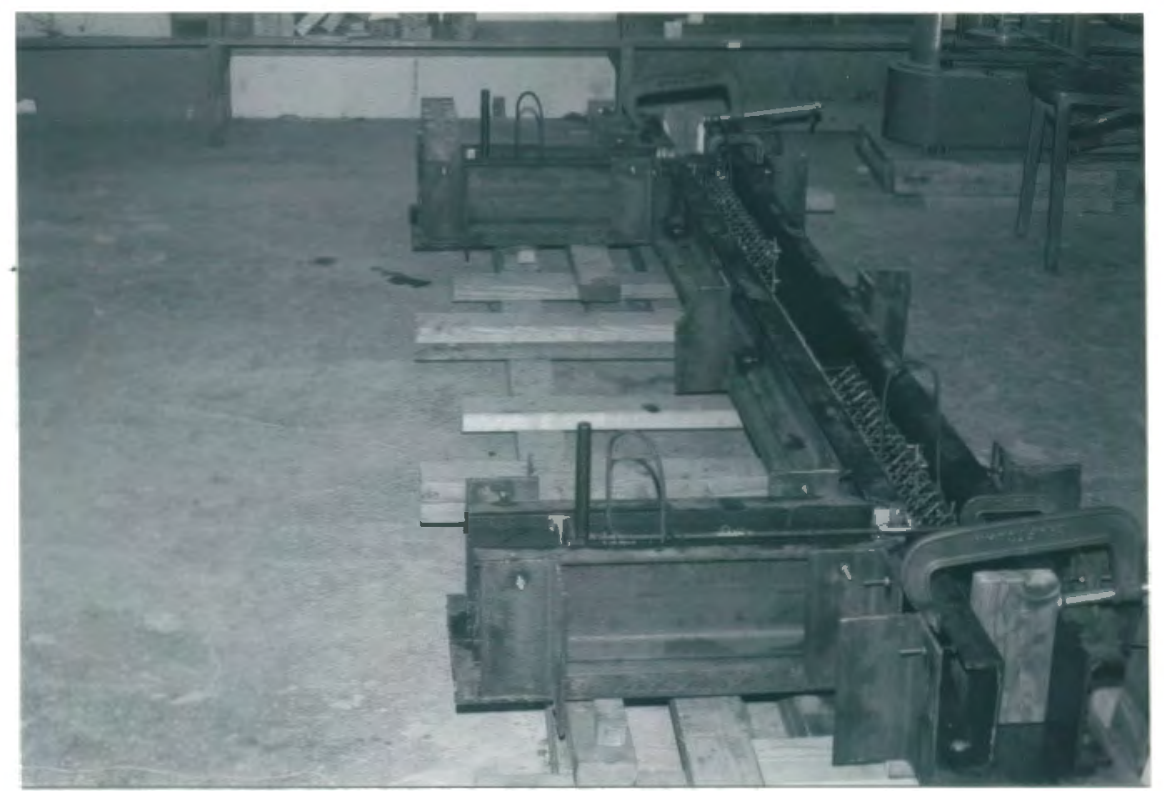

Fig. 4.8. The relnforcing cages positioned in the forms before concrete casting 
Finally, the formwork was caulked at the side form-base channel corners, and oiled about 24 hours before concrete casting.

\subsubsection{Fabrication of Reinforcing Cages}

a) Column Cage. For ease of construction a special detall was set up for the two column cages. Because of the geometry of the frame and congestion of steel at the beam-column intersection, it was necessary to develop the column relnforcing bars by welding them to a top plate. Likewlse, the column end called for a spectal detall for the reaction point. The cages consisted of four reinforcing bars welded to two plates. The detalls of these cages for Frames USD-1 and LD-1 are shown in Figures 3.13 and 3.32 .

F1rst, the plates were cut to the cross-section dimensions of the column. However the depth for the bottom plate was cut about 0.05-in. less so as to easily position it in the forms. Next, the bottom plate was machined with a mill on the three sides of the plate which contact the forms. Then, a 1/16 in. deep V-Notch was machined along the centerline of the bottom plate. This V-Notch accepts the knife-edge support of the test apparatus. Finally, holes were drilled in both plates for inserting the reinforcing bars.

Four reinforcing bars were placed in the holes of the top and bottom plate. Column ties were inserted before welding the bars to the plates. Careful attention was given to the overall length of the cage as the bars were welded. After welding, the cage was checked for squareness and overall length. Then the ties were positioned along the length of the cage and tied at all four corners with \#16 gage wire. Finally, a 3/4-in. diameter $x 1^{\prime}-0^{\prime \prime}$ long steel rod was welded to the centerline of the bottom 
plate. This rod is a part of the corner rotation measuring device which is discussed in section 4.3 .3 .

b) Beam Cage. Frist, the reinforcement bars were cut to the proper length as shown in Figures 3.12 and 3.31. Then a bar bending device was used for those bars needing a standard hook. Next, the bars were longitudinally positioned as shown in Figures 3.10 and 3.29 . The bars were supported at four points with $12^{\prime \prime} \times 12^{\prime \prime}$ plywood veneer panels. These panels included four holes drilled in the pattern conforming to the cross-section. Finally, the stirrups were placed and tied with 非 16 gage wire at each point where a bar existed. The first stirrup began at $(s / 2)$ from the support face of the column.

\subsubsection{Placement of Reinforcing Cages}

The beam and column cages were placed in the forms on steel chairs which were used to align the cages with respect to bottom and side channels of the forms. The chairs were placed at the negative and positive bending moment regions. Also, the column and beam reinforcing bars were tied together with $\#_{1} 16$ gage wire at the beam-column intersection. This provided a rigid connection and prevented the reinforcing bars from moving when the concrete was placed. Four photographs of the reinforcing steel positioned in the forms are shown in Figures 4.5 through 4.8 . A $15 / 16^{\prime \prime} I . D$. steel pipe was inserted and vertically aligned at the beamcolumn intersection. This pipe is part of the lateral load assembly, as discussed in section 4.4.1c.

Lifting hooks made from $\left.\right|^{2}$ bars were placed at four locations. These hooks were used together with a 1-ton hoist to lift the frame out 
of the forms.

\subsubsection{Casting and Curing of Concrete}

The concrete was poured in two batches. The columns were cast from the first batch and the beam was cast from the second batch. At least three control cylinders were poured from each batch. The proportions by weight of fine aggregate, coarse aggregate, cement and water for the two frames are shown in Table 4.1.

A small internal vibrator, as shown in Figure 4.9, was used to consolidate the concrete. The top of the concrete was screeded with a flat plece of wood and trowel finished. Finally, the forms were cleaned with a wet rag. Figure 4.10 shows the final stage of casting.

About four hours after concrete placement, cotton curing mats were moistened and placed on the specimen and cylinder molds. Two days later, the specimen and cylinders were removed and placed in cotton curing mats up to one day before testing. After five days, a cylinder was capped and tested in a hand-operated hydraulic testing machine for its compressive strength. If the strength was within 400 psi of the specified compressive strength, the specimen and cylinders were cleaned and placed in the test $\mathrm{rig}$.

The overall geometry of the test frames was measured after casting, as shown in Table 4.2. Also, member widths and depths were measured where instrumentation was applied. These average values are presented in Table 4.3. This table also shows concrete covers, concrete strengths and refnforcing steel yleld strengths. 
TABLE 4.1

CONCRETE MIX PROPORTIONS BY WEIGHT

\begin{tabular}{|c|c|c|c|c|c|c|c|}
\hline FRAME & BATCH & $\begin{array}{l}\text { CEMENT } \\
\text { (1b) }\end{array}$ & $\begin{array}{l}\text { WATER } \\
\text { (1b) }\end{array}$ & $\begin{array}{l}\text { FINE } \\
\text { AGG. } \\
\text { (1b) }\end{array}$ & $\begin{array}{c}\text { COARSE } \\
\text { AGG. } \\
\text { (1b) }\end{array}$ & $\begin{array}{r}\text { SLUMP } \\
(\mathbf{I n})\end{array}$ & $\begin{array}{l}\text { BATCH VOL. } \\
(\mathrm{cu} f \mathrm{t})\end{array}$ \\
\hline \multirow{2}{*}{ USD-1 } & 1 & 47 & 24 & 118 & 86 & 7 & 1.90 \\
\hline & 2 & $701 / 2$ & 34 & 177 & 129 & $71 / 4$ & 2.83 \\
\hline \multirow{2}{*}{ LD-1 } & 1 & 59 & 30 & 148 & 108 & $71 / 4$ & 2.38 \\
\hline & 2 & 59 & 31 & 138 & 108 & 7 & 2.32 \\
\hline
\end{tabular}




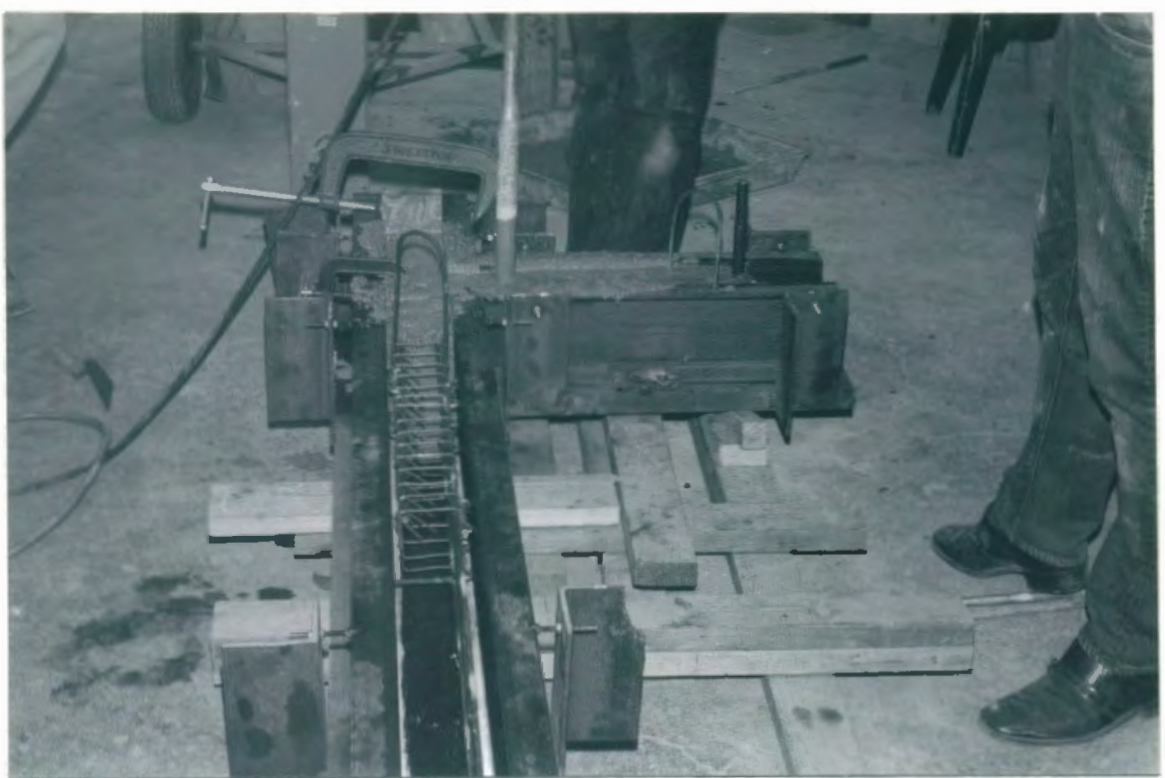

Fig. 4.9. Casting and consolidating the concrete

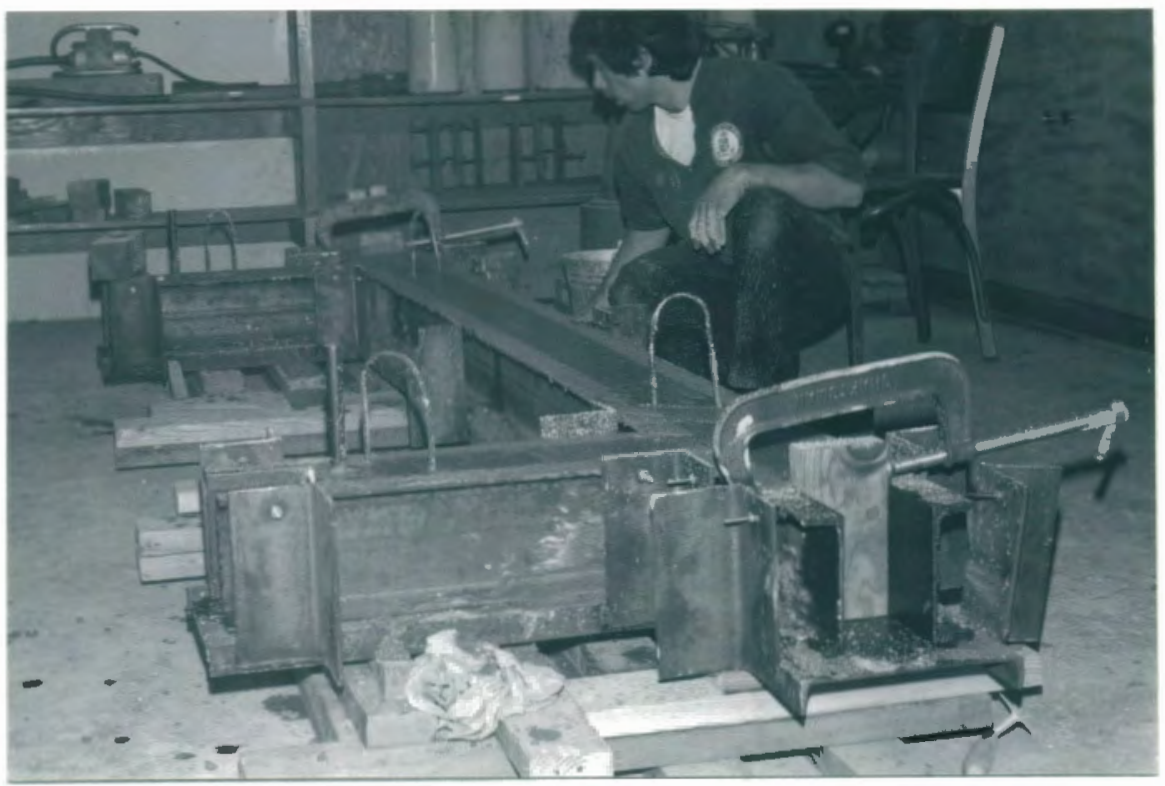

Fig. 4.10. Cleaning the forms after casting 

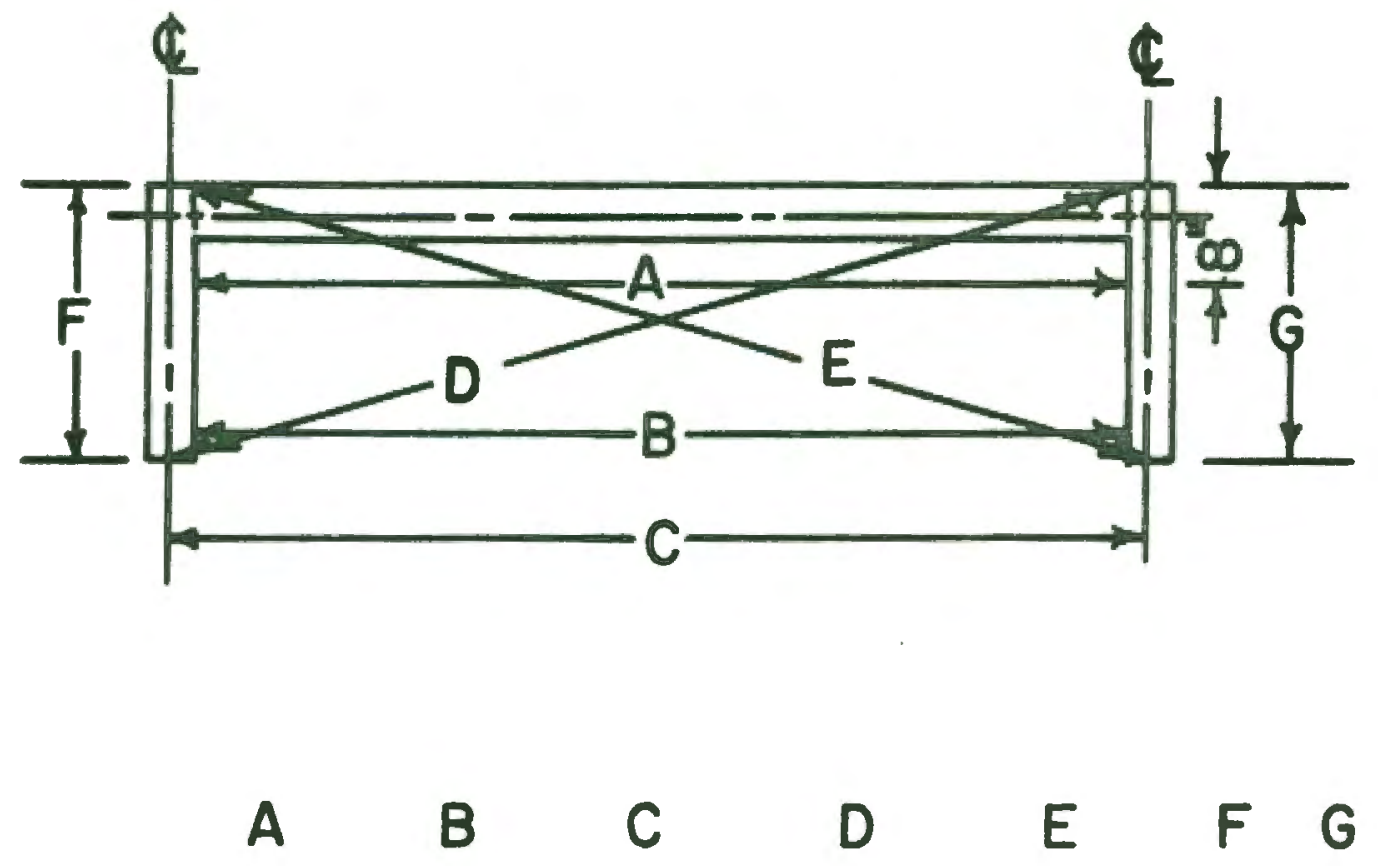

FRAME USD-1

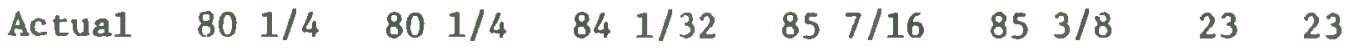

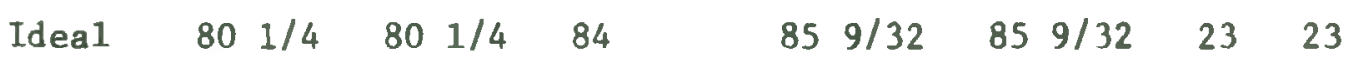

FRAME LD-1

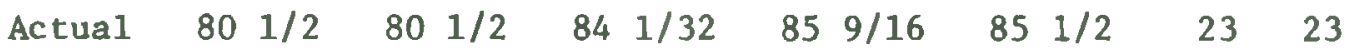

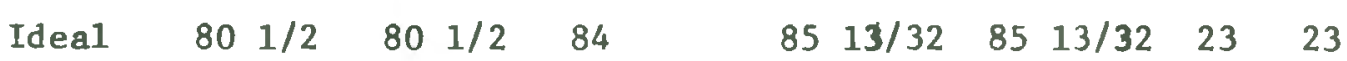

TABLE 4.3

PRINCIPLE PROPERTIES OF THE FRAMES

\begin{tabular}{|c|c|c|c|c|c|c|c|}
\hline Frame & Member & $\begin{array}{c}\text { h } \\
\text { in. }\end{array}$ & $\begin{array}{l}b \\
\text { in. }\end{array}$ & $\begin{array}{l}\text { Mom. } \\
\text { Region }\end{array}$ & $\begin{array}{l}d_{c} \\
\text { in. }\end{array}$ & $\begin{array}{l}f_{c}^{\prime} \\
\text { psi }\end{array}$ & $\begin{array}{r}\mathrm{f}_{\mathrm{y}} \\
\mathrm{ks} 1\end{array}$ \\
\hline \multirow{2}{*}{ USD-1 } & Co 1 & 3.764 & 6.041 & $\pm M$ & .75 & 4421 & 59.1 \\
\hline & $\mathrm{Bm}$ & 4.032 & 6.107 & $\begin{array}{l}+\mathrm{M} \\
-\mathrm{M}\end{array}$ & $\begin{array}{r}.94 \\
.75\end{array}$ & 4126 & $\begin{array}{l}59.1 \\
79.6\end{array}$ \\
\hline \multirow[b]{2}{*}{ LD-1 } & $\mathrm{Col}$ & 3.499 & 6.036 & $\pm M$ & .75 & 5414 & 59.1 \\
\hline & $\mathrm{Bm}$ & 4.029 & 6.096 & $\begin{array}{l}+M \\
-M\end{array}$ & $\begin{array}{l}.90 \\
.90\end{array}$ & 4444 & $\begin{array}{l}66.0 \\
66.0\end{array}$ \\
\hline
\end{tabular}




\subsection{MEASUREMENT METHODS}

The main purpose of this experimental work was to study the behavior of reinforced concrete frames subjected to gravity loads and a lateral load.

The following measurements were taken:

(1) measurements of column loads (P), beam loads (Q), and lateral load $(\mathrm{H})$.

(2) curvatures at various locations

(3) corner rotations

(4) lateral deflections.

\subsubsection{Loads and Pressures}

Three independent pressure supplies were used to apply the column loads, beam loads and the lateral load. The pressure was applied with three hand-operated pumps. The pumps had adjustable pressure rellef valves. The instrumentation system is schematically diagrammed in Figure 4.11 .

Column loads were applied with 30-ton capacity rams. Because column loads were the same, column rams were connected to a single pump through a system of hydraulic hoses and a manifold. The pressure was measured by a calibrated strain-gauge pressure transducer, and checked by a pressure gage. Both measuring devices had a capacity of 10,000 psi. Similarly, the beam loads were applied by a 20-ton capacity ram. The lateral load for Frame USD-1 was applied by a 10-ton capactty ram. The test apparatus had to be modified slightly for Frame LD-1 for which a 12-ton capacity ram was used. Beam and lateral loads were measured 


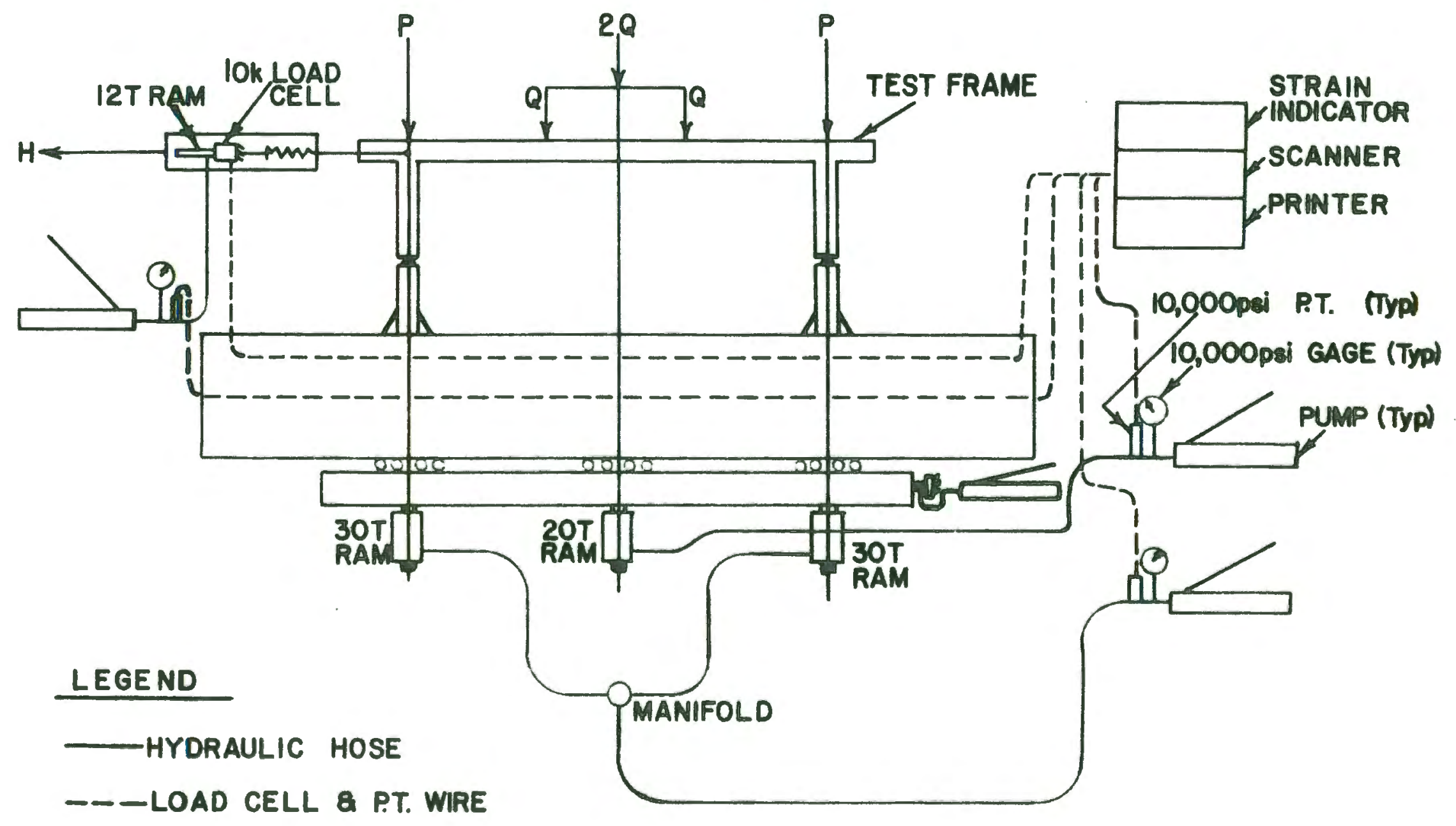

FIG.4.II LOADING INSTRUMENTATION 
using pressure transducers. In addition, 10-kip capacity load cell was used for measuring the lateral load for Frame LD-1.

Calibration Method. The pressure transducer and the load cell were calibrated in terms of output voltage. It involved applying a known load and recording the output voltage from either the transducer or load cell in $\mu \mathrm{v} / \mathrm{v}$ (microvolts per volt). The test setup, which is schematically shown in Figure 4.12, consisted of the Material Testing System electrohydraulic testing machine, a strain indicator connected to a scanner, and the pressure supply system.

The loads to the ram were applied by the MTS and measured with the MTS digital voltmeter. At the same load level, output voltage from the transducer or load cell was recorded on the strain indicator. This step was repeated for several load levels over the operating range of the pressure supply system. The above step was repeated for descending load leve1s.

The calibration curves are shown in Figures 4.13 through 4.15 . Because the lateral load ram was changed for testing LD-1, two calibrations are shown in Figure 4.14 .

\section{$\underline{4.3 .2}$ Curvatures}

Because it was necessary to measure bending moments at various locations on the beam and columns, measurement devices called curvaturemeters were used. These devices are described by earlier investigators $(14,25,26)$. The locations of the curvature-meters are shown in Figure 4.16. The plan view of a curvature meter is shown in Figure 4.17. A curvature meter measures the deformation over a gage length on opposite sides of the member. From deformations, the average strain on the top 


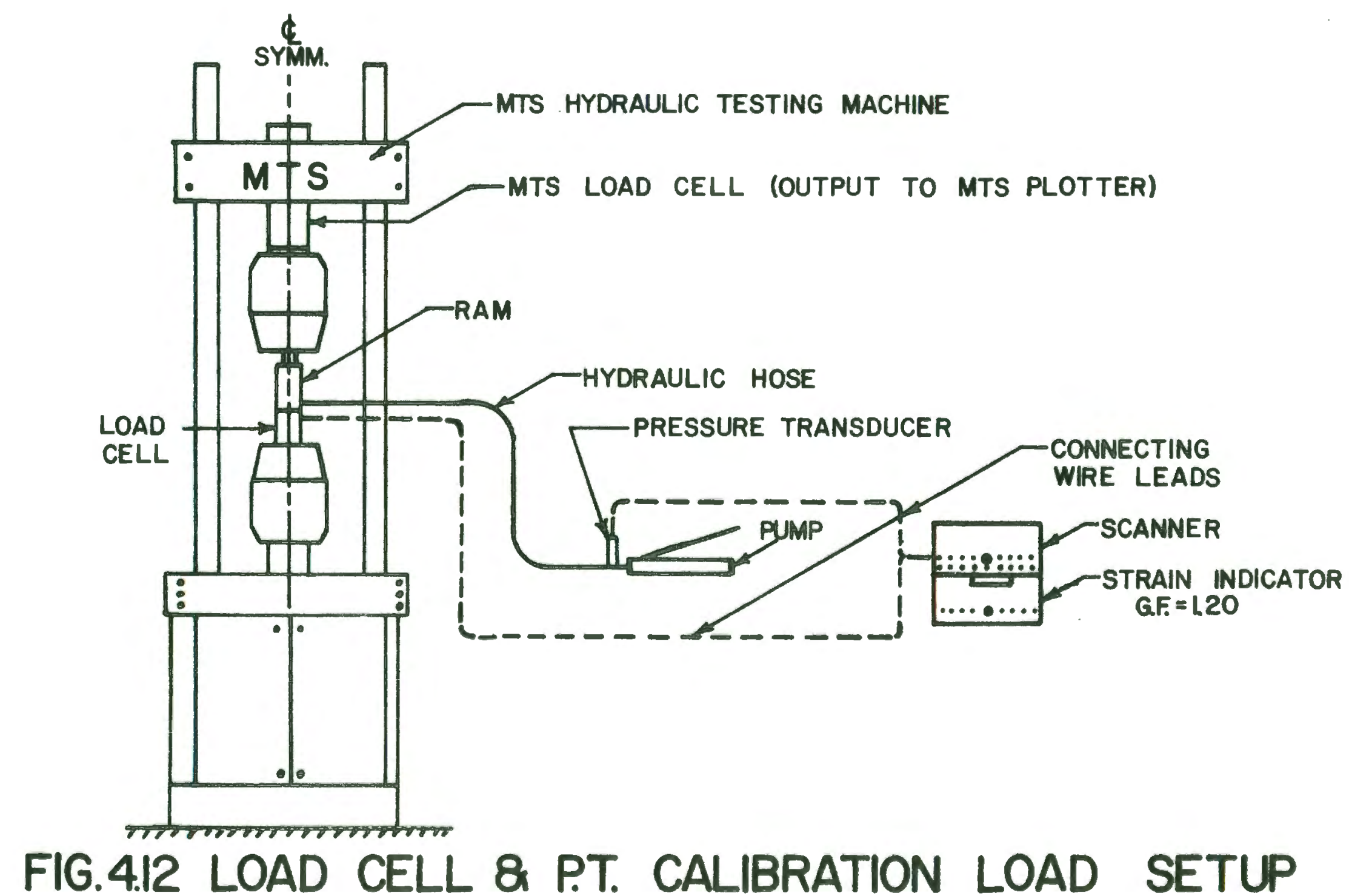




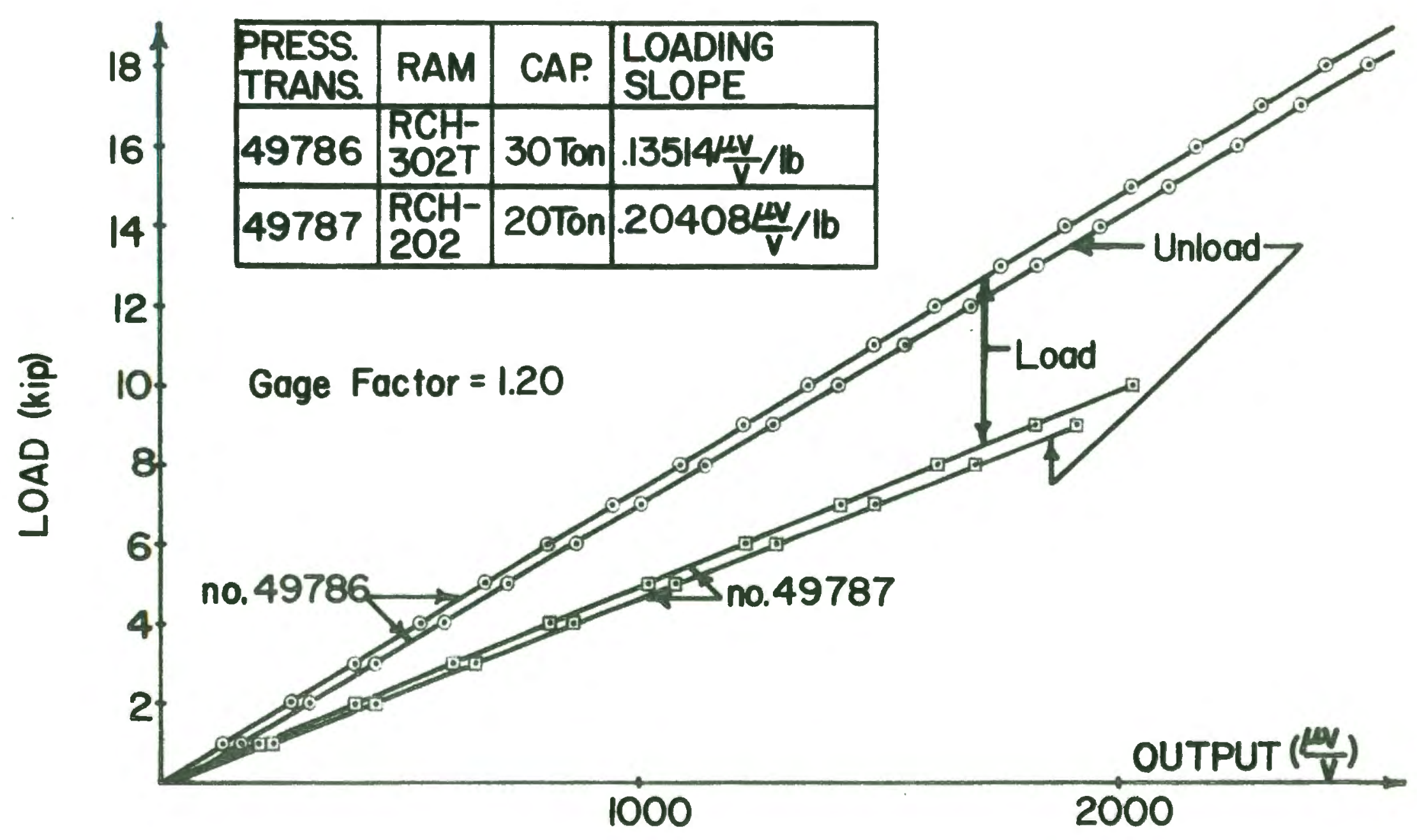

FIG.4.13 PRESSURE TRANSDUCER (no.s 4978687) CALIB. 总 


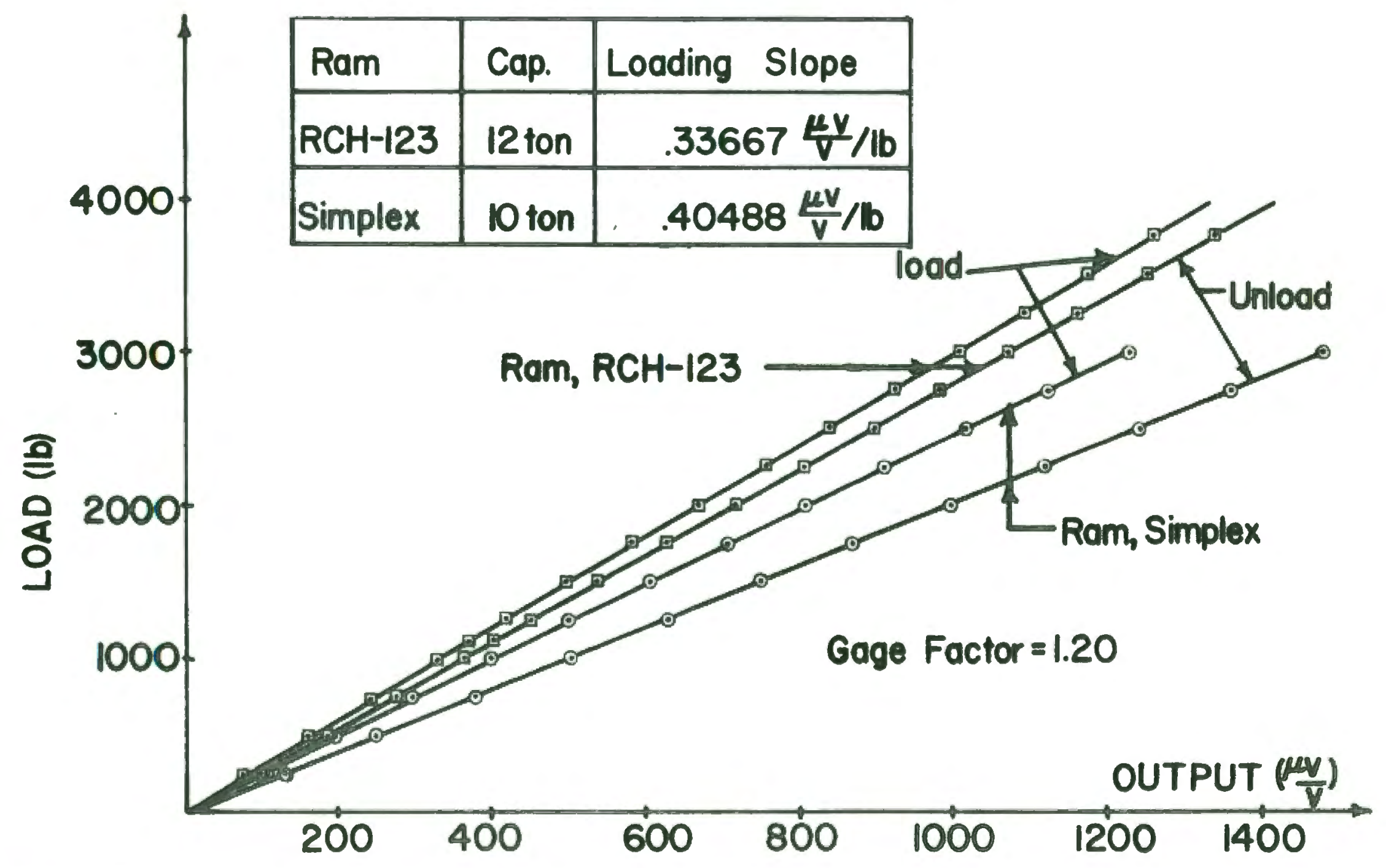

FIG.4.14 PRESSURE TRANSDUCER (no.49904) CALIB. 


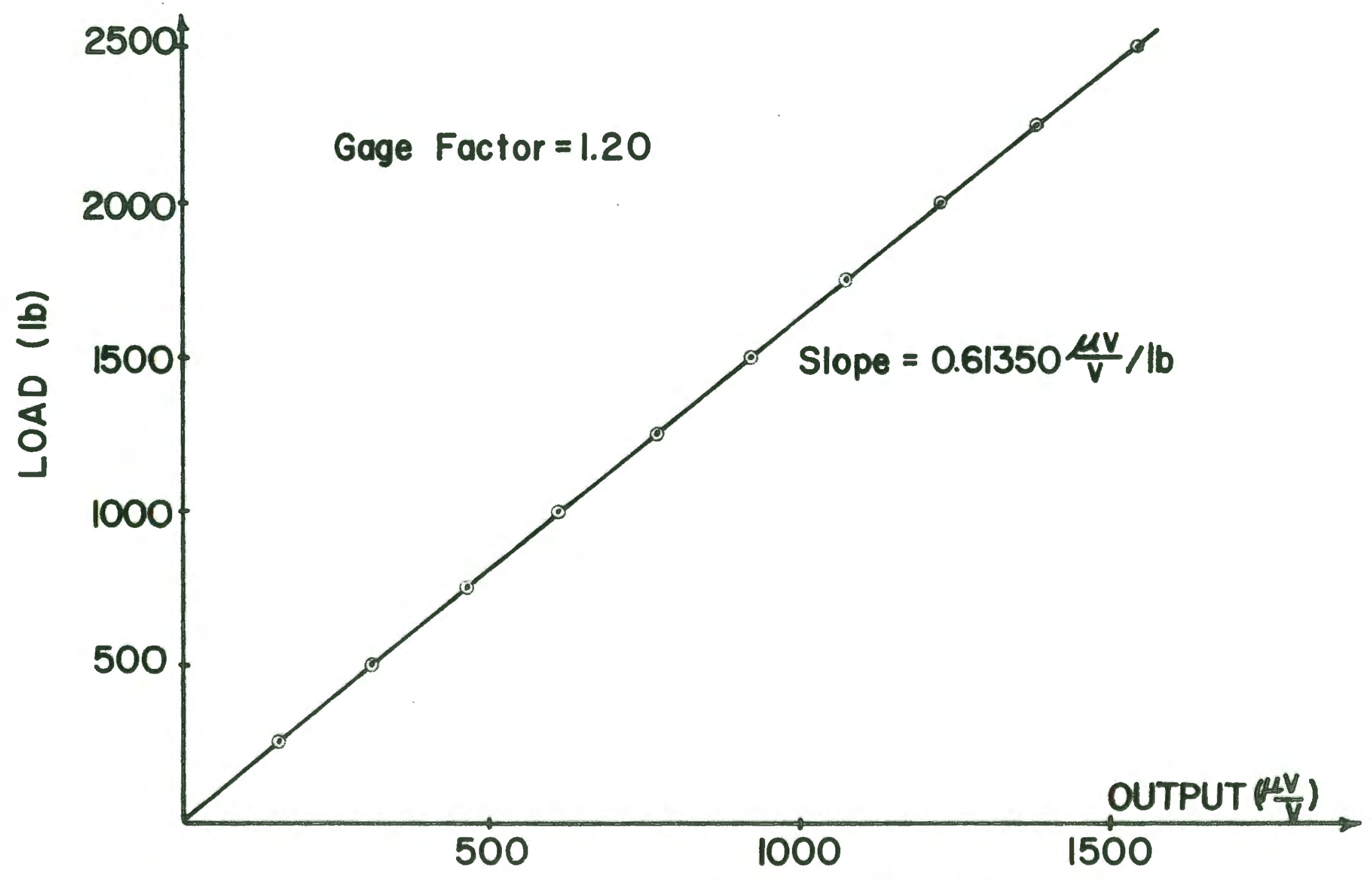

FIG. 4.15 LOAD CELL (no. 2146) CALIBRATION 

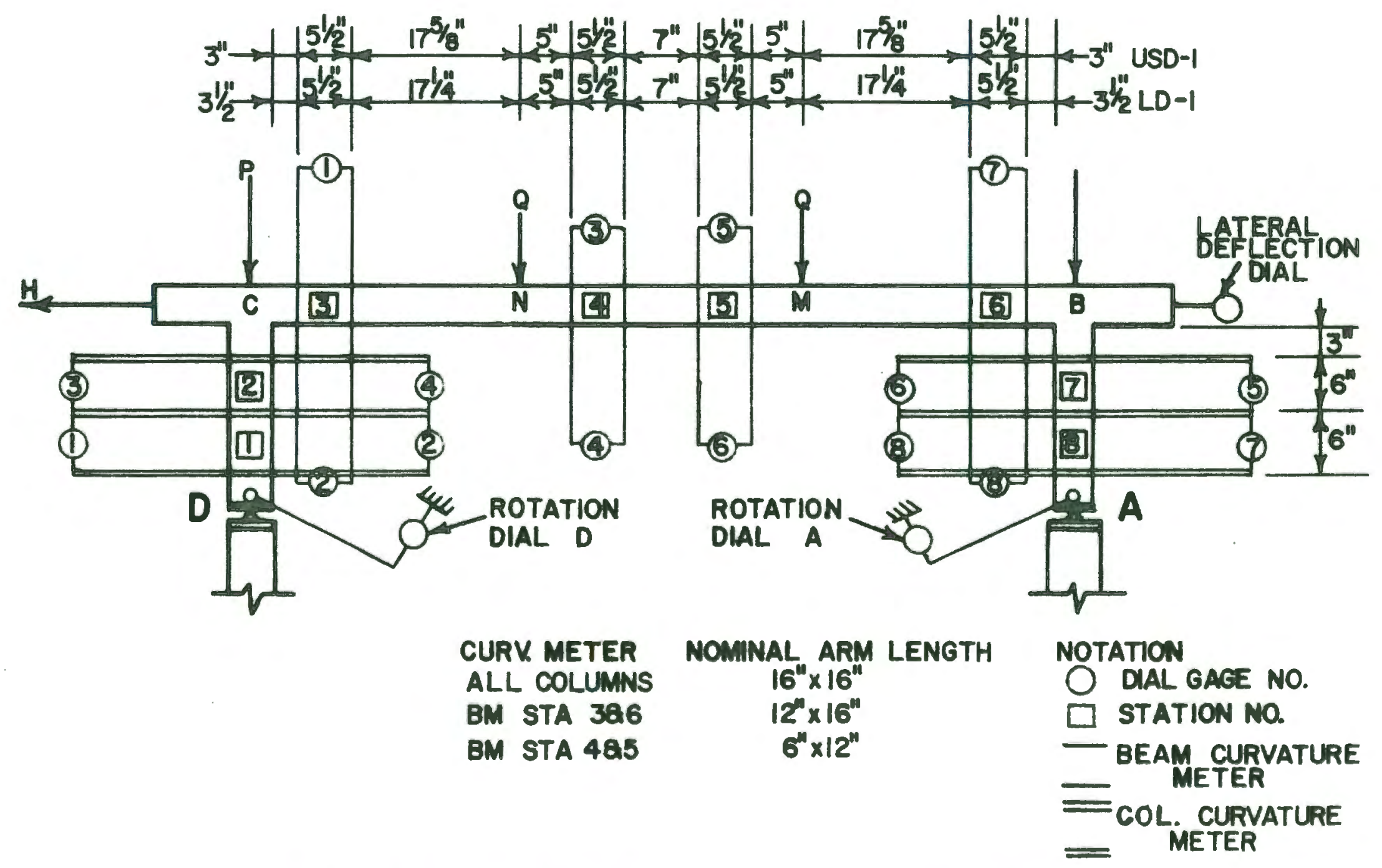

FIG.4.16 INSTRUMENTATION DIAGRAM 
and bottom fibers and the corresponding curvature is determined.

These curvatures were used to determine the bending moment at the center of the gage length. All computations are done by the computer program FRAGO as described in section 5.1 .1 .

The main parts of a curvature-meter are the arms, saddles, and dial gages. The arms were made from steel angles which were welded to U-shaped saddles. A mount for the dial gage was connected at the end of each arm. The dial gages had an accuracy of .001 in. and a plunger range of 1.00 in. The dial gages were positioned at a reading of about 0.5 in. This was done to allow movement in either direction.

Curvature meters were installed by first marking the exact positions of the meters on the test frame (Figure 4.16). Metal strips (1/16" $\mathrm{x}$ $\left.1 / 2^{\prime \prime} \times 6^{\prime \prime}\right)$ were glued to the frame at these locations. Next, steel plates $\left(1 / 3 \times 2^{\prime \prime} \times 6^{\prime \prime}\right)$ were centered over the strip. Finally, the curvature meters were centered over the plates and tightened with $1 / 4-$ in bolts. A $1 / 4$ in. gap between the top of the specimen and curvature meter was provided to prevent restraint. A photograph of several curvature meters in position is shown in Figure 4.19.

\subsubsection{Corner Rotations}

The corner rotations at $A$ and $D$ were measured with a device shown in Figure 4.18. It consisted of an 18-in. 1ong steel angle welded to a 3-in. long 13/16-in I.D. steel pipe. This assembly was fastened to the test frame joint by sliding the pipe over the 3/4-in. diameter bar cast in the frame. Two $1 / 4-1$. diameter set screws secured the assemb1y to the bar. A 2-in. x 4-in. x 5/32-in. plate was welded to the other end of the arm. The plunger of the dial gage was positioned perpendicular 

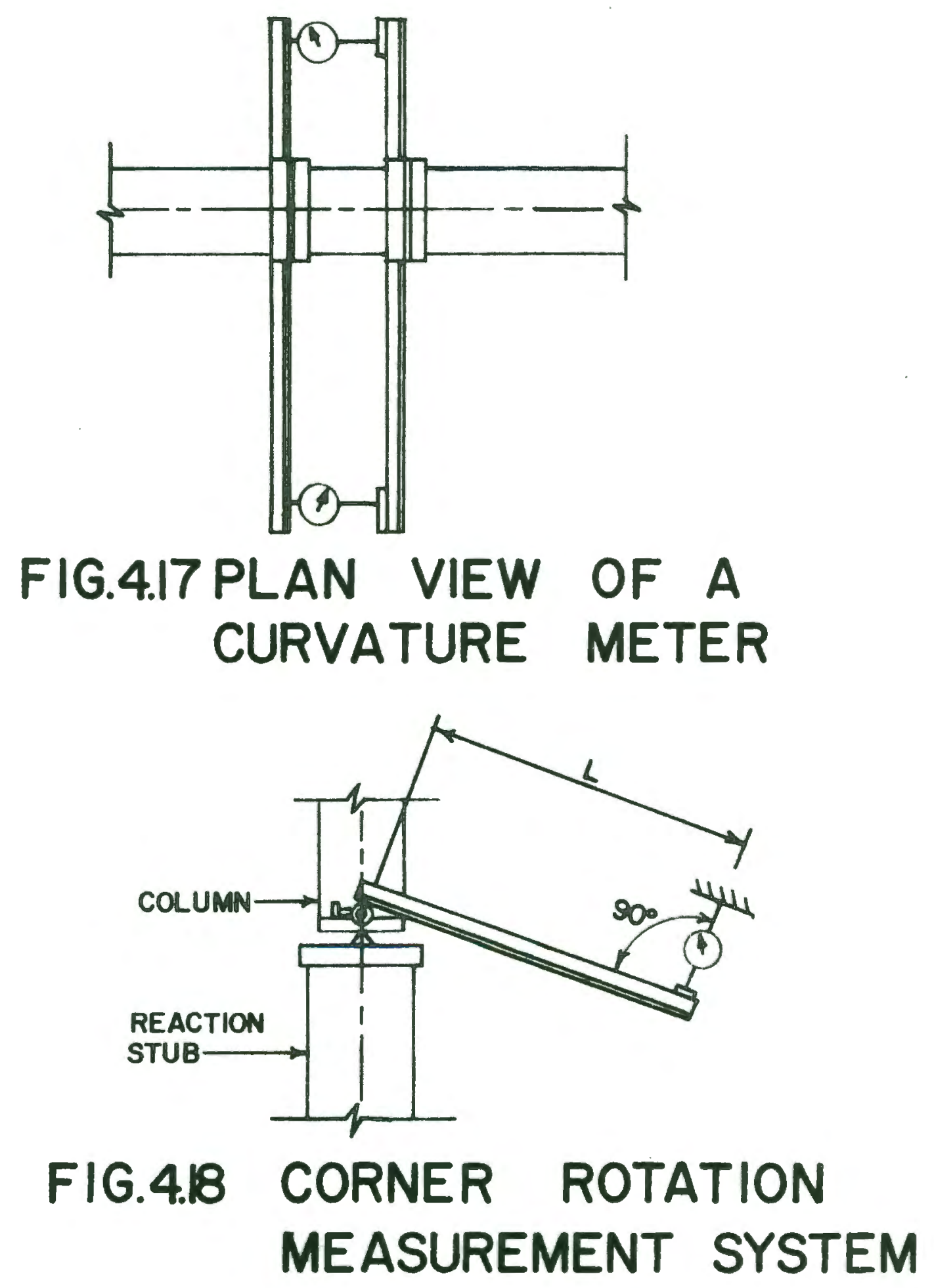
to the end plate.

The angular rotation $(\theta)$ is determined by the relationship:

$$
\theta=\frac{\Delta D R}{L}
$$

where $\triangle D R$ is the change in dial gage reading, and $L$ is the length of the arm as shown in Figure 4.18.

\subsubsection{Lateral Deflection Measurement}

The lateral deflection was measured with a 2-in. travel dial gage. This dial gage, located at corner B beam stub shown in Figure 4.16, measured the lateral deflection relative to the laboratory floor. A Photograph of the measuring device is shown in Figure 4.20.

\subsection{TEST APPARATUS}

The components of the loading system, schematically diagramed in Figure 4.21, are briefly described in the following section. Reference (27) includes a detailed description of the loading system. Also, a typical test procedure is outlined below.

\subsubsection{Description of Apparatus}

The loading system consists of five main parts: two column load devices, a beam load device, a lateral load assembly, a stationary concrete reaction beam, and a movable steel beam. The gravity (beam and column) loads react on the test frame through three pairs of bearing devices interconnected by prestressing strands. A sway adjustment ram as shown in Figure 4.23 is provided at one end of the movable steel beam which can move the steel beam laterally to adjust to the test frame lateral movement. Figure 4.22 is a photograph of the test apparatus. 


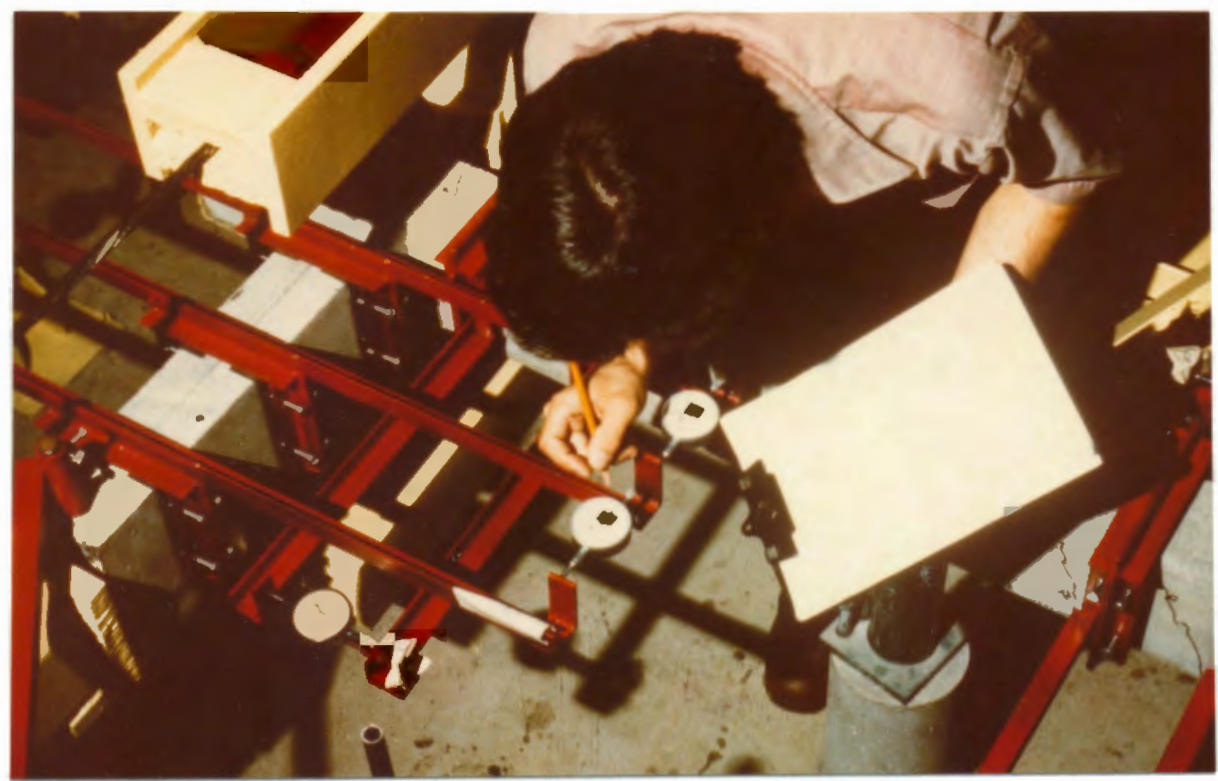

Fig. 4.19. Curvature-meters in position

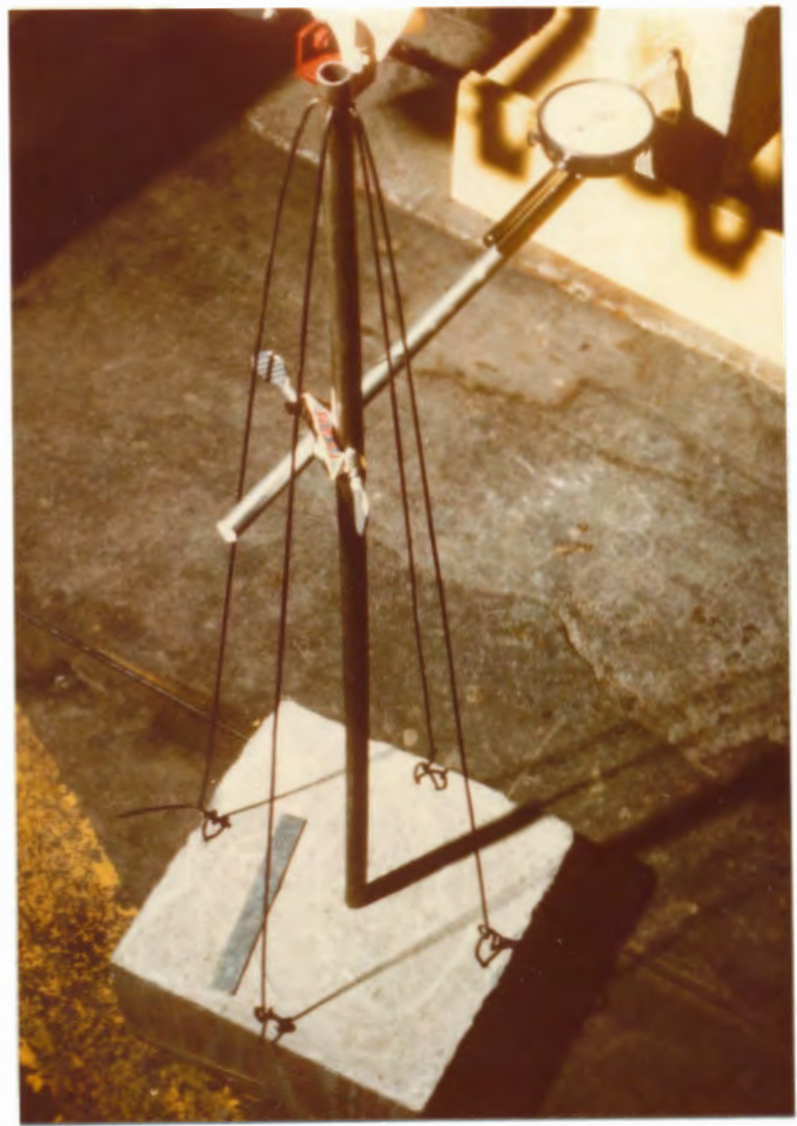

Fig. 4.20. Lateral deflection measuring device 


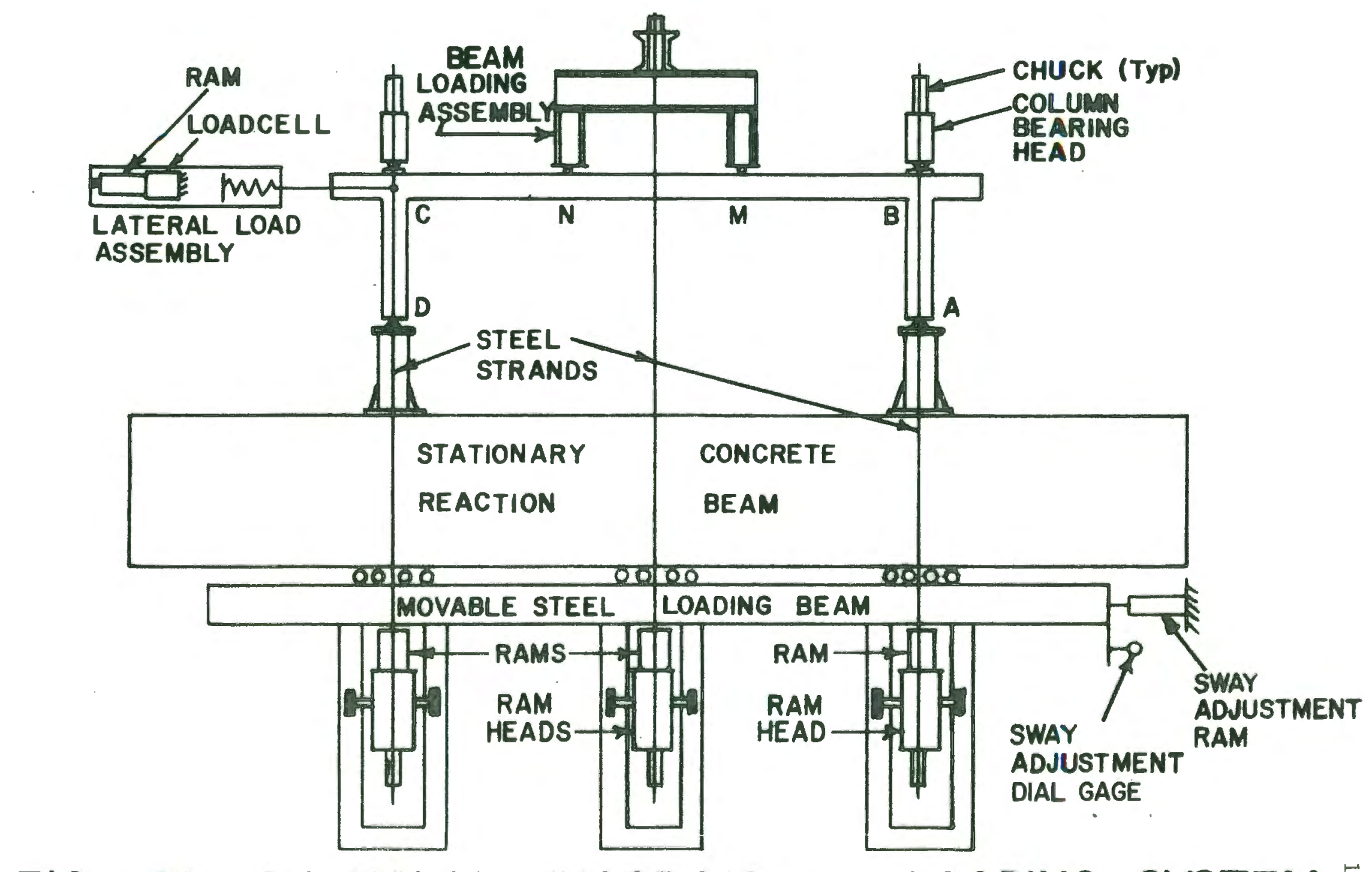

FIG.4.2I SCHEMATIC DIAGRAM OF LOADING SYSTEM 


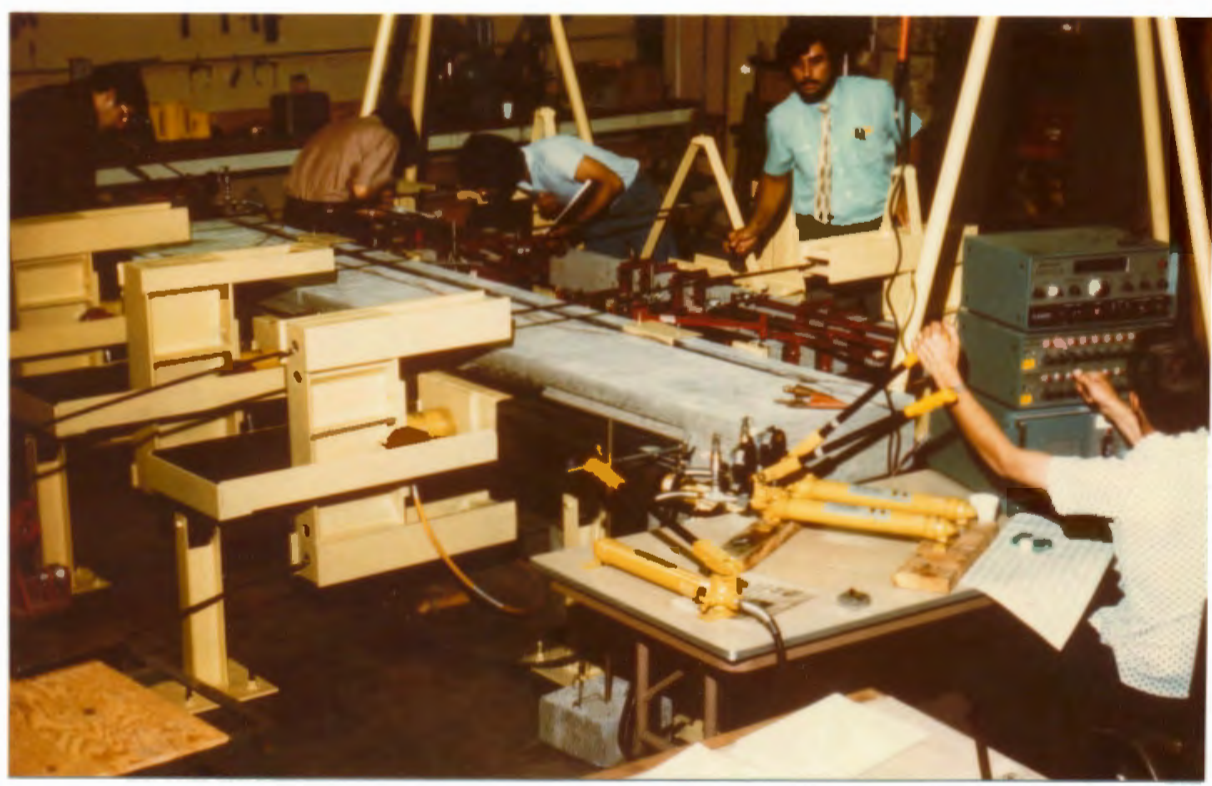

Fig. 4.22. Test apparatus

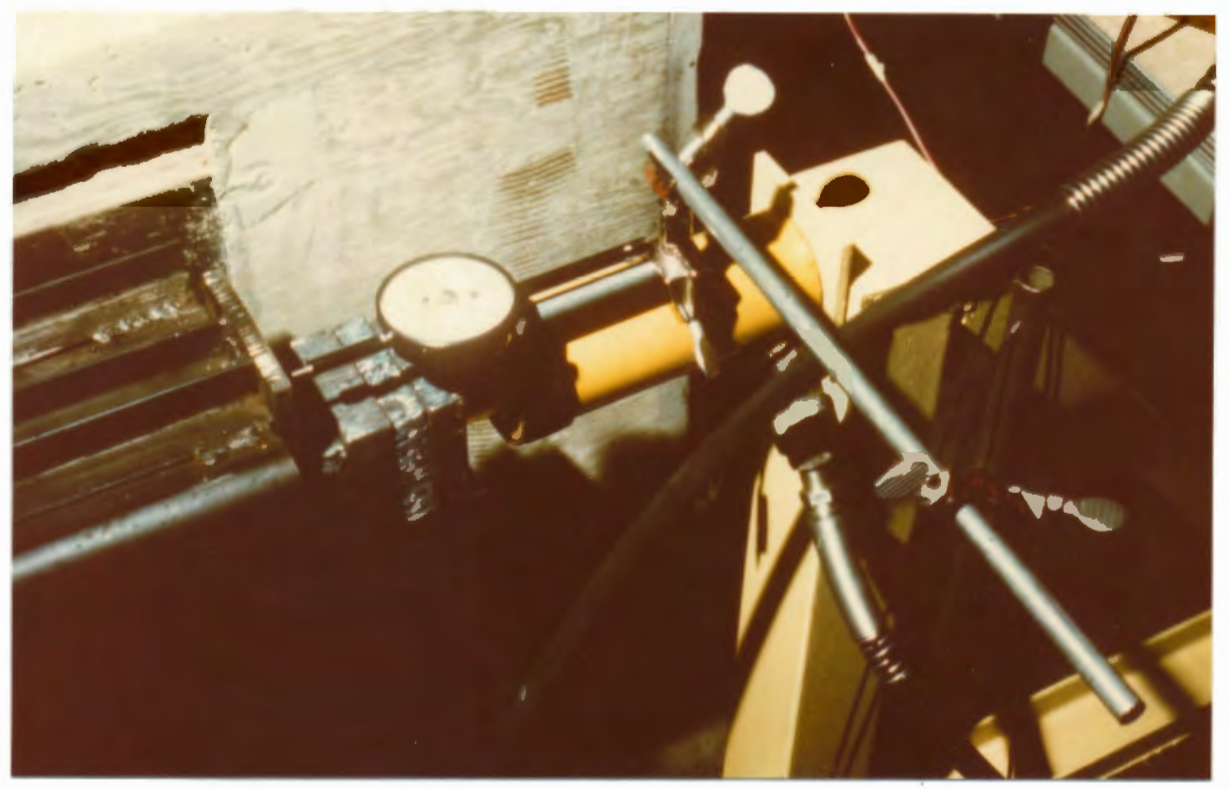

Fig. 4.23. Sway adjustment ram and dial gage 
a) Column Load Devices. The column load device is composed of a bearing head and ram head coupled together by two prestressing strands. The load is applied by a hydraulic ram connected to the ram head. When the ram is extended, it reacts against the ram head which transmits the load through two prestressing strands to the bearing head. The reaction at the bearing head is the load to the test frame.

The ram head, which is U-shaped, is made from steel plates and sections of wide flange welded together. It is supported on a steel angle frame by two wheels which permit it to move perpendicular to the movable steel beam. This steel angle frame is supported by a wheel at one end, which allow it to move laterally; and by the movable steel beam at the other end.

The bearing head, which is about $7 \mathrm{ft}$ from the ram head, is similarly constructed. However, the bearing head has a knife-edge welded to it which transmits the load to the columns.

Two $1 / 2$ inch $\emptyset$ prestressing strands connect the ram head and bearing head together. These two strands are located in the same vertical plane as the column centerline of the test frame. The top and bottom strands are about 38-in. and 12-in. from the laboratory floor. Chucks are used to connect the strands to the heads.

b) Beam Load Device. The beam load device is similar to the column load device. The load transmitted from the beam ram head was sp1it into two forces by a yoke system (beam loading assemb1y).

c) Lateral Load Assembly. The ram and load cell centerlines for the lateral load assembly, which are mounted on a vertical column stub, are about $2^{\prime}-2^{\prime \prime}$ from the laboratory floor. When the ram is extended it 
reacts against a $4 "$ x 4 " bearing plate. This bearing plate transmits the load to the test frame by two 1/4-in. diameter rods. The load from these rods is transferred to the test frame with a 3/4-in. diameter rod inserted in the pipe sleeve as discussed in section 4.2.3. Also, between the ram and test frame, the load transmits through a colled spring shown in Figure 4.21. This spring helps keep the lateral load constant as the test frame is deflected latera11y.

d) Concrete Reaction Beam and Movable Steel Beam. A concrete reaction beam, mounted to the laboratory floor, withstands the reaction forces from the reaction stubs and the movable steel beam. The centerline of the $1^{\prime}-2^{\prime \prime}$ wide $\times 2^{\prime}-0^{\prime \prime}$ deep beam is about $2^{\prime}-2^{\prime \prime}$ from the laboratory floor.

The 10-ft long movable steel beam, which is simply supported by rollers, is used to support the three ram heads. A hydraulic ram, as shown in Figure 4.23, is placed at one end of the beam. By using this ram and a dial gage, the movable steel beam was positioned laterally the same distance as the test frame lateral deflection. This was to insure that the stands were always perpendicular to the loading beam as testing was in progress.

\subsubsection{Test Procedure}

a) Pre-test Procedure. The test frame was leveled in the horizontal direction to prevent biaxial bending in the colums and torsion in the beam. This was done by using screw jacks which supported the test frame. The bearing heads were then positioned at the load points of the test frame. The top and bottom strands for each bearing head were adjusted to the same length so that they would carry equal loads. This was checked by 
loading the columns with about a 6-k1p load and then tapping the strands by a piece of thin steel flat bar. If the sound frequencles were about the same, then it was concluded that the stands had approximately equal loads.

Finally, the column loading strands were aligned with the column centerlines. A transit, which was about 15-ft behind the bearing head, was set up on the right column centerline. The vertical halrline of the transit, as shown in Figure 4.24, was aligned with the column centerline. Then the column cable was positioned on this centerline. Next, a measuring tape was used to position the other strands. The alignment was checked by applying a column load of 2.5 kips. The allgnment was good if the frame lateral deflection was less than .001 In.

b) U1timate Load Test. After the test frame was aligned, zero readings of the pressure transducers and the load cell were taken. Then, a 500-1b column load was applied to seat the frame. At this load, which is the seating load, zero readings of all the curvature-meter dials, rotation dials and the lateral deflection dial were taken.

The sequence of test loads were applied as follows:

Sequence 1. The beam and column load increments were applied in 8 levels to a maximum column and beam load of 15.67-kip and 1.96-kip. The Q/P ratio was malntalned at .125 .

Sequence 2. The lateral load was applied incrementally to fallure while maintaining the maximum beam and column loads.

Sequence 3. The lateral load from sequence 2 was reduced to zero and the column and beam loads were reduced to 75 percent of their original values. Finally, the lateral load was reapplied to failure (for Frame LD-1 only). 
At each load level for sequences 1 and 2 , the curvature-meter dials, corner rotation dials and the lateral deflection dial were read and recorded (see Figure 4.25). Also, as shown in Figure 4.26, the visible cracks were marked with a marker for each load increment. As shown in Figure 4.27, the beam and column loads were monitored to prevent load relaxation in the strands caused by either elastic stretching, or creep and moment redistribution in the test frame. Two readings were recorded on the pressure transducers and the load cell, one when curvature meters were first read and one after the readings were completed. About ten minutes were needed to read and record all the dial gages.

The lateral load for sequence 2 was first applied in nominal 200-1b increments. During this load application, the load vs. deflection was plotted to detect nonlinearity in the test frame. When this response became nonlinear, the nominal load increments were reduced to $50-1 \mathrm{~b}$. As the frame approached failure, the critical value needed was the ultimate lateral load. This was achieved by continuously monitoring the load cell of the lateral load assembly. During and after failure the lateral load could not be maintained. To obtain the descending portion of the lateral load vs. deflection curves, deformation rather than lateral load was applied.

In summary, the loading for sequence was stopped when three conditions were observed:

(1) a reduction in the lateral load capacity under increasing lateral deflection,

(2) two well defined hinges, including concrete spalling, observed in the beam (collapse mechanism),

(3) lateral deflection of about one inch. 
During the loading for sequence 3 , only the lateral deflections were recorded.

After the frame was tested, photographs were taken with both the instrumentation on and off the specimen. Finally, the control cylinders were tested for their compressive strength.

\subsubsection{Sources of Error}

This section briefly describes some critical aspects of the loading system and test frame. Reference (12) includes a more complete description of the sources of error involved in testing unbraced frames.

Three factors have the most influence on the behavior of unbraced frames (12). They are:

1. column strength when column failures occurred

2. alignment of frame (Figure 4.28a)

3. precise direction and specific point of application of column loads (Figure 4.28b)

The first factor does not apply to frame tests in this series because the hinge formed in the beam. The concrete strength does not significantly affect the bending capacity of the beam. However, factors 2 and 3 hive a significant affect on the lateral load response of the test frames. Two idealized models, as shown in Figure 4.28 were used to study the degree of error in the frame.

The first model, as shown in Figure 4.28a, had a parallelogram geometry but with column load, perpendicular to the beam. The second model, as shown in Figure 4.28b, had perfect geometry but with column loads slightly inclined. 
The effects of both models is to cause an extraneous lateral load acting to the right. Therefore, the column load $\mathrm{P}$ can be broken down into two loads; a load acting along the column axis, and a lateral load acting along the beam direction. If the column and geometry are perfect than lateral load - deflection response for the frame should cause a zero displacement under full gravity load. However if there is some imperfection then some displacement will occur. The required lateral load needed to bring the structure to zero displacement may be called the extraneous lateral load caused by imperfection in either the frame geometry or loading. Therefore, for small angles, the imperfection angle, $\alpha$, would be

$$
a_{1}=\mathrm{TAN}^{-1} \frac{\mathrm{H} / 2}{\mathrm{P}}
$$




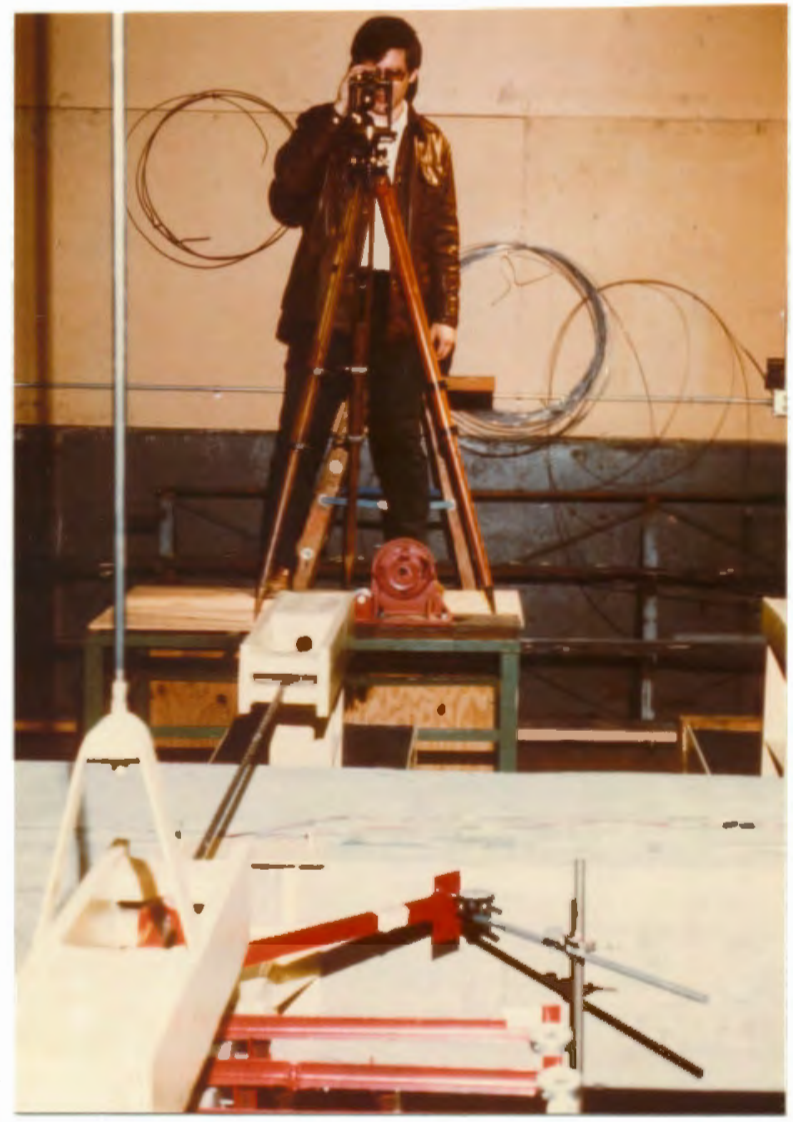

Fig. 4.24. Aligning the right column strand

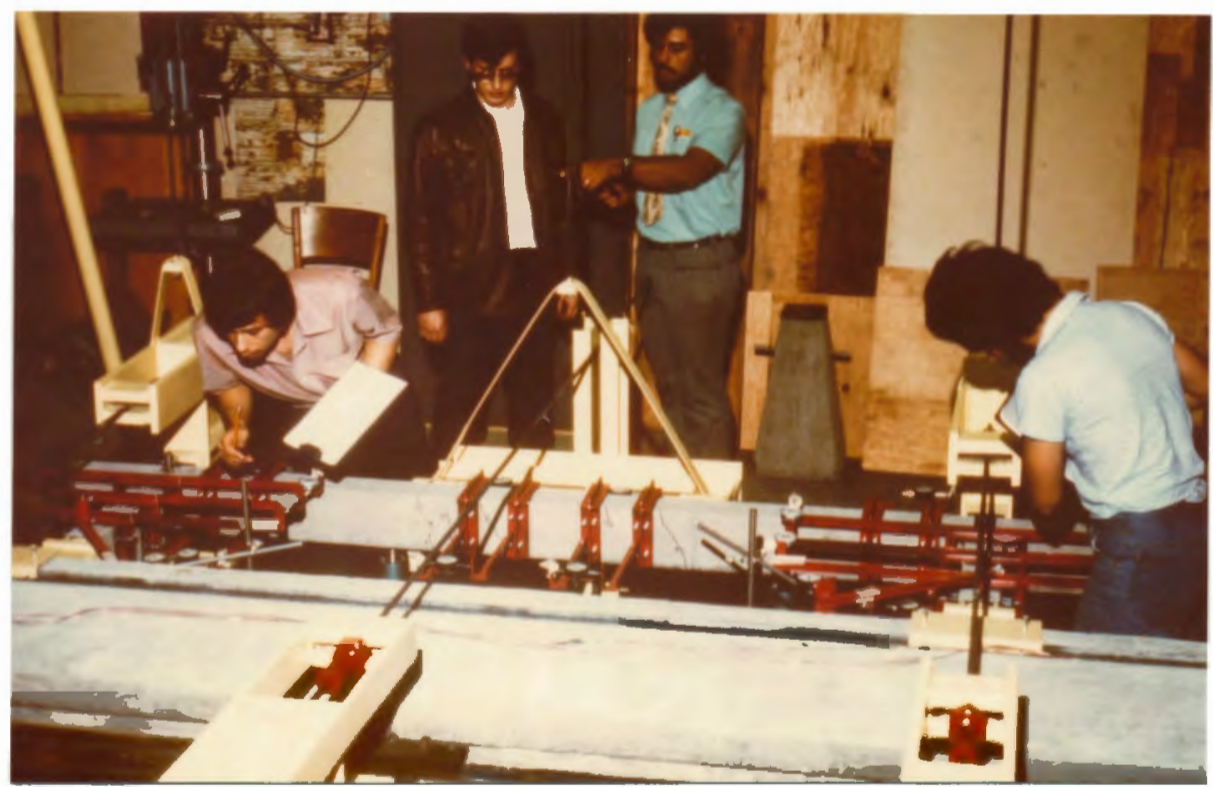

Fig. 4.25. Reading the curvature-meter dials 


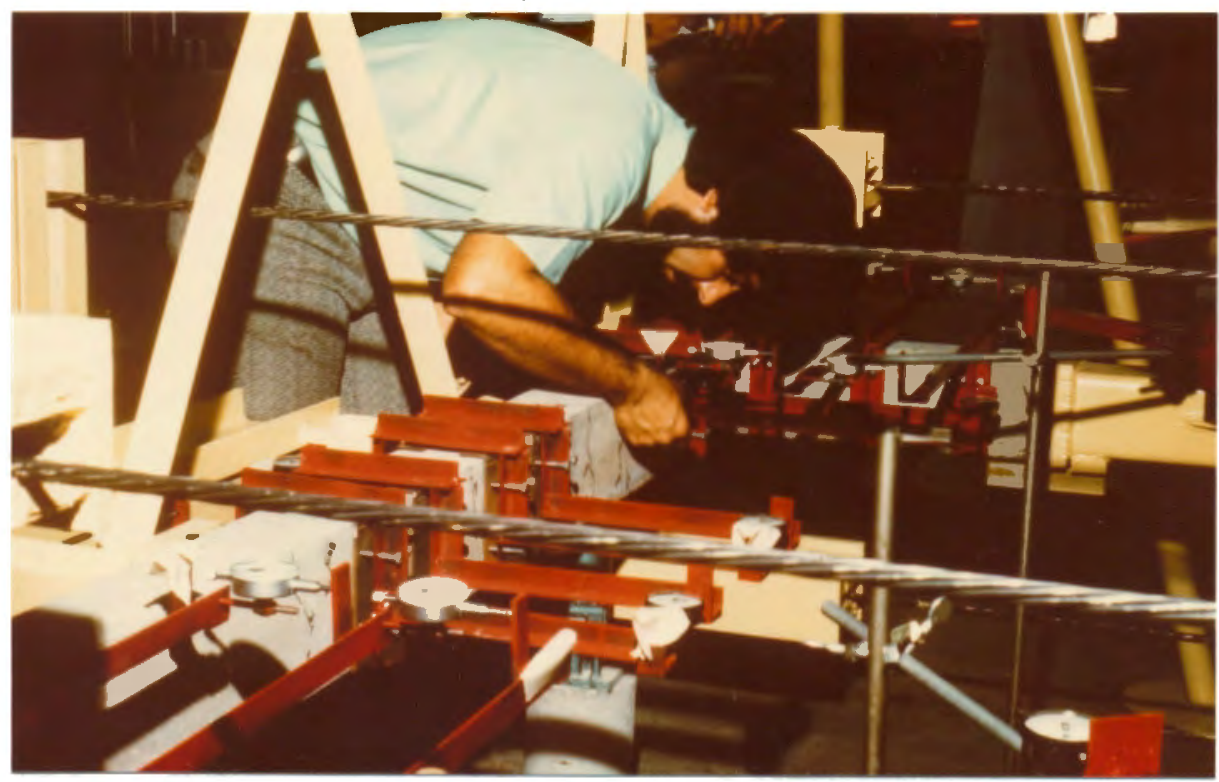

Fig. 4.26. Marking flexural cracks at the positive moment region of the beam

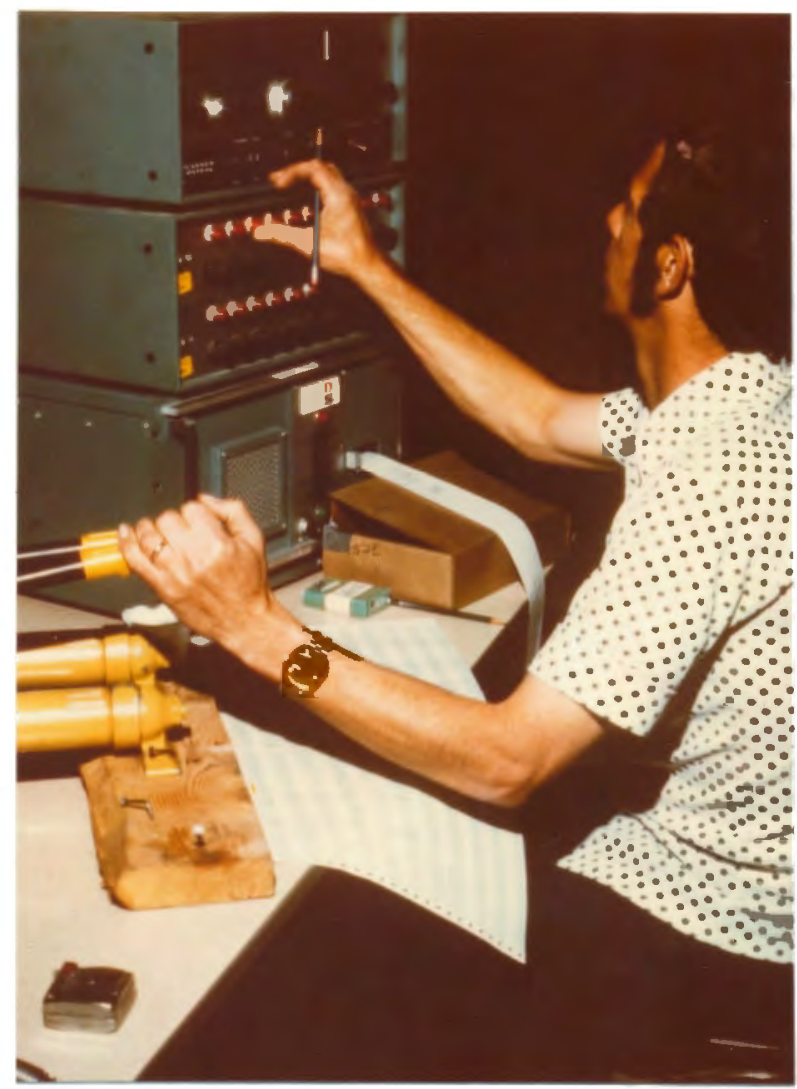

Fig. 4.27. Monitoring loads and pressures with the strain indicator 


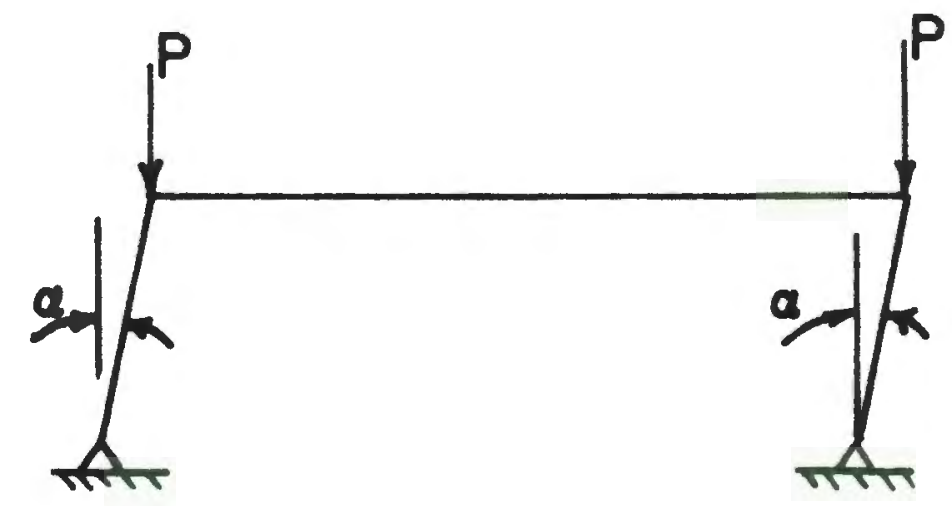

(a) IMPERFECTION IN FRAME GEOMETRY

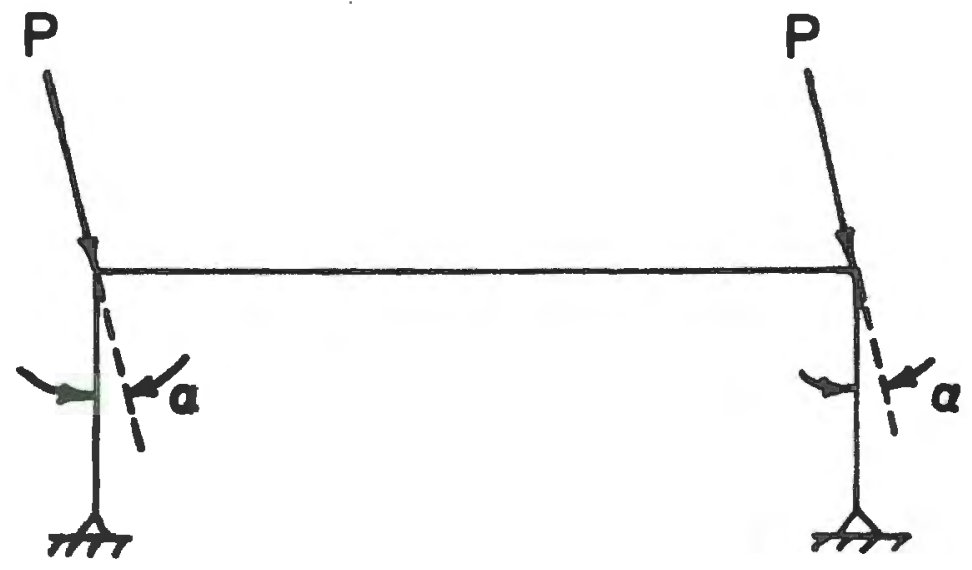

(b) IMPERFECTION IN LOADING

FIG.4.28 FRAMES WITH IDEALIZED IMPERFECTIONS 
CHAPTER V

TEST RESULTS

This chapter describes the test behavior of Frames USD-1 and LD-1. Both frames were tested to failure under gravity and lateral loads. Frames USD-1 and LD-1 were designed, as discussed in Chapter III, under the same loading conditions. Frame USD-1 was designed by the Ultimate Strength method while Frame LD-1 by a Limit Design method.

\subsection{DATA REDUCTION}

This section describes how the measured data was processed into refined data. The refined data are presented in a serles of six graphs for Frames USD-1 and LD-1.

\subsubsection{Moments at the Curvature-Meter Stations}

The recorded strain measurements from the pressure transducers and the load cell were used to determine loads for each load increment. The relationships between the strain readings and the loads were determined from the calibration curves given in section 4.3.1. The column thrust was assumed as the sum of beam load ( $Q$ ) and column load (P) while the axial load in the beam was assumed as zero. Lateral loads for Frames USD-1 and LD-1 given in the test results are computed from the load cell.

The dial readings from the curvature-meters (four stations in the beam and two in the columns as shown in Figure 4.16) were machine processed into average curvatures and surface strains at the midpoint of the station by program FRAGO $(14,26)$. The input for FRAGO is similar to member 
input for NONFIX7. The ultimate concrete strain was taken as $\varepsilon_{\mathrm{u}}=.0038$ while the maximum ordinate on the stress-strain curve was taken as 1.0 . A $\mathrm{P}-\mathrm{M}-\emptyset \mathrm{t}$ curve for the cross-section at each station is generated by FRAGO for different axial loads. Finally, the moment is determined by finding the moment corresponding to that curvature and input axial load. Program FRAGO calculates the moment for cross-sections with symmetrical reinforcement. In this frame test series, columns were symmetrically reinforced; but not the beams. Nevertheless, Input for the beam was entered as symmetrically reinforced. To check the error caused by this input, $P-M-\emptyset t$ curves for two cases were generated. This was done using program PMPHI by first determining P-M- $\emptyset$ t for a symetrical cross section with the properties of a typical station, say station 3 of Frame USD-1 $\left(\rho=\rho_{1}\right.$ and $\left.\rho^{\prime}=\rho_{1}\right)$. Next, the compression steel was removed $\left(\rho^{\prime}=0\right)$ and the above step repeated. It was observed that the stiffnesses, moment capacities, and ultimate curvatures were nearly identical (for example the moment capacities were within $1 \%$ of each other).

Also, because of nonsymmetrical cross-sections in the beam, provisions had to be made to account for reversed curvature at beam corner station 6. This was done by running station 6 on FRAGO with the negative and positive bending cross sections.

The indicated moments from program FRAGO underestimate the true bending moment (28). This was found to be true for the beam because FRACO assumes the concrete to be cracked under tensile strain. However, the column moments are more accurate since they are axially loaded thus cracking prevented. 


\subsubsection{Moments at the Critical Sections}

There are six critical sections which were studied. The critical section locations, bending moment capacities and symbols used in the graphs are shown in Figure 5.1. Four critical sections exist at the two corners ( $B$ and $C$ ), one at the beam load (M), and one at the positive moment cutoff point (M'). More plastic hinges are capable of forming, however, and the critical sections listed here best represent the Inelastic behavior of the frames.

Indicated moments at the critical sections were determined by extending the moment diagrams indlcated by the curvature-meters at various stations. Figure 5.2 shows the method for determining the total moment diagrams. Also as shown in Figure 5.3, it was possible to determine the spread of hinging.

The calculation for beam bending capacities $\left(M_{p}\right.$ or $\left.M_{u}\right)$ were calculated using the ACI 318-71 provisions. These provisions, which were also used in the design, replace the true concrete compressive stress distribution with an equivalent rectangular stress block. Short column bending capacities for various axial loads were calculated from a subroutine in NONFIX7. The above values were close to the design values given in Chapter III. The differences were caused by changes in the concrete strength $\left(f_{c}^{\prime}\right)$ and the measured covers $\left(d_{c}\right)$.

\subsubsection{Description of Results}

The behavior of the frames is given by six graphs described below. These graphs are used to determine the behavior of the frame as we11 as the behavior of the members. 


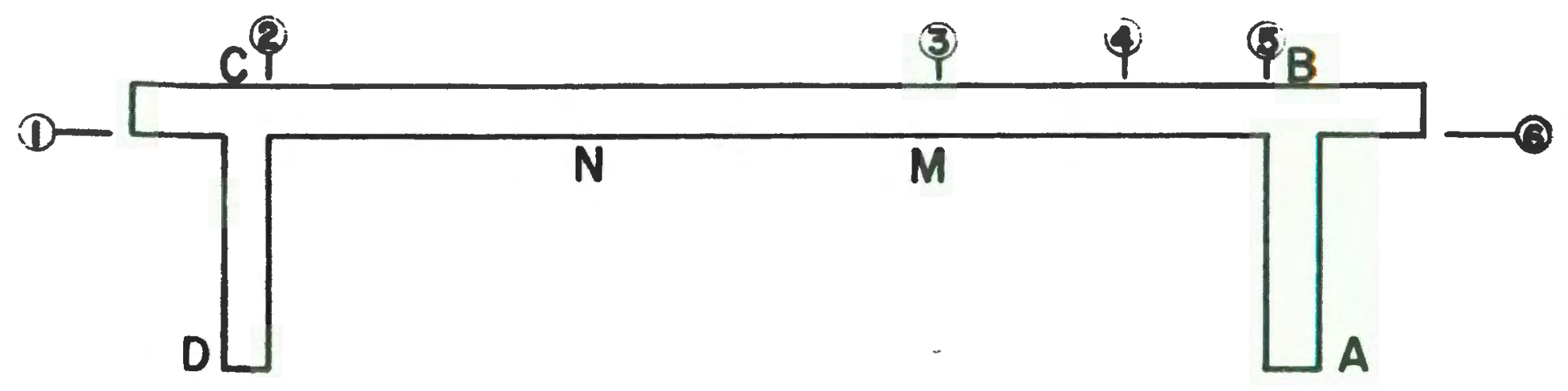

\begin{tabular}{|c|c|c|c|c|c|c|}
\hline \multirow{3}{*}{$\begin{array}{l}\text { Critical } \\
\text { Section }\end{array}$} & \multirow{3}{*}{ Station Description } & \multirow{2}{*}{\multicolumn{4}{|c|}{ Strength, $M_{p}$ in-k }} & \multirow{3}{*}{$\begin{array}{l}\text { Symbol } \\
\text { for } \\
\text { Figures }\end{array}$} \\
\hline & & & & & & \\
\hline & & M- & $\mathrm{Mt}$ & M- & Mt & \\
\hline $1 \& 6$ & $\begin{array}{l}\text { Highly stressed } \\
\text { Region in column }\end{array}$ & 56 & 56 & 52 & 52 & $0, \Delta$ \\
\hline 2 & $\begin{array}{l}\text { Highly stressed } \\
\text { Region in beam }\end{array}$ & 50 & 18 & 41 & 20 & - \\
\hline 3 & $\begin{array}{l}\text { Highly stressed } \\
\text { Region in beam }\end{array}$ & 0 & 36 & 0 & 41 & 0 \\
\hline 4 & $\begin{array}{l}\text { Positfve moment } \\
\text { Cutoff point }\end{array}$ & 25 & 18 & 20 & 20 & $\square$ \\
\hline 5 & $\begin{array}{l}\text { Highly stressed } \\
\text { Region in beam }\end{array}$ & 50 & 18 & 41 & 20 & $\Delta$ \\
\hline
\end{tabular}

FIG. 5.I CRITICAL SECTIONS 


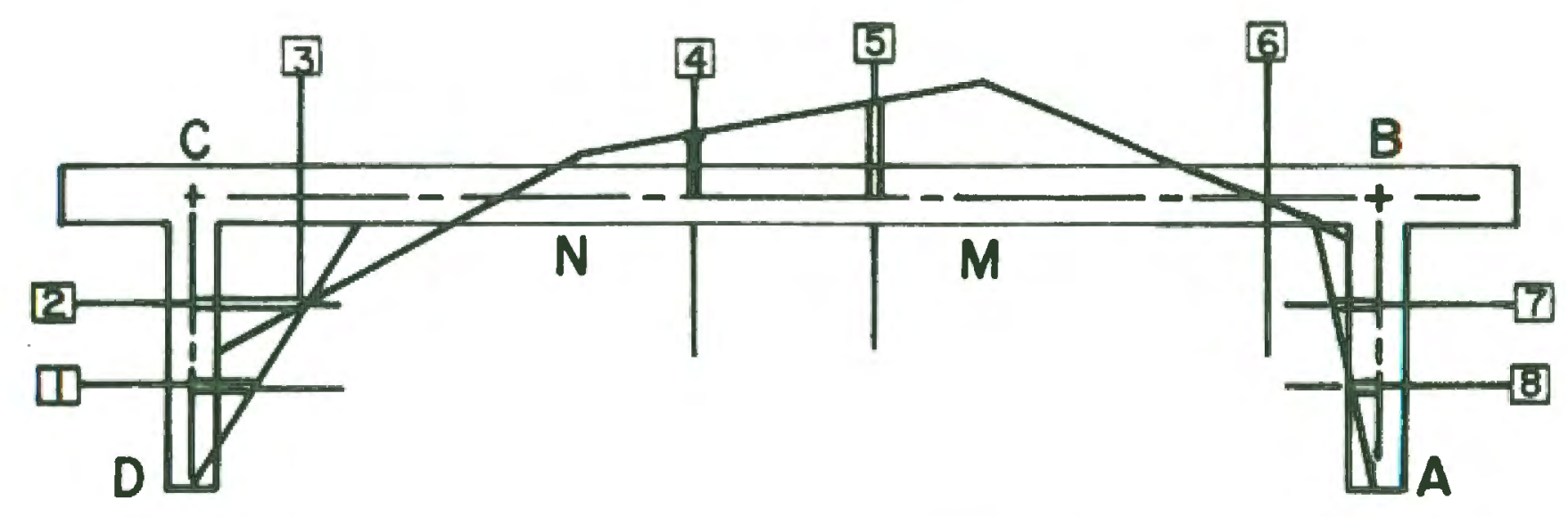

FIG.5.2 FRAME MOMENTS

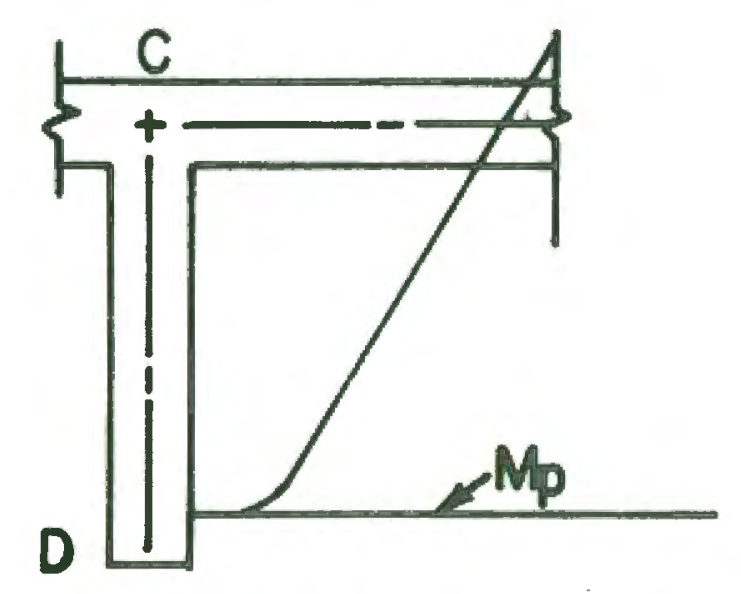

FIG.5.3 SPREAD OF HINGING AT CORNER C 
a) Column Thrust vs. Indicated Moment. These graphs show the column thrust vs. the column indicated moment at the beam soffit level. The critical sections are shown in Figure 5.1. These curves show the actual eccentricity ratio for the critical sections under gravity loading. The theoretical eccentricity ratio $\mathrm{e} / \mathrm{h}$ at the critical section is based on an elastic moment distribution. The stiffness factors used in the moment distribution are based on center-to-center lengths and gross cross-sections (excluding all stee1). Also shown on these figures are the partial column interaction diagram and the beam negative moment capacity at corner $C$.

b) Lateral Load vs. Moment. These graphs show the load vs. indicated moment for the six critical sections listed in Figure 5.1. These curves determine the collapse mechanism for the frames and are used to predict the amount of moment redistribution.

As previously defined, the index of moment redistribution is based on the amount of lateral load needed to cause the frame to fail after the first hinge forms. Mathematically, the expression is $\mathrm{H}_{2} / \mathrm{H}_{\mathrm{ULT}}$; where $\mathrm{H}_{2}=\mathrm{H}_{\mathrm{ULT}}-\mathrm{H}_{1}$ and $\mathrm{H}_{1}$ is the lateral load at first hinge formation. Approximate values for $\mathrm{H}_{1}$ can be determined from the beam and column moments at corner $C$. Because of the racked beam assumption of the data reduction program FRAGO, the column moments were considered more accurate. Therefore, $\mathrm{H}_{1}$ was determined when the column moment at the beam soffit level reached the $M_{P}$ capacity of the beam at corner $C$.

The lateral load $\mathrm{H}_{1}$, may also be called the lateral load at first yield because the yield moment $M_{y}$ for the beam at corner $C$ is about $98 \%$ of the ultimate moment $M_{p}$. The moment-curvature diagrams for the beam 
at corner $C$ are shown in Figures 3.6 ant 3.22 for Frames USD-1 and $L D-1$, respectively.

The moments in the beam and column at each corner should theoretically be equal, however some differences were observed. These differences can be attributed to three causes: (1) the cracked beam assumption of program FRAGO, (2) differences in the column and beam shear forces at the joint block, and (3) accidental eccentricity of the column loads caused by either strand misalignment or non-induced eccentricities caused by variation in the column concrete strength.

c) Lateral Load vs. Deflection. These curves show the nonlinearity in the frame under lateral loads. They help determine the level of lateral load that causes the first hinge to form $\left(\mathrm{H}_{1}\right)$. Also, they give some idea about serviceability.

The ductility index of the frames in the lateral direction may be defined as the ratio of lateral deflection at ultimate load to lateral deflection at first yield. The equation $D_{L}=\Delta_{u} / \Delta_{y}$; where $D_{L}$ is the lateral ductility index, $\Delta_{u}$ is the lateral deflection at ultimate and $\Delta_{y}$ is the lateral deflection at first yield. These values are calculated for Frames USD-1 and LD-1 and are used to compare the ductilities of the frames. Since $\mathrm{H}_{1}$ is based on the load that causes hinging rather than ylelding, the ductility indices are slightly underestimated.

d) Load vs. Corner Rotations. These graphs are used simflarly with the lateral load deflection graph to show non-1inearity in the frames. They also show the rotation under gravity loads. The ductility of the frames at the two corners (A and D) may be defined in terms of rotation. The expression is $D_{\theta}=\theta_{u} / \theta_{y}$; where $D_{\theta}$ is the rotation ductility index, 
$\theta_{u}$ is the rotation at ultimate and $\theta_{y}$ is the rotation at first yleld. As explained in the previous section, the ductility indices are slightly underestimated.

\section{e) Components of the Moment in the Leeward Column. The moment}

in the leeward column critical section $M_{c}$, before the first hinge forms, is due to three sources: (1) due to beam loads, Q, (2) due to lateral load H, and (3) due to sway deflection. Mathematically, the total moment $M_{c}$ is

$$
M_{c}=M_{Q}+M_{H}+M_{P-\Delta}
$$

where $M_{Q}$ is the gravity moment, $M_{H}$ is the lateral load moment, and $\mathrm{M}_{\mathrm{P}-\Delta}$ is the P- $\Delta$ moment. All these moments act clockwise on the member. Since the column thrust $(P+Q)$ and lateral deflections are measured values, the $\mathrm{P}-\Delta$ moment can be determined at any load increment. The lateral load elastic moment is $\mathrm{M}_{\mathrm{H}}=\mathrm{HL}_{\mathrm{c}} / 4$. From data reduction, $\mathrm{M}_{\mathrm{C}}$ is a known value. Therefore, the gravity moment can be found by rearranging equation (5.1):

$$
M_{Q}=M_{c}-\left(M_{H}+M_{P-\Delta}\right)
$$

After the first hinge forms the total moment $M_{c}$ becomes $M_{P}$ while the lateral load moment remains at $\mathrm{M}_{\mathrm{H}}=\mathrm{H}_{1} \mathrm{~L}_{\mathrm{c}} / 4$. The $\mathrm{P}-\Delta$ moment increases by $(P+Q) \Delta_{2}$ where $\Delta_{2}$ is the added deflection after first hinge. This added $P-\Delta$ moment must be balanced by a column shear so as to keep the column moment $M_{P}$ constant. Thus, this shear force, which is $2(P+Q) \Delta_{2} / I_{c}$ as glven in Section 2.4 .1 , causes an additional moment component in a counterclockwise direction. Therefore, equation (5.1) is changed to Include the added moment $M^{\prime}$ : 


$$
M_{C}=M_{Q}+M_{H}+M_{P-\Delta}-M^{\prime}
$$

or

$$
M_{Q}=M_{C}-\left(M_{H}+M_{P-\Delta}\right)+M^{\prime}
$$

The above equations are applied after the first hinge forms. Finally, the components of the moments in the leeward column are drawn for each lateral load increment.

f) Lateral Load vs. Moment Magnification Factor. From the previous graph the magnification factor may be defined as the ratio of total moment to primary moment. Mathematically, this factor is $\delta=M_{c} /\left(M_{c}-M_{P-\Delta}\right)$; where $M_{c}$ is the total moment determined from data reduction and $M_{P}-\Delta$ is the P- $\Delta$ moment. Two values of interest are the magnification factors at first hinge $\left(\delta_{y}\right)$ and at ultimate load $\delta_{u}$.

\section{1 .4 Data Reduction Check}

The indicated moments at the column critical sections were checked against the statics of the frame. Figure 5.4 shows the deformed shape of the frame under the effects of gravity and lateral loads. This figure shows the indicated moments at corners $B$ and $C$ of the columns $\left(M_{B}\right.$ and $\left.M_{C}\right)$, the measured column thrust $(P+Q)$, measured sway deflection $\Delta$ and a measured lateral load $\mathrm{H}$.

The equilibrlum equations for both columns, where counterclockwise moments are positive, are shown below:

$$
\begin{aligned}
& +M_{B}+(P+Q) \times \Delta+V_{L} \times 19^{\prime \prime}=0 \text { (windward column) } \\
& +M_{C}+(P+Q) \times \Delta+V_{W} \times 19^{\prime \prime}=0 \text { (leeward column) }
\end{aligned}
$$



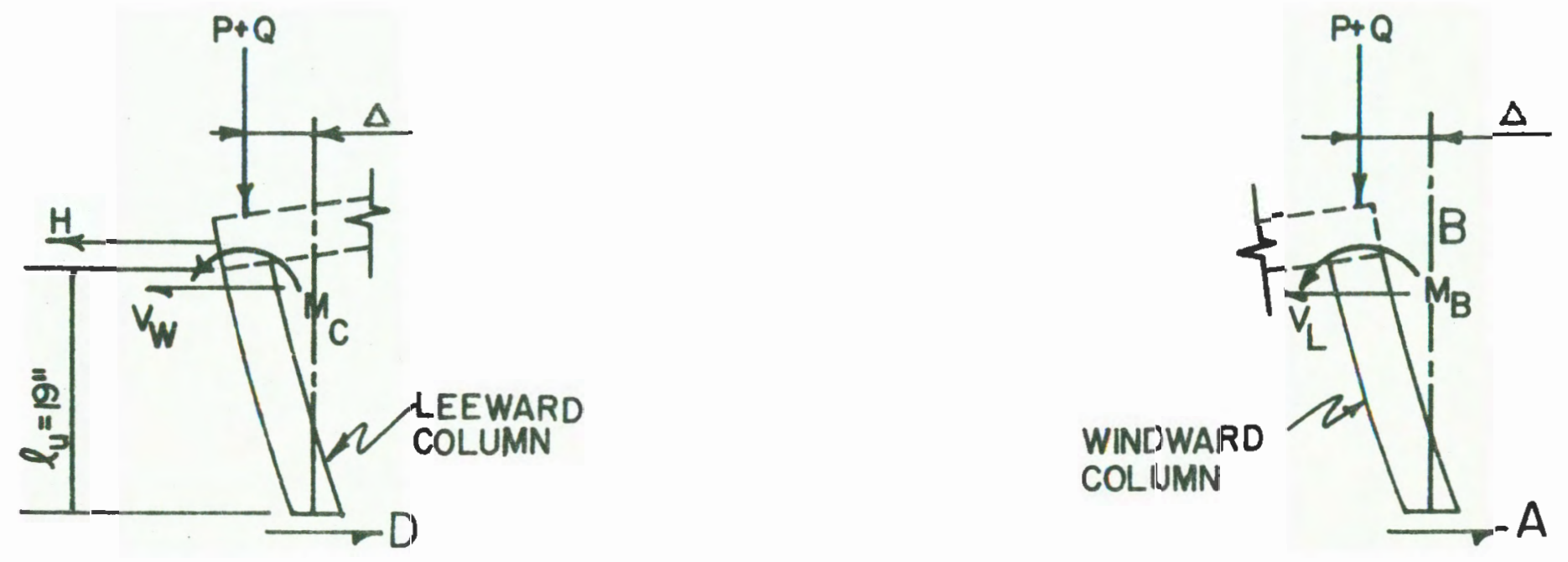

FIG.5.4 STATICS OF THE FRAME 
Adding the above equations:

$$
\begin{aligned}
& \left(V_{L}+V_{W}\right) \times 19^{\prime \prime}+2(P+Q) \times \Delta+\Sigma M(2 \text { corners })=0 \\
& \text { Since }\left(V_{L}+V_{W}\right)=H \\
& 19 \times H+2(P+Q) \Delta+\Sigma M(2 \text { corners })=0
\end{aligned}
$$

Because of inherent physical measurement errors, as well as computer modeling errors in FRAGO, the indicated moments do not satisfy the statics check completely, 1.e., the above equations, in general, do not equal zero. This deviation from statics may be termed $\Delta M$; where

$$
\Delta M=19 \times H+2(P+Q) \Delta+\sum M(2 \text { corners })
$$

If $\Delta \mathrm{M}$ is positive, the indicated moments are lower than the actually induced moments. Equation 5.9 was applied to the test frames for each load level. The largest $\Delta M$ and average $\Delta M$ for all the load levels will be reported for the frames.

\subsection{FRAME USD-1}

\subsubsection{Frame Description}

Frame USD-1, des1gned by the U1timate Strength method, represented the bottom panel of a five story building where the Q/P ratio is .125 . The design details of the frame are described in Chapter III while the "as built" properties showing the concrete strengths, reinforcement yield strengths and dimensions are given in Tables 4.2 and 4.3 of Chapter IV.

The columns, consisting of 3-3/4-in. thick by 6-in. wide cross sections, were reinforced with four \#3 reinforcing bars and tied together with \#12 gage ties at 3-3/4-in. spacing. The first tie was placed 
$17 / 8-1$. from the soffit of the beam. The 4 by 6 in. beams were reInforced with $\# 3$ bars which were tailored according to the moment envelope diagram. Closed stirrups made from 12 gage wire were used for shear reinforcement in the beam, except in the middle third, at a spacing of $\mathrm{s}=1.56-1 \mathrm{n}$. The first stirrup was placed $\mathrm{s} / 2$ from the column face.

The frame was tested on the sixth day after concrete casting. The column and beam concrete strengths were 4421 and 4126 psi respectively. The critical sections and their bending capacities are given in Figure 5.1. The frame was designed so that the hinge would form at corner $C$ in the beam.

The beam and column loads were measured with pressure transducers. However, the lateral load was measured with the pressure transducer only because the load cell was not available. Nevertheless, the lateral load measurements were revised after Frame LD-1 was tested for which both pressure transducers and a load cell were used. During the testing of Frame LD-1 it was observed that the pressure transducer and load ce11 measurements differed by about 9 percent. Since the load cell was more accurate, the measured lateral loads for Frame USD-1 were revised according to the relationship between the pressure transducer and load cell.

\section{2 .2 Results}

a) Column Thrust vs. Indicated Moment. The column thrust vs. indicated moments for the column critlcal sections are shown in Figure 5.5. The columns had a clear height-thickness ratio $1_{u} / \mathrm{h}=10.1$, nominal $\psi=2$, and $F_{C}^{\prime}=4421$ psi. The beam and column loads were increased to 
1.93 kips and 15.66 kips which caused a maximum column thrust of 17.59 kips. At this load, the indicated moment in the leeward column increased to 28 in-k. When the lateral load was applied the leeward column moment increased to a maximum moment of 50 in-k which is the negative bending moment capacity of the beam at corner $\mathrm{C}$.

The flexural cracks in the beam, which were first noted during testing at a column load $(\mathrm{P})$ of $10 \mathrm{k}$, cause more gravity moment to be transferred to the stiffer members (uncracked columns). The P-M relationship (Figure 5.5) shows this increasing column gravity moment at a column thrust of about $10 \mathrm{k}$.

The theoretical moment at the intersection of the member centerlines is given by the relationship $M=F Q L_{b}=(.18)(1.93)(84)=29.2$ in-k. This gives a moment of $(19 / 21)(29.2)=26.4$ in $-\mathrm{k}$ at the beam soffit level which compares favorably with the indicated moment of 28 in-k. The theoretical e/h ratio is obtained from the relationship e/h $=M /(P+Q) h=$ $(26.4) /(17.59)(3.75)=.40$. This is shown on Figure 5.5 as a dashed Iine.

b) Lateral Load vs. Moment. Figure 5.6 shows the lateral load vs. moment for the critical sections 1isted in Figure 5.1. As shown in this figure the first hinge formed in the beam at corner $\mathrm{C}$ at about $\mathrm{H}=2000 \mathrm{1b}$. As further load was applied this section maintained its hinging moment $\left(M_{P}=50\right.$ in-k) while other critical sections were reaching their bending capacities. It appears From Figure 5.6 that the moment capacity at critical section $M\left(M_{P}=36\right.$ in-k) was close to its capacity at an ultimate lateral load of $22701 \mathrm{~b}$. Also, the bending moment at critical section M' (positive moment cutoff point) was close 
to 1 ts section capacity of $M_{P}=18$ in-k. The moment at critical section $M^{\prime}$ underwent reversed curvature at about $H=6001 \mathrm{~b}$.

As shown in Figure 5.6 , the moments at critical sections $M$ and $M^{\prime}$ (shown by $O$ and $\square$ ) remained at 33 in-k and 12 in-k for the last few load increments. Since the moments at $M$ and $M^{\prime}$ are 3 in-k and 6 in-k from their bending capacities, some internal stress redistribution must be occurring in the region between $M$ and $M^{\prime}$. This is probably caused by creep which prevents these critical sections from reaching $M_{P}$. However, the less-stressed joint at B, which is less subject to creep, shows Increasing corner moments for the last few load increments.

After the second hinge formed at $M$ the frame became unstable. The index of moment redistribution for this frame is $\mathrm{H}_{2} / \mathrm{H}=270 / 2270=$ $12 \%$.

The moments at corner $B$ in the beam and column differed by about 7 in-k after the full gravity loads were applied. As stated in section $5.1 .3 \mathrm{~b}$, this is caused by either accidental eccentricity in the column loads or the cracked beam assumption of program FRAGO.

The error analysis for this frame, as discussed in section 5.1.4, shows that the average moment needed to satisfy equilibrium $(\Delta M)$ for all the load increments 1 s about $+4 \mathrm{in}-\mathrm{k}$. The largest value, which is at the ultimate load, is about $\Delta M=+10$ in $-k$. The positive sign means that the indicated moments are less than the actually induced moments. c) Lateral Load vs. Deflection. The lateral load vs. deflection graph is shown in Figure 5.7. Under full gravity loads, the frame deflected .008-in, opposite to the direction of applied lateral load. With application of lateral load the response was nearly linear 
up to a lateral load of about 2000 lb. Beyond $H=20001 \mathrm{~b}$, which is the hinging load $\mathrm{H}_{1}$, the slope of the curve became flatter as the frame reached an ultimate lateral load of $22701 \mathrm{~b}$.

The deflections at service and factored lateral loads are .094 in. and .146 in. As shown in Flgure 5.7, the frame stiffnesses at both load levels are nearly the same.

The ductility index for this frame is $D_{L}=\Delta_{u} / \Delta_{y}=.446 / .29=1.5$. d) Load vs. Corner Rotations. The load vs. corner rotations for $A$ and $D$ are shown in Figure 5.8. Under gravity loads the rotations at $A$ and $D$ turned in an opposite direction to the predicted sense. This is probably caused by imperfections in the frame geometry and by eccentrically applied column loads. During the pretest procedure, the columns slipped off the knife-edge of the reaction stub as the beam was loaded. Measurements of the frame geometry revealed that the centerline-to-centerline dimensions of 84-in. at the top and bottom had changed to $83-7 / 8-1 \mathrm{n}$ and $84-1 / 8-1 \mathrm{n}$. respectively. This caused slightly Inclined columns with a joint angle at $C$ af about $90.3^{\circ}$. This angle may be large enough to help cause the column ends at $A$ and $D$ to turn opposite to the predicted sense.

With lateral loads the column ends turned in the right direction and at $\mathrm{H}=2000 \mathrm{1b}$. the curve slopes became flatter. The ductility indices at $A$ and $A$ are $D_{\theta A}=\theta_{u} / \theta_{y}=.022 / .016=1.4$ and $D_{\theta D}=.022 / .014=$ 1.6 .

e) Components of the Moments in the Leeward Column. The components of the moment graph are shown in Figure 5.9. The P- $\Delta$ moment when the first hinge formed $(H=2000 \mathrm{lb})$ is $5.3 \mathrm{in}-\mathrm{k}$. The $\mathrm{P}-\Delta$ moment for the 
entire frame at the ultimate lateral load $(H=2270-1 b)$ is 7.9 in-k.

As shown in Figure 6.9 , the gravity moment, ${ }_{Q}{ }_{Q}$, is nearly the same during lateral loading.

f) Latera1 Joad vs. Moment Magnification Factor. Figure 5.10 shows the lateral load vs. moment magnification factor graph. Corresponding to the $\mathrm{P}-\Delta$ moments from above, the moment magnification factor at first hinge is $\delta_{y}=M_{c} /\left(M_{c}-M_{P-\Delta}\right)=50 /(50-5.3)=1.12$. The magnification factor for the frame at ultimate is $\delta_{\mathrm{u}}=50 / 50-7.9=1.19$.

\subsubsection{Test History, Sequence of Cracking, and Hinge Formation}

The testing procedure differed slightly from the procedure given in section 4.4 .2 of Chapter IV. The main difference was that the column loading strands were not aligned with a transit. The revised alignment procedure is explained in the following paragraph.

A pencil line was extended from the centerline of the leeward column on to the stationary reaction beam. Next, a plumb-bob was used to center the loading strand over the leeward column centerline. Then, the windward column loading strand was placed $83-7 / 8-i n$. (top dimension of Frame USD-1) from the leeward column loading strand. This dimension was checked at the ram and bearing head locations. Fina1ly, the alignment was checked by loading the columns with a $2.5 \mathrm{kips}$ load to see if any lateral deflection occurred. The alignment was good and the test proceeded in the usual way.

No problems were met during the test. A column load of 10 kips and beam load of 1.25 kips caused hairline cracks in the negative moment region of the beam at corner $\mathrm{C}$ and in the positive moment region between $\mathrm{M}$ and $\mathrm{N}$. However, the columns remained uncracked, 
After the full gravity loads were applied the frame deflected .008 in. to the right. Th1s causes a negligible $P-\Delta$ moment equal to $(17.59)(.008)=.14 \mathrm{in}-\mathrm{k}$. Therefore, the imperfection angles for the frame geometry and the loading system, as discussed in section 4.4.3, are within good accuracy.

The lateral loads were first applied in 200-1b. increments. When the frame behaved nonlinearly, as detected by the lateral-1oad deflection curve plotted as testing progressed, the increments were reduced to $100-1 b$.

At about $\mathrm{H}=2000 \mathrm{lb}$ the flexural cracks in the beam at corner $\mathrm{C}$ and between $M$ and $N$ widened and the slope of the lateral-load deflection curve became flatter. Near the ultimate load the curvature-meter dials deflected continuously, however all the dial gages were read at the ultimate load of $H=2270-1 b$. A descending point on the lateral-load deflection curve was measured as the frame underwent mechantsm motion. With full beam and column loads on, the lateral load was reduced to zero which resulted in a frame lateral deflection of 1.047-1n. The frame deflection and crack widths reduced somewhat when the gravity loads were removed. Frame USD-1 was not reloaded with lateral loading as discussed in section $4.4 .2 b$.

The overall crack pattern is shown in Figure 5.11. The cracking pattern for the first hinge w11l be described first followed by the description of the second hinge.

Figure 5.12 is a photograph of the hinge at corner $C$. This photograph reveals that the major flexural cracks occur in the vicinity of about four inches (approximately equal to $4 / 3 \mathrm{~d}$ ) from the support 
face. $\Lambda$ the negative moment cutoff point, as may be seen near the right in Figure 5.12, a flexural crack formed at about $H=1600$ lb. This flexural crack moved vertically about 2 -in. toward the compression fiber. Near the half-depth of the beam, this crack inclined about $45^{\circ}$ and finally progressed to within 1-in. of the compression fiber. A photograph of the compression face at corner $C$ is shown in Figure 5.13. This figure shows that concrete spalling extended about 2 -in from the support face.

The positive moment region, between points $M$ and $N$, is shown in Figure 5.14. From the analysis of the data, the second hinge formed at M. This is shown clearly in Figure 5.15, which shows that the major flexural crack extended nearly to the compression face. The flexural crack at $M^{\prime}$ (positive moment cutoff point), as shown in Figure 5.16, is similar to the crack at the negative moment cutof point. Figure 5.16 also reveals that the beam at corner $B$ remained free of cracks. 


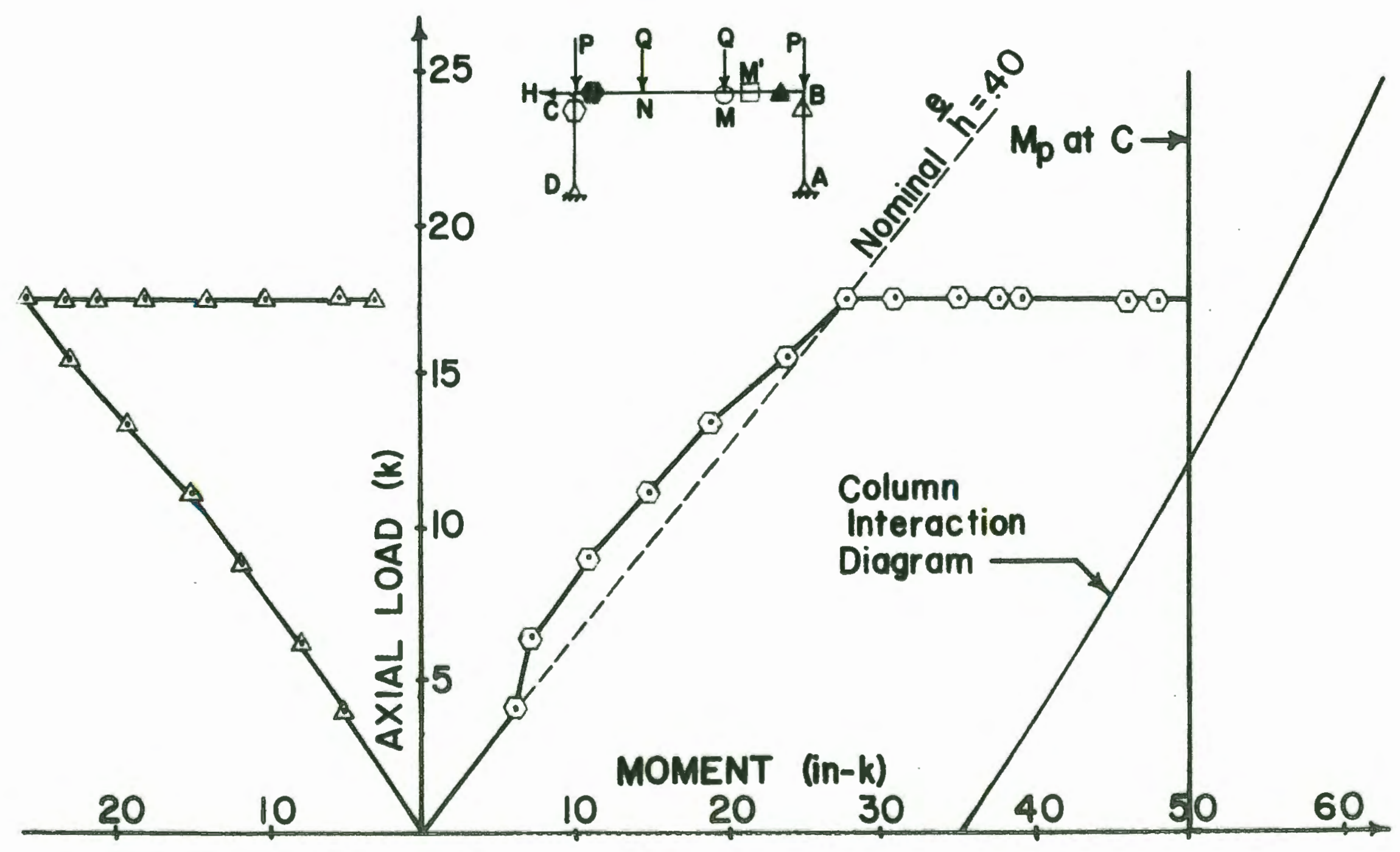

FIG.5.5 AXIAL LOAD vs. MOMENT, FRAME USD-I 


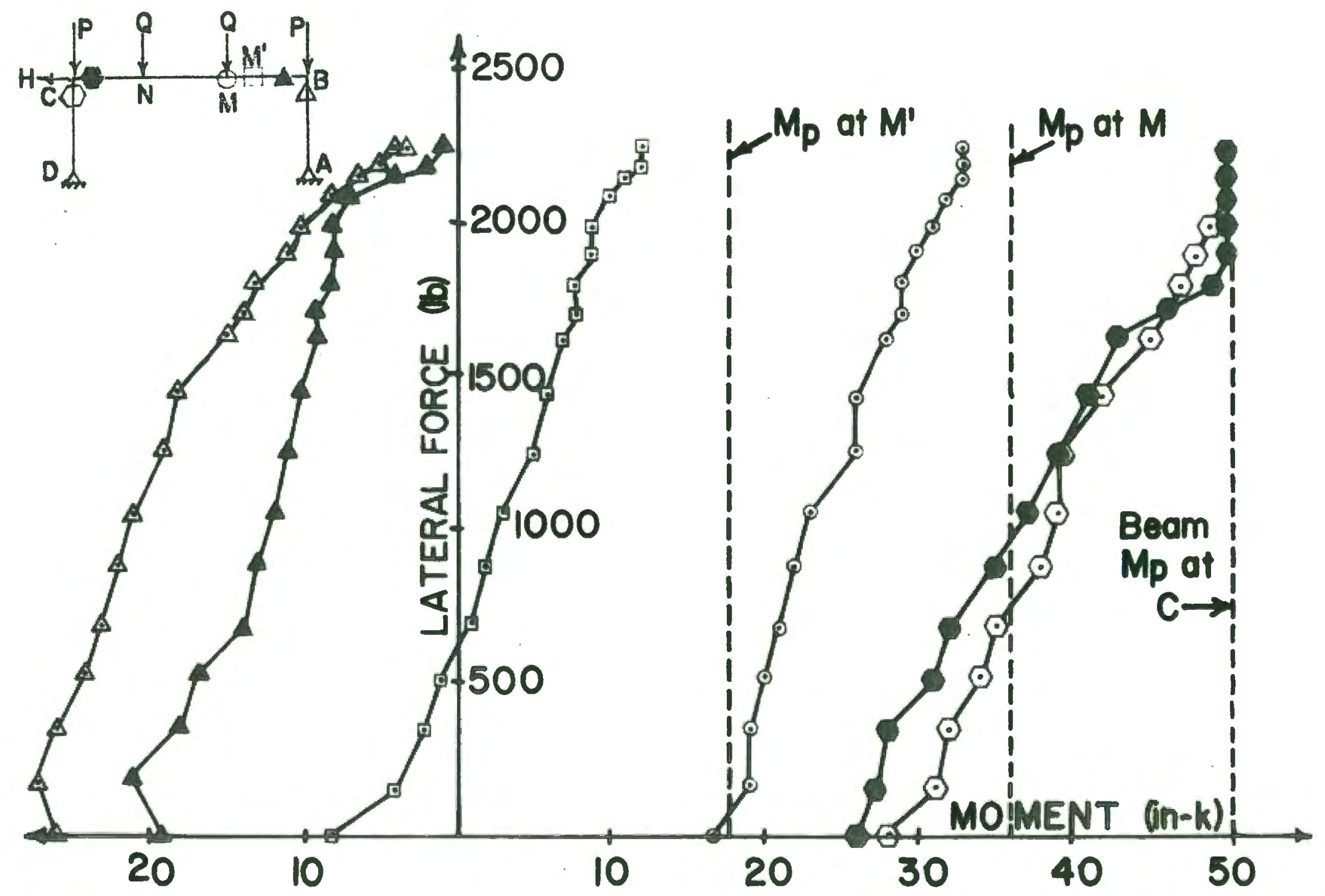

FIG.5.6 LATERAL FORCE vs. MOMENT, FRAME USD-I 


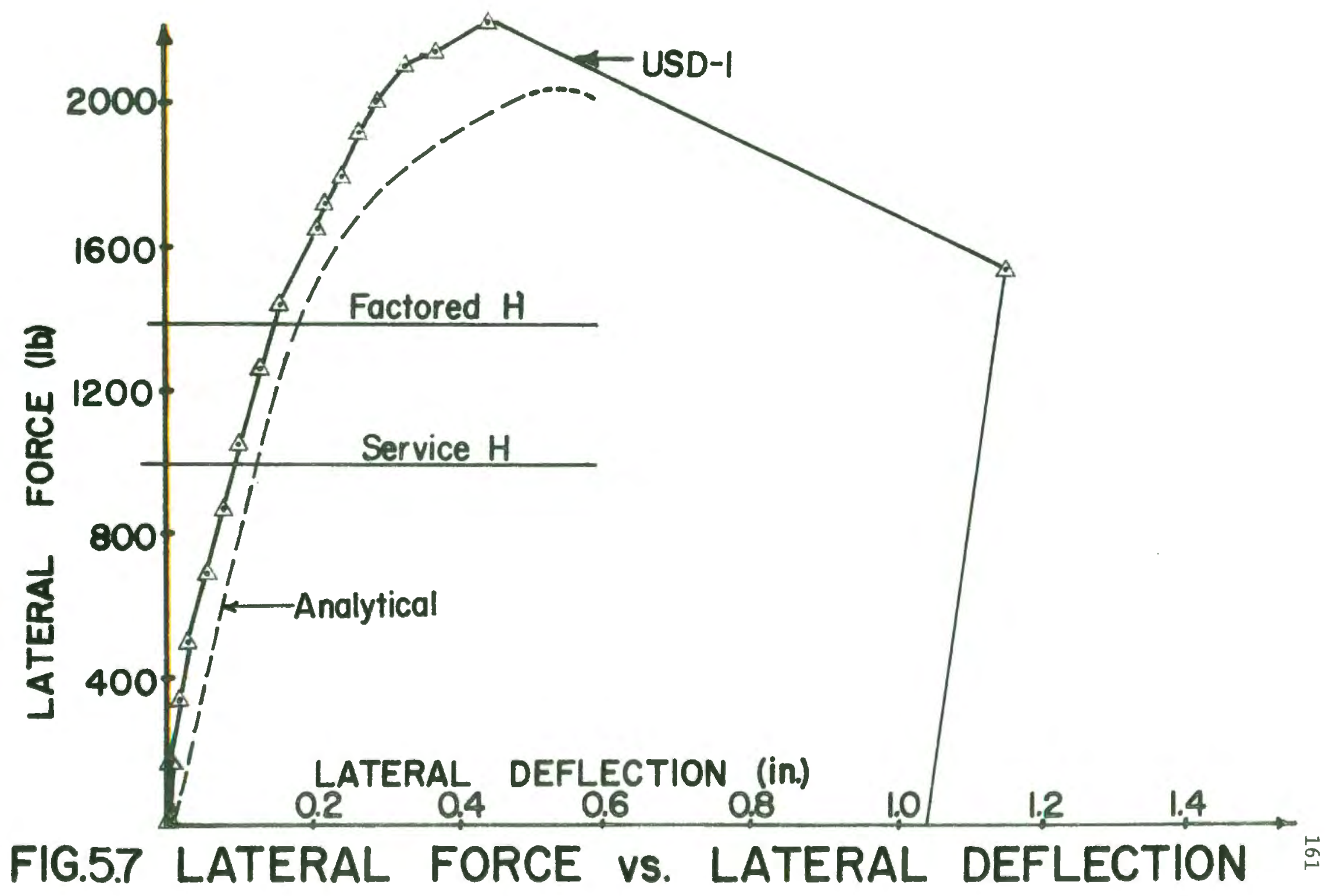




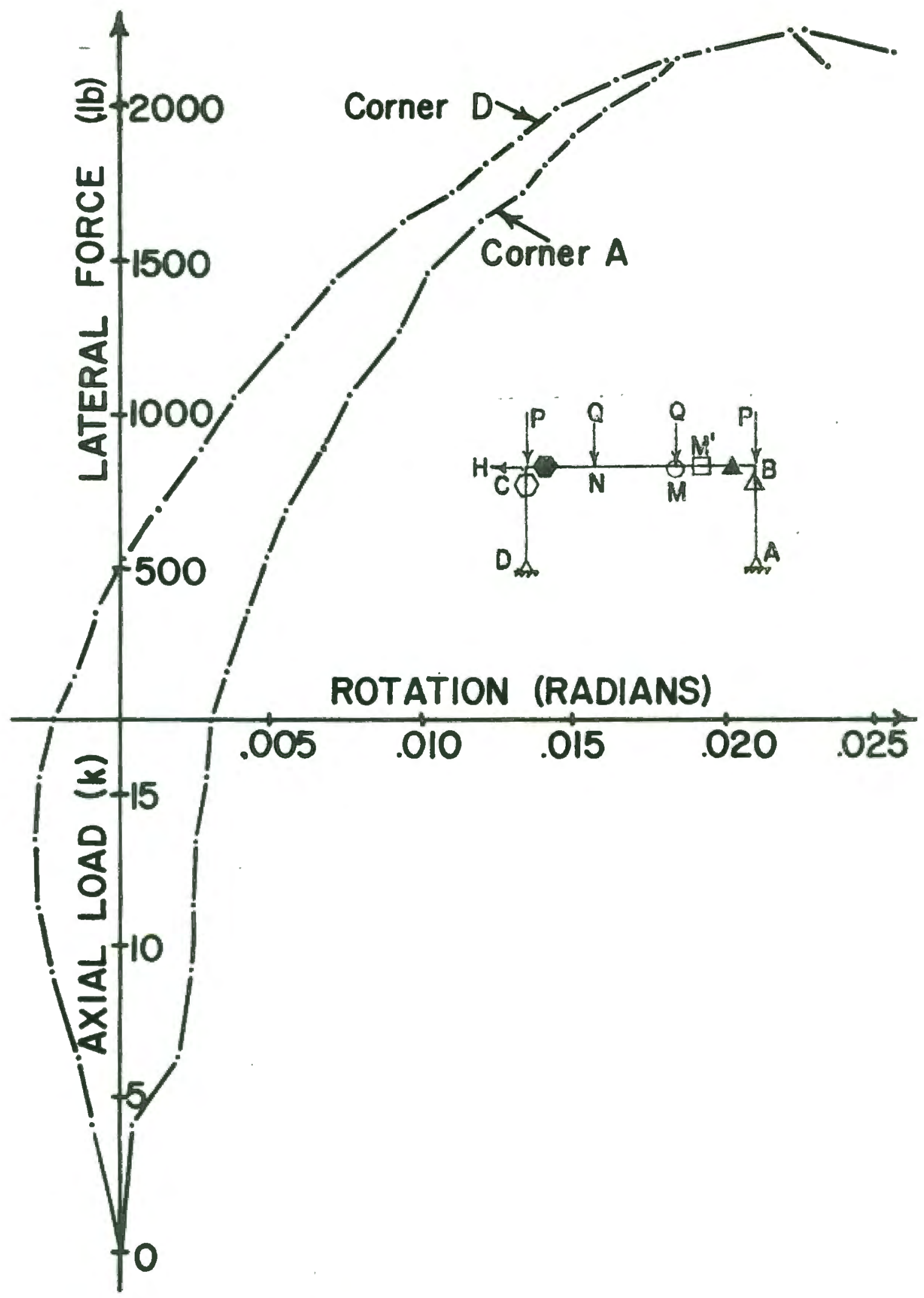

FIG.5.8 CORNER ROTATIONS, USD-I 


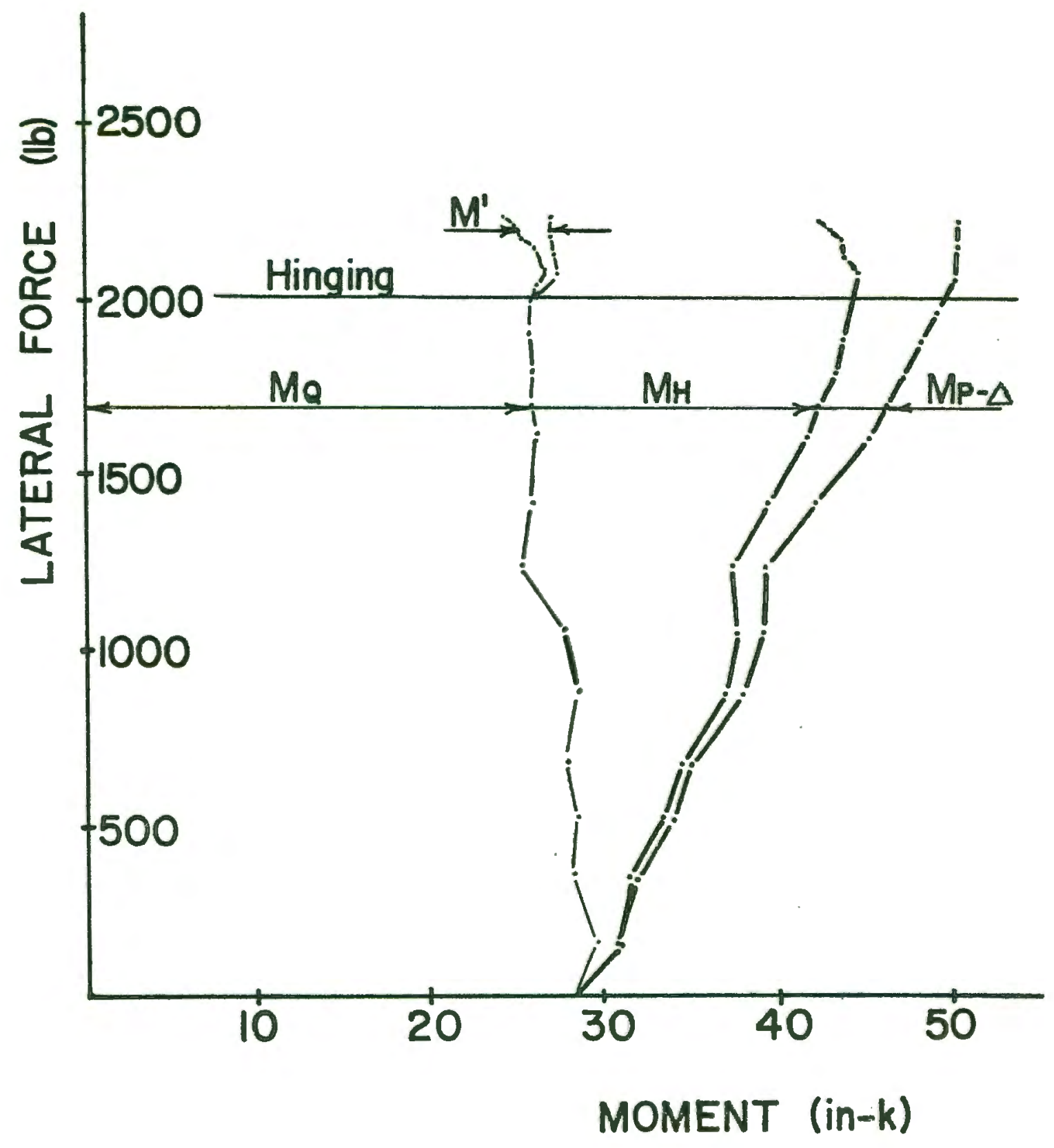

FIG.5.9 COMPONENTS OF MOMENT IN LEEWARD COLUMN, USD-I 


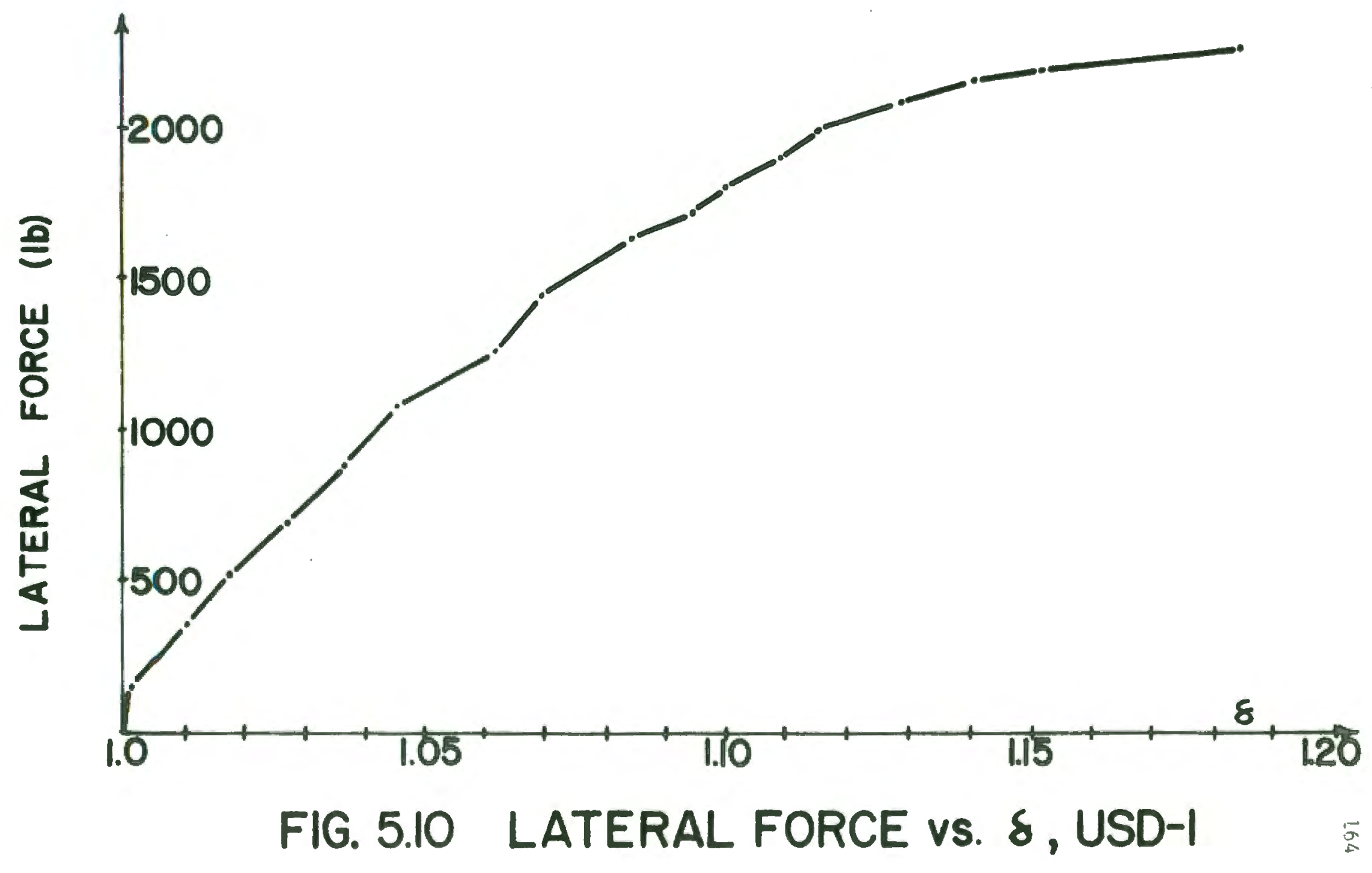




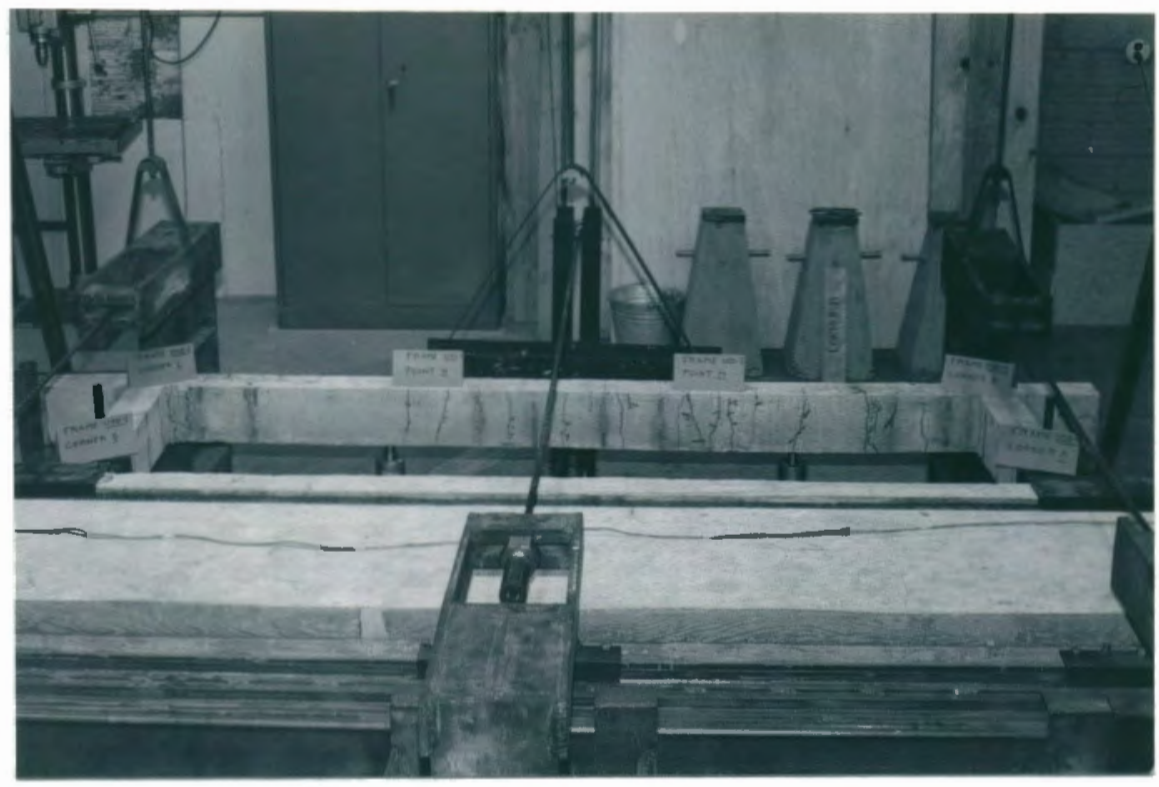

F1g. 5.11. Overall view of frame USD-1 after failure

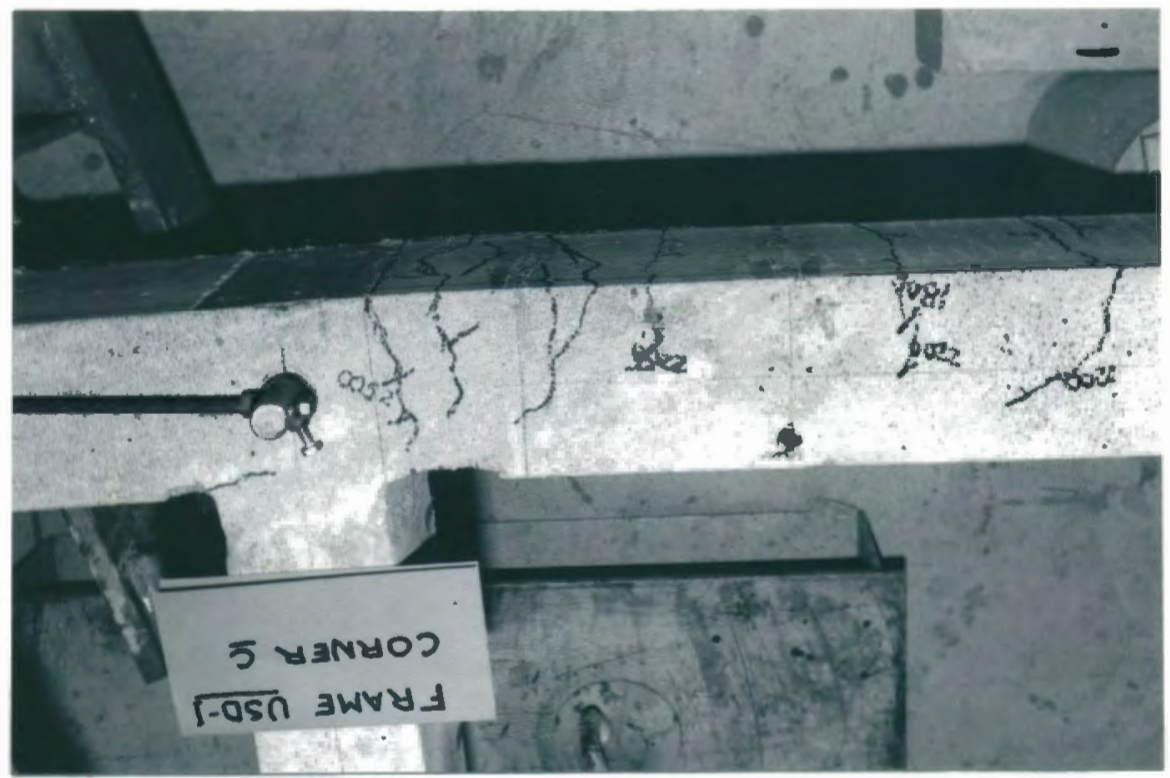

Fig. 5.12. Plastic hinge at corner $\mathrm{C}$ 


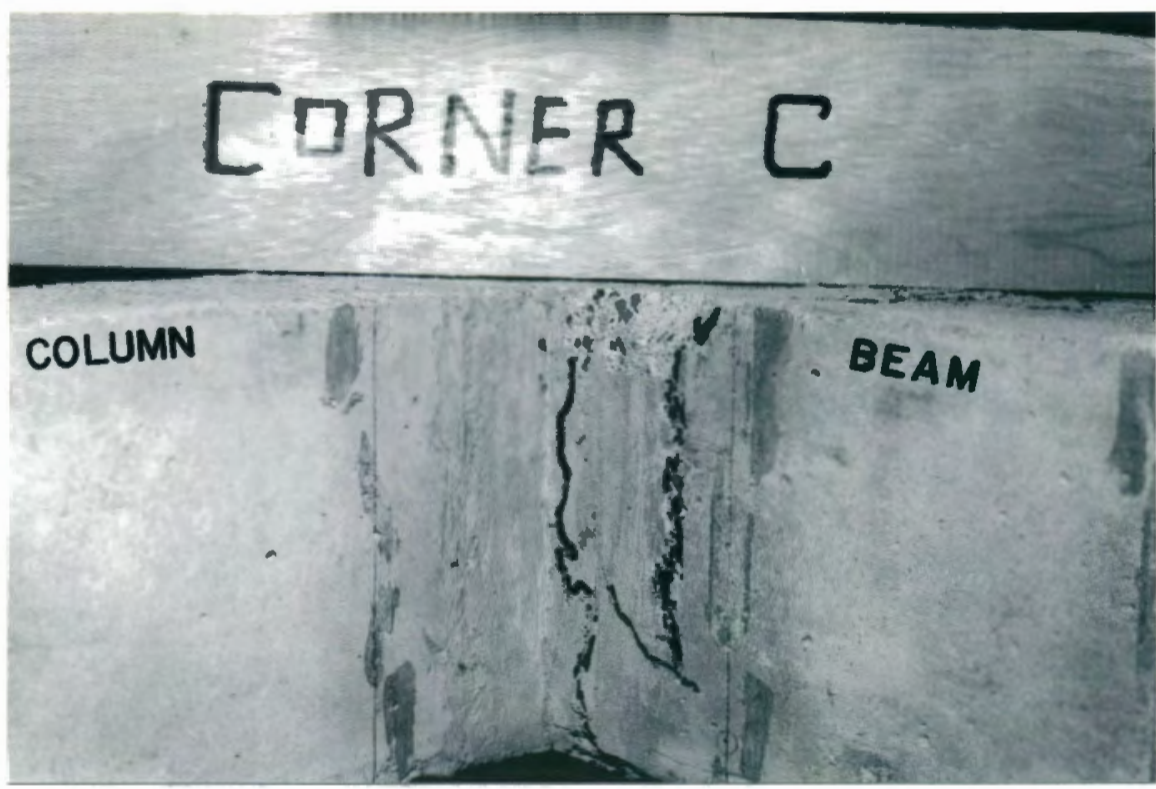

Fig. 5.13. Concrete spalling at corner C

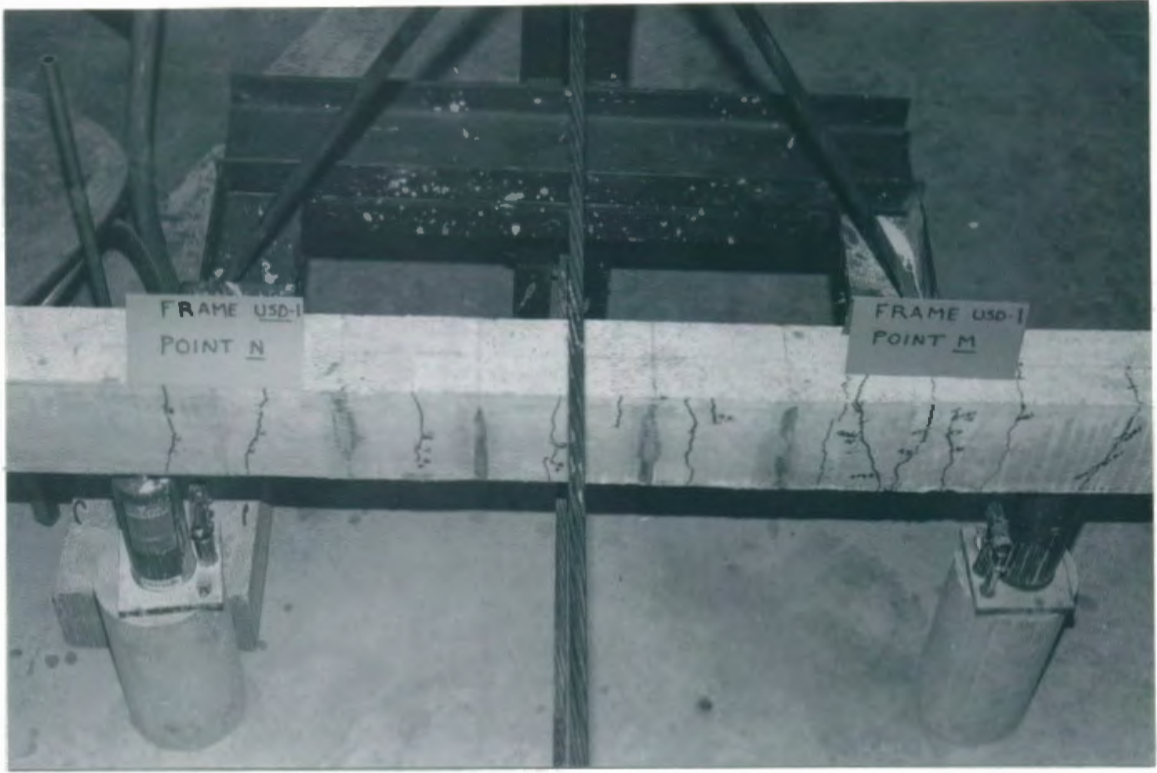

Fig. 5.14. Flexural cracks in the middle third of the beam 


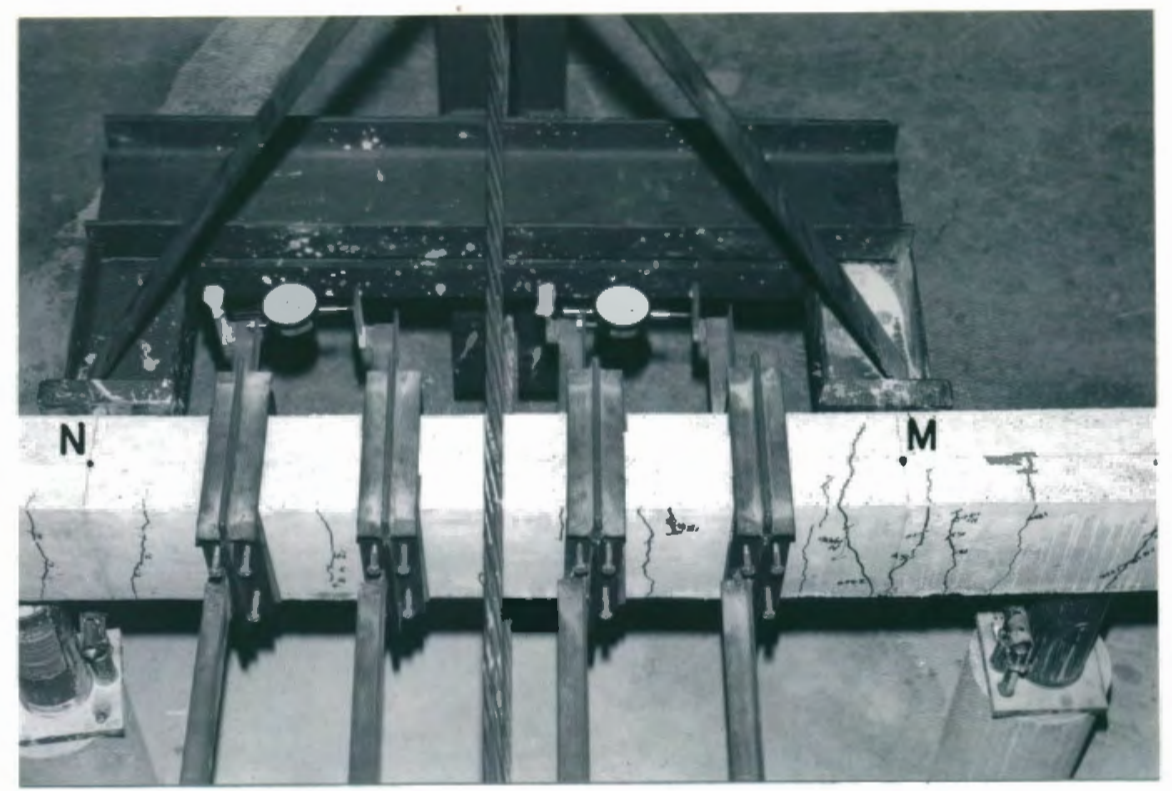

Fig. 5.15. Flexural crack at $M$

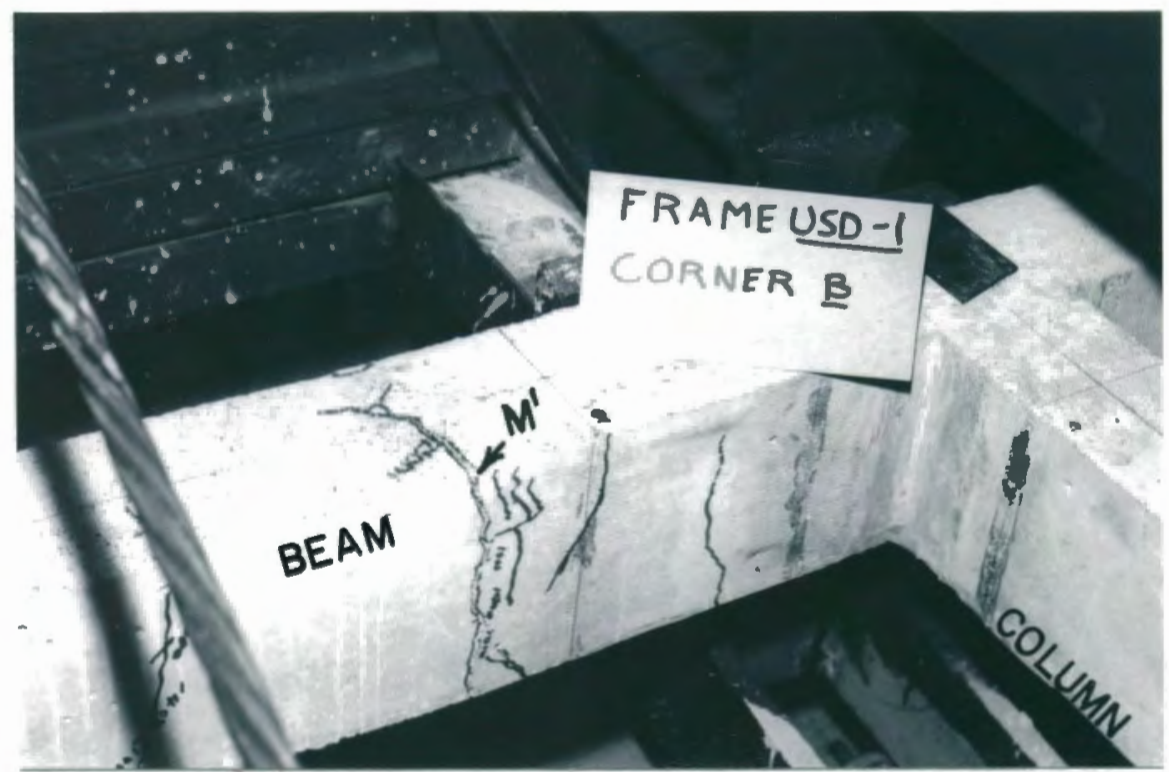

Fig. 5.16. Flexural-shear crack at $\mathrm{M}^{\prime}$ (positive moment cutoff point) 


\subsection{FRAME LD-1}

\subsubsection{Frame Description}

Frame LD-1, designed by a Limit Design method, represented the bottom panel of a five story bullding where the Q/P ratio is .125 . The design details of the frame are described in Chapter III while the "as built" properties showing the concrete strengths, reinforcement yleld strengths and dimensions are given in Tables 4.2 and 4.3 of Chapter IV.

The columns, consisting of $3-1 / 2-1$ n thick by $6-1$. wide cross sections, were reinforced with four \#3 reinforcing bars and tied together with \#12 gage wire ties at 3-1/2-in. spacing. The first tie was placed 1-3/4-in from the soffit of the beam. The $4 \times 6$ in. beams were reinforced with \#3 reinforcing bars which were tallored according to the moment envelope diagram. Closed stirrups made from \#12 gage wire were used in the beam, except in the middle third, at a spacing of $s=1.58-i n$. The first stirrup was placed $s / 2$ from the face of the support.

The frame was tested on the seventh day after concrete casting. The column and beam concrete strengths were 5414 and 4444 psi. The critical sections and their bending capacities are given in Figure 5.1.

\section{3 .2 Results}

a) Column Thrust vs. Indicated Moment. The column thrust vs. indicated moments for the column critical sections are shown in Figure 5.17. The columns had a clear height-thickness ratio $1_{\mathrm{u}} / \mathrm{h}=10.9$, nominal $\psi=2$ and $\mathrm{f}_{\mathrm{c}}^{\prime}=5414 \mathrm{psi}$. The beam and column loads were Increased to 
$1.92 \mathrm{kips}$ and $15.39 \mathrm{kips}$ respectively which caused a maximum column thrust of $17.31 \mathrm{kips}$. At this load, the indicated moment in the leeward column increased to 26-in-k. When the lateral load was applied this moment increased to a maximum moment of 41 in-k which is the negative bending moment capacity of the beam at corner $\mathrm{C}$.

During the application of gravity loads the P-M relationship shows slightly increasing column moments which is caused by beam cracking. The theoretical elastic moment at the intersection of the member centerlines is given by the relationship $M=F L_{b}=(.18)(1.92)(84)=$ 29.0 in-k. This gives a moment of $(19 / 21)(29.0)=26.2$ in-k at the beam soffit level which compares favorably with the column indicated moments at corners $B$ and $C$ of 25 and $26-i n-k$. This gives a theoretical $e / h$ ratio of $\mathrm{M} /(P+Q) h=26.2 /(17.31)(3.5)=.43$.

b) Lateral Load vs. Moment. Figure 5.18 shows the lateral force vs. moment for the critical sections given in Figure 5.1. This curve shows that the beam capacity at corner $C\left(M_{P}=41\right.$ in-k) is reached at a lateral load of about $1500 \mathrm{lb}$. Up to this load the H-M relationship for each critical section is nearly linear. With further application of lateral load the bending capacity of critical section $M$ $\left(M_{P}=41-i n-k\right)$ was approached at an ultimate lateral load of $18201 \mathrm{~b}$. Also, the slope of $\mathrm{H}-\mathrm{M}$ curve for bending moment at critical section $\mathrm{M}^{\prime}$ (positive moment cutoff point) became flat at this load level. With two hinges in the beam at $C$ and $M$ the frame became unstable. Framle $L D-1$ had a moment redistribution index of $\mathrm{H}_{2} / \mathrm{H}_{\mathrm{ult}}=320 / 1820=18 \%$.

At the end of the gravity load application the differences between the beam and column moments at corners $B$ and $C$ were 11 in-k and 10 in-k. As discussed before, this is caused primarily by the cracked 
beam assumption of program FRAGO.

The error analysis for this frame, as discussed in Section 5.1.4, shows that the average moment needed to satisfy equilibrium $(\Delta M)$ for all the load increments is about $+3 i n-k$. The largest value, which is at the ultimate load, is about $+8 i n-k$. The positive sign means that the indicated moments are less than the actually induced moments.

c) Lateral Load vs. Deflection. The lateral load vs. deflection graph is shown in Figure 5.19. Because of either eccentricity of applied column loads or imperfections in the frame geometry, Frame LD-1 deflected .048-in. to the right after the full gravity loads were applied.

The $H-\triangle$ response is nearly linear up to a lateral load of about $1500 \mathrm{lb}$. At this load, the curve flattens out because of hinging in the beam at corner $C$. At a lateral load of $18201 \mathrm{~b}$. the frame became unstable as shown by the descending part of Figure 5.19. Frame LD-1 had a ductility index of $\mathrm{D}_{\mathrm{L}}=\Delta_{\mathrm{u}} / \Delta_{\mathrm{y}}=.608 / .205=3.0$

Under the reloading cycle (sequence 3) the Erame was able to withstand a lateral load of 1480-1b. This is about 81 percent of the original ultimate load. Also, as shown in Figure 5.19, the slopes of the two $H-\Delta$ curves (frame stiffuesses) are nearly the same.

The deflections at service and factored loads are .098 in. and .157 in. As shown in Figure 5.19, the rrame stiffness at the factored load is lower than the frame-stiffness at the service load.

d) Load vs. Corner Rotations. The corner rotations at A and D are shown in Figure 5.20. Under gravity loads the rotation at $D$ was in the anticipated direction while the rotation at A was nearly zero. With lateral load application the curves indicated nonlinearity 
at about a load of $1500 \mathrm{lb}$ (first hinge). The slope of the curves became flatter as the frame approached failure.

The rotation ductility indices at corners $A$ and $D$ are $D_{\theta A}=\theta_{u} / \theta_{y}=$ $.0206 / .0101=2.0$ and $D_{\theta D}=.0257 / .0137=1.9$.

e) Components of the Moments in the Leeward Column. The components of the moment graph are shown in Figure 5.21. The P- $\Delta$ moment when the first hinge formed $(H=15001 \mathrm{~b})$ was $3.5 \mathrm{ln}-\mathrm{k}$. Just before the second hinge formed $(H=1780 \mathrm{lb})$ the $\mathrm{P}-\Delta$ moment was $7.8 \mathrm{in}-\mathrm{k}$. The $\mathrm{P}-\Delta$ moment for the entire frame at the ultimate lateral load ( $H=18201 \mathrm{~b}$ ) was 10.5 in-k. As shown in Figure 5.21, the gravity moment $M_{Q}$ decreases slightly during lateral loading. This is probably caused by decreasing column stiffness as can be seen by the moment-curvature diagram of Figure 3.23.

f) Lateral Load vs. Moment Magnification Factor. F1gure 5.22 shows the lateral load vs. moment magnification factor. Corresponding to the P- $\Delta$ moments given above, the moment magnification factor at first hinge is $\delta_{y}=M_{c} /\left(M_{c}-M_{P-\Delta}\right)=41 /(41-3.5)=1.09$. Just before the second hinge forms $(H=1780 \mathrm{lb}) \delta$ is $41 /(41-7.8)=1.23$. The magnification factor at ultimate is $\delta_{\mathrm{u}}=41 /(41-10.5)=1.34$.

Because the frame deflected to the right under gravity loading, the magnification factor was less than 1.0 for lateral loads less than about $300 \mathrm{lb}$.

\subsubsection{Test History, Sequence of Cracking, and Hinge Formation}

The column loading strands were aligned with the transit. according to the procedure given in Chapter IV.

No speclal difficulties were encountered during the test. However, 
the frame deflected .048-in. to ghe right after the full gravity loads were applied. This indicated that either the geometry of the frame was slightly imperfect or that the column loads were applied with some initial eccentricity.

The angle of imperfection, $\alpha$, can be estimated from the idealized models of section 4.4.3. These models are shown in Figure 4.28 for the imperfection in Frame Geometry, and the imperfection in Loading. The lateral load needed to bring the structure back to zero lateral displacement, as shown in Figure 5.19, is about 300 1bs. Thus, the imperfection angle is $\tan ^{-1} \frac{\mathrm{H} / 2}{\mathrm{P}}=\tan ^{-1} \frac{.3 / 2}{15.67}=.5^{\circ}$

Hairline cracks in the beam at corner $\mathrm{C}$ and between $\mathrm{M}$ and $\mathrm{N}$ were first observed at a beam load of 1.50 kips. Some of these cracks, between $M$ and $N$, were inclined about $10-30^{\circ}$ to the vertical indicating that the beam loads had slight torsional eccentricities.

The lateral load was first applied in 200-1b increments to a nominal load of $1400 \mathrm{lb}$. At this load the flexural cracks in the beam at corner $C$ widened and extended vertically to the compression face. Lateral load increment was decreased to $100-1 \mathrm{~b}$ and the overall $\mathrm{H}-\Delta$ response became more nonlinear up to a maximum lateral load of $18201 \mathrm{~b}$. No curvature-meter deals were read at this load. The last curvaturemeter dial reading was at $H=1780 \mathrm{lb}$. Several descending points on the lateral deflection dial were recorded as the frame underwent a collapse mechanism. During the descending portion, a secondary compression failure was noted in the beam at corner $C$. Next, the lateral load was removed which caused the frame to recover some lateral deflection. The lateral deflection at this point was 1.00 in. Finally, the gravity loads were 
reduced to 75 percent of their or Iginal values and the frame was retested under lateral load.

Figures 5.23 and 5.24 show two overall views of the frame after failure. The crack pattern and the hinge formations for Frame LD-1 were similar to Frame USD-1. However, in general the cracks for Frame LD-1 were larger because of the reloading cycle. Reload cracks for Frame LD-1 were marked with an "R".

Figure 5.25 is a photograph of the plastic hinge at corner $C$. The major flexural cracks, as shown in Figure 5.25, occur in the vicinity of about 3 inches (approximately equal to d) from the support face. About 12 inches from the column face, a slightly inclined flexuralshear crack occurred at the negative moment cutoff point (Figure 5.26). In Figures 5.25 and 5.26, concrete spalling can be seen in the compression face of the beam at $C$ and at the negative moment cutoff point.

Figures 5.27 and 5.28 show the major cracks which developed while the frame was approaching a mechanism. The second plastic hinge was difficult to distinguish because it was the last hinge to form and therefore underwent less inelastic deformation than did the hinge at $C$. However, the data reduction for the first loading cycle showed that the second hinge formed at $M$ while the bending moment at $M^{\prime}$ was close to its capacity. It appears from Figure 5.28 that a hinge formed at $M^{\prime}$ as characterized by the large flexural-shear crack. However, this crack formed during the reloading cycle with 75 percent of the original beam loads. As discussed in Chapter II, the second hinge is more likely to occur near corner B because of smaller beam loads.

Figure 5.29 shows a positive moment flexural crack in the beam at corner $B$. This crack occurred during the reloading cycle. 


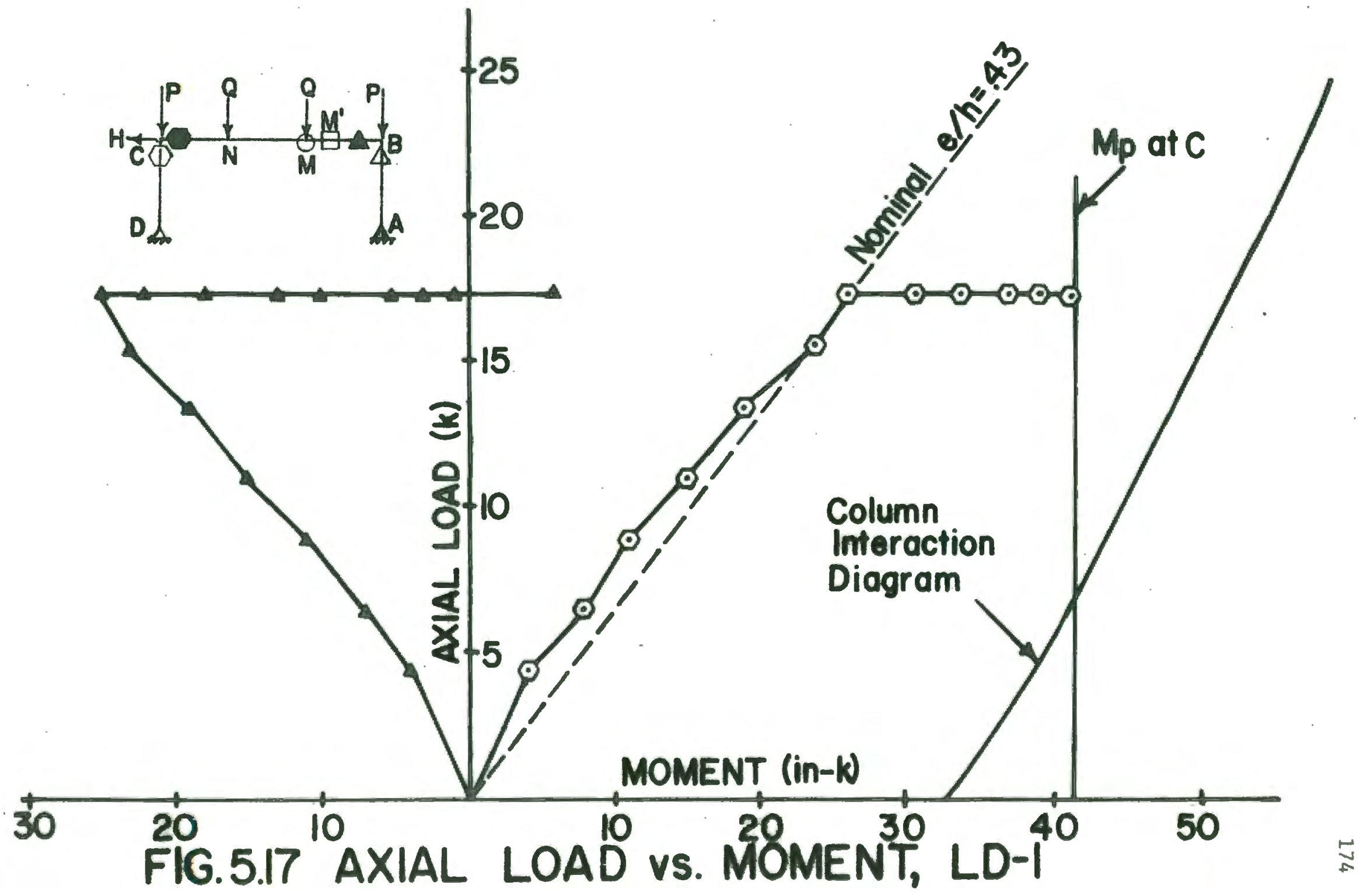




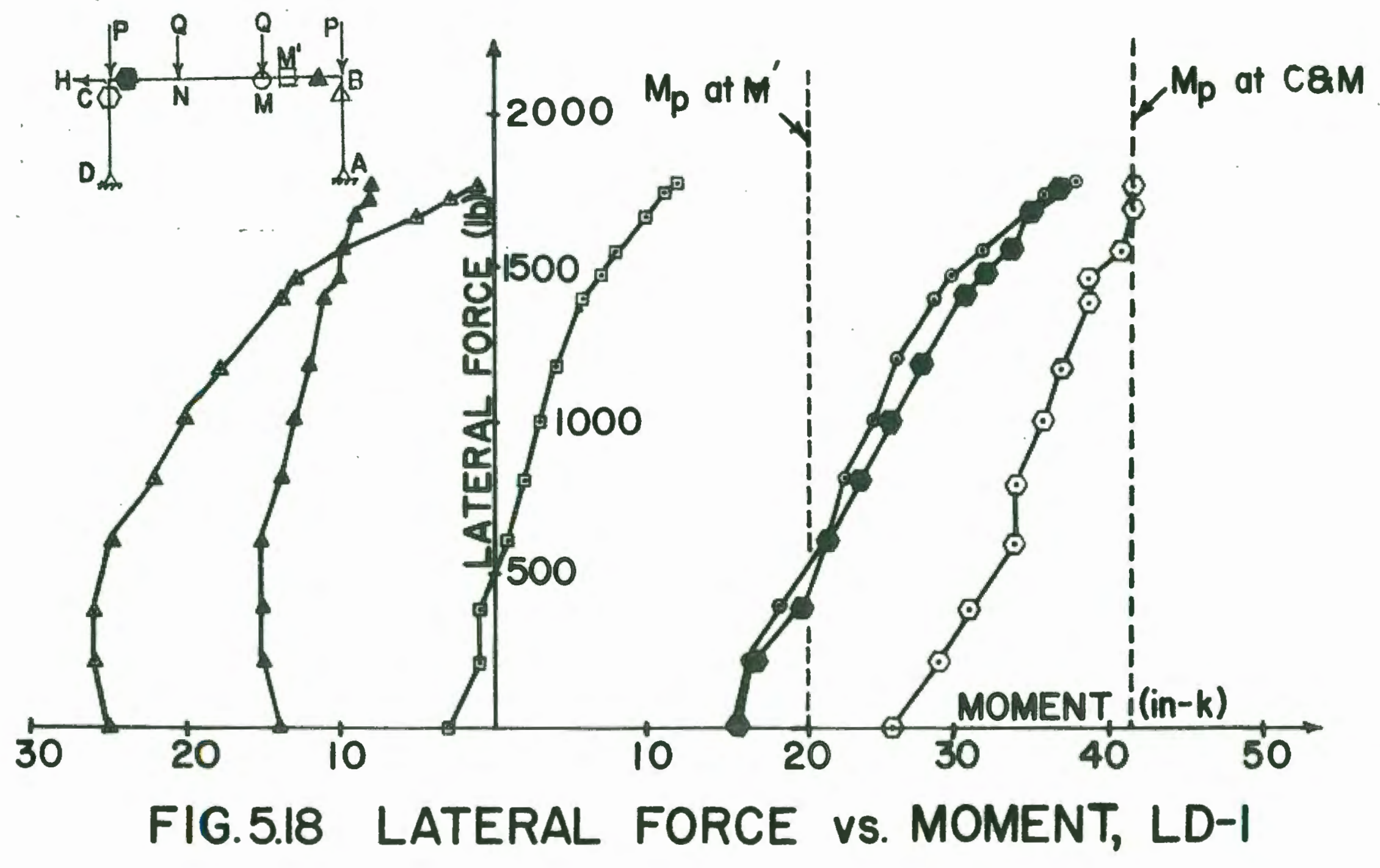




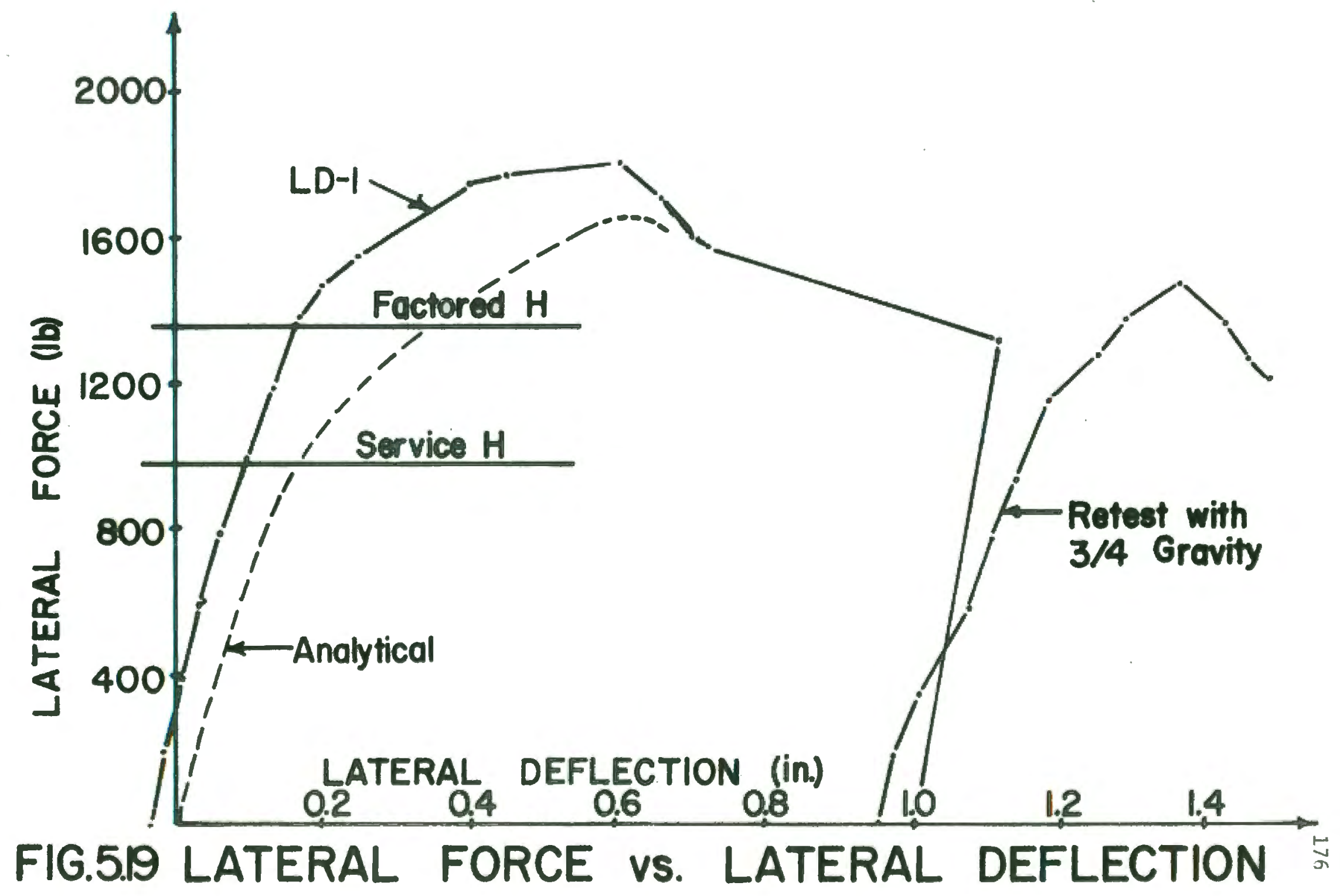




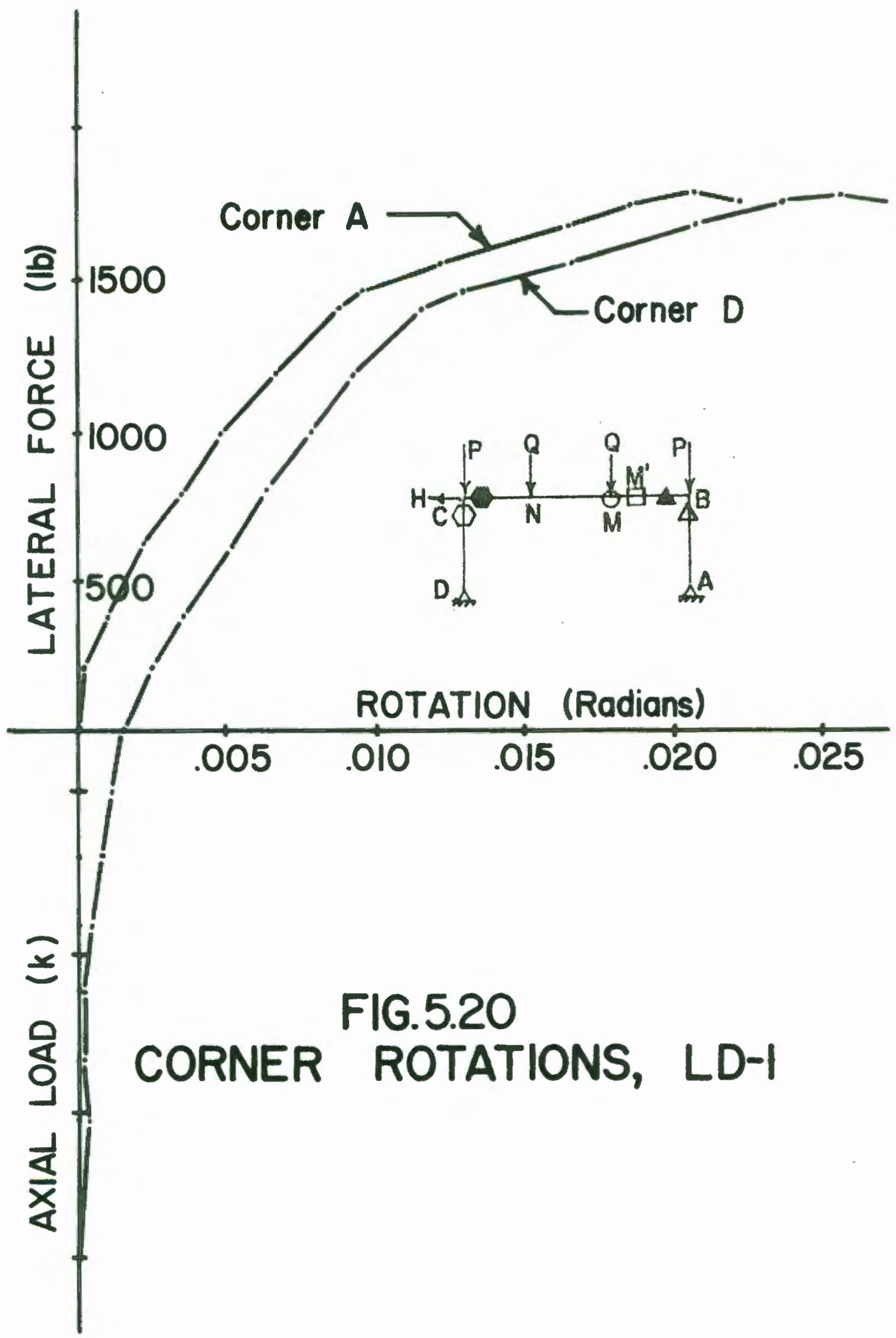




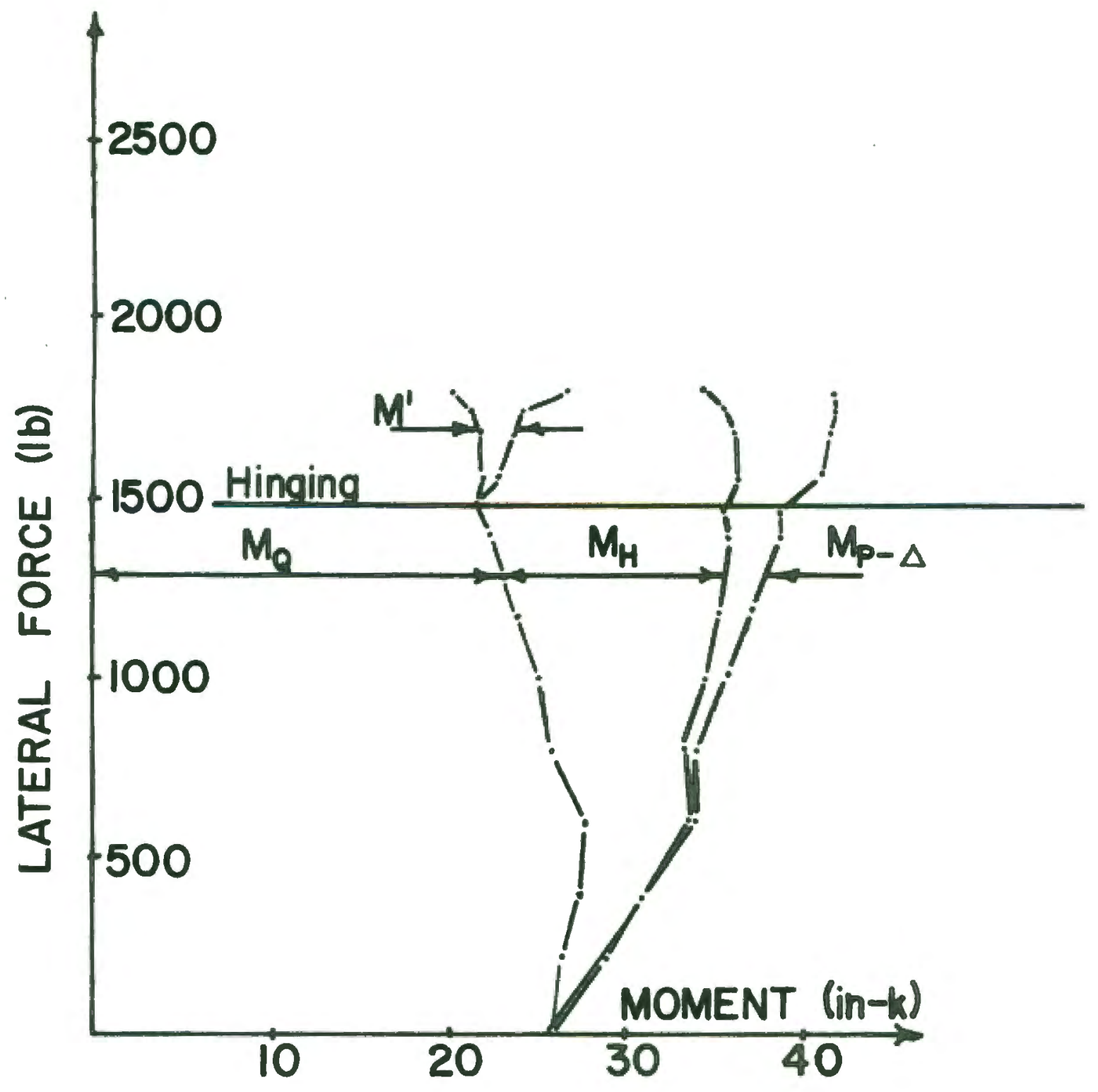

FIG.5.2I COMPONENTS OF MOMENT IN LEEWARD COLUMN, LD-I 


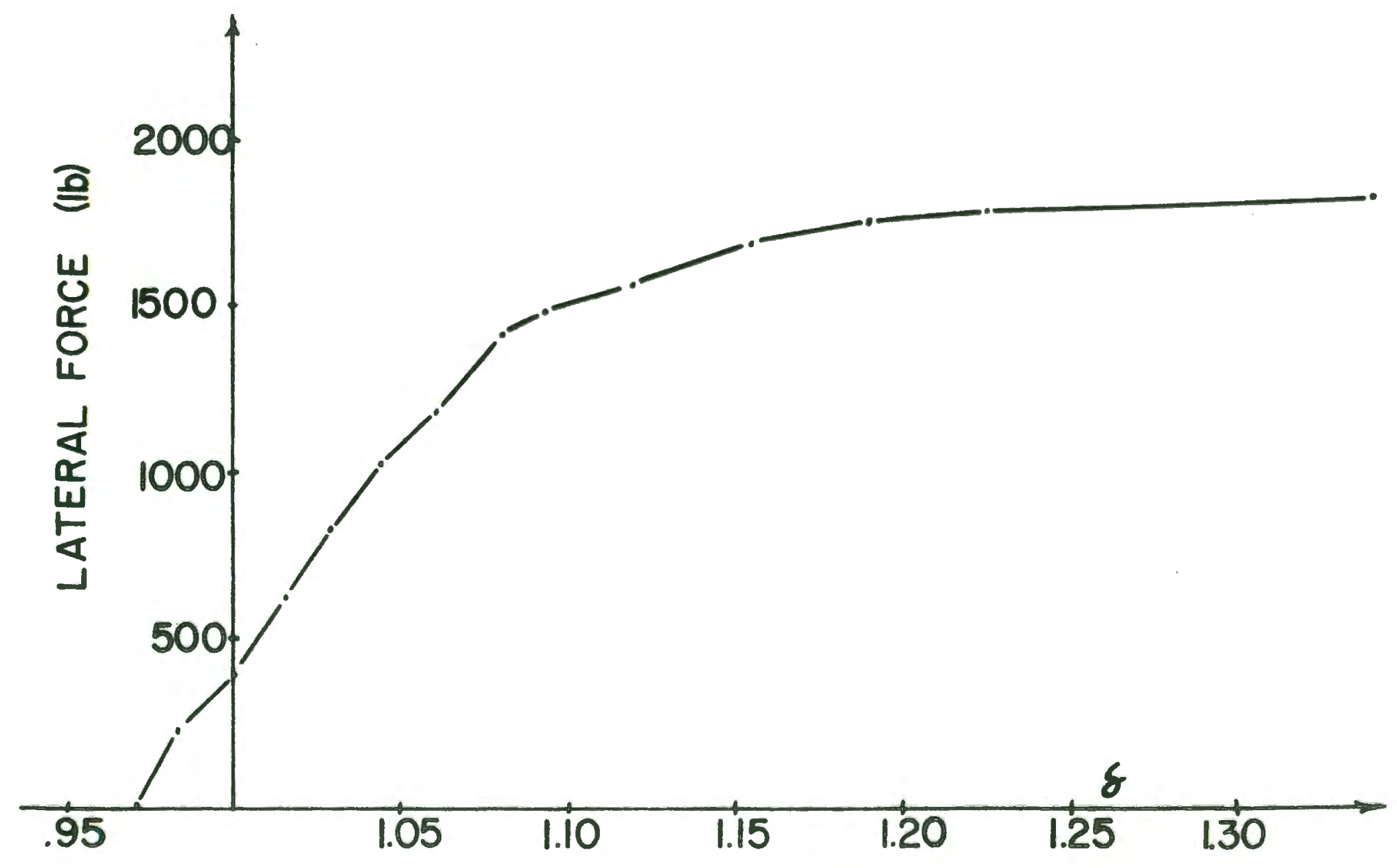

FIG.5.22 LATERAL FORCE vs. \&, FRAME LD-I 


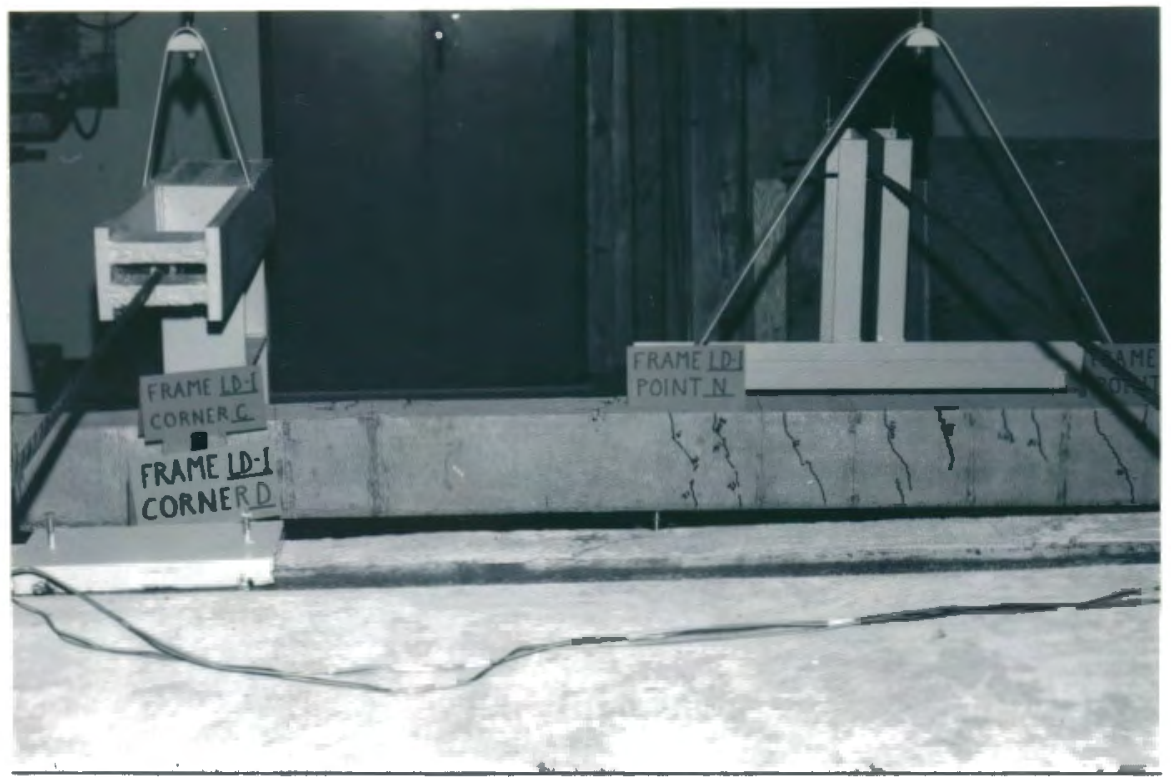

Fig. 5.23. Overall view of frame LD-1 after failure

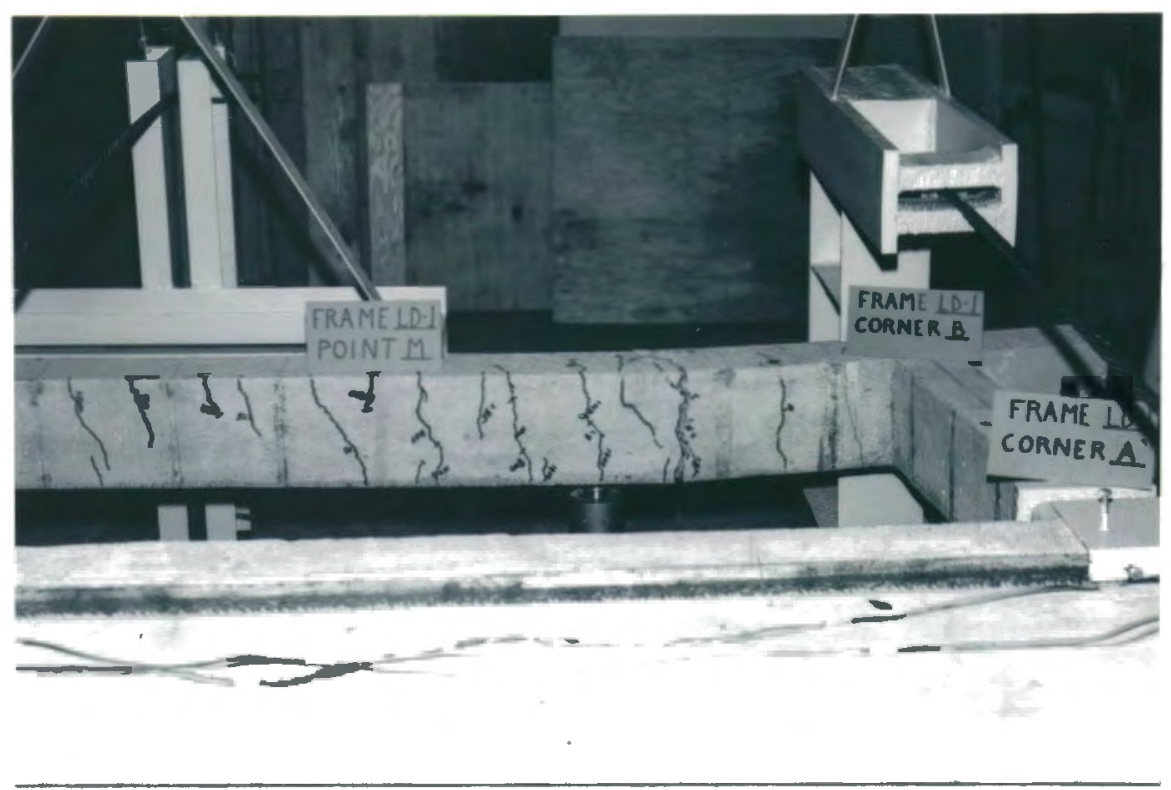

Fig. 5.24. Overall view of frame LD-1 after failure 


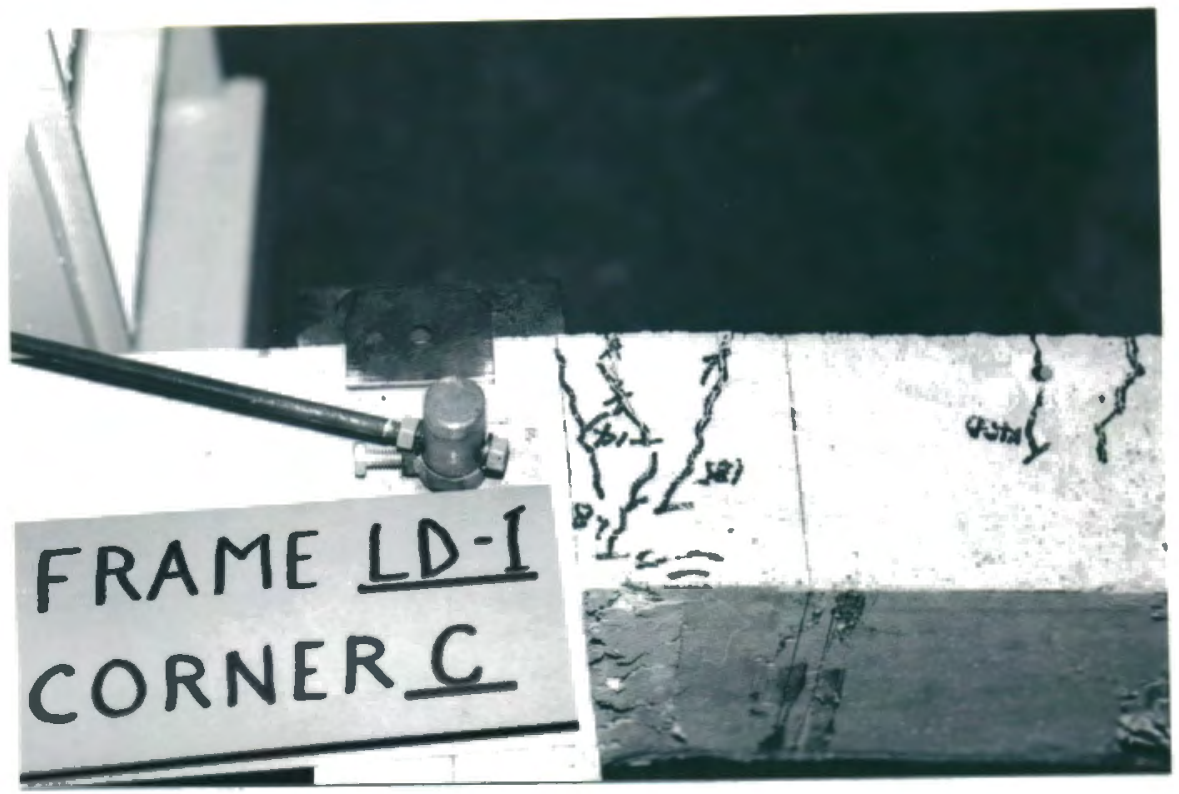

Fig. 5.25. Plastic hinge at corner C

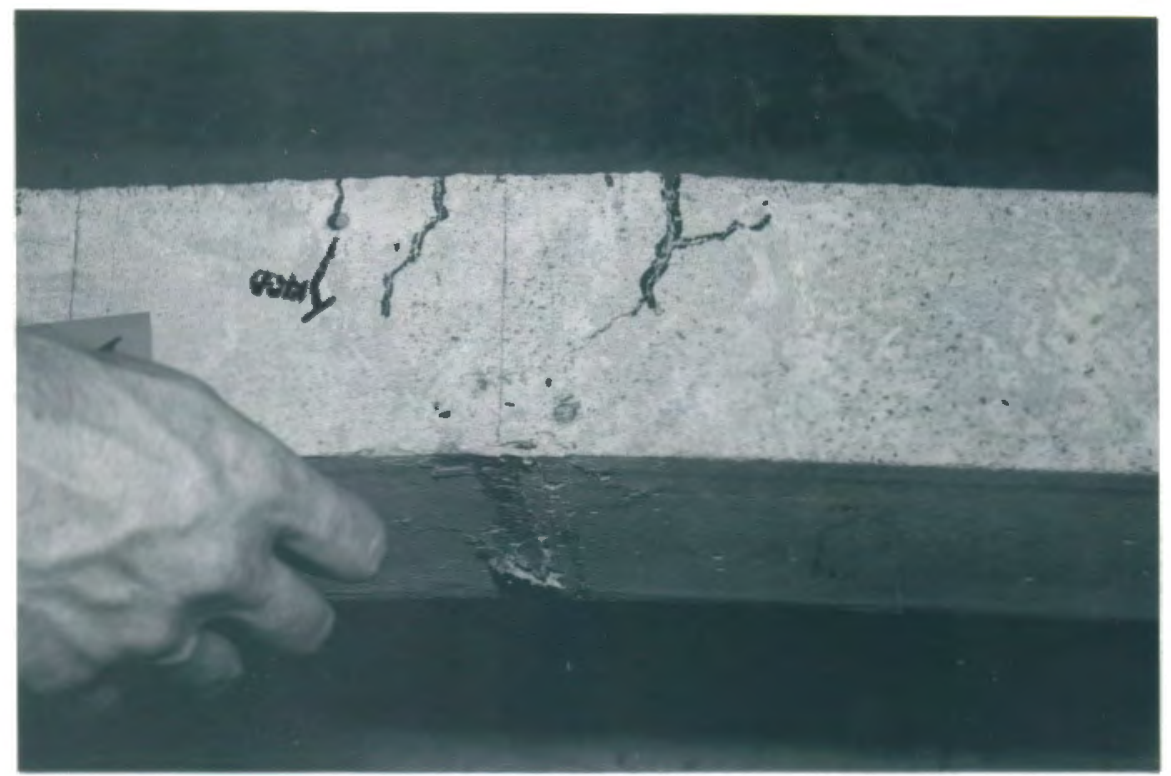

Fig. 5.26. Flexural-shear crack at negative moment cutoff point 


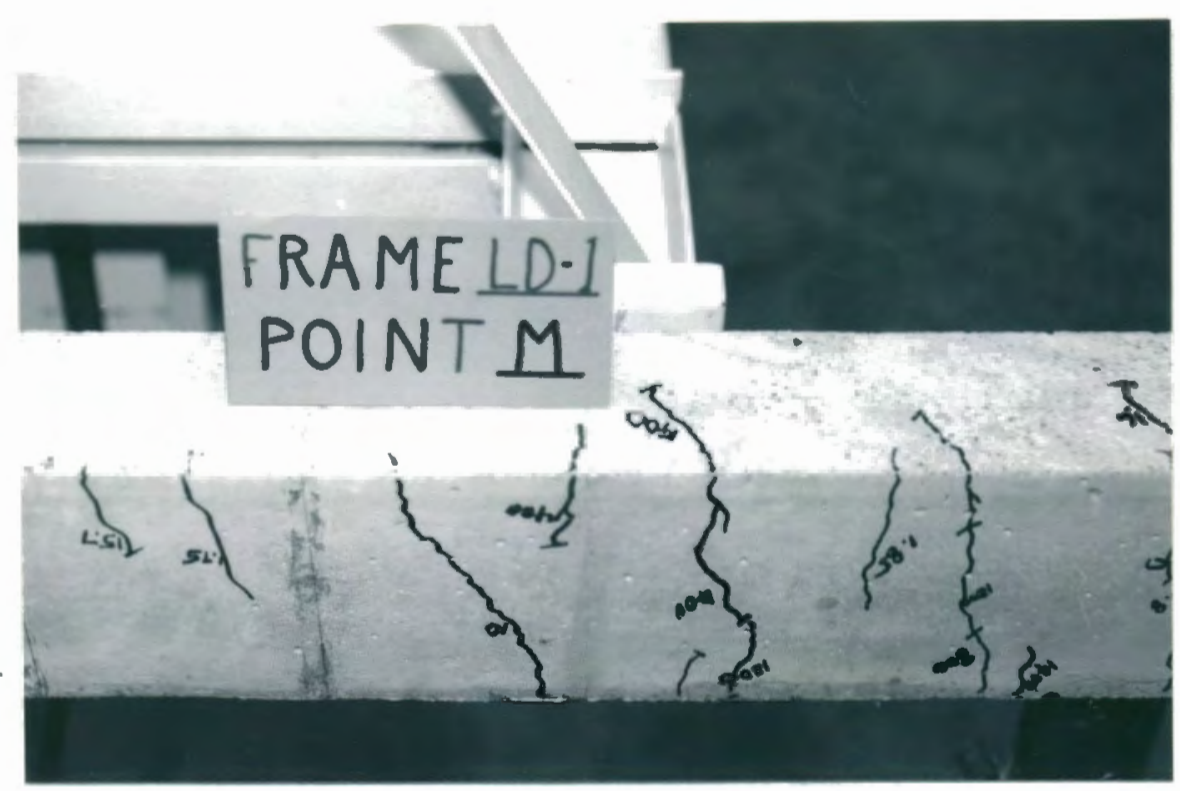

Fig. 5.27. Flexural cracks near M

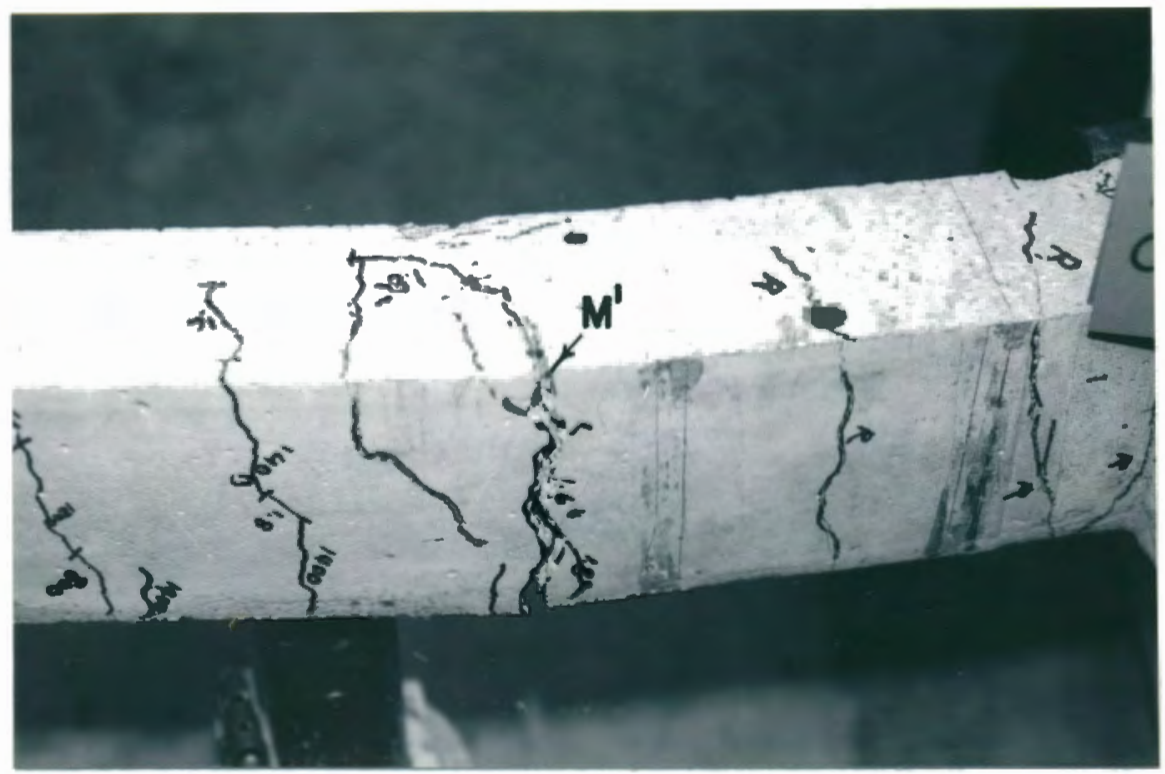

Fig. 5.28. Flexural-shear crack at $\mathrm{M}^{\prime}$ (positive moment cutoff point) 


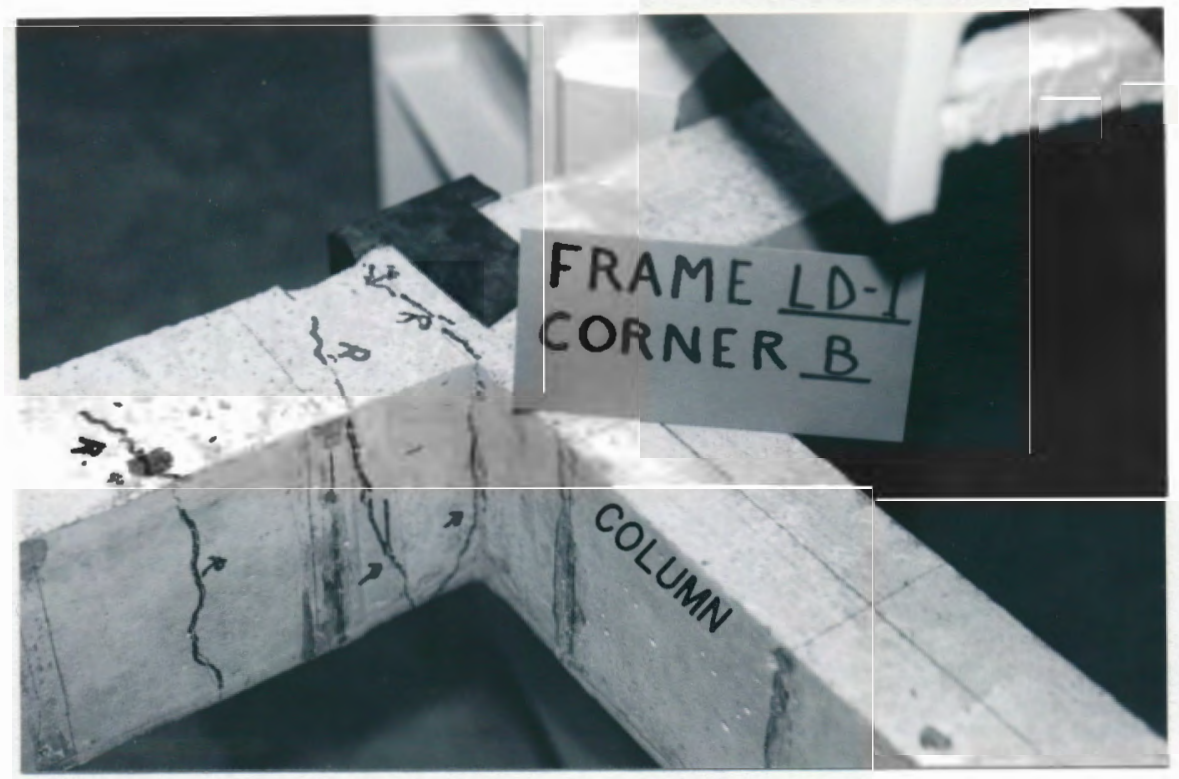

Fig. 5.29. Flexural crack at B (occurred during reload cycle) 


\subsection{COMPARISON OF FRAMES USD-1 AND LD-1}

Table 5.1 is a summary of some of the important values determined from data reduction. For both frames two plastic hinges formed in the beams ( $C$ and $M$ ) which led to a collapse mechanism. The collapse mechanism is shown in Figure 5.30. The frames will be compared with regard to serviceability, ultimate load capacity, moment redistribution, rotational capacity, ductility, yield safety, and economy.

As shown in Flgure 5.31 and Table 5.1 the lateral deflections under service loads are similar. This is justified, because both frames possessed almost Identical columns.

Frame USD-1 reached its first yield load at $\mathrm{H}_{1}=2000 \mathrm{lb}$ wh1le Frame LD-1 required $\mathrm{H}_{1}=1500 \mathrm{1b}$. Both frames showed enough rotational capacity at corner $\mathrm{C}$ and moment redistribution as they approached an u1timate load of $2270 \mathrm{lb}$ for Frame USD-1 and $1820 \mathrm{lb}$ for Frame LD-1. As shown in Table 5.1, Frame LD-1 had a larger moment redistribution Index, $\mathrm{H}_{2} / \mathrm{H}_{\mathrm{ult}}(18 \%$ vs. $12 \%)$. Frame LD-1 was designed based on the princlples of moment redistribution, however the moment redistribution for Frame USD-1 calls for some explanation. Theoretically, if reinforced concrete frames behave elasto-plastically, the plastic hinges at corner $C$ and point $M$ should occur at the same lateral load if both sections were designed for the same loading condition. For Frame USD-1, loading condition II (Gravity \& Lateral) controlled the design at $C$ while loading condition I (Gravity) controlled the design at $M$. Therefore, since the first plastic hinge forms at $C$, some extra capacity is ava1lable at section $M$. In addition, reinforced concrete members do not behave elasto-plastically, rather, in a round house fashion which gives rise 
to more moment readjustments during loading.

Both frames showed enough rotational capacity in the beam at corner $\mathrm{C}$. The shear span ratios near the negative moment are $\mathrm{M} / \mathrm{Vd}=7.0$ and 6.3 for Frames USD-1 and LD-1, respectively. As expected, the inelastic deformation occurred over a finite length rather than at a point as assumed in the mechanism design of Frame LD-1. Also, the flexural cracking at the negative moment cutoff point helps the region to rotate and distribute the additional moment to less critical sections. However, flexural-shear cracks should be avoided in regions where the first hinge forms.

The factor of safety against first yield may be defined as the ratio of lateral load at first hinge to service lateral load. These values are given in Table 5.1 which show enough yield safety. Roth ratios should be higher because the beam and column test loads were 27 percent higher than the service lodds.

The column slenderness ratios $\left(\mathrm{L}_{\mathbf{u}} / \mathrm{r}\right)$ for Frames USD-1 and $\mathrm{LD}-1$ were 17.6 and 18.8 , respectively. These values are reasonably close because the column cross sections are nearly identical.

The material volumes for both frames are shown in Table 5.2. This table gives the concrete and steel volume in the beam and columns. The volume of steel ( $\left.A_{s} \times L\right)$ is multiplied by the yield strength ( $\left.f_{y}\right)$ to reflect the savings in selecting different grades of reinforcement. Finally, Table 5.2 compares the material volumes for both frames. Table 5.2 shows that savings in the column concrete volume (no savings in the beam) and total reinforcement for Frame LD-1 are 7\% as compared to Frame USD-1. However, a $27 \%$ savings for Frame LD-1. occurs 
occurs for the steel at the negative moment region. This savings relieves the steel congestion at the beam-column 1ntersection, and also allows for better consolidation of concrete.

\subsection{COMPARISON OF TEST RESULTS WITH NONFIX7 AND STABILITY DOMAINS}

This section compares the test results with the analytical computer program and the elasto-plastic stability model.

The general nonlinear program NONFIX7, as discussed in Chapter II (Section 2.3.1), was used to predict the behavior of Frames USD-1 and LD-1. The input for the joint-members was entered as 5.35 times stiffer than the members: This was done to simulate the greater stiffness of the joint block and also to shift the critical moment section at the center of the joint block to the support face of the beam. A more complete discussion of the stiffened joint procedure is given in Reference (12).

The analytical lateral-1oad deflection curves, as shown by a dashed line, are plotted together with the experimental results in Figures 5.7 and 5.19 for Frames USD-1 and LD-1 respectively. These curves show less stiffness than the experimental curves. This is caused by neglecting the tensile strength of the concrete. The predicted ultimate lateral loads for USD-1 and LD-1 are $91 \%$ and $88 \%$ of the measured u1timate lateral 1oads.

Comparisons between the test frames and the elasto-plastic model are made by considering the stability domains of Figure 2.11. As discussed In Section 2.4.4, Figure 2.11, three domalns were defined by Curve A and Curve B. Figure 2.11 is reproduced in this section as Figure 5.32. The first domain (Domain I) is to the right of Curve A. This region represents frames that are unstable before any lateral load can be applied, 
i.e., $\mathrm{H}_{1}=\mathrm{H}_{2}=0$. The second domain (Domain II) lies between Curves $\mathrm{A}$ and $B$ and represents cases where the frame is stable for lateral loads up to $\mathrm{H}_{1}$, i.e., $\mathrm{H}_{1}>0$, but $\mathrm{H}_{2}=0$. Frames that lie to the left of curve $B$, Domain IIJ, are stable until a mechanism forms, i.e., $\mathrm{H}_{1}$ and $\mathrm{H}_{2}>0$.

In addition to Frames USD-1 and LD-1, two other frames tested in this series and designed by the same method as described in Chapter III are shown in Figure 5.32. They are designated as Frames USD-2 and LD-2: where Frame USD-2 was designed by the U1timate Strength method and Frame LD-2 was designed by the Limit Design method. Both frames represented the lowest leve1 of a 7-story building and were designed for $50 \%$ higher column and lateral loads than Frames USD-1 and LD-1. The test results are reported in Reference (27).

The stiffnesses of the beam and column are calculated from the moment-curvature curves as shown in Figure 2.12 of Section 2.4.5. The values $\psi$ and $\frac{P+Q}{P_{E}}$ were calculated from the stiffnesses and are plotted in Figure 5.32. The positions of the four test frames al1 lie within the stable domain (stable for both $\mathrm{H}_{1}$ and $\mathrm{H}_{2}$ ). This shows good correlation between the analytical stability results and physical tests. 
TABLE 5.1

SUMMARY OF TEST RESULTS

\begin{tabular}{|l|c|c|c|c|c|c|}
\hline Frame & $\begin{array}{c}\mathrm{H}_{\text {serv }} \\
(\mathrm{k})\end{array}$ & $\begin{array}{c}\Delta_{\text {serv }} \\
(\mathrm{in})\end{array}$ & $\begin{array}{c}\mathrm{H}_{\mathrm{des}} \\
(\mathrm{k})\end{array}$ & $\begin{array}{l}\mathrm{H}_{\mathrm{u} 1 \mathrm{t}} \\
(\mathrm{k})\end{array}$ & $\begin{array}{l}\mathrm{H}_{1} \\
(\mathrm{k})\end{array}$ & $\begin{array}{l}\mathrm{H}_{2} \\
\mathrm{k}\end{array}$ \\
\hline USD-1 & 1.07 & .094 & 1.37 & 2.27 & 2.00 & .27 \\
\hline LD-1 & 1.07 & .098 & 1.37 & 1.82 & 1.50 & .32 \\
\hline
\end{tabular}

\begin{tabular}{|l|l|l|l|l|l|l|}
\hline Frame & $\mathrm{H}_{\mathrm{ult}} / \mathrm{H}_{\mathrm{des}}$ & $\mathrm{H}_{2} / \mathrm{H}_{\mathrm{ult}}$ & $\mathrm{H}_{1} / \mathrm{H}_{\text {serv }}$ & $\mathrm{D}_{\mathrm{L}}$ & $\mathrm{D}_{\theta \mathrm{A}}$ & $\mathrm{D}_{\theta \mathrm{D}}$ \\
\hline $\mathrm{USD}-1$ & 1.66 & .12 & 1.9 & 1.5 & 1.4 & 1.6 \\
\hline $\mathrm{LD}-1$ & 1.33 & .18 & 1.4 & 3.0 & 2.0 & 1.9 \\
\hline
\end{tabular}

TABLE 5.2

MATERIAL SAVINGS

\begin{tabular}{|c|c|c|c|c|c|c|}
\hline & $\begin{array}{l}\text { Vol. of Conc. } \\
\text { Bm. }\left(\ln ^{3}\right)\end{array}$ & $\begin{array}{l}\text { Vol. of Conc. } \\
\text { Col. }\left(\text { in }^{3}\right)\end{array}$ & \multicolumn{3}{|c|}{$\begin{array}{l}\text { Vol. of Bm. } \\
\text { Steel } \\
\left(A_{S} L\right) \times f_{y}\end{array}$} & $\begin{array}{l}\text { Vol. of } \mathrm{Col} \\
\text { Steel } \\
\left(\mathrm{A}_{\mathrm{S}} \mathrm{L}\right) \times \mathrm{f}_{\mathrm{y}}\end{array}$ \\
\hline USD-1 & 1926 & 517.5 & 849 & 948 & 1797 & 1.196 \\
\hline LD-1 & 1932 & 483.0 & 624 & 1053 & 1677 & 1.196 \\
\hline $\begin{array}{l}\% \text { savings }= \\
\frac{(\mathrm{USD}-1)-(\mathrm{LD}-1)}{(\mathrm{USD}-1)}\end{array}$ & $=0 \%$ & $7 \%$ & $27 \%$ & $-11 \%$ & $7 \%$ & $0 \%$ \\
\hline
\end{tabular}




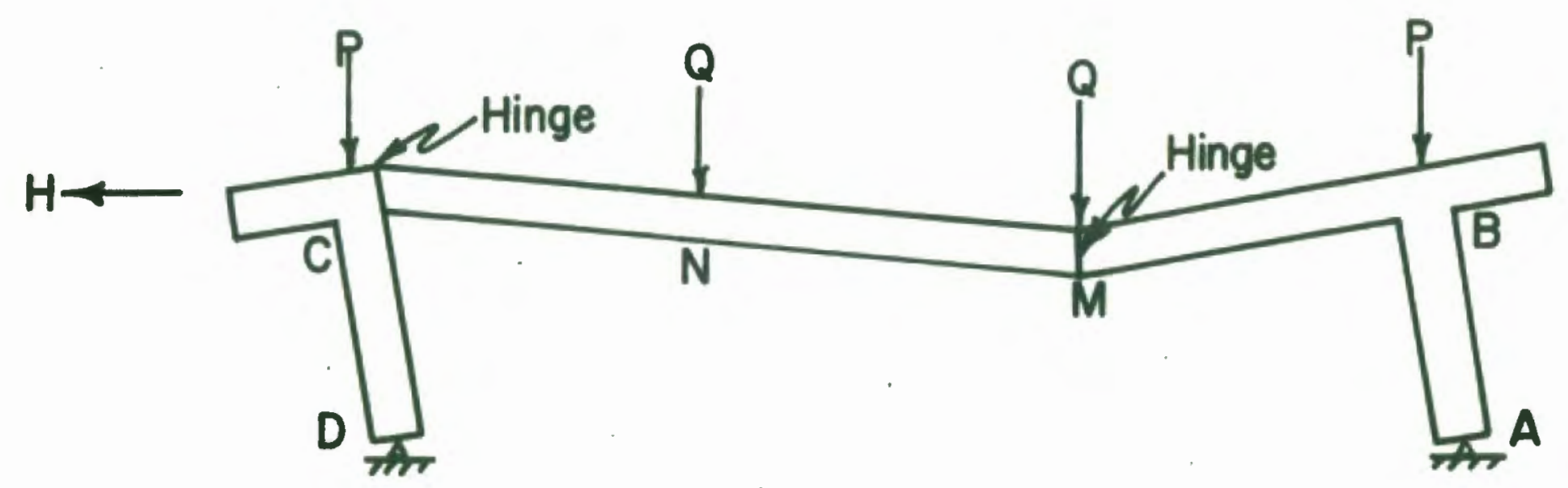

FIG.5.30 COLLAPSE MECHANISM FOR FRAMES USD-I\& LD-I 


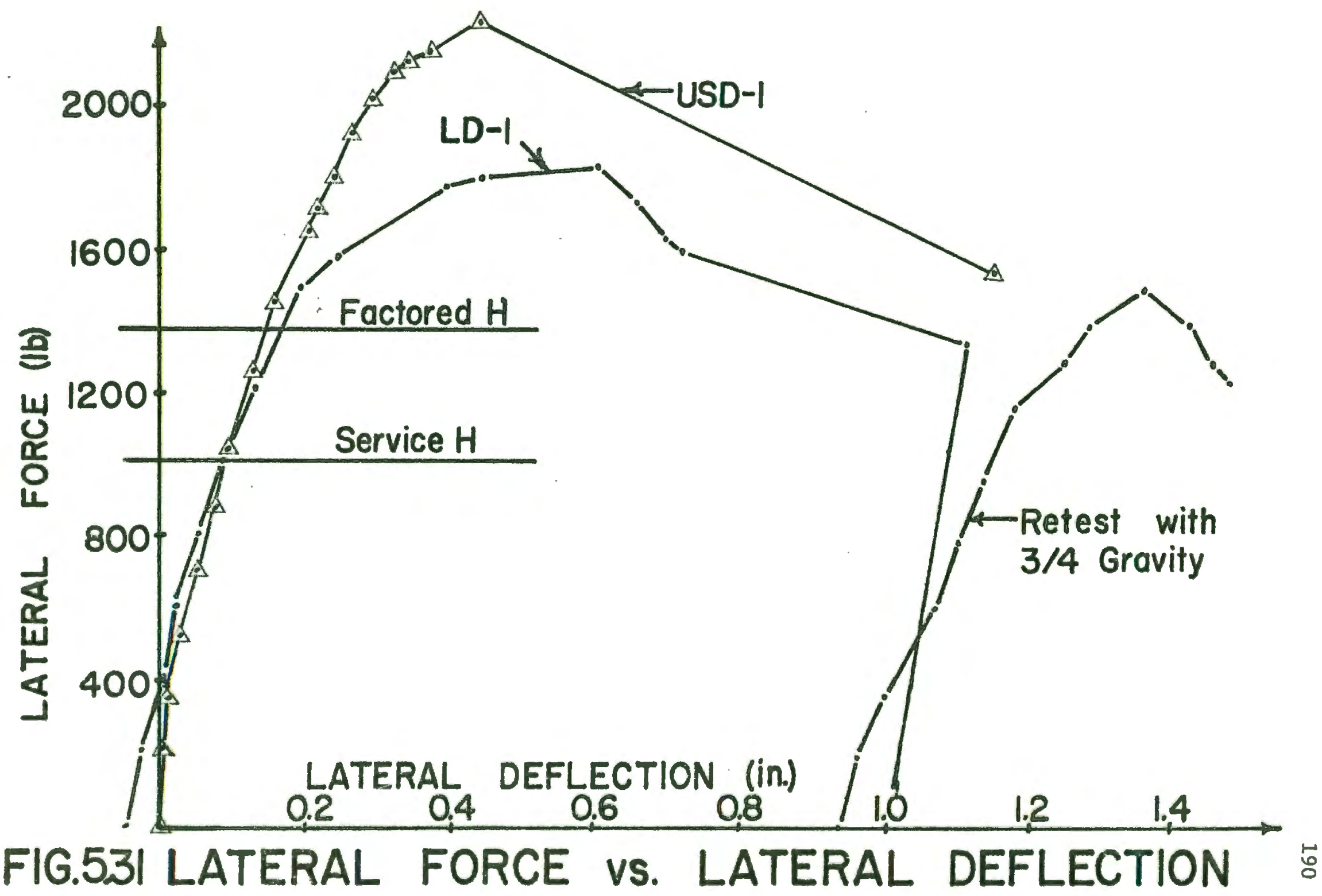




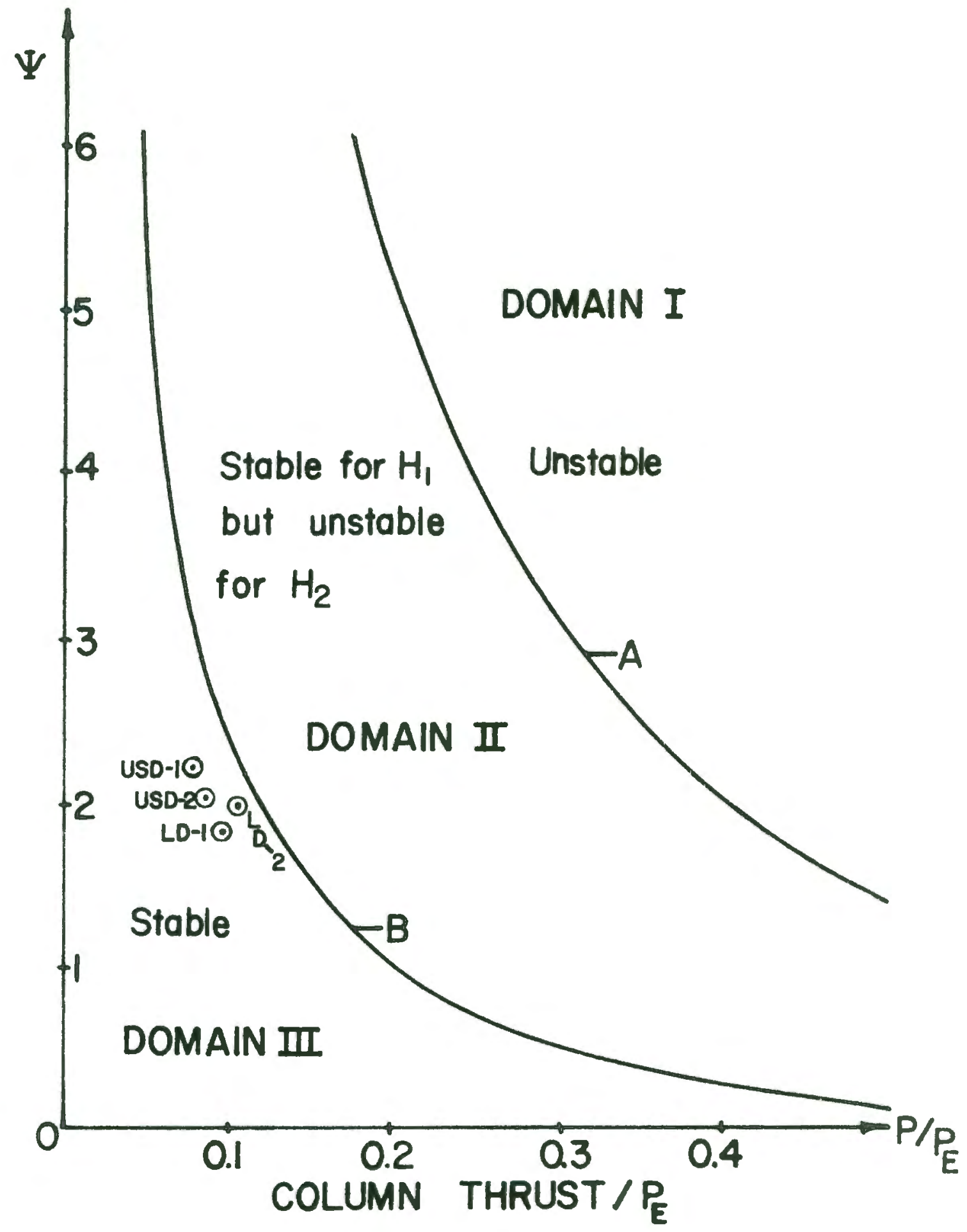

FIG. 5.32 FRAME TESTS COMPARED TO STABILITY DOMAINS 
CHAPTFR VT

SUMMARY, ('ONCIJUSTONS, ANI) RECOMMENDATIONS

The main objective of this study was to determine whether Limit Design could be applied to low-rise unbraced reinforced concrete frames. The investigation was carried out both analytically and experimenta11y.

In the analytical part, two mathematical models were used to determine the behavior of the frames. The first method used a nonlinear program, which takes into account the material and geometric nonlinearity, to analyze the behavior of unbraced frames. Several cases of frames with different reinforcement ratios and under different beam to column load ratios were investigated. For each frame the gravity loads were increased proportionately to $3 / 4$ of the ultimate frame capacity. Then, lateral load was applied to failure while keeping the beam and column loads constant.

The second mathematical model solved for the frame stability equation by assuming elasto-plastic moment curvature relationships for members. The model was applied separately to two cases; one when the second hinge formed at the leeward corner and the other when it formed at beam load location. Also, the stability solution was carried out by reducing the frame to a column attached to a linear spring.

In the experimental part, two frames were designed by two different methods and tested to failure. Frame USD -1 was designed by Ultimate Strength design while Frame LD-1 was designed by a Limit Design method. Both frames were designed for the same loads. The columns were 2i-in 
high while the beam was $84-$ in lont. The loading procedure consisted of proportionately loading tic beisin and column up to the design load, and then applying the lateral load to fallure.

Based on the results of the analytical and experimental parts of this investigation, the following conclusions are valid:

1. The computer study showed that combined mechanism fallures occur for frames representative of up to a nine story bullding.

2. The comparison between the computer results and the frame stability analysis shows good correlation.

3. The stability equation, as derived from the elasto-plastic stability model, is independent of where the second plastic hinge forms.

4. Frames USD-1 and LD-1 both remained in stable equilibrium until two plastic hinges formed in the beam. The ultimate loads of Frames USD-1 and $L D-1$ exceeded the design lateral load by $66 \%$ and $33 \%$, respectively.

5. Both frames had nearly the same lateral stiffness and deflection at service load.

6. The nonlinear program predicted the response of Frames USD-1 and LD-1 with reasonable accuracy.

7. The Merchant-Rankine formula predicted the $P-\Delta$ effects in unbraced frames with reasonable accuracy.

8. The savings in column concrete volume and beam steel, were $7 \%$, and the reduction in beam steel at the negative moment region was $27 \%$, for Frame LD-1 as compared to Frame USD-1.

9. The second cycle lateral load capacity for Frame LD-1 was $81 \%$ of the original. 
10. Limit Design may be used for low-rise unbraced reinforced concrete structures.

The following recommendations are made:

1. So as to study more realistic unbraced frames, the analytical and frame tests should be extended to include multi-bay frames.

2. The tensile strength of the concrete should be included in the nonlinear computer programs. 


\section{REFERENCES}

1. ACI Comittee 318, Building Code Requirements for Reinforced Concrete (ACI318-71), American Concrete Institute, Detroit, 1970.

2. Glanville, W. H., and Thomas, F. G., "The Redistribution of Moments in Reinforced Concrete Beams and Frames," Journal ICE, London, V. 3, No. 7, 1936, pp. 291-329.

3. Macch1, G., "E1astic Distribution of Moments on Continuous Beams," Flexural Mechanics of Reinforced Concrete, ACI SP-12, 1965, pp. 213-224.

4. Mattock, A. H., "Rotational Capacity of Hinging Regions in Reinforced Concrete Beams," Flexura1 Mechanics of Reinforced Concrete, ACI SP-12, 1965, pp. 143-180.

5. Corley, W. G., "Rotational Capacity of Reinforced Concrete Beams," ASCE Proc., Vo1. 92, ST5, October 1966, pp. 121-146.

6. Broms, B., and Viest, I. M., "Design of Long Reinforced Concrete Columns," ASCE Proc., Vo1. 90, No. ST5, Oct., 1964.

7. Pfrang, E. O., and Siess, C. P., "Behavior of Restrained Reinforced Concrete Columns," ASCE Proc., Vo1. 90, No. ST5, Oct., 1964.

8. Breen, J. E., "The Restrained Long Concrete Column As a Part of a Rectangular Frame," ACI Journal, Proc. Vol. 61, No. 5, May, 1964, pp. 563-587.

9. Furlong, R. W., and Ferguson, P. M., "Tests of Frames with Columns in Single Curvature," Symposium on Reinforced Concrete Columns, American Concrete Institute SP-13, 1966.

10. Ferguson, P. M., and Breen, J. E., "Investigation of the Long Concrete Column in a Frame Subject to Lateral Loads," Symposium on Reinforced Concrete Columns, ACI SP-13, 1966, pp. 75-119.

11. Blomeler, G. A., and Breen, J. E., "Effect of Yielding of Restraints on Slender Concrete Columns with Sidesway Presented," Reinforced Concrete Columns, ACI SP-50, 1975, Pp. 41-65.

12. Rad, F. N., "Behavior of Single Story Two-Column Reinforced Concrete Frames Under Combined Loading," Ph.D. Dissertation, The University of Texas, December, 1972. 
13. Gunnin, B. L., "Nonlinear Analysis of Planar Frames," Ph.D. Dissertation, The University of Texas, January 1970.

14. Breen, J. E., "The Restralned Long Concrete Column as a Part of a Rectangular Frame," Ph.D. Dissertation, The University of Texas, June, 1962.

15. Hognestad, E., "A Study of Combined Bending and Axial Load in Reinforced Concrete Members," University of Illinols Bulletin, Engineering Experiment Station Bulletin Series No. 399, November, 1951 .

16. Bolton, A., "A Simple Understanding of Elastic Critical Loads," The Structural Englneer, Vol. 54, No. 6, June, 1976, pp. 213-218.

17. U1t1mate Strength Design Handbook, Vol. II, American Concrete Institute, SP-17A, Detro1t, 1970.

18. American Institute of Steel Construction, Manual of Steel Construction, 7th ed., New York, 1970.

19. Beedle, L. S., Plastic Design of Steel Frames, John Wiley \& Sons, Inc., New York, 1958.

20. Horne, M. R., Plastic Theory of Structures, The MIT Press, Cambridge.

21. Wood, R. H., "Effective Lengths of Columns in Multi-Story Buildings," Parts 1, 2, and 3, The Structural Engineer, Nos. 7, 8, and 9, Vo1. 52, July, August, and September 1974.

22. ACI-ASCE Committee 428, "Progress Report on Code Clauses for Limit Design," ACI Journal, Sept., 1968, pp. 713-720.

23. Park, R., and Paulay, T., Reinforced Concrete Structures, John Wlley \& Sons, Inc., New York, 1975.

24. Mattock, A. H., Discussion of "Rotational Capacity of Reinforced Concrete Beams," ASCE Proc., Vo1. 93, ST2, Apr11 1967, pp. 519-522.

25. Furlong, R. W., "Long Columns in Single Curvature as Part of Concrete Frames," Ph.D. Dissertation, The Unfversity of Texas, June, 1963.

26. Blomeler, G. A., "Effect of Yielding Restraints on Slender Concrete Columns in Braced Frames," Ph.D. Dissertation, The University of Texas, August, 1968.

27. Samiee Nejad, N., "An Experimental Investigation of Unbraced Reinforced Concrete Frames," Thesis, Portland State University, June, 1977. 
28. Fowler, T. J., "Reinforced Concrete Columns Governed by Concrete Compression," Ph.D. Dissertation, The University of Texas, January, 1966.

29. Ferguson, P. M., Reinforced Concrete Fundamentals, John Wiley \& Sons, Inc., New York, 1973. 